\author{
UNIVERSIDADE DE SÃO PAULO \\ ESCOLA DE EDUCAÇÃO FÍSICA E ESPORTE
}

\title{
ANÁLISE MULTIVARIADA DA COMPOSIÇÃO CORPORAL EM JOVENS ESPORTISTAS E NÃO ESPORTISTAS
}

Dalmo Roberto Lopes Machado

SÃO PAULO

-2009 - 


\section{ANÁLISE MULTIVARIADA DA COMPOSIÇÃO CORPORAL EM JOVENS ESPORTISTAS E NÃO ESPORTISTAS}

DALMO ROBERTO LOPES MACHADO

Tese apresentada à Escola de Educação Física e Esporte da Universidade de São Paulo, como requisito final para obtenção do título de Doutor em Educação Física. 


\section{AGRADECIMENTOS}

A Deus pelo dom da vida, inspiração, provisão e sustentação em cada etapa deste projeto. Tudo foi possível, somente pelo amor, graça e total dependência dEle.

Ao meu orientador Prof. Dr. Valdir J. Barbanti por suas brilhantes intervenções, de forma adequada e sempre no momento exato. Pude aprender muito mais do que os assuntos discutidos; aprendi com seu exemplo, sua postura, conduta, atitude e ética profissional. Um respeitado orientador que desde o mestrado, tornou-se companheiro e, logo, um grande amigo fraterno e querido.

Ao meu mais recente amigo Prof. Dr. Sérgio Oikawa, o estatístico brilhante, grande responsável pela proposição do modelo multivariado deste estudo. Pessoas como você estão totalmente fora da tendência gaussiana de normalidade, você é daqueles "outliers" que surgem em nossa vida pra equacionar nossos $\hat{Y}$, de uma prontidão absurda, competente e excelente. Da mesma forma ao IME - CEA da USP pela assessoria e orientação estatística em diversas etapas desta tese.

À minha querida esposa Wania, que sempre incentivou e apoiou minha carreira acadêmica. Sempre foi muito mais do que uma mãe dedicada e amorosa às nossas filhas. Soube ser minha amiga, consoladora, conselheira e mulher. Meu eterno amor e dedicação a você, querida, na doença e na saúde...

Às minhas filhas lara e Vanessa, perdão pelo tempo e atenção que deixei de dispensar a vocês em função das minhas obrigações acadêmicas. Amo demais a vocês duas e todo o meu esforço é pra tentar oferecer Ihes um futuro melhor.

Aos meus amigos e companheiros (por ordem de saída do doutorado) Dr. Enrico Puggina, Dr. Marcos Rocha e Dr. Gustavo Borges pelos momentos impagáveis de ricas discussões acadêmicas. Pelo acréscimo na vida pessoal na 
informalidade de nossas saídas pra "comer alguma coisa", pela convivência, suporte e apoio (em todos os sentidos), o meu muito obrigado, amigos! Nossa convivência é tão sólida que não tenho dúvida, perdurará pelo resto das nossas vidas.

À GE, na pessoa do Gustavo Montagnini - Health Care Product Manager pela viabilização e providências do comodato para a DXA, sem o qual este estudo não teria acontecido. Igualmente à Sanny - American Medical do Brasil Ltda., pela concessão dos equipamentos antropométricos. É muito bom ter parceiros que colocam o apoio e incentivo à pesquisa acima dos interesses meramente comerciais.

Aos meus alunos, ex-alunos companheiros do GECIAF, GEPAFE, GEPEMENE, CELAPAM e à FCT-UNESP. Se fosse nomeá-los as páginas permitidas para agradecimentos seriam insuficientes. Obrigado pelo apoio e ajuda nas coletas, em especial à Camila Buonani, Lorrane Araújo e Yasser Kassab.

Aos nossos pais (meus e de minha esposa) e familiares. Espero que tenham orgulho de mim como tenho de fazer parte de vocês.

À Cnpq pelo fomento e suporte financeiro durante esses anos de doutoramento. À CPG que gerenciou essa concessão e por todo apoio e orientação processual. Obrigado Ilza e Márcio (à Lourdes também desde o mestrado) pela prontidão, competência e gentileza constantes no trato comigo. 


\section{SUMÁRIO}

Página

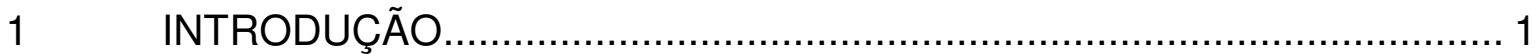

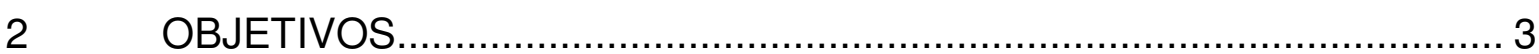

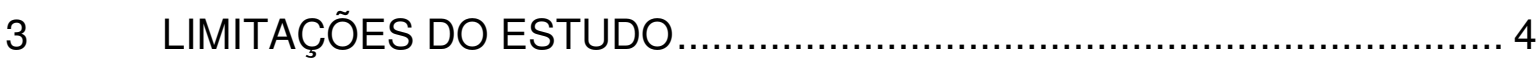

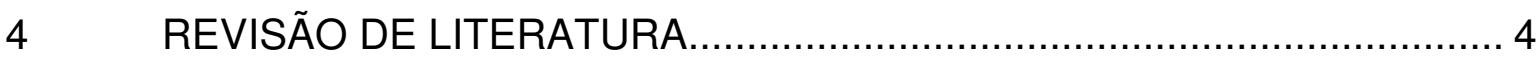

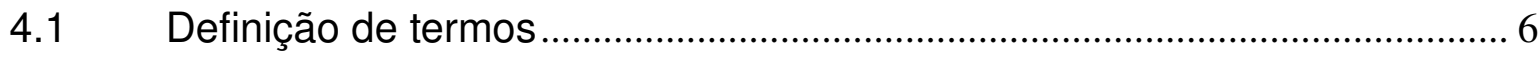

4.2 Absortometria de raios-X de dupla energia - DXA .................................. 8

4.2.1 Aplicabilidade da DXA em crianças e adolescentes .................................. 12

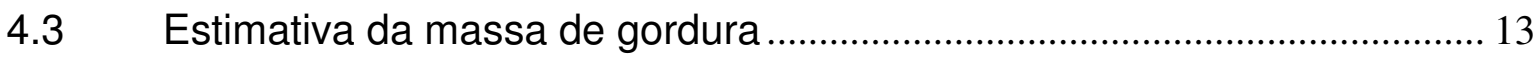

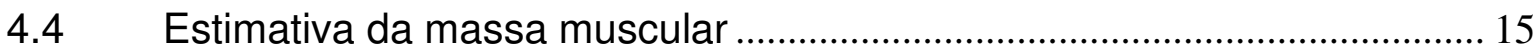

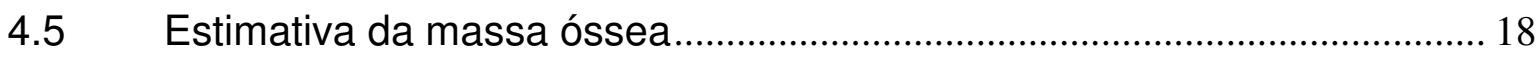

4.6 Pico de velocidade de crescimento............................................................ 20

4.7 Modelos pediátricos antropométricos mais utilizados................................. 24

4.8 Procedimentos estatísticos na proposição de modelos............................... 30

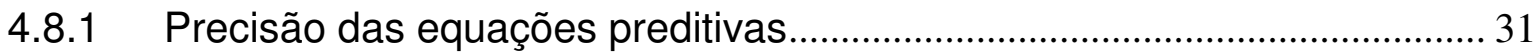

4.8.2 Relação entre variáveis explicativas e variáveis de resposta..................... 32

4.9 Composição corporal do jovem esportista................................................. 33

5 MATERIAIS E MÉTODOS ........................................................... 40

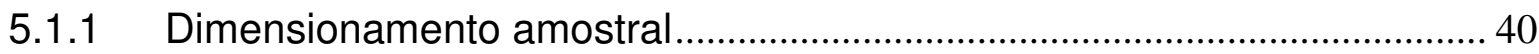

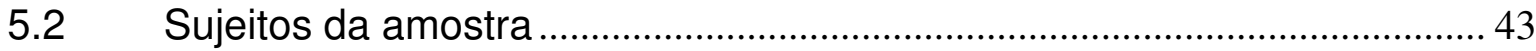

5.2.1 Classificação de esportistas e não-esportistas ............................................ 43

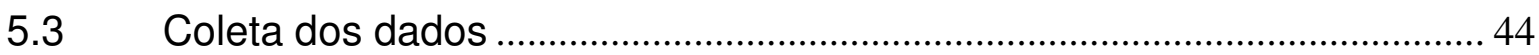

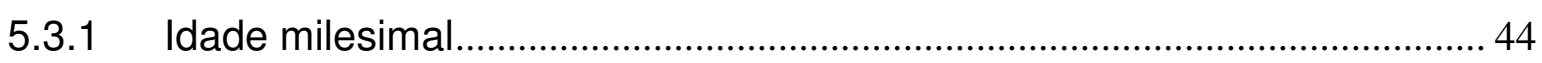

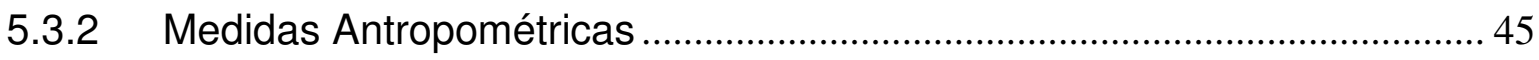

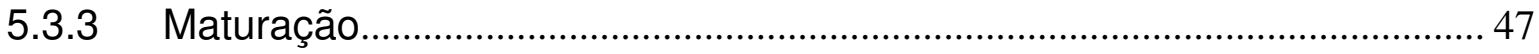

5.3.4 Composição corporal multicomponente ...................................................... 48

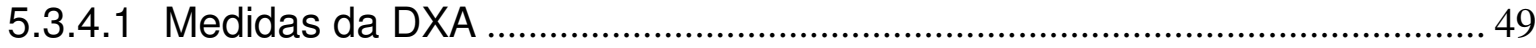




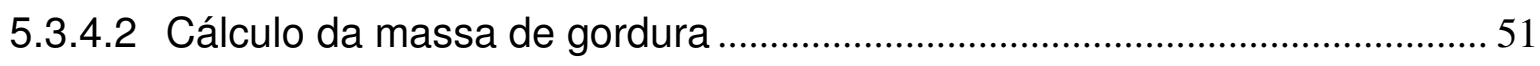

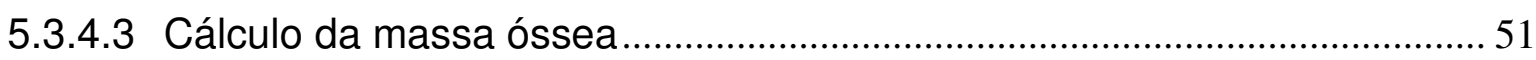

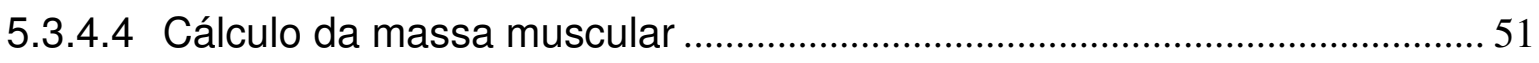

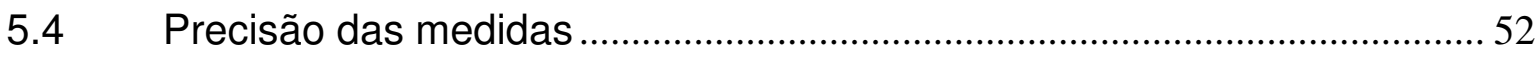

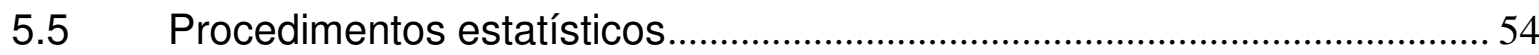

5.6 Proposição de modelo multivariado da composição corporal ..................... 54

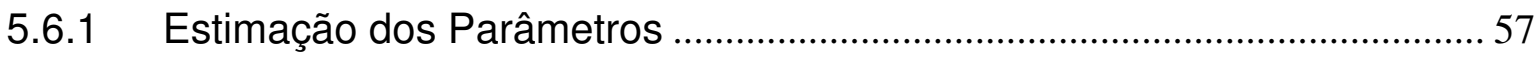

5.6.2 Teste de Hipóteses sobre os Parâmetros..................................................... 57

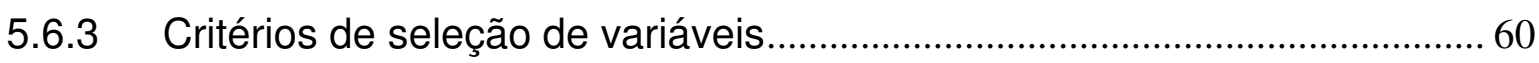

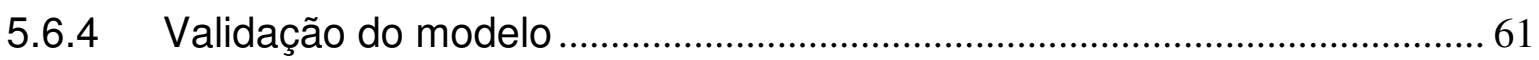

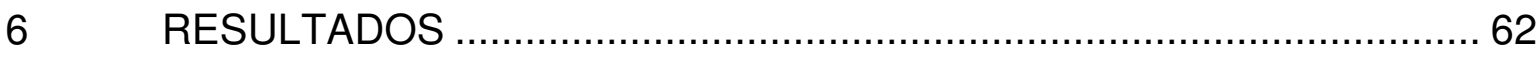

6.1 Descrição da composição corporal .............................................................. 64

6.2 Correlações da composição corporal ..................................................... 73

6.3 Análise multivariada da composição corporal ............................................... 75

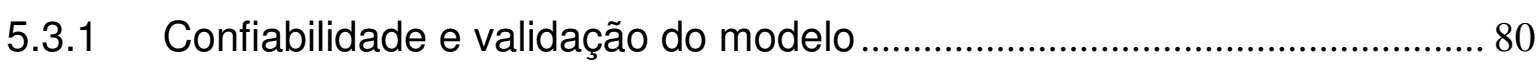

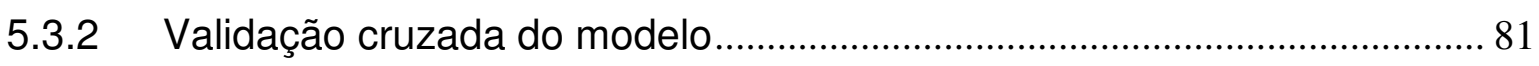

6.4 Composição corporal de esportistas e não esportistas ................................. 81

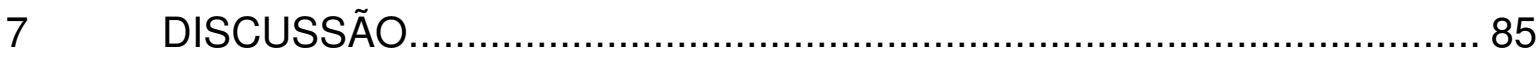

7.1 A composição corporal dos jovens ……............................................... 86

7.2 Composição corporal e a prática esportiva............................................. 90

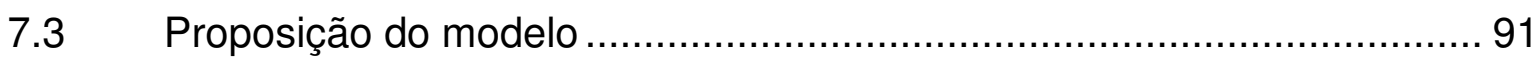

$7.4 \quad$ O modelo de análise multivariada.......................................................... 93

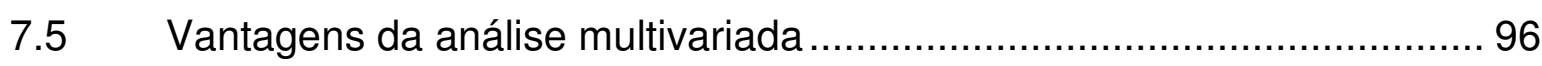

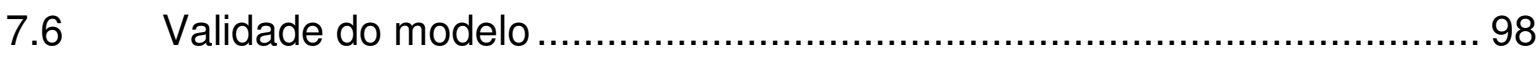

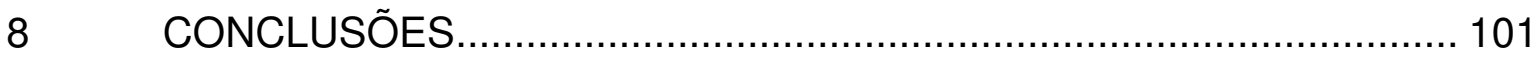

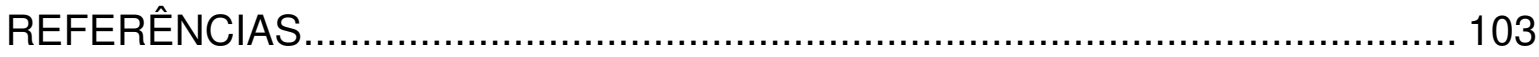

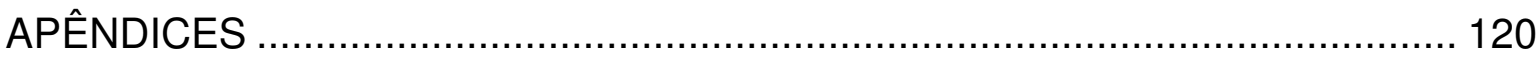




\section{LISTA DE TABELAS}

Página

TABELA 1. Comparação dos métodos para estimativa da massa músculo-esquelética em humanos.

TABELA 2. Modelos antropométricos da composição corporal para crianças e adolescentes. 25

TABELA 3. Idade (anos) para início, especialização e alto rendimento em diferentes modalidades esportivas. 34

TABELA 4. Determinação do tamanho da amostra. 42

TABELA 5. Classificação do Pico de Velocidade de Crescimento. 48

TABELA 6. Erro técnico de medida absoluto (ETM) e relativo (ETM\%), das medidas de dimensões corporais, DXA, dobras cutâneas, perímetros e diâmetros ósseos.

TABELA 7. Representação para a Análise de Variância Multivariada (MANOVA) para a partição da soma de quadrados entre a regressão e o erro. 58

TABELA 8. Critérios de aproximações de estatística F para teste de hipótese $\mathrm{HO}$.

TABELA 9. Valores mínimo, máximo, média e desvio padrão das variáveis de jovens do sexo masculino.

TABELA 10. Distribuição por idade cronológica, média de PVC total e relativa (\%) de jovens Esportistas (ES) e Não-esportistas (NE) de 8 a 18 anos do sexo masculino.

TABELA 11. Análise descritiva das medidas de tendência central de massa de gordura, massa muscular e massa óssea em jovens do sexo masculino.

TABELA 12. Valores de média e desvio padrão (dp) dos componentes da CC e significância estatística (*) para as idades 
subseqüentes, em jovens de 8 a 18 anos do sexo masculino.

TABELA 13. Valores de média e desvio padrão (dp) e significância estatística (*) para as idades subseqüentes, da CC em jovens de -5 a 3 anos do PVC

TABELA 14. Coeficiente de correlação entre massa de gordura (MG), massa óssea (MO), massa muscular (MM), variáveis categóricas e antropométricas, em jovens do sexo masculino. 73

TABELA 15. Matriz de correlação entre variáveis explicativas e de respostas, em jovens do sexo masculino. 74

TABELA 16. Ajuste de modelo de regressão multivariada para predição da composição corporal em jovens do sexo masculino.

TABELA 17. Valores de $\beta$ para cada componente da composição corporal em jovens do sexo masculino.

TABELA 18. Medidas de tendência central comparativas entre esportistas (ES) e não esportistas (NE) de massa de gordura, massa muscular e massa óssea em jovens do sexo masculino .81

TABELA 19. Modelo antropométrico multicomponente para cálculo simultâneo da massa de gordura (MG), massa óssea (MO) e massa muscular (MM). 


\section{LISTA DE FIGURAS}

Página

FIGURA 1. Níveis de composição corporal ( $\mathrm{N}=$ nitrogênio; $\mathrm{CH}=$ carboidratos). (Adaptado de WANG et al., 1992).

FIGURA 2. Momento do pico de velocidade de crescimento de rapazes (a) e moças (b) (Adaptado de MIRWALD et. al., 2002).

FIGURA 3. Posicionamento do avaliado no scanner. 50

FIGURA 4. Box-plots da massa de gordura, massa muscular e massa óssea em jovens do sexo masculino.

FIGURA 5. Distribuição da massa de gordura (MG), massa muscular (MM) e massa óssea (MO) em jovens do sexo masculino.

FIGURA 6. Correlação, distribuição e dispersão entre variáveis de resposta (MG, MO e $\mathrm{MM}$ ) de jovens esportistas e nãoesportistas do sexo masculino.

FIGURA 7. Distribuição multivariada dos resíduos para massa de gordura (MG), massa óssea (MO) e massa muscular (MM) de jovens do sexo masculino de 8 a 18 anos de idade.

FIGURA 8. Box-plots comparativos entre esportistas (ES) e não esportistas (NE) da massa de gordura, massa muscular e massa óssea em jovens do sexo masculino. 82

FIGURA 9. Correlação, distribuição e dispersão multivariada Sem (a)

e Com (b) transformação (Log) dos dados de Massa de Gordura (MG), Massa Óssea (MO) e Massa Muscular (MM) de jovens do sexo masculino.

FIGURA 10. Comparação entre modelos Bicomponente e Multicomponente da Composição Corporal. 


\section{LISTA DE GRÁFICOS}

Página

GRÁFICO 1. Gordura relativa (\%G) em atletas de ambos os sexos em diversos esportes (Baseado em MALINA, 2007).

GRÁFICO 2. Setores da distribuição proporcional da composição corporal em jovens do sexo masculino.

GRÁFICO 3. Distribuição amostral proporcional por idade (8 a 18 anos) e anos para o PVC (-5 a 3) de jovens do sexo masculino.

66

GRÁFICO 4. Representação gráfica, dispersão e tendência da gordura corporal por idade (8 a 18 anos) e anos para o PVC (-5 a 3) de jovens do sexo masculino.

GRÁFICO 5. Representação gráfica, dispersão e tendência da massa muscular por idade (8 a 18 anos) e anos para o PVC (-5 a 3) de jovens do sexo masculino. 68

GRÁFICO 6. Representação gráfica, dispersão e tendência da massa óssea por idade (8 a 18 anos) e anos para o PVC (-5 a 3) de jovens do sexo masculino.

GRÁFICO 7. Dispersão entre os valores preditos e observados da composição corporal de jovens do sexo masculino.

GRÁFICO 8. Proporções da composição corporal de gordura, osso e músculo de jovens esportistas e não-esportistas do sexo masculino. 83

GRÁFICO 9. Valores comparativos por idade cronológica entre esportistas (ES) e não esportistas (NE) da massa de gordura (MG; a), massa óssea (MO; b) e massa muscular (MM; c) em jovens do sexo masculino de 8 a 18 anos. 
GRÁFICO 10. Valores comparativos por anos para O PVC entre esportistas (ES) e não esportistas (NE) da massa de gordura (MG; a), massa óssea (MO; b) e massa muscular (MM; c) em jovens do sexo masculino de -5 a 3 anos do PVC.

GRÁFICO 11. Comparação da Composição Corporal do estudo atual (PPTE) com modelo de referência (CNRC). 99 


\section{LISTA DE SIGLAS}

$\begin{array}{ll}\mathcal{E} & \text { Erro máximo desejado } \\ Z_{\gamma} & \text { Grau de confiança } \\ \sigma^{2} & \text { Variabilidade } \\ \gamma & \text { Índice de confiança } \\ \bar{X} & \text { Média amostral } \\ \text { \%G } & \text { Porcentual de gordura } \\ n & \text { Número amostral } \\ \text { ANOVA } & \text { Análise de variância } \\ \text { ACT } & \text { Água corporal total } \\ \text { AP } & \text { Altura de pernas } \\ \text { ATC } & \text { Altura tronco-cefálica } \\ \text { CC } & \text { Composição corporal } \\ \text { CMO } & \text { Conteúdo mineral ósseo } \\ \text { Dc } & \text { Densidade corporal } \\ \text { DXA } & \text { Absortometria de raios-X de dupla energia } \\ \text { DMO } & \text { Densidade mineral óssea } \\ \text { EPE } & \text { Erro padrão de estimativa } \\ \text { ES } & \text { Esportistas } \\ \text { Fda } & \text { Fração da data de avaliação } \\ \text { Fdn } & \text { Fração da data de nascimento } \\ \text { NE } & \text { Não esportistas } \\ \text { IMC } & \text { Índice de massa corporal } \\ \text { IMG } & \text { Índice de massa de gordura } \\ \text { IMIG } & \text { Índice de massa isenta de gordura } \\ \text { K } & \text { Potássio } 40 \\ \text { MG } & \text { Massa de gordura } \\ \text { MIG } & \text { Massa isenta de gordura } \\ \text { MTM } & \text { Massa de tecido mole } \\ \text { MM } & \text { Massa muscular } \\ \text { MO } & \text { Massa óssea } \\ \text { MR } & \text { Massa residual } \\ \text { N } & \text { Nitrogênio } \\ \text { PRESS } & \text { Predictive Sum of Squares } \\ \text { PVC } & \text { Pico de velocidade de crescimento } \\ \text { Q } & \text { Coeficiente de PRESS } \\ \text { RM } & \text { Ressonância magnética } \\ \text { SPREss } & \text { Erro de PRESS } \\ \text { TC } & \text { Tomografia Computadorizada } \\ \text { TM } & \text { Massa de tecido magro } \\ \text { TMA } & \text { Tecido magro apendicular } \\ & \end{array}$




\section{LISTA DE APÊNDICES}

Página

APÊNDICE 1 - Autorização da Instituição de Ensino 121

APÊNDICE 2 - Termo de Consentimento Livre e Esclarecido ........................... 122

APÊNDICE 3 - Planilha de coleta de dados ................................................... 126

APÊNDICE 4 - Valores comparativos do teste $t$ (Student) para amostras independentes, de média e desvio padrão (dp) da CC, e significância estatística (Sig.), valores de F, t e graus de liberdade ( $\mathrm{gl}$ ), entre jovens esportistas (ES) e não esportistas (NE) do sexo masculino de 8 a 18 anos.

APÊNDICE 5 - Valores medidos e preditos da CC de jovens de 8 a 18 anos de idade do sexo masculino.

APÊNDICE 6 - Dados da amostra de referência. 


\title{
RESUMO
}

\section{ANÁLISE MULTIVARIADA DA COMPOSIÇÃO CORPORAL EM JOVENS ESPORTISTAS E NÃO ESPORTISTAS}

\author{
Autor: DALMO ROBERTO LOPES MACHADO \\ Orientador: PROF.DR. VALDIR JOSÉ BARBANTI
}

Modelos antropométricos são alternativas mais usadas no estudo da composição corporal (CC) de campo, contudo as propostas bicompartimentais acarretam vieses na sua interpretação. Os objetivos deste estudo foram quantificar, relacionar, comparar e predizer a CC de jovens, considerando idade, maturação e prática esportiva, a partir de uma análise multivariada referenciada por Absortometria de Raios X de Dupla Energia (DXA). Quatrocentos e oito sujeitos de 8 a 18 anos, foram agrupados em esportistas (ES) e não-esportistas (NE), classificados por idade e pico de velocidade de crescimento (PVC). Foram determinadas a massa de gordura (MG), massa óssea (MO) e massa muscular (MM). Das 36 medidas antropométricas iniciais, nove foram as resultantes no modelo utilizado $\left({ }_{n} Y_{m}={ }_{n} X_{(r+1)(r+1)} \beta_{m}+{ }_{n} \mathcal{E}_{m}\right)$. O aumento contínuo da CC com a idade, apresentou expressivas variações inter-individuais nas idades próximas ao PVC. As mudanças da CC foram previsíveis e apresentaram velocidades distintas de desenvolvimento, mais coincidentes com as alterações maturacionais. A equação antropométrica multivariada apresentou altos coeficientes de determinação e baixos 
erros de estimativa. A validação interna do modelo (PRESS $=0,95 ; 0,93 ; 0,96$ ), o coeficiente $\left(Q^{2}=0,97 ; 0,97 ; 0,98\right)$ e a confiabilidade (SPRESS $=0,09 ; 0,01 ; 0,08$ ), respectivamente para $\mathrm{MG}, \mathrm{MO}$ e $\mathrm{MM}$, permitiram recomendar sua aplicação para populações com características semelhantes a esta amostra. Não houve diferenças significantes entre ES e NE na MM e MO, mas foram encontradas na MG.

Palavras-chave: Composição corporal, DXA, Equações, Modelo, Crianças, Adolescentes. 


\title{
ABSTRACT
}

\section{MULTIVARIED ANALYSIS OF THE BODY COMPOSITION IN YOUNG SPORT PRACTIONERS AND NOT SPORT PRACTIONERS}

\author{
Author: DALMO ROBERTO LOPES MACHADO \\ Adviser: PROF. DR. VALDIR JOSÉ BARBANTI
}

Anthropometric models are the most common alternatives used in field body composition (BC) studies, but the bicompartmental models can cause bias in analysis. The objectives of this study was to quantify, relate, compare and predict the $\mathrm{BC}$ on youth, considering age, maturation and sport practice from a referenced multivariate analysis by Dual Energy Absorptiometry X-Ray (DXA). Four hundred and eight subjects from 8 to 18 years old were grouped in sport practitioners (SP) and non practitioner (NP), classified by age and peak high velocity (PHV). Fat mass (FM), bone mass $(B M)$ and muscle mass $(\mathrm{MM})$ was determined. From the 36 anthropometric initial measurements, nine resulted in the utilized model $\left(\mathbf{n} \mathbf{Y}_{\mathbf{m}}={ }_{n} \mathbf{X}_{(\mathbf{r}+1)(r+1)} \beta_{m}+{ }_{n} \varepsilon_{m}\right)$. The continuous increase of the BC related by age expressed inter-individual variations on the PHV ranging ages. The body composition changes were predictable and showed distinct development velocities that coincide with the maturational modifications. The equations showed high determinations coefficients and low estimative errors. Internal validation of the model (PRESS $=0.95$; $0.93 ; 0.96)$, the coefficient $\left(Q^{2}=0.97 ; 0.97 ; 0.98\right)$ and reliability ( $S_{\text {PRESS }}=0.09 ; 0.01$; 
0.08) respectively for $\mathrm{FM}, \mathrm{BM}$ and $\mathrm{MM}$ allowed to recommend it's application for populations with the same characteristics of the subjects in this study. There was no significant differences between SP and NP for MM and BM, but was differences on FM.

Keywords: Body composition, DXA, Equations, Model, Children, Adolescents. 


\section{INTRODUÇÃO}

A sociedade moderna tem se valido dos recursos tecnológicos para facilitar suas tarefas habituais resultando na adoção de um estilo de vida com características hipocinéticas, dada à enorme redução da participação motora nas suas atividades do cotidiano. $\mathrm{O}$ aumento do comportamento sedentário pode levar a sobrepeso e/ou obesidade, afetando a saúde e o bem-estar. Em casos extremos, pode acarretar $\mathrm{o}$ aparecimento de outras doenças como as coronarianas, a hipertensão, determinados tipos de câncer, diabetes mellitus não-insulinodependente, doença de vesícula biliar, dislipidemia, osteodistrofia, podagra (gota) e doenças pulmonares.

Esta incidência perniciosa hipocinética não se limita apenas à população adulta. Como decorrência, nos últimos anos mais de $20 \%$ das crianças americanas apresentou altos índices de sobrepeso e obesidade (KOTTKE, WU \& HOFFMAN, 2003).

A mesma tendência também ocorre no Brasil (IBGE, 2006). No estudo da tendência secular do estado nutricional de adolescentes, os últimos levantamentos do IBGE (2006) revelam que o sobrepeso aumentou nas últimas décadas de 3,9\% (1974-1975) para $18 \%$ (2002-2003) e a obesidade foi de $0,1 \%$ (1974-1975) para $1,8 \%$ (2002-2003). Outros estudos nacionais confirmam esta propensão (MONTEIRO \& CONDE, 1999; MONTEIRO, SILVA \& NAZÁRIO, 1999; MONTEIRO, BENICIO, CONDE \& POPKIN, 2000), alertando para a necessidade de um monitoramento eficaz e sistemático, além da efetivação de programas e ações preventivas.

Um estilo de vida tipicamente sedentário envolvendo crianças e jovens acarreta alterações metabólicas com riscos diversos para a saúde. A responsabilidade profilática do sobrepeso e da obesidade não é exclusiva de uma classe profissional, mas do esforço conjunto de todos os que têm um contato sistemático com as crianças, incluindo o profissional de educação física.

Além da possibilidade de atuação preventiva da educação física, há o interesse na intervenção e orientação de exercícios visando o rendimento esportivo. No desporto infanto-juvenil, o desempenho motor em parte é dependente das estruturas corporais do praticante e da prontidão para o movimento a partir do 
estágio maturacional. $\mathrm{O}$ avanço das técnicas de treinamento para jovens exige hoje maior exatidão nas orientações, direcionamento do planejamento e adequação morfológica para determinadas práticas esportivas. Entretanto, quando se pretende intervir nas orientações de exercícios ou no estilo de vida do jovem adolescente, esbarra-se numa questão metodológica quanto à exata determinação da $\mathrm{CC}$, e qual sua interdependência com a maturação e a prática esportiva.

Geralmente as competições esportivas infanto-juvenis, além de adotarem uma classificação distinta para cada modalidade, não levam em conta as diferenças de maturação, do volume muscular, da estrutura esquelética, da constituição física e do tamanho corporal. Assim, não é incomum notar grandes diferenças físicas entre competidores de uma mesma categoria, quando apenas a idade é considerada, implicando em eventuais injustiças desportivas. Por outro lado, ainda não é conclusivo o que se sabe sobre os processos que levam à prontidão $\mathrm{e}$ amadurecimento dessas estruturas durante a adolescência, nem quanto dessas dimensões corporais são dependentes do estado maturacional, exigindo assim maior atenção dos organizadores de eventos esportivos, quando crianças são expostas num contexto competitivo.

Parte dessas questões poderiam ser minimizadas, se algumas formas de quantificação dessas estruturas corporais (músculo, gordura e ossos), bem como sua relação com diferentes idades e estágios de maturação fossem mensuráveis de forma mais objetiva. Permanece, porém um desafio aos pesquisadores da área. Como quantificar as estruturas da CC durante a maturação na adolescência, de forma prática, segura e a baixo custo, mediante procedimentos válidos, considerando os estágios da maturação e o envolvimento em práticas esportivas?

A investigação e quantificação dos componentes minerais, teciduais, ósseos e musculares apresentam alternativas bem estabelecidas, entretanto 0 acompanhamento das relações desses componentes durante o crescimento na infância e adolescência, bem como sua relação com a maturação biológica, ainda são inconclusivos. Além do mais, os recursos para estas estimativas geralmente são restritos, complexos e dispendiosos, limitando sua aplicação em grandes populações. Recursos mais acessíveis como as medidas antropométricas, não envolvem análise multicomponente da CC. 
As propostas antropométricas atuais para estimar, por exemplo, a gordura corporal em crianças e adolescentes, além de específicas para determinadas populações, em geral assumem modelos bicomponentes a partir da densidade corporal (Dc), limitando as generalizações e a precisão na estimativa dos demais componentes corporais. Quando a gordura é estimada a partir da Dc (massa magra e massa gorda), não podem ser consideradas as variações do conteúdo mineral ósseo (CMO), ACT, proteína e massa isenta de gordura (MIG) durante uma fase da vida de importantes mudanças, a infância e a adolescência.

Portanto, estudos que levem em conta o fracionamento do peso corporal de forma multicomponente, considerando a associação com a maturação e as práticas esportivas, parecem desejáveis para uma interpretação mais precisa dos constituintes corporais. Sobretudo, a interpretação da dinâmica da CC durante o crescimento e a maturação na adolescência, pode prover valiosa informação no acompanhamento do crescimento humano.

Com exceção dos recursos disponíveis para uso em ambiente de laboratório, não foi encontrada nenhum estudo da estimativa da CC de forma multicomponente para grandes populações, considerando a maturação e a prática esportiva para jovens brasileiros.

Assim, uma interface entre esta lacuna e a investigação da CC de forma compartimentada em crianças e adolescentes, deve contribuir para o avanço do conhecimento e da atuação profissional.

2

\section{OBJETIVOS}

a) Identificar e quantificar os componentes da composição corporal, considerando maturação, idade cronológica e prática esportiva referenciados por análise multicomponente da composição corporal;

b) Relacionar massa muscular, massa óssea e massa de gordura com idade cronológica, maturação e prática esportiva;

c) Propor equações estatísticas preditivas para estimar tecidos ósseo, muscular e adiposo a partir de medidas antropométricas e testar esses modelos 
mediante validação cruzada, estabelecendo os erros de estimativa e confiabilidade do modelo; e

d) Comparar os componentes da composição corporal entre jovens esportistas e não esportistas.

3

\section{LIMITAÇÕES DO ESTUDO}

Algumas limitações do estudo podem ser apontadas como: a) não foram averiguados fatores nutricionais, sociais, econômicos ou hereditários que pudessem interferir na CC dos sujeitos deste estudo; e, não foram verificadas as práticas de treinamento esportivo (intensidades, cargas, periodicidade, volume de treino, exigências da modalidade, entre outras.). Embora outras técnicas mais sofisticadas pudessem ser empregadas, a modelagem do estudo foi planejada de acordo com os recursos disponíveis.

4

\section{REVISÃO DE LITERATURA}

Durante o desenvolvimento do corpo, a composição do organismo ocorre pelo processo de acúmulo de nutrientes e de outros substratos, dando origem aos tecidos, órgãos e massa corporal, ocorrendo estruturação desses elementos em blocos, com suas formas e funções específicas (HEYMSFIELD, LOHMAN, WANG \& GOING, 2005).

As técnicas de análise da CC revelam que as modificações dessas construções (blocos) estão relacionadas à idade e ao estágio metabólico. Cientistas de diferentes disciplinas bem como profissionais da área da saúde, recorrem às medidas de CC em animais e humanos, com propósitos de pesquisas e de diagnósticos. Para que as investigações sejam eficientes, torna-se necessária a consideração de três questões interligadas e que definem pesquisas de CC: 1 . Modelos e seus pressupostos; 2. Procedimentos metodológicos utilizados; e 3. Variabilidade biológica da CC. 
A primeira dessas questões (modelos e seus pressupostos) inclui os padrões e os princípios que envolvem a CC, seus componentes, as definições específicas e as relações entre esses componentes. Do ponto de vista bioquímico, por exemplo, entre 30 e 40 componentes principais no corpo humano. Quando combinados, permitem agrupamentos em diferentes níveis mediante estruturação em algumas formas matemáticas, chamadas assim de modelos. Um desses modelos clássicos é a estimativa da MIG a partir da $A C T$, assumindo que a MIG=ACT/0,732 (PACE \& RATHBUN, 1945), composta de $73,2 \%$ de água (valores constantes em adultos).

A pesquisa da CC caminha para um consenso em aceitar o modelo de classificação de níveis, em que a massa corporal é considerada como a soma de todos os componentes em cada um dos cinco níveis: atômico, molecular, celular, órgão-tecidual e de corpo total (WANG, PIERSON \& HEYMSFIELD, 1992). Certos princípios são inerentes a este modelo e ultimamente as propostas de CC tendem a obedecer a esta conceituação (FIGURA 1). A soma de todos os componentes em cada um dos cinco níveis é equivalente à massa corporal.

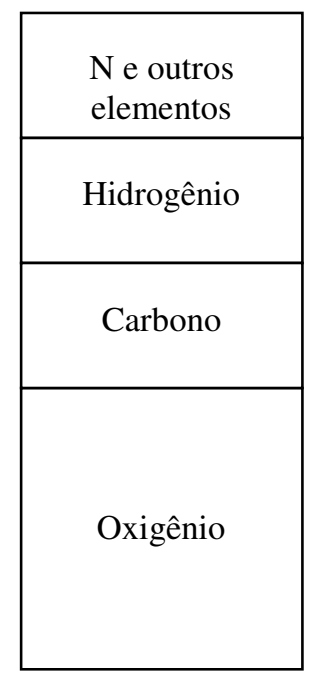

Nível Atômico

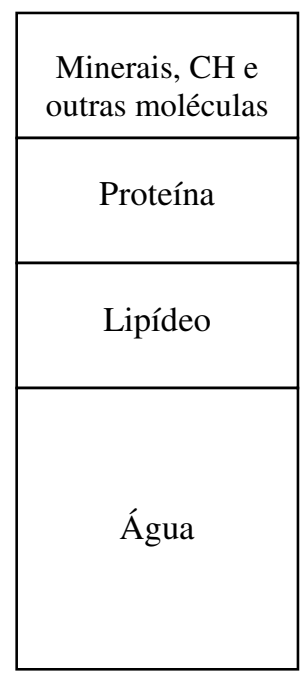

Nível Molecular

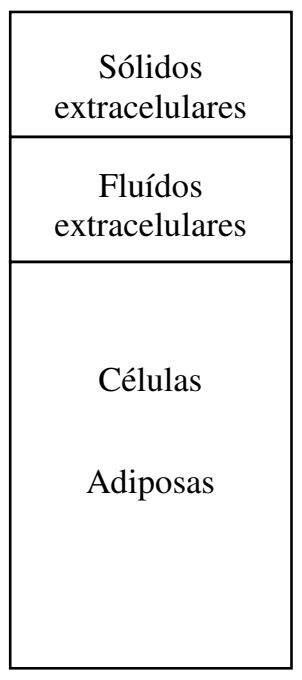

Nível Celular
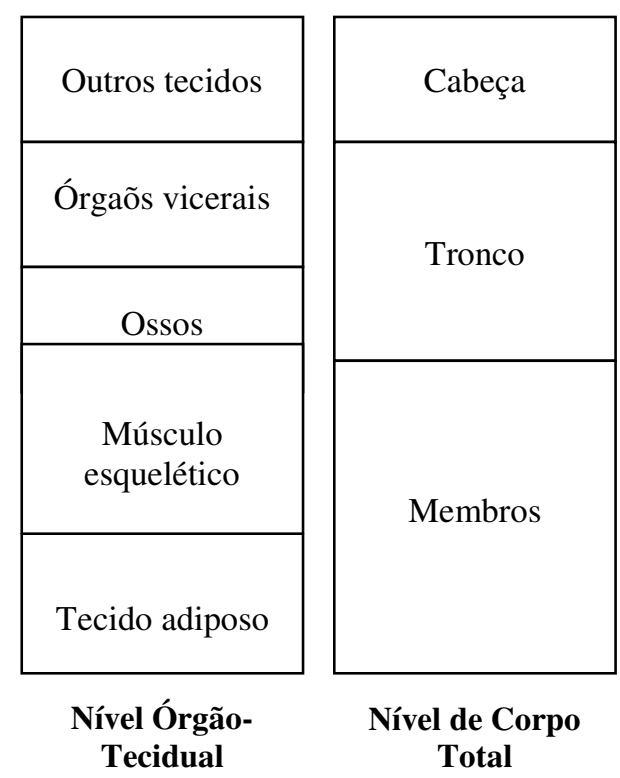

FIGURA 1. Níveis de composição corporal ( $\mathrm{N}=$ nitrogênio; $\mathrm{CH}=$ carboidratos). (Adaptado de WANG et al., 1992). 
A segunda questão das pesquisas da CC relaciona-se aos procedimentos metodológicos utilizados. Diferentes métodos estão disponíveis para medidas in vivo e in vitro, dentro dos principais componentes dos cinco níveis apresentados (FIGURA 1). Muitos métodos permitem estabelecer relações intrasujeitos dentre os componentes intra e inter níveis, permitindo formulação de modelos específicos ou novas formas de combinações, muito embora a maioria das propostas multicomponentes ocorra no nível molecular.

A terceira questão de pesquisa da CC está relacionada à sua variabilidade biológica intra e inter sujeitos - e esta envolve as mudanças na CC relacionada às condições individuais fisiológicas e patológicas. As considerações desta questão nas investigações incluem fatores de crescimento, desenvolvimento, envelhecimento, raça, nutrição, efeitos hormonais e atividade física, bem como algumas doenças e medicamentos que podem afetar a CC (SHEN, ST-ONGE, WANG \& HEYMSFIELD, 2005).

\subsection{Definição de termos}

Durante o século passado diferentes componentes da CC foram estabelecidos por autores variando em quantidade, terminologia e métodos das medidas (HEYMSFIELD et al., 2005). Todavia as terminologias precisam ser estabelecidas para unificação dos avanços tecnológicos. Sendo assim, alguns termos recentemente aceitos pelos pesquisadores da área, passaram a melhor definir a classificação da CC e suas aplicações. Portanto, cabem aqui algumas definições terminológicas adotadas para este estudo.

A primeira delas refere-se ao termo "multicompartimental" ou "multicomponente". Embora o termo em inglês "multicomponent" possa ser mais bem traduzido por multicomponente, a literatura da área emprega "multicomponente" e "multicompartimento" de forma intercambiária. Por compartimento pode se entender as divisões possíveis dos níveis de estudo da CC, como aqueles definidos por WANG et al. (2002), ou seja, a forma de partição de cada nível, enquanto o termo "componente", refere-se ao elemento que, ou o que entra na composição de alguma coisa (PRIBERAM, 2008) ou compartimento. Por exemplo, os multicomponentes do nível atômico seriam oxigênio, carbono, hidrogênio, $\mathrm{N}$ e outros elementos distribuídos 
em 4 compartimentos. Neste caso, os componentes $\mathrm{N}, \mathrm{K}, \mathrm{Ca}$, $\mathrm{Na}$ estão no mesmo compartimento (FIGURA 1). Do nível molecular, os componentes de água, lipídeo, proteína, minerais, $\mathrm{CH}$ e outras moléculas também são alocadas em apenas 4 compartimentos. Na compartimentação órgão tecidual, teríamos o tecido adiposo, músculo esquelético, ossos, órgãos viscerais e outros tecidos em 5 compartimentos. Desta forma, os componentes implicam nos elementos da CC enquanto os compartimentos refletem a quantidade de divisões ao armazená-los. A partir dessa reflexão, o termo multicomponente será adotado para este estudo.

Outro termo que gera confusão é a expressão FFM (fat free-mass) traduzida como massa "livre" de gordura ou massa "isenta" de gordura. Entretanto a palavra "livre" (do Lat. = Liberu) caracteriza liberdade, absolvido, liberado, em liberdade, sem restrições. Embora também caracterize isenção, parece um termo mais forte para expressar ausência de. Por sua vez, "isenta" (do Lat. Exemptu) conota dispensado, desobrigado, eximido, independente, implicando certa parcialidade. Uma vez que FFM contém gordura essencial, proteína, carboidratos, tecidos minerais moles e ósseos além de fluídos intra e extracelulares, o termo "isenta" comporta melhor essa condição. Desta forma "massa isenta de gordura" será adotado neste estudo, como o termo preferido para caracterizar FFM (fat free-mass).

O significado do termo lipídeo ou gordura, por exemplo, na pesquisa da CC é caracterizado de forma diferente (SHEN et al., 2005) das outras áreas. Lipídio inclui todo material biológico extraído com solventes lipídicos como éter e clorofórmios. Esses lipídios extraídos compreendem triglicérides, fosfolipídios e estruturas lipídicas que são encontradas em quantidades relativamente menores in vivo (SHEN et al., 2005). Por outro lado, gordura refere-se de forma específica à família dos lipídios constituída em triglicérides (WANG et al., 1992). Embora esta terminologia não seja uniforme, há uma tendência do termo lipídeos ser usado para todo lipídeo extraído por éter ou clorofórmio a partir dos tecidos e o termo gordura, para as triglicérides.

Ainda que amplamente utilizado nas primeiras pesquisas da $\mathrm{CC}$, o termo massa magra tem passado por um aprimoramento conceitual por conta de estudos mais recentes envolvendo tecnologias mais avançadas, pois os modelos de $\mathrm{CC}$ incluem determinados componentes que esse termo não define de forma precisa 
ou representativa (HEYMSFIELD et al., 2005). Um termo similar, massa de tecido mole (MTM), é utilizado em modelos de CC principalmente em referência à DXA (Dual energy $X$-ray absorptiometry). Este é o caso do presente estudo, que tem na DXA o referencial para CC.

\subsection{Absortometria de raios-X de dupla energia - DXA}

A técnica de Absortometria de raios-X de dupla energia (DXA) é baseada na atenuação diferencial da energia transmitida de dois fótons que incidem através dos ossos e tecidos moles (HEYMSFIELD, WANG, HESHKA, KEHAYIAS, \& PIERSON, 1989). O indivíduo é rastreado (ato de transferir dados visuais para o computador através de mapeamento, varredura ou exame) com fóton a dois níveis de energia e absorção diferenciados. Os fótons são gerados por fontes de "GADOLINIUM" (DPA - Absortometria de duplo fóton) ou fontes de raios-X (JENSEN, 1992). Diversos estudos têm descrito as bases teóricas da DXA para estimativa da composição do tecido mole e do tecido mineral ósseo (MAZESS, BARDEN, BISEK \& HANSON, 1990; JOHNSON \& DAWSON-HUGHES, 1991; ROUBENOFF, KEHAYIAS, DAWSON-HUGHES \& HEYMSFIELD, 1993; PIETROBELLI, WANG, FORMICA, \& HEYMSFIELD, 1998).

O suplemento do estudo da DXA está na sua utilização para medir a CC regional e total, compreendendo a determinação da Dc $\left(\mathrm{g} / \mathrm{cm}^{2}\right), \mathrm{CMO}(\mathrm{g})$, massa de tecido magro (TM, g) isenta de mineral ósseo, MG (g), MTM=TM+MG (g) e MIG = $\mathrm{TM}+\mathrm{CMO}(\mathrm{g})$.

Revisões realizadas sobre a precisão da DXA na estimativa da CC (PETROSKI \& PIRES-NETO, 1996; KOHRT, 1998; LOHMAN, HARRIS, TEIXEIRA \& WEISS, 2000; GENTON, HANS, KYLE, \& PICHARD, 2002) indicam validade empírica e teórica do método na estimativa de MG e da MIG. Embora a precisão esteja bem estabelecida na literatura a variabilidade entre populações ou a utilização de diferentes equipamentos e softwares precisa ser considerada.

Nas comparações com algum outro método de referência, o erro padrão da estimativa (EPE) deve ser menor do que 3\% para que a DXA possa ser aceita como método de referência. Erros excedentes a 4\% mostram muita variabilidade e entre $3 \%$ a 4\%, a validade é considerada limitada (LOHMAN, 1992). 
Assim, novos softwares têm sido testados para que a estimativa dos componentes da CC seja aprimorada.

Duas formas principais de leitura são utilizadas: fan-beam e pencilbeam. A tecnologia fan-beam possui Raios-X de feixes múltiplos, possibilitando maior velocidade e mais alta resolução de imagem. Já os equipamentos com tecnologia pencil-beam são dotados de apenas um par de feixes de Raios-X. Ou seja, o exame é mais demorado e a resolução da imagem é menor.

Porém, modelos multicomponentes demonstraram que os resultados da DXA (pencil beam) estão bem relacionados com a CC (KOHRT, 1998; TATARANNI \& RAVUSSIN, 1995). Entretanto o exame com DXA (fan-beam) tem sido o caminho mais indicado para estimativa da CC (SCHOELLER, TYLAVSKY, BAER, CHUMLEA, EARTHMAN, FUERST, HARRIS, HEYMSFIELD, HORLICK, LOHMAN, LUKASKI, SHEPHERD, SIERVOGEL \& BORRUD, 2005) por apresentar maior definição do CMO e MTM. Contudo, não há propostas de padronização validada, o que tem gerado grande variação nos critérios metodológicos, nos tipos de equipamentos, nos softwares utilizados bem como nas características das populações investigadas.

A DXA pode ser utilizada em populações humanas de todas as idades por causa da baixa exposição radiológica. A exposição de varredura de corpo total abrange de 0,02 a 1,5 mrem dependendo do instrumento e da velocidade da varredura. Porque este valor representa limites muito abaixo das dosagens anuais permitidas para o ser humano (4-6 mrem) e muito menor do que outros procedimentos convencionais de raios- $X$ (25 a 270 mrem, raios- $X$ de tórax, varredura por TC), a DXA é altamente recomendada em populações de todas as idades (LOHMAN \& CHEN, 2005).

Entretanto o exame não é indicado para gestantes, sendo recomendados exames preliminares de gravidez antes da DXA. Softwares especiais também estão disponíveis para a utilização em crianças, que consideram a maior hidratação do tecido magro, com um coeficiente de atenuação diferenciado. Erros sistemáticos na estimativa da CC observados em estudos com porcos e bebês, indicam limitações e portanto, a necessidade de avanços nos estudos dessas populações (SVENDSEN, HAARBO, HASSAGER \& CHRISTIANSEN, 1993). 
Ingestão de alimentos e fluídos têm apenas pequenos efeitos sobre a DXA (LOHMAN \& CHEN, 2005). Para ilustrar, quando 1 a $4 \mathrm{~kg}$ de fluído contendo sal é removido por hemodiálise, a estimativa da massa magra diminui com pequenas mudanças no CMO ou MG (LOHMAN \& CHEN, 2005).

A CC de sujeitos maiores que $193 \mathrm{~cm}$ ou mais largos (58 a $65 \mathrm{~cm}$ ) não pode ser estimada de forma direta, pois parte do corpo fica fora da área de varredura da DXA (LOHMAN \& CHEN, 2005). Nesse sentido, algumas alternativas têm sido apresentadas quanto à posição corporal no momento do exame. O que é sugerindo para sujeitos maiores que a mesa, varredura com os joelhos flexionados (SILVA, BAPTISTA, MINDERICO, RODRIGUES, PIETROBELLI, TEIXEIRA \& SARDINHA, 2004) e os valores ajustados a partir da utilização de modelos de correção para estimativa de CMO, MG, e TM. Quando os indivíduos são mais largos que a área de varredura, a técnica de leitura de metade do corpo pode ser utilizada (TATARANNI \& RAVUSSIN, 1995), os autores recomendam este procedimento para indivíduos largos, diante da alta similaridade e simetria bilateral. Softwares mais atuais já incluem esse tipo de análise automaticamente.

Existem três versões comerciais de aparelhos, diferindo na configuração de hardware e software entre os fabricantes. Os três fabricantes se referem aos seus equipamentos como QDR (Hologic, Waltham, MA), DPX (General Electric Lunar Corporation, Madison, WI) e XR (STRATEC Biomedical Systems AG, Fort Atkinson, $\mathrm{WI})$. As características de cada um deles foram sintetizadas por GENTON et al. (2002).

Uma vez que a DXA provê a proporção de gordura e MIG para cada pixel, as estimativas de gordura são medidas da MTM e tecido ósseo, aumentando a precisão do cálculo dos componentes corporais. Diferente das técnicas de TC e ressonância magnética (RM) em que o pixel é determinado para captação exclusiva de tecido adiposo ou do tecido magro, na DXA os dois tecidos são analisados simultaneamente, numa única varredura e com menor incidência de radiação.

Um pressuposto que sustenta a DXA é que as medidas não são afetadas pela espessura antero-posterior do corpo. Muito embora esta suposição seja esperada para espessuras corporais menores que $20 \mathrm{~cm}$, espessuras maiores que $25 \mathrm{~cm}$ podem ter algum efeito na precisão da estimativa (LASKEY, LYTTLE, 
FLAXMAN \& BARBER, 1992), os atuais softwares consideram essas diferenças na atenuação e velocidade de varredura de corpo total (SHYPAILO, BUTTE \& ELLIS, 2008).

Outro pressuposto está relacionado à área corporal analisada para obter os dados da CC e o grau de associação da gordura total não analisada. Numa quantificação óssea dos tecidos moles de corpo total é estimado que $40 \%$ a $45 \%$ dos 21000 pixels são excluídos a partir dos cálculos dos valores de tecido mole. Assim, à medida que a composição da área excluída difere da área considerada, há o início de erro sistemático para esse indivíduo. Portanto, com a capacidade da DXA em analisar simultaneamente os dois tecidos, há diminuição de erros na estimativa de gordura corporal. Por conseqüência, maiores valores de gordura podem ser detectados por incluir adipócitos ósseos e musculares.

A estimativa da CC pela DXA em relação a cada região supõe que a composição é igualmente representada por unidade de volume, calculados em valores corporais totais. A influência de braço e tórax sobre a CC total pode ser subrepresentada, dada à área óssea relativamente maior dessas regiões (ROUBENOFF et al., 1993). Embora os softwares efetuem aproximações desse problema, trata-se de uma informação do fabricante e é difícil avaliar quão bem a CC é estimada pelas porções não analisadas. Assim, a consideração da área apendicular (relativa aos membros corporais) deve ser considerada no momento de se efetuar os cálculos dos componentes corporais.

Quando o valor do índice de massa corporal (IMC) é elevado podem ocorrer distorções nas interpretações da CC por DXA. A acurácia da DXA em medir gordura corporal pode ser considerada em três diferentes caminhos: 1) A possibilidade de ocorrer erro sistemático nas comparações com outros métodos de referência, com variação na magnitude para diferentes populações e instrumentos. Assim o erro sistemático pode implicar em imprecisão do método de referência, na estimativa da DXA ou na combinação de ambos. 2) O EPE para porcentual de gordura (\%G) deve ser menor que 3\% para que um método de referência possa ser aceitável. Se exceder a 4\% há muita variabilidade e limitação da validade. Muitos métodos tendem a superestimar gordura em população magra e subestimá-la em população obesa. 3) Novos softwares são constantemente testados para determinar 
se a precisão das estimativas aumenta. Desta forma, modelos multicomponentes são essenciais para a validação da DXA.

Um sumário de estudos para validação da DXA foi realizado por LOHMAN et al. (2000) sugerindo que DXA e modelos multicomponentes aumentaram nos últimos anos os valores médios da estimativa da MG de $1 \%$ a $3 \%$ pelo método pencil-beam; a DXA apresentou EPE de 4,4kg na estimativa de MM, contra 1,6kg na comparação com análise por ativação de nêutrons e diferenças da MG, MIG e MO entre $1 \%$ a $5 \%$ considerando tipos de análise (fan-beam e pencil-beam). Todavia estudos em animais ainda são os recursos mais atraentes, uma vez que permitem validação desse método por análise da carcaça animal (LOHMAN \& CHEN, 2005).

Nesse sentido, SVENDSEN et al. (1993) usaram Lunar DPX para mensurar a carcaça de 7 porcos entre 35 e 95kg obtendo uma diferença média de apenas 2,2\% entre DXA e análise química. O erro padrão para a análise de regressão foi de 2,9\%. Em outro estudo, PICAUD, RIGO, NYAMUGABO, MILET e SENTERRE (1996) observaram que o peso corporal foi estimado com alta precisão, mas a MG foi superestimada pela DXA. Todavia, a estimativa do peso corporal, CMO e conteúdos da MG foram altamente correlacionados com análise química de porção óssea cinza, cálcio e gordura química $(r=0,955$ a 0,999) e apresentaram excelente reprodutibilidade.

Estes resultados confirmam a precisão da DXA em estimar os componentes corporais que não sofrem os efeitos da hidratação (MG e MO). Esta questão torna-se de alta relevância, uma vez que durante o crescimento da infância à vida adulta, a hidratação relativa corporal diminui.

\subsubsection{Aplicabilidade da DXA em crianças e adolescentes}

Por causa da baixa exposição à radiação e das mudanças na MIG durante o crescimento e desenvolvimento (LOHMAN, 1986) a DXA é considerada ideal para a estimativa da CC em crianças e adolescentes e no mapeamento das mudanças corporais que ocorrem durante toda a vida (LOHMAN \& CHEN, 2005). Embora durante o crescimento e desenvolvimento ocorra maior hidratação da MTM, a variação da estimativa do \%G por DXA é menor que $1 \%$. 
Existem modelos de referência diferenciados para CC de crianças e adolescentes utilizando DXA, especificamente entre as idades entre 5 e 19 anos (ELLIS, SHYPAILO, ABRAMS \& WONG, 2000). Estas análises confirmam as primeiras estimativas para MIG e MG (FOMON, HASCHKE, ZIEGLER \& NELSON 1982) a partir de dados da literatura.

É reconhecido que o alto nível de hidratação da MIG e o baixo nível do CMO limitam a precisão dos modelos bicomponentes que utilizam pesagem hidrostática ou deslocamento de ar por pletismografia (FIELDS, GORAN \& McCRORY, 2002). Assim, o uso de modelos multicomponentes nos estudos da CC em crianças teria mais sentido, muito embora não sejam universais. Por outro lado, as propostas multicomponentes de análise da CC normalmente envolvem o nível molecular, enquanto as medidas antropométricas abrangeriam o nível órgão tecidual.

Desta forma a DXA passa a ser uma alternativa de grande potencial tanto nos estudos de pesquisa como na aplicação clínica pediátrica. Não só pela baixa exposição radiológica e pela praticidade e rapidez na estimativa dos multicomponentes corporais, mas por permitir melhores interpretações da CC da criança e adolescente durante o crescimento e por possibilitar associação com as estimativas antropométricas.

A possibilidade de estimativa dos três principais componentes (MG, TM e $\mathrm{CMO}$ ), figura nos dois principais constituintes do nível celular da CC (CMO e fluído extracelular). A relevância deste fato se dá pela expectativa de desidratação de até $70 \%$ que ocorrerá até por volta dos primeiros 120-140 meses (10-11 anos) (SOPHER, SHEN \& PIETROBELLI, 2005). Embora estes dois componentes (CMO e fluído extracelular) aumentem com a idade, não diferem em taxas relativas entre si, mas não são metabolicamente homogêneos com respeito às diferentes idades, assim os resultados devem ser interpretados de acordo com estas proporções (FOMON et al., 1982).

\subsection{Estimativa da massa de gordura}

Já está consolidada na literatura na maioria das suas investigações, uma associação entre o aumento da MG e o risco de indicadores de doenças cardiovasculares, lesões da coronária em adultos, crianças e adolescentes. Embora 
o IMC, a estimativa do \%G por dobras cutâneas possam predizer fatores de risco, há necessidade de programar o uso de métodos mais precisos e reprodutíveis da estimativa da gordura corporal regional e total (SARDINHA \& TEIXEIRA, 2005). Os equipamentos de DXA mais atuais possibilitam melhores estimativas, uma vez que eles são capazes de distinguir os componentes do tecido mole com maior precisão.

Diversos recursos estão disponíveis para estimar gordura corporal total ou tecido adiposo. Os métodos por imagem como tomografia computadorizada (TC) axial e RM são utilizados para análise do tecido adiposo no nível órgão tecidual. Conforme proposto por WANG, PIERSON JR e HEYMSFIELD (1992) têm alta precisão e também alto custo. Outros métodos como a DXA e o deslocamento de ar por pletismografia estimam a gordura corporal total no nível de componente tecidual e molecular com custos menores. Gordura corporal total e massa de tecido adiposo não podem ser entendidas como sinônimas, pois o tecido adiposo contém $80 \%$ de gordura e esta também pode ser encontrada em outros tecidos (i.e. ósseos, medulares, teciduais e músculares).

Geralmente o conceito de \%G tem sido utilizado para relacionar gordura e saúde. Todavia a utilização do termo \%G passa atualmente por mudanças, uma vez que sua relação com o peso corporal ignora a variação intersujeitos da MIG (WELLS, 2001). Por exemplo: dois indivíduos podem diferir no \%G quando tiverem equivalentes MIG, mas diferentes valores de $M G$ ou quando eles tiverem similar $M G$, mas diferente MIG.

Em crianças, por exemplo, durante o crescimento, a variação da MIG representa $2 / 3$ do $\% G$, sugerindo que o uso do $\% G$ para definir obesidade é dependente da MIG. Esta questão é crucial durante o crescimento (WELLS, 2001). SARDINHA e TEIXEIRA (2005) lembram uma forma de regularizar este problema, utilizando índices para massa de gordura (IMG) e para MIG (IMIG), capazes de detectar as mudanças nos estoques de gordura e de MIG durante o crescimento. As mudanças anuais ocorrentes nos meninos são mais dependentes do IMIG do que do IMG. Nas meninas, as mudanças longitudinais são similares para IMIG e IMG até aos 16 anos, quando então as mudanças da CC são atribuídas ao IMG. Essas observações sustentam a necessidade de monitorar a extensão que cada 
componente contribui para as mudanças na CC de meninos e meninas durante certas fases de crescimento.

Existem estudos que têm proposto valores de referência para IMG e IMIG para uma ampla faixa etária adulta (SCHUTZ, KYLE \& PICHARD, 2002) e pediátrica (NAKAO \& KOMIYA, 2003). Todavia há necessidade de avanços nas pesquisas que façam a associação entre o IMG com a obesidade relacionada às doenças, como forma de julgar sua aplicação de modo mais específico para várias idades (SARDINHA \& TEIXEIRA, 2005).

Dentre outras medidas antropométricas, as medidas de dobras cutâneas têm sido geralmente utilizadas para expressar a gordura corporal por representar bem suas proporções. Todavia a considerável variabilidade inter-sujeitos e as taxas de variação dos depósitos de gordura num determinado local sugerem que as comparações podem ser fortemente influenciadas por idade, sexo, raça, local da dobra cutânea e grau de obesidade. Assim, os modelos descritivos desenvolvidos para populações com características específicas devem considerar esses fatores. Dobras cutâneas utilizadas de forma exclusiva ou combinadas com outros tipos de medidas antropométricas têm sido empregadas para substituir adiposidade corporal em estudos relacionados à saúde (SARDINHA, TEIXEIRA, GUEDES, GOING \& LOHMAN, 2000; TEIXEIRA, SARDINHA, GOING \& LOHMAN, 2001).

Em relação à adiposidade corporal e na distribuição de gordura na promoção da saúde, a prioridade das evidências empíricas mostra que o aumento da adiposidade está associado ao risco de doenças cardiovasculares e lesões arteriais e coronarianas em crianças e adolescentes. Dobras cutâneas podem ser usadas para estimar \%G e identificar as crianças e adolescentes com tais riscos. Entretanto há necessidade de programar e ampliar o uso de métodos mais precisos para estimar o acúmulo do tecido adiposo regional e total (SARDINHA \& TEIXEIRA, 2005).

\subsection{Estimativa da massa muscular}

Métodos para determinação da CC em humanos enfatizam a estimativa da gordura corporal enquanto as técnicas para estimar TM ou MM são limitadas (LUKASKI, 1987; HEYMSFIELD et al., 2005). Certamente esta ênfase reflete em parte, a demanda de a comunidade científica estimar o \%G por ser um preditor de 
risco de desenvolvimento de doenças crônicas. Todavia com o avanço das técnicas de análise multicompartimentada, tem ocorrido uma reavaliação da importância na estimativa in vivo da estrutura músculo-esquelética, principalmente no campo da performance esportiva.

A estrutura muscular é representada em três formas de músculo: esquelético, liso e cardíaco. O músculo esquelético ou estriado representa

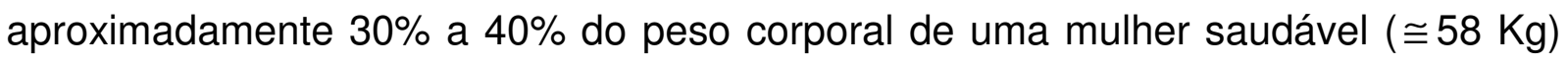
ou de um homem ( $\cong 70 \mathrm{Kg}) \quad\left(\mathrm{ICRP}^{1}\right.$ apud LUKASKI, 2005). Em adultos, são encontrados maiores volumes musculares nos membros inferiores do que no restante do corpo (cabeça, tronco e membros superiores).

A necessidade de determinar a MM total ou regional reflete interesses multidisciplinares. Uma vez que a estrutura músculo esquelética é exigida para o movimento, estudiosos do exercício têm interesse em relacionar as estimativas de MM com vários tipos de performance esportiva aeróbia e anaeróbia (LUKASKI, 2005).

Indicadores antropométricos têm sido utilizados para estimar a MM, a partir de algumas medidas corporais. Geralmente um grupo muscular é selecionado com o pressuposto de que estas medidas refletem a MM daquela região e que esta estimativa é diretamente proporcional à MM corporal. Um exemplo bastante utilizado desse procedimento foi apresentado nos anos 60 por JELLIFFE (1966), onde o perímetro do músculo pode ser estimado a partir de uma simples variável, o perímetro de braço corrigido pelo tecido adiposo.

Entretanto a precisão desse procedimento foi investigada por HEYMSFIELD, OLAFSON, KUTNER e NIXON (1979), ao observarem que em sujeitos muito obesos, a área muscular de braço neste modelo foi superestimada entre $15 \%$ a $25 \%$ em comparação a valores referenciados por TC. Novas equações foram propostas reduzindo o erro intra-individual para 7\% a $8 \%$ da área muscular de braço (HEYMSFIELD, McMANUS, SMITH, STEVENS e NIXON, 1982). De forma semelhante de como ocorre com a gordura corporal, quando os valores de outros

\footnotetext{
${ }^{1}$ International Commission of Radiological Protection (ICRP). Report of the task group on reference man. Oxford: Pergamon Press. p.108-112, 1975.
} 
componentes da CC extrapolam a normalidade, percebe-se uma tendência de viés nos resultados da estimativa muscular.

Ainda que estes resultados sejam encorajadores, não se conhece a precisão ou sensibilidade para monitorar pequenas mudanças na $\mathrm{MM}$ associados à perda ou ganho de peso corporal. Nem tampouco o acompanhamento das mudanças da estrutura muscular durante 0 processo de crescimento e maturação, principalmente por se tratar de modelos propostos para população adulta.

Outras técnicas de mensuração da MM têm sido propostas com base no metabolismo endógeno, envolvem análise de excreção urinária de creatina (LUKASKI, 2005) e do aminoácido 3-metilhistidina, técnicas nucleares que consideram o conhecimento das características físicas e a distribuição biológica de potássio e $\mathrm{N}$ e análise de bio-impedância elétrica (LUKASKI, 2005), entre outras.

Em contraste aos métodos indiretos, técnicas radiográficas permitem visualizar diretamente os componentes da CC, incluindo tecido adiposo, osso e músculo. Além de proporcionar respostas diferenciadas dos tecidos, possibilitam medidas regionalizadas e de corpo total. As três técnicas mais utilizadas são: TC, imagem por RM e Absortometria por raios-X de dupla energia (DXA).

TABELA 1. Comparação dos métodos para estimativa da massa músculo-esquelética em humanos.

\begin{tabular}{cccccc}
\hline Método & Precisão & Exatidão & Aplicabilidade & Abrangência & Custo \\
\hline Antropometria & 3 & $?$ & 4 & R, CT & 1 \\
Creatina & 2 & 2 & 1 & CT & 3 \\
$\begin{array}{c}\text { Tomografia } \\
\text { computadorizada }\end{array}$ & 5 & 4 & 4 & R, CT & 5 \\
$\begin{array}{c}\text { Ressonância } \\
\text { magnética }\end{array}$ & 5 & 4 & 4 & R, CT & 5 \\
$\quad$ DXA & 5 & 4 & 4 & R, CT & 4 \\
Bio-impedância & 4 & $?$ & $?$ & R & 1 \\
\hline
\end{tabular}

Nota. R=regional e CT=corpo total e DXA=Absortometria de raios-X de dupla energia. Sistema de nível: escala ascendente, $1=$ menor e $5=$ maior. (Adaptado de HEYMSFIELD et al., 2005). 
A TABELA 1 compara as características de alguns dos métodos mais utilizados na estimativa da MM in vivo, adaptada de LUKASKI (2005).

Embora inicialmente a DXA tenha sido proposta para estimativa regional do $\mathrm{CMO}$ e área de densidade, esta técnica tem-se refinado na estimativa dos outros componentes do tecido mole (LUKASKI, 1993). A DXA mostrou ser o método mais vantajoso, pois apresenta o menor custo e mesma eficácia dos métodos mais caros e eficácia muito superior na estimativa da MM em relação aos recursos mais baratos.

No entanto, a seleção do método depende do recurso disponível e da intenção da investigação experimental, além do acesso ao equipamento, da segurança e da conveniência metodológica para o uso geral. Ou seja, a escolha da técnica depende das considerações práticas e limitações de cada método em relação à hipótese experimental de estudo proposta.

Nesta direção, KIM, WANG, HEYMSFIELD, BAUMGARTNER e GALLAGHER (2002) desenvolveram e validaram modelos preditivos para estimativa da $\mathrm{MM}$ apendicular em adultos e 4 anos mais tarde para crianças e adolescentes (KIM, SHEN, GALLAGHER, JONES, WANG, WANG, HESHKA \& HEYMSFIELD, 2006). A partir da estimativa do TMA obtida por DXA, a MM total é estimada, assumindo como pressuposto que a maior parte (>90\%) está concentrada nos membros superiores e inferiores. Assim, mediante equações preditivas, torna-se possível calcular a MM:

Para adultos (KIM et al., 2002)

(Equação 1)

$\mathrm{MM}=1,19 \times \mathrm{Ma}-1,65$;

(R2=0,96, $\mathrm{EPE}=0,163 \mathrm{~kg}, \mathrm{P}=0,001)$

Para crianças (KIM et al., 2006)

(Equação 2)

$\mathrm{MM}=1,003+0,039 \times$ Peso corporal $-1,315$

$(\mathrm{R} 2=0,985, \mathrm{EPE}=0,524 \mathrm{~kg}, \mathrm{P}=0,001)$

\subsection{Estimativa da massa óssea}

Historicamente um dos principais obstáculos para estimar a CC tem sido a dificuldade na quantificação in vivo do tecido ósseo. Os primeiros estudos se 
baseavam na análise do esqueleto total, secções ósseas e em clichês radiográficos padronizados (MALINA, 2005). Esses estudos sugeriam variabilidade da mineralização e $\mathrm{MO}$ associadas à idade, sexo, raça e fatores étnicos. A partir das novas tecnologias, incluindo a DXA, foram possíveis novas percepções do esqueleto como componente da CC e do status mineral ósseo.

Os ossos mostram contribuição distinta na composição do tamanho total do esqueleto ou da estatura. Essas proporções variam com a idade, sexo e etnia (MALINA, BOUCHARD \& BAR-OR, 2004) e provavelmente influenciam a estimativa da CC. Dados têm demonstrado que a relação da altura tronco-cefálica (ATC) para a estatura, que é um índice da contribuição relativa do tronco e cabeça, representa uma unidade de relação com os membros inferiores, especificamente, a estatura subisquial (estatura menos a ATC).

A relação é maior na infância e declina durante 0 amadurecimento até a adolescência. Esta taxa (relação) alcança seu ponto mais baixo no início do estirão de crescimento na adolescência, pois as pernas têm seu estirão primeiro. A partir de então, o tronco aumenta sua taxa de crescimento da adolescência tardia até a fase adulta jovem. Durante as quatro décadas seguintes de vida, a ATC começa a declinar o que pode ser atribuído à compressão ou eventual perda de elasticidade dos discos intervertebrais com o avanço da idade (MALINA, 2005).

Como o porcentual da massa corporal, a hidratação óssea do esqueleto, compreende cerca de $3 \%$ do peso do feto para o recém nascido e cerca de $6 \%$ a $7 \%$ da massa corporal em adultos jovens, o CMO compreende cerca de $2 \%$ do peso corporal na infância e $4 \%$ a $5 \%$ em adultos (MALINA, 2005). A MO isenta de gordura é composta por mineral ósseo e pela matriz óssea orgânica. A relação do peso entre a porção cinza (compostos ósseos hídricos) e a porção seca, provê a estimativa do CMO. Embora a densidade óssea diminua com a idade da fase adulta à velhice, a percentagem da porção cinza varia entre os ossos (TROTTER \& HIXON, 1974) durante esse mesmo período.

Considerando que o CMO medido pela DXA representa a parte óssea cinza (ash) da MO total, torna-se necessária a consideração da porção óssea úmida (dry). Aproximadamente $1 \mathrm{~g}$ de MO contém 0,9582 de porção óssea cinza, assim, BALLOR (1996) estimou que a porção óssea cinza representa cerca de 95,82\% da 
MO total, assim o peso esquelético deveria ser corrigido, multiplicando o $\mathrm{CMO}$ (medido por DXA) por 1,0436. Ainda que existam significantes diferenças na estimativa do CMO entre sistemas comerciais DXA, isto deverá representar um impacto mínimo sobre a estimativa multicomponente da CC (MODLESKY et al., 1999).

A estrutura óssea de rapazes pesa em média cerca de $95 \mathrm{~g}$ a menos que das moças durante a infância, invertendo-se na idade adulta para cerca de 4,0 e 2,8kg, respectivamente masculino e feminino (MALINA, 2005). O CMO corporal total ou regional aumenta da infância para a adolescência, embora existam diferenças no delineamento anatômico em mapeamento feito por DXA. Não existem diferenças sexuais no CMO da cabeça e tronco durante a infância até a adolescência e também não há diferenças do $\mathrm{CMO}$ regional e total para os membros durante a infância (MALINA, 2005).

As meninas apresentam diferenças ligeiramente maiores do CMO total e regional (de membros) até o início do estirão de crescimento da adolescência (por volta dos 12 anos). Porém durante o estirão dos meninos, o mineral ósseo de membros e de corpo total acumula maiores taxas do que as meninas, contribuindo para as diferenças do CMO total e de membros (MALINA, BOUCHAR \& BAR-OR, 2004). Esse aumento continua até por volta dos 20 anos, com menores taxas nas meninas persistindo durante a idade adulta.

As diferenças sexuais da CC são pouco significantes na infância, entretanto passam a ser estabelecida durante o estirão na adolescência, refletindo maiores proporções na MIG, CMO (especificamente no esqueleto de membros) e MM nos meninos. Assim, a consideração das estruturas da CC (gordura, músculo e ossos) e as diferenças estabelecidas durante a maturação e crescimento, persistem até a idade adulta, refletindo mudanças dos componentes específicos com o avanço da idade. Certamente o tempo individual em que essas proporções acontecem é dependente do tempo de maturação de cada pessoa (MACHADO, 2004).

\subsection{Pico de velocidade de crescimento}

Outro importante componente a ser considerado nas mudanças da CC é a maturação. As formas de verificação da maturação por muito tempo têm sido 
feitas através de observação hormonal em laboratório, desenvolvimento glandular, observação médica, períodos da dentição, fases da ocorrência da menarca, distribuição da pilosidade tegumentária, auto-avaliação das características sexuais secundárias e desenvolvimento esquelético, entre outras (DUKE, LITT \& GROSS, 1980).

Nas investigações da área da educação física o recurso mais utilizado tem sido a maturação puberal (ou sexual) que é determinada por observação do desenvolvimento das características sexuais secundárias, sendo observado o desenvolvimento das mamas para as meninas, genitálias e testículos para os meninos e pilosidade pubiana para ambos. A idade esquelética é outro importante indicador na determinação do estágio maturacional e por estar associada aos indicadores de maturação sexual, foi utilizado como método de referência para a idade sexual (características sexuais secundárias). Todavia o alto custo e complexidade operacional têm reduzido sua utilização nos estudos da ciência esportiva (MACHADO, 2004).

Outro procedimento disponível é o acompanhamento do crescimento somático, que pode ser definido como um processo em que os indivíduos alteram de modo contínuo a magnitude do seu tamanho e forma corporal num dado intervalo de tempo. O acompanhamento envolve monitoramento das variações antropométricas, sendo a idade do PVC um dos seus mais importantes indicadores (MALINA \& BOUCHARD, 1991).

Durante o PVC da adolescência, ocorrem aceleração e desaceleração do crescimento esquelético refletindo num grande incremento do crescimento pondero-estatural. A idade do PVC é o indicador mais comumente utilizado em estudos longitudinais na maturidade somática do adolescente (MALINA \& BOUCHARD, 1991). Assim, mediante o acompanhamento do crescimento, pode-se detectar o momento em que o indivíduo atinge o PVC. Obviamente, seriam necessárias várias medidas durante um determinado período do crescimento, o que tornaria essa metodologia inviável para investigações transversais quando apenas a realização de uma única medida fosse possível.

Neste sentido, MIRWALD, BAXTER-JONES, BAILEY e BEUNEN (2002) desenvolveram uma técnica prática e não invasiva, que requer apenas uma 
avaliação das medidas antropométricas, capaz de predizer a distância em anos em que um indivíduo se encontra da sua idade do PVC.

A partir do modelo I para determinação do PVC proposto em 1978 por PREECE e BAINES (1978), foi realizada uma série de interações entre a estatura, ATC e altura de pernas (AP) de um grupo de crianças canadenses acompanhado durante 7 anos. A identificação do momento exato do pico máximo de crescimento fornece um marcador comum para refletir a ocorrência de outras velocidades da dimensão do corpo intra e inter indivíduos. Usando os sincronismos diferenciais conhecidos do crescimento da estatura, da ATC e AP- definida pela diferença entre a estatura e a ATC (FIGURA 2), pressupõe-se que as relações proporcionais de mudança entre essas medidas, provêm uma indicação do status maturacional (MIRWALD et al., 2002).

Rapazes

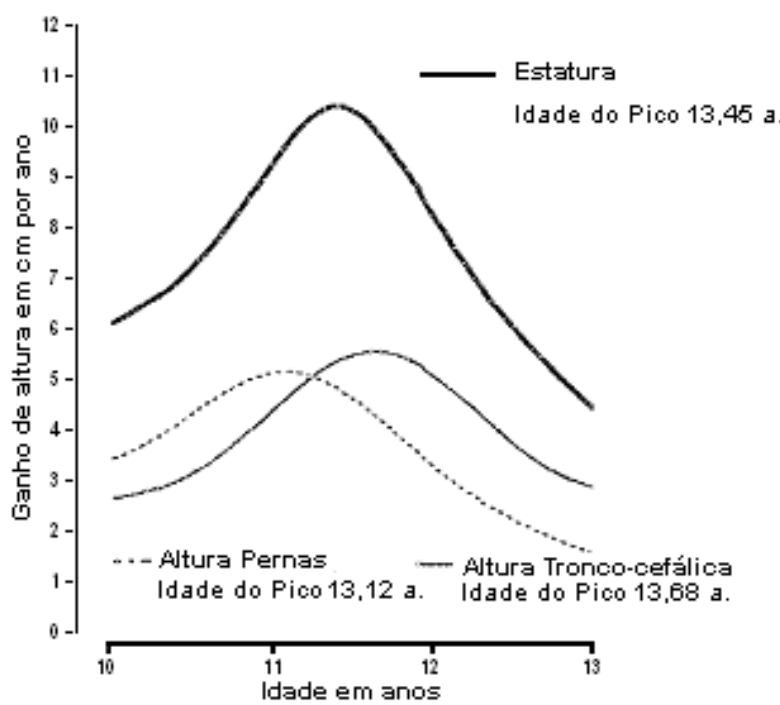

Moças

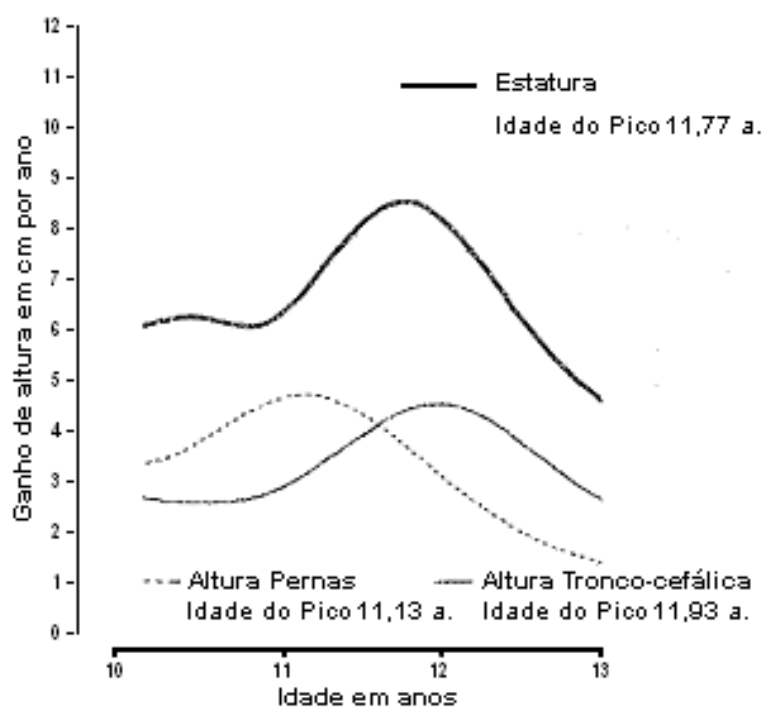

FIGURA 2. Momento do pico de velocidade de crescimento de rapazes (a) e mocas (b) (Adaptado de MIRWALD et. al., 2002).

A partir desses dados e replicação do estudo em amostras canadenses e belgas, um modelo obtido da combinação das três populações foi sugerido como o mais indicado, por sua característica generalista. 
Para rapazes

(Equação 3)

$P V C=-9,236+0,0002708 \times($ AP $\times$ ATC $)-0,001663 \times(I \times$ AP $)+0,007216 \times(I \times$ ATC) $+0,02292 \times(P / E)$

$\left(\mathrm{R}=0,94 ; \mathrm{R}^{2}=0,891 ; \mathrm{EPE}=0,592\right)$

\section{Para moças}

(Equação 4)

$P V C=-9,376+0,0001882 \times($ AP $\times$ ATC $)+0,0022 \times(I \times A P)+0,005841 \times(I \times A T C)+$ $0,002658 \times(\mathrm{I} \times \mathrm{P})+0,07693 \times(\mathrm{P} / \mathrm{E})$

$\left(R=0,94 ; R^{2}=0,89 ; E P E=0,569\right)$

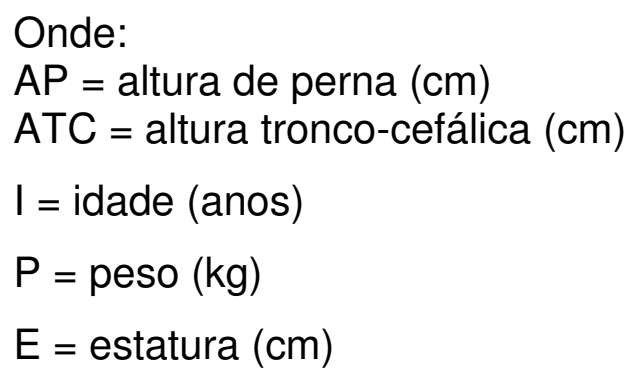

Nesse modelo, foram incluídas medidas de interação entre altura de perna e altura sentada, entre idade e altura de perna, entre idade e altura sentada, bem como razão ente peso e estatura. Aceitáveis índices de determinação e erro padrão da estimativa foram obtidas, além do mais, os resultados indicaram que o modelo de predição pode estimar o estado maturacional com intervalo de erro de \pm 1 ano, em $95 \%$ dos casos.

O nível de precisão do modelo tem sido utilizado em diversos outros estudos, sendo possível sua aplicação em diferentes delineamentos de pesquisa. Sua utilização encontra aplicação na comparação com maturação sexual entre jovens ativos e não-ativos no esporte (GEITHNER, WOYNAROWSKA \& MALINA, 1998), na indicação das limitações na utilização das características sexuais secundárias para comparações entre sexos (SHERAR, BAXTER-JONES \& MIRWALD, 2004), na predição da estatura adulta final, a partir das curvas do pico de velocidade da estatura (SHERAR, MIRWALD, BAXTER-JONES \& THOMIS, 2005) e na investigação dos efeitos do treinamento sobre o crescimento e maturação 
(MATTHEWS, BENNELL, MCKAY, KHAN, BAXTER-JONES, MIRWALD \& WARK, 2006).

Os estudos nacionais envolvendo o PVC ainda são escassos, mas os achados têm sido altamente associados ao desempenho motor (MACHADO, BONFIM \& COSTA, 2009), e às alterações da CC (BERGMANN, BERGMANN, LORENZI, PINHEIRO, GARLIPP, MOREIRA, MARQUES \& GAYA, 2007, MACHADO et al., 2009).

\subsection{Modelos pediátricos antropométricos mais utilizados}

Medidas antropométricas, especialmente as dobras cutâneas podem ser utilizadas para estimar Dc, MIG, MG e \%G desde que aplicados em modelos válidos e apropriados para crianças e adolescentes. Algumas dessas pesquisas produziram estimativas bem próximas da verdadeira (DURNIN \& RAHMAN, 1967; BROOK, 1971; LOHMAN, 1986; SLAUGHTER, LOHMAN, BOILEAU, HORSWILL, STILLMAN, VAN LOAN \& BEMBEN, 1988; WESTSTRATE \& DEURENBERG, 1989; DEURENBERG, PIETERS \& HAUTVAST, 1990).

A partir das primeiras tentativas de MATIEGKA em 1921 de estimar a gordura corporal a partir de seis dobras cutâneas, BROSEK e KEY em 1951 foram os primeiros a utilizar a relação entre dobras e Dc para estimar gordura. Em uma das primeiras propostas pediátricas para estimativa da gordura a partir das dobras cutâneas, DURNIN e RAHMAN (1967) compararam 105 adultos jovens (Idades: 1836 anos; Masc=60; Fem=45) com 86 adolescentes (Idades: 12-16 anos; Masc=48; Fem=38), classificando-os inicialmente em magros, intermediários, "rechonchudos" (sobrepesados) e obesos. As dobras cutâneas resultantes da regressão foram das mesmas regiões para ambos os sexos (bíceps, tríceps, subescapular e suprailíaca).

No entanto, as dobras cutâneas mais utilizadas nos modelos preditivos da CC em crianças e adolescentes têm sido as dobras tricipital e subescapular (TABELA 2). Porcentual de gordura em crianças, determinadas por estas ou mais dobras, normalmente apresentam boa relação com Dc referenciada por pesagem hidrostática $(r=0,65$ a 0,90). Todavia as investigações podem ser controversas quando crianças muito pequenas ou muito obesas são envolvidas nas observações (HARSHA, FRERICHS \& BERENSON, 1978). 
TABELA 2. Modelos antropométricos da composição corporal para crianças e adolescentes.

\begin{tabular}{|c|c|c|c|}
\hline Medidas & População & Equação (modelo) & Autores/origem \\
\hline $\begin{array}{l}\text { Dc=Densidade } \\
\text { X=Bíceps }+ \\
\text { Tríceps }+ \\
\text { Subescapular+ } \\
\text { Suprailíaca }\end{array}$ & Rapazes & $\begin{array}{l}\mathrm{Dc}=1,1533-0,0643 \text { LOG }(X) \\
\mathrm{Dc}=1,1620-0,0630 \text { LOG }(X) \\
\mathrm{Dc}=1,1369-0,0598 \text { LOG }(X) \\
\mathrm{Dc}=1,1599-0,0717 \text { LOG }(X)\end{array}$ & $\begin{array}{l}\text { DURNIN \& RAHMAN, } 1967 \\
\text { (Idades: } 13-15 \text { anos) } \\
\text { (Idades: } 16-19 \text { anos) } \\
\text { (Idades: } 13-15 \text { anos) } \\
\text { (Idades: } 16-19 \text { anos) }\end{array}$ \\
\hline $\begin{array}{l}\text { Dc=Densidade } \\
\text { X=Bíceps }+ \\
\text { Tríceps }+ \\
\text { Subescapular }+ \\
\text { Suprailíaca }\end{array}$ & $\begin{array}{l}\frac{\text { Rapazes }}{\text { Pré-púberes }} \\
\text { Moças } \\
\text { Pré-púberes }\end{array}$ & $\begin{array}{l}D c=1,1690-0,0788 \text { LOG }(X) \\
D c=1,2063-0,0999 \text { LOG }(X)\end{array}$ & $\begin{array}{c}\text { BROOK, } 1971 \\
\text { (Idades: } 01-11 \text { anos) } \\
\mathrm{n}=23 \\
\text { Inglaterra }\end{array}$ \\
\hline $\begin{array}{l}\text { X=Tríceps }+ \\
\text { Subescapular } \\
\mathrm{C}=\text { Constante }\end{array}$ & $\begin{array}{c}\text { Rapazes } \\
7 \text { anos }(C=-3,4) \\
10 \text { anos }(C=-4,4) \\
13 \text { anos }(C=-5,4) \\
16 \text { anos }(C=-6,4) \\
\text { Mocas } \\
7 \text { anos }(C=-1,4) \\
10 \text { anos }(C=-2,4) \\
13 \text { anos }(C=-3,4) \\
16 \text { anos }(C=-4,4)\end{array}$ & $\% G=1,35(X)-0,012(X)^{2}-C$ & $\begin{array}{l}\text { LOHMAN, } 1986 \\
\text { (Idades: } 08-18 \text { anos) } \\
\text { Diversos estudos }\end{array}$ \\
\hline $\begin{array}{l}\mathrm{X}=\text { Tríceps }+ \\
\text { Subescapular } \\
\text { até } 35 \mathrm{~mm} \\
\mathrm{C}=\text { Constante }\end{array}$ & $\begin{array}{c}\text { Rapazes Brancos } \\
\text { Pré-púberes }(\mathrm{C}=1,7) \\
\text { Púberes }(\mathrm{C}=3,4) \\
\text { Pós-púberes }(\mathrm{C}=5,5) \\
\text { Rapazes Negros } \\
\text { Pré-púberes }(\mathrm{C}=3,2) \\
\text { Púberes }(\mathrm{C}=5,2) \\
\text { Pós-púberes }(\mathrm{C}=6,8)\end{array}$ & $\% G=1,21(X)-0,008(X)^{2}-C$ & $\begin{array}{c}\text { SLAUGHTER et al., } 1988 \\
\text { (Idades: } 09-16 \text { anos) } \\
n=242 \\
\text { USA }\end{array}$ \\
\hline $\begin{array}{c}\mathrm{X}=\text { Tríceps }+ \\
\text { Subescapular } \\
>35 \mathrm{~mm}\end{array}$ & $\begin{array}{l}\text { Rapazes } \\
\text { Mocas } \\
\end{array}$ & $\begin{array}{l}\% G=0,783(X)+1,6 \\
\% G=0,546(X)+9,7\end{array}$ & $\begin{array}{l}\text { SLAUGHTER et al., } 1988 \\
\text { (Idem) }\end{array}$ \\
\hline $\begin{array}{c}\text { X=Tríceps + } \\
\text { Panturrilha }\end{array}$ & $\frac{\text { Rapazes }}{\text { Mocas }}$ & $\begin{array}{l}\% G=0,735(X)+1,0 \\
\% G=0,610(X)+5,1\end{array}$ & $\begin{array}{l}\text { SLAUGHTER et al., } 1988 \\
\text { (Idem) }\end{array}$ \\
\hline $\begin{array}{c}\text { X=Bíceps + } \\
\text { Tríceps }+ \\
\text { Subescapular } \\
+ \text { Suprailíaca } \\
\text { Idade (anos) }\end{array}$ & $\begin{array}{l}2-\frac{\text { Rapazes }}{18 \text { anos }} \\
2-\frac{\text { Moças }}{10 \text { anos }} \\
11-18 \text { anos }\end{array}$ & $\begin{array}{l}\mathrm{Dc}=(1,1315+(0,0018 \text { (Idade }- \\
\text { 2)) })-(0,0719-(0,0006 \text { (Idade } \\
-2) \mathrm{LOG}(\mathrm{X}))) \\
\mathrm{Dc}=(1,1315+(0,0004 \text { Idade }- \\
\text { 2) })-0,0719-(0,0003 \text { Idade }- \\
\text { 2) LOG }(\mathrm{X}) \\
\mathrm{Dc}=(1,1350+(0,0031 \text { Idade }- \\
\text { 10) }-0,0719-(0,0003 \text { Idade - } \\
\text { 2) LOG }(\mathrm{X})\end{array}$ & $\begin{array}{c}\text { WESTSTRATE \& } \\
\text { DEURENBERG, } 1989 \\
\\
\text { (Idades: } 07-10 \text { anos) } \\
n=68 \\
\text { (Idades: } 02-18 \text { anos) } \\
n=2285 \\
\text { Alemanha }\end{array}$ \\
\hline $\begin{array}{l}\text { X=Bíceps + } \\
\text { Tríceps + } \\
\text { Subescapular } \\
+ \text { Suprailíaca } \\
\text { Idade (anos) }\end{array}$ & Rapazes & $\begin{array}{l}\mathrm{Dc}=1,1133-0,0561 \mathrm{LOG}(\mathrm{X})+ \\
1,7\left(\text { Idade } 10^{-3}\right) \\
\text { Dc }=1,1187-0,063 \mathrm{LOG}(\mathrm{X})+ \\
1,9\left(\text { Idade } 10^{-3}\right)\end{array}$ & DEURENBERG, 1990 \\
\hline
\end{tabular}


BROOK em 1971 investigou as relações entre as medidas de dobras cutâneas propostas por DURNIM e RAHAMAN (1967) e ACT, mediante diluição de óxido de deutério. Entretanto as crianças investigadas eram de ambos os sexos e tinham entre um e 11 anos de idade, enquanto a equação para estimar densidade de DURNIM e RAHAMAN (1967) foi proposta para sujeitos de 13 a 19 anos.

Embora este autor tenha se fundamentado na medida de água corporal total (ACT) para estimar gordura corporal, os pressupostos que se seguiram assumiam que a água do tecido magro era constante. Assumiam ainda que a partir dos quatro meses de vida, o conteúdo de água do tecido magro de crianças não diferia dos adultos ou de outros animais.

Assim, os dados desse estudo quando ajustados para fornecer uma equação de regressão com coeficiente de 0,73 em relação à $A C T$, resultou em novas equações para crianças de um a 11 anos de idade, a partir das mesmas quatro dobras utilizadas anteriormente.

Em 1986, LOHMAN faz uma importante revisão dos 25 anos anteriores da pesquisa da $\mathrm{CC}$ envolvendo crianças e adolescentes e propõe importantes considerações às propostas existentes. Seu enfoque figura nas constantes dos modelos até então, na aplicação das técnicas de CC e na origem dessas constantes, visto que foram desenvolvidas a partir de estudos em cadáveres adultos. Já menciona a necessidade de substituir os usuais modelos bicompartimentais, uma vez que a maturação química não vinha sendo considerada nesses procedimentos.

Nesse estudo, LOHMAN (1986) já esboça algumas propostas de diferentes investigadores, na consideração dos multicomponentes da CC. Considera que o jovem adolescente tem maior quantidade de água corporal com menor Dc que o adulto, o que refletiria em menor estimativa de gordura calculada com os modelos até então existentes. A diminuição da água corporal durante a adolescência representa $72 \%$ a $73 \%$ da estimativa da gordura corporal nessas idades, permitindo superestimar a massa corporal magra e subestimar a gordura.

Da infância até a vida adulta, o CMO varia em ambos os sexos de $3,7 \%$ para $6,8 \%$, considerando ainda o componente mineral do tecido não ósseo. Assim, quando essas análises são efetuadas transversalmente, podem fornecer o processo das mudanças do $\mathrm{CMO}$ e a Dc de forma mais precisa, tornando mais precisa também 
a estimativa do \%G corporal. Nessa revisão LOHMAN (1986) apresenta a estimativa da Dc nas diferentes idades, do nascimento aos 22,5 anos de vida. A partir dessa abordagem, a relação entre dobras cutâneas e densidade é apresentada de forma detalhada, bem como as comparações entre modelos bi e multicomponentes. Uma importante observação desse estudo está no anúncio do motivo da diminuição de água corporal. O aumento da massa magra durante o crescimento não pode explicar a diminuição da água observada em rapazes e moças, uma vez que tecido magro tem maior quantidade de água (77\%). Assim a principal causa da diminuição observada estaria na diminuição do espaço extra-celular.

São indicados ainda quatro principais problemas na estimativa da CC em crianças e adolescentes, que foram essenciais para as investigações subseqüentes da área:

1. Equações derivadas para crianças e jovens são geralmente estimadas a partir de um amplo campo de sujeitos (pré-púberes, púberes e pós-púberes);

2. O desenvolvimento de regressões geralmente se origina em um método de CC e um sistema de dois componentes, provendo vieses na estimativa de gordura para sujeitos quimicamente imaturos. Principalmente se forem utilizados na densitometria, hidrometria ou espectrometria de potássio $40\left(\mathrm{~K}^{40}\right)$.

3. Poucas equações têm sido extensivamente validadas de forma cruzada em outras populações, bem como a identificação de subamostras não têm sido realizada de forma eficiente (i.e. sujeitos de origem esportiva ou de diferentes etnias).

4. Variação nos locais de medidas de dobras cutâneas, perímetros ou diâmetros ósseos.

A partir dessas considerações e por atender parte dessas questões, LOHMAN (1986) sugere a utilização da equação proposta por BOILEAU et al (1985). Entretanto, nesse modelo, quando o fator maturacional foi considerado, os valores do intercepto variaram entre as idades. Assim, as idades propostas nos modelos preditivos de Dc, têm maior alusão à distinção maturacional que etária. LOHMAN 
(1986) ainda alerta que em populações de esportistas, as estimativas podem apresentar direções equivocadas nas necessidades de perda de peso corporal ou nas adequações da CC, não devendo ser empregadas nessas populações.

Em 1988 LOHMAN participa do estudo mais evidente e utilizado na área, para estimativa da gordura corporal em crianças e adolescentes, os modelos de SLAUGHTER, LOHMAN, BOILEAU, HORSWILL, STILLMAN, VAN LOAN e BEMBEN (1988), que consideravam três diferentes abordagens: a) Dc a partir da pesagem hidrostática e volume residual; b) Dc e ACT; c) Dc, água e mineral ósseo.

A derivação do modelo considerou nove dobras cutâneas, quatro estágios de maturação, os sexos e etnia (brancos e negros). O estudo envolveu 310 crianças, adolescentes e adultos sendo desenvolvido em Illinois $(n=182)$ e replicado no Arizona $(n=182)$. A classificação por maturação sexual (TANNER, 1962) foi utilizada para agrupar os jovens em pré-púberes, púberes, pós-púberes e adultos. Embora a amostra tenha sido composta por escolares envolvidos em programas de esporte, esse critério não foi utilizado para discriminar os sujeitos.

Medidas de Dc (por pesagem hidrostática), ACT (por diluição de deutério), CMO (por absortometria óssea de rádio e ulna de ambos os braços) e nove dobras cutâneas (tricipital, biciptal, subescapular, axilar média, suprailíaca, suprailíaca anterior, abdominal, coxa média e panturrilha) foram consideradas no modelo preditivo. Porém após a regressão, as dobras tricipital e subescapular apresentaram validade externa nas amostras investigadas e na literatura. Assim foram gerados modelos quadráticos considerando diferenças étnicas e maturacionais nos meninos enquanto nas meninas, esta distinção não se observou. As diferenças de maturação e etnia para ambos os sexos também não foi discriminante quando a soma das dobras (tricipital e subescapular) excedia a $35 \mathrm{~mm}$.

Nesse mesmo período, apenas um ano mais tarde, WESTSTRATE e DEURENBERG (1989) se preocupavam em apresentar formas mais objetivas no diagnóstico da obesidade infantil. A partir das equações de DURNIN \& WOMERSLEY (1974) e das referências sobre Dc disponíveis na literatura, (publicações de FOMON, 1982), esses autores propuseram modelos ajustados para determinação do \%G no lugar de utilizar as equações para conversão de Siri e Brozek. Não foi considerada nestas equações a volatilidade da Dc durante o crescimento. Esta nova proposta 
abrangia estimativas da CC para rapazes dos dois aos 18 anos enquanto dois modelos eram utilizados para as moças (2 a 10 e 11 a 18 anos).

O principal pressuposto dessa proposta se fundamentava na variação da densidade da MIG nas diferentes idades. Além do modelo de referência (pesagem hidrostática) empregado nas propostas até então, não considerar a distinção do tecido magro, a participação do avaliado no momento da medida era um fator decisivo na estimativa da densidade da MIG. Assim, um modelo de dobras cutâneas que corrigisse a Dc para cada idade e sexo, poderia ser uma alternativa mais viável para estimar o \%G corporal durante o crescimento.

Entretanto algumas considerações precisam ser feitas ao serem adotados tais modelos. A despeito da inocuidade, da interpretação imediata das informações, da menor exigência de cooperação do avaliado, dos baixos custos e do não requerimento de pessoal altamente qualificado, o uso de dobras cutâneas é uma alternativa de medida duplamente indireta. Esses modelos são originários de populações específicas e podem apresentar precisão variável quando aplicadas a outras populações. Não há padronização das técnicas de medidas, os modelos são derivados de regressões o que pode comprometer sua exatidão e as medidas são influenciadas pela variabilidade entre os avaliadores.

Todavia, o interesse pela investigação no campo da CC pediátrica se expande rapidamente (SARDINHA et al., 2000), bem como o uso de modelos que exijam recursos com boa relação custo-benefício. Uma temática que sustenta essa questão é que a criança não é um adulto em miniatura, assim, modelos propostos para adultos não são apropriados para crianças e adolescentes.

A disponibilidade de ferramentas para quantificar a CC pediátrica tem sido desenvolvida para certas populações e grupos etários e a aplicação dessas ferramentas deve implicar em importantes informações conceituais. Entretanto algumas lacunas como a quantificação dos componentes da CC para cada estágio etário ou maturacional, entre outros tópicos, tornam a pesquisa da CC pediátrica ainda muito dinâmica e crescente nessa área de investigação (SOPHER, SHEN \& PIETROBELLI, 2005). 


\subsection{Procedimentos estatísticos na proposição de modelos}

O campo das pesquisas da CC tem alcançado um estágio de maturidade no seu desenvolvimento. As três áreas inseparáveis a serem contempladas nos procedimentos de proposição de modelos preditivos envolvem os modelos propriamente ditos e seus papéis, a metodologia e os efeitos biológicos.

Elementos da CC são mensuráveis no corpo total ou em regiões específicas. Os componentes (alteráveis) de um elemento são tipicamente definidos pelo volume de distribuição desses. Os 11 principais elementos bioquímicos corporais ou os exogenamente administrados (como o brometo) podem ser medidos in vivo por um ou mais métodos. Todos os elementos são identificáveis mediante propriedades radioativas, eletromagnéticas e fisiológicas (SUN \& CHUMLEA, 2005).

Uma vez medida a propriedade, esta deve ser matematicamente transformada numa massa desse componente de interesse. O processo de transformação requer o uso de uma função matemática, que pode ser arbitrariamente chamada de: equações do tipo I ou equações do tipo II (HEYMSFIELD, WANG, BAUMGARTNER \& ROSS, 1997).

A equação do tipo I é baseada em uma relação empírica entre o componente e a propriedade medida. O método de referência é utilizado para estimar o componente em um grupo bem definido de sujeitos, em que a propriedade é também medida. A equação preditiva estatisticamente derivada do componente é desenvolvida e então validada (validação cruzada) em um novo grupo de sujeitos. Essa equação preditiva pelo componente é chamada de descritiva ou função matemática do tipo I. Há um grande número dessas equações baseadas na propriedade exemplificada no nível atômico de componentes.

Exemplos de equações do tipo I:

$$
\begin{aligned}
\text { Gordura } & =0,65 \times \text { Peso corporal }-0,21 \times \text { Estatura }+14,1 & & (\text { Equação 5) } \\
\text { MIG } & =0,85 \times \text { Altura }^{2} / \text { Impedância elétrica }+3,04 & & (\text { Equação 6) } \\
\text { Músculo } & =18,9 \times \text { Creatina }+4,1 & & (\text { Equação 7) }
\end{aligned}
$$


O segundo tipo de equação é o tipo II, baseada na relação estável entre propriedades e componentes, muitos dos quais podem ser compreendidos com base na sua fundamentação biológica. Estas equações são também chamadas de equações mecânicas. São encontrados diversos exemplos no nível atômico ou como são conhecidos, componentes de alto nível.

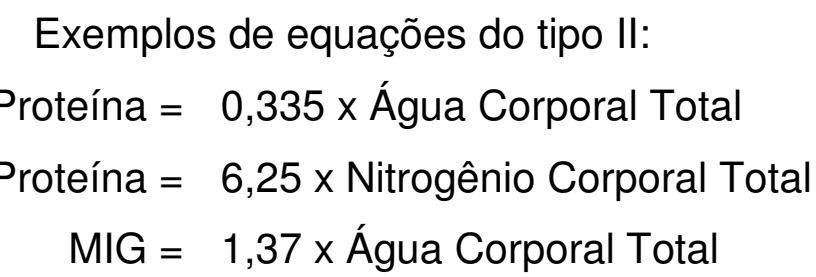

(Adaptado de HEYMSFIELD et al., 1997)

Métodos de CC do tipo I são desenvolvidos a partir de métodos de referência estabelecidos. Por exemplo: antropometria, bio-impedância, interactância de raios infravermelho, incluem erros a partir dos seus métodos de referência, portanto não servem como padrão de referência.

Por outro lado, os métodos de CC do tipo II podem, como alguns métodos de análise por ativação de nêutrons, DXA, pesagem hidrostática e RM são geralmente citadas como referência padrão in vivo. Julgar a aplicabilidade de um método de referência requer uma análise dos riscos de erros a partir de duas questões principais: o modelo e a técnica. Alguns modelos são extremamente estáveis enquanto outros não. Por exemplo: modelos baseados em relações químicas (N/proteína=0,16) são muito estáveis sobre quase todas as circunstâncias. Modelos desenvolvidos a partir de relações não químicas (i.e. $\mathrm{ACT} / \mathrm{MIG}=0,732$ ) são menos estáveis por serem influenciados por doença, gravidez, estágios do amadurecimento entre outras condições que derivam do "normal" (HEYMSFIELD et al., 1997).

\subsubsection{Precisão das equações preditivas}

De acordo com a estatística comum, a precisão de uma equação preditiva quando aplicada em diferentes amostras deve ser a mesma da amostra original. Uma variável predita por uma equação é conhecida como variável de 
resposta e é predita por outras variáveis utilizadas na equação (explicativas). SUN e CHUMLEA (2005) lembram alguns fatores que afetam a precisão de uma equação preditiva:

- Validade da variável de resposta;

- Precisão das variáveis preditivas;

- Relação estatística e biológica intra e inter-variáveis explicativas e a variável de resposta;

- Métodos estatísticos usados para formular a equação; e

- Tamanho da amostra.

Geralmente os modelos utilizados para calcular o \%G e valores de MIG a partir da densitometria, utilizam o modelo de dois componentes (DURNIN \& RAHMAN, 1967; LOHMAN, 1986; SLAUGHTER et. al., 1988; WESTSTRATE \& DEURENBERG, 1989; DEURENBERG, 1990), derivados de pesagem hidrostática corrigida pelo volume residual. A precisão da pesagem hidrostática e volume residual são muito sensíveis e estão relacionados ao desempenho dos sujeitos no momento das medidas, implicando no aumento do erro de medidas (SUN \& CHUMLEA, 2005) principalmente quando medidas de crianças estão envolvidas. Além do mais, modelos de dois componentes incorretamente assumem que a densidade da MIG e a fração de água são constantes em todas as idades e sexos (LOHMAN 1986; CHUMLEA et al., 1999), limitando assim sua utilização em população pediátrica.

Desta forma, modelos multicomponentes devem ser utilizados quando incluem Dc, CMO, ACT (LOHMAN, 1986; SUN, CHUMLEA, HEYMSFIELD, LUKASKI, SCHOELLER, FRIEDL, KUCZMARSKI, FLEGAL, JOHNSON \& HUBBARD, 2003), muito embora ocorra um acúmulo de erros de medidas nestes modelos, potencializando os erros ao serem calculados os valores da $\mathrm{CC}$ (HEYMSFIELD, LICHTMAN, BAUMGARTNER, WANG, KAMEN, ALIPRANTIS \& PIERSON, 1990).

\subsubsection{Relação entre variáveis explicativas e variáveis de resposta}

Variáveis de resposta geralmente são aquelas que se pretende estimar (variáveis dependentes). Variáveis explicativas abrangem peso, estatura, 
circunferência corporal, dobras cutâneas e medidas de bioimpedância elétrica ou todas as medidas utilizadas para explicar (predizer) determinado componente. Estas medidas são obtidas com relativa facilidade, baixo custo e boa precisão (CHUMLEA \& GUO, 2000). A inclusão de variáveis explicativas num modelo depende da relação estatística e biológica com a variável de resposta. Variáveis explicativas para \%G são inicialmente medidas por índices do tecido adiposo subcutâneo facilmente obtido por medidas de dobras cutâneas e circunferências corporais. Medidas relacionadas ao tamanho corporal são possíveis variáveis explicativas para \%G e MIG (SUN et al., 2003). Estatura, peso e IMC têm relação positiva com MIG e gordura corporal total e medidas de bioimpedância elétrica são importantes explicativas de MIG (SUN et al., 2003).

A composição e Dc também podem ser medidas pela resistência corporal a condutividade elétrica. $O$ índice de resistência, $S^{2} / R$ onde $S$ é estatura em $\mathrm{cm}$ e R é resistência em ohms, tem sido considerado como um dos mais significantes preditores da MIG (GUO et al., 1989, SUN et al., 2003). Conseqüentemente, quando a resistência fizer parte das variáveis explicativas, MIG é uma variável de resposta apropriada (SUN \& CHUMLEA, 2005). Entretanto algumas considerações são necessárias nesse tipo de associação:

Alguns estudos que utilizam variáveis explicativas inadequadas para estimar CC podem considerar apenas a relação estatística e não a biológica. Por exemplo, dobras cutâneas têm sido usadas para previsão de MIG, a despeito da baixa relação entre essas variáveis. A própria bioimpedância elétrica (isoladamente) também tem sido utilizada para predizer percentagem de gordura, embora haja apenas uma fraca relação biológica e estatística entre estas medidas (SUN \& CHUMLEA, 2005). A inclusão de variáveis explicativas com forte relação biológica e estatística para predizer a variável desejada em uma equação, certamente aumenta seu potencial preditivo (SUN \& CHUMLEA, 2005).

\subsection{Composição corporal do jovem esportista}

A CC é um dos fatores que pode influenciar o desempenho atlético do jovem esportista e, portanto, passa a ser de vital interesse de atletas e técnicos (MALINA, 2007). Tão importante quanto conhecer como os diferentes componentes 
da CC variam com a idade, sexo, status maturacional durante a adolescência é entender os efeitos do treinamento esportivo sobre a CC, os limites fisiológicos impostos pelo treinamento, as expectativas e o volume dessa prática em cada idade.

A inserção da criança e adolescente no esporte deve ter objetivos diferentes daqueles, por exemplo, que meramente se prestam a atender as expectativas dos pais e treinadores. Neste sentido, BARBANTI (2005) lembra alguns cuidados adicionais que devem ser levados em conta: o treino com crianças não deve se basear em modelos adultos, a vitória não deve ser encarada como referencial de sucesso, interesses e motivações dos adultos podem incidir negativamente sobre a auto-estima da criança, deve-se considerar o tempo individual de crescimento e desenvolvimento, a postura da platéia ao assistir competições infantis deve ser diferente de quando assistem jogos entre adultos.

TABELA 3. Idade (anos) para início, especialização e alto rendimento em diferentes modalidades esportivas.

\begin{tabular}{lccc}
\hline Modalidade & Início da Prática & Especialização & Alto Rendimento \\
\hline Atletismo & $10-12$ & $13-14$ & $18-25$ \\
Basquetebol & $8-9$ & $10-12$ & $20-25$ \\
Ciclismo & $14-15$ & $16-17$ & $21-24$ \\
Esgrima & $7-8$ & $10-12$ & $20-25$ \\
Futebol & $8-10$ & $11-14$ & $20-26$ \\
Futsal & $6-8$ & $10-12$ & $20-26$ \\
Ginástica Artística (fem.) & $6-7$ & $9-10$ & $15-20$ \\
Ginástica Artística (mas.) & $6-7$ & $12-14$ & $18-24$ \\
Ginástica Rítmica & $6-7$ & $10-12$ & $15-20$ \\
Judô & $8-9$ & $12-14$ & $20-26$ \\
Natação & $4-7$ & $10-12$ & $18-24$ \\
Remo & $12-14$ & $16-18$ & $22-26$ \\
Tênis & $6-8$ & $12-14$ & $22-28$ \\
Voleibol & $11-12$ & $14-15$ & $22-28$ \\
\hline (Adaptado de BARANTI & & \\
\hline
\end{tabular}

(Adaptado de BARBANTI, 2005) 
Embora não existam regras gerais ou idades ideais para determinar a prática esportiva juvenil, BARBANTI (2005) resumiu os períodos etários para início, especialização e alto rendimento das principais modalidades praticadas no Brasil (TABELA 3).

A CC é importante para o desempenho esportivo dos atletas, principalmente nas tarefas que envolvem o deslocamento corporal. Modalidades esportivas que exigem transferência do corpo em direções verticais ou horizontais podem ter o desempenho reduzido se o excesso de peso ou gordura estiver presente. Além do mais, determinadas modalidades utilizam o peso corporal como critério de categorização, o que torna crucial sua precisa determinação. Em atletas do sexo feminino, a avaliação da CC tem sido explorada na relação entre gordura corporal, ciclo menstrual e densidade óssea (HERGENROEDER \& KLISH, 1990). Desta forma, a avaliação da CC é um importante recurso que pode ser utilizado por professores de educação física e técnicos desportivos, para monitorar os efeitos de programas, maximizarem o desempenho esportivo, e no uso clínico, monitorar a saúde dos adolescentes.

Um grande número de indicadores na avaliação da CC está disponível. Os métodos de maior precisão estimativa, fundamentados em sofisticadas técnicas de laboratório, encontram dificuldades na aplicação prática. Outros são práticos na aplicação de campo, porém perdem na precisão estimativa. Desta forma, técnicos, instrutores e educadores físicos devem escolher o recurso que atenda às suas necessidades, reconhecendo o erro associado a cada um deles.

O passo inicial está na determinação do peso corporal que deve estar entre $90 \%$ e $110 \%$ do peso ideal. HERGENROEDER e KLISH (1990) apresentam valores de referência para jovens de ambos os sexos, dos 12 aos 17 anos e para adultos acima dos 18 anos. Todavia o uso referencial do peso corporal pode representar numa armadilha na indicação das adequações necessárias da CC do jovem atleta. Assim, o fracionamento do peso em MG, MM, MO e outros substratos podem dar uma idéia mais clara das reais necessidades do esportista.

O tamanho corporal do jovem esportista ainda é influenciado por seu status maturacional. Com poucas exceções, jovens esportistas tendem a estar na mediana ou acima dela, dos valores de referência para estatura e peso (MALINA, 
2007). As exceções envolvem ginastas e skatistas femininas. Jovens atletas de elite também tendem a ser maturacionalmente mais adiantados do que seus pares etários, embora exista variação entre modalidades. Maturação precoce é associada com maiores volumes, força, potência musculares e menor \%G em rapazes, figurando em vantagens para determinados esportes.

As discussões da CC de jovens esportistas, portanto devem considerar as diferenças individuais do status maturacional, e os estudos raramente consideram variação associada à maturidade em jovens atletas (MALINA, 2007), o que torna a questão num potencial fator de confusão na avaliação da CC dessa população. Uma vez que a MIG segue um padrão de crescimento similar à estatura e peso corporal resultando em alta correlação, muitos estudos atuais de aplicação de campo limitamse na determinação da gordura corporal ou na mera determinação do \%G.

FLECK (1983) relata a tendência dos atletas americanos terem maiores índices de gordura, naquelas modalidades em que o peso corporal é sustentado, como canoagem, caiaque (masc $=13 \%$; fem $=22 \%$ ) e nadadores ( $\operatorname{masc}=12 \%$; fem $=20 \%$ ). Por outro lado, menores \%G são encontrados nos atletas envolvidos em modalidades categorizadas pelo peso corporal como lutas ( $8 \%$ ) e boxe (7\%), nas atividades de corridas de velocidades ( $\operatorname{masc}=7 \%$; fem $=14 \%$ ) e maratonas ( $\operatorname{masc}=6 \%$ ). Atletas envolvidos em modalidades onde o tamanho corporal pode ser uma vantagem como basquete, vôlei, apresentam os maiores volumes de tecido muscular.

MALINA (2007) apresenta numa revisão sobre CC em jovens atletas e os índices médios para cada modalidade em diversos estudos ao redor do mundo. Parte desses índices está expresso comparativamente no GRÁFICO 1.

Valores percentuais baixos de gordura corporal, embora possam representar teoricamente vantagens em determinados esportes, não implica necessariamente numa dependência para seu sucesso. WILMORE, BROWN e DAVIS (1977) observaram que muitas corredoras de classe nacional e internacional tinham \%G de $12 \%$. Todavia um corredor que bateu o recorde americano de meia distância tinha 17\%. Obviamente uma menor \%G nesse atleta traria impacto sobre seu desempenho. 


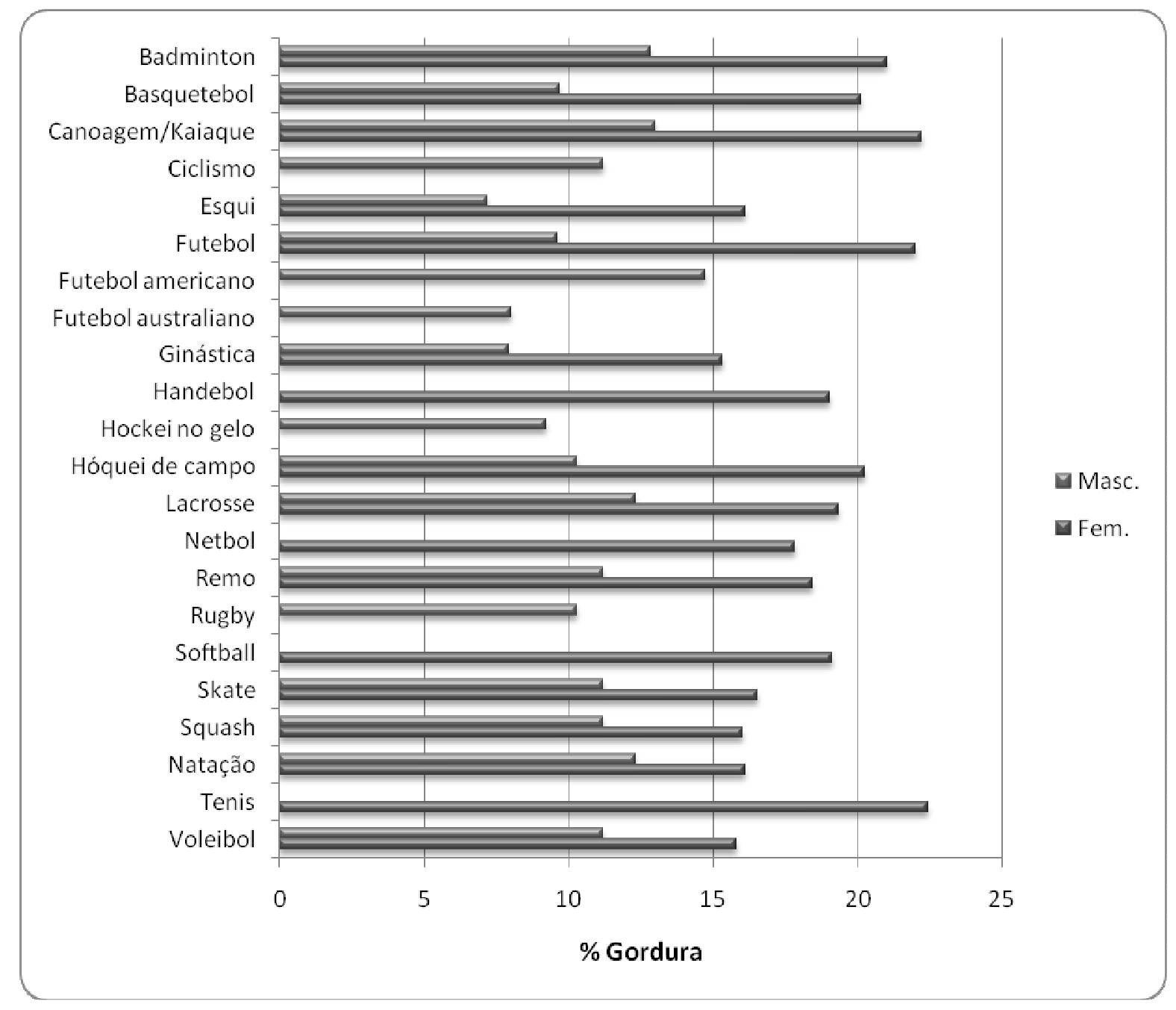

GRÁFICO 1. Gordura relativa (\%G) em atletas de ambos os sexos em diversos esportes (Baseado em MALINA, 2007).

Outro caso foi de uma mulher com $36 \%$ de gordura que estabeleceu um recorde mundial para a corrida de 50 milhas (WILMORE, BROWN \& DAVIS, 1977). Além da quantidade de gordura, nesses casos, não terem sido determinantes para 0 sucesso dos atletas, entre as modalidades esportivas, existe considerável variabilidade mesmo em atletas de alto nível (HERGENROEDER \& KLISH, 1990).

O foco de discussões da CC geralmente envolve atletas femininas, compreendendo baixos níveis de gordura, maturação sexual tardia, menstruações irregulares e distúrbios alimentares. Entre os atletas masculinos, a preocupação é especialmente na categorização esportiva por pesos, principalmente no pugilismo (MALINA, 2007). 
Outra componente da CC que está diretamente associada ao exercício físico é a estrutura esquelética. Diversos estudos têm demonstrado os efeitos do exercício sobre a densidade mineral óssea (DMO) de atletas de elite, quando comparados a sujeitos não atletas de mesma idade (DRINKWATER, 1994; LOHMAN, 1995). Os resultados desses estudos indicam um significativo aumento da DMO em indivíduos envolvidos em exercícios de cargas elevadas ou de alto impacto. Comparações entre atletas de diferentes modalidades sustentam esta idéia, porque ginastas e levantadores de peso, em média têm maior DMO do que nadadores (DRINKWATER, 1994), por exemplo. Indivíduos com maior DMO podem sobressairse em determinados esportes (p.e. ginastas), enquanto em outras modalidades esportivas aqueles com baixa DMO levam vantagens (p.e. natação).

A massa magra consiste de músculo esquelético, tecidos ósseo, tecido conectivo e outros tecidos. Devido à dificuldade das técnicas de avaliação da CC em campo, nem sempre é possível separar MM de ossos. Por esta razão, os estudos relacionam as mudanças que o exercício promove na massa magra como um todo, considerando principalmente os efeitos sobre a estrutura músculo-esquelética. Uma dessas alternativas está no ganho de força observado em estudos de treinamento, envolvendo adultos jovens (20-30 anos), idosos (65-75 anos) (ROTH, IVEY, MARTEL, LEMMER, HURLBUT, SIEGEL, METTER, FLEG, FOZARD, KOSTEK, WERNICK \& HURLEY, 2001) e crianças (CHRISTOU, SMILIOS, SOTIROPOULOS, VOLAKLIS, PILIANIDIS \& TOKMAKIDIS, 2006).

Treinamento de força é mais efetivo do que resistência para investigar o aumento da MIG, que envolve tecido conjuntivo, sangue, moléculas de hidrogênio e proteínas do músculo esquelético (BARBANTI, 2001). Por outro lado, os efeitos sobre a MG, são percebidos após aplicação de exercícios de característica aeróbia.

Efeitos de treinamento também podem resultar em diferenças da MIG entre membros dominantes versus não dominantes. Alguns estudos têm demonstrado maiores dimensões no braço dominante de tenistas (DALEN, LAFTMAN, OHLSEN \& STROMBERG, 1985; HAAPASALO, SIEVANEN, KANNUS, HEINONEN, OJA, VUORI, 1996). Assim, parece que algumas diferenças entre praticantes e não praticantes de exercício podem ser atribuídas ao treinamento. 
Muito embora exista uma relação condicional entre carga de exercício e a constituição física, a estimulação mecânica é necessária para o eficiente crescimento e manutenção da estrutura músculo-esquelética ao longo da vida. Estudos com animais têm demonstrado que poucas repetições de cargas são capazes de produzir tensões de alta magnitude, enquanto altas taxas de cargas são necessárias para estimular a osteogênese e a hipertrofia muscular (JAKICIC, CLARK, COLEMAN, DONNELLY, FOREYT, MELANSON, VOLEK \& VOPE, 2001; WILLIAMS, TEIXEIRA \& GOIG, 2005). Ou seja, para altas magnitudes de capacidade de carga, são necessários maiores volumes.

Diversos fatores como idade, hormônios, níveis de nutrientes e a genética, indiscutivelmente afetam a resposta óssea num determinado programa de exercícios, todavia é preciso mais investigação para definir o tipo e a quantidade de exercícios necessários para promover osteogênese nas diferentes idades. Estudos em crianças e adolescentes são particularmente importantes, pois pesquisas sugerem benefícios permanentes nos parâmetros de MM e estrutura óssea, quando exercícios de carga óssea são realizados em idades precoces (JAKICIC et al., 2001).

Estudos que relatam o efeito do treinamento sobre a CC em crianças e adolescentes ainda são inconclusivos e, portanto não podem precisar a carga nem quando (na maturação) essas diferenças passam a ser efetivas. Além do mais, os efeitos reais do exercício sobre a MM e MO de jovens precisam ser mais bem elucidados, a partir da compreensão do desenvolvimento dessas estruturas durante 0 crescimento puberal.

Com base no relato da literatura apresentado, algumas premissas foram assumidas previamente para a realização deste estudo:

a) Os recursos de análise tecidual corporal multicomponente por DXA e modelos preditivos disponíveis na literatura, são referenciais válidos e de aceitável precisão para estimar gordura, CMO e MIG de jovens ES e NE, sendo necessária a avaliação conjunta desses componentes para a correta estimativa da CC;

b) A classificação da maturação pelo pico de velocidade do crescimento (PVC) é válida durante o crescimento puberal, apresentando melhor associação com o crescimento tecidual corporal, figurando numa alternativa de classificação maturacional mais atrativa do que outros recursos biológicos; 
c) A prática esportiva programada pode acarretar diferenças na CC de adolescentes ES e NE, ao menos a partir de determinadas idades, fases do desenvolvimento e para determinadas tarefas de desempenho motor.

\section{MATERIAIS E MÉTODOS}

Foram apresentados os planos, objetivos e direções gerais do estudo em alguns encontros com os diretores, administradores, professores e técnicos desportivos das instituições. Em seguida foi efetuado um levantamento do "n" disponível, classificação por idade e prática esportiva dos eventuais voluntários. Nesse momento foram obtidos os termos de consentimento dos responsáveis administrativos das instituições envolvidas para a pesquisa (APÊNDICE A).

Os sujeitos do estudo foram convidados a participar voluntariamente, e os pais/responsáveis receberam um termo de consentimento livre e esclarecido informando o procedimento, data, local e horário previstos para a coleta dos dados (APÊNDICE B).

O estudo seguiu as diretrizes e normas que regulamentam a pesquisa com seres humanos (lei 196/96), sendo informados aos participantes todos os propósitos e métodos utilizados no estudo e ressaltando o direito dos mesmos, de desistir do experimento a qualquer momento. Após obtenção de termo de consentimento livre e esclarecido dos pais ou responsáveis, os dados foram coletados. O projeto inicial deste estudo foi submetido ao Comitê de Ética e Pesquisa da EEFEUSP sob Protocolo de Pesquisa no. 2006/32 tendo sido aprovado em 30 de março de 2007. O estudo seguiu o modelo de corte transversal de caráter descritivo.

\subsubsection{Dimensionamento amostral}

Um adequado dimensionamento amostral foi planejado para estimativa da viabilidade do projeto, impacto do custo e tamanho amostral ideal. O estudo foi submetido ao Instituto de Matemática e Estatística - IME/USP para determinação do erro e confiança das equações para cada amostral pretendido. Na tentativa de 
minimizar os erros na proposição do modelo preditivo no objetivo "c" deste estudo, foi estimada a amostra desejável a partir de erro mínimo e máximo pretendidos.

Para determinar o tamanho da amostra foi preciso fixar o erro máximo desejado $(\mathcal{E})$ com algum grau de confiança $\left(Z_{\gamma}\right)$ e conhecer alguma informação a priori da variabilidade da população $\left(\sigma^{2}\right)$ (BOLFARINE \& BUSSAB, 2005). Nesse caso, o \%G foi selecionado como referência, por se tratar da variável de maior tendência à variabilidade. A partir dos dados de uma amostra similar ao deste estudo $(n=454)$, capaz de fornecer informação de estudos aplicados previamente para esta variável, foi determinado o tamanho amostral. Os dados dessa amostra e todo dimensionamento dessa população de referência está expressa no APÊNDICE F. Nesta amostra de referência, havia estimativa antropométrica do \%G (SLAUGHTER et al., 1988) de crianças e adolescentes entre 7 e 17 anos do sexo masculino, classificados em ES ( $n=277)$ e NE $(n=177)$, porém, sem a informação de maturação (PVC). A distribuição do \%G foi muito semelhante para os grupos de ES e de NE, sendo a variabilidade e a média dos dados ligeiramente menor para o grupo ES.

Como o objetivo do estudo foi ajustar um modelo preditivo para cada componente da CC, sugeriu-se estimar um tamanho amostral n para toda a amostra, e distribuir este $n$ entre os grupos de ES e NE, tendo assim $\frac{n}{2}$ indivíduos em cada grupo. Pois, segundo resultados em outros estudos (DEURENBERG, PIETERS \& HAUTVAST, 2003), a variabilidade do \%G não deveria ser muito diferente nos dois grupos. Isso foi confirmado nas análises prévias, onde se observou semelhança entre as medidas de variabilidade da amostra de referência. Assim, o estimador proposto por BOLFARINE e BUSSAB, (2005) foi utilizado para determinar $\mathrm{n}$ dado por:

$$
n=\left[\frac{z_{\gamma} s}{\varepsilon}\right]^{2}
$$

Com $\varepsilon$ e $\gamma$ fixados, de tal modo que $z_{\gamma}$ indica o valor tal que a probabilidade de se obter um valor inferior a este na distribuição normal padrão Z é dada por: $P\left(Z<z_{\gamma}\right)=\frac{1+\gamma}{2}$ com $0 \leq \gamma \leq 1$. A seguir, mostra-se como calcular o valor 
estimado para $\sigma^{2}: s^{2}=\sum_{i=1}^{n} \frac{\left(X_{i}-\bar{X}\right)^{2}}{n-1}$, em que $X_{i}$ é o i-ésimo $\% \mathrm{G}$ corporal e $\mathrm{n}$ o tamanho da amostra de referência e $\bar{X}$ é a média amostral dada por $\bar{X}=\sum_{i=1}^{n} \frac{X_{i}}{n}$.

$\mathrm{Na}$ TABELA 4, são apresentados valores para $\mathrm{n}$, fixando valores para $\varepsilon$ e para $\gamma$ (índice de confiança) e com o valor estimado para $\sigma$ igual a $11,43 \mathrm{~kg}$, sendo este o desvio padrão da amostra de referencia.

TABELA 4. Determinação do tamanho da amostra.

\begin{tabular}{c|cc}
\hline$\gamma\left(z_{\gamma}\right)$ & $\varepsilon$ & $n$ \\
\hline & 1,00 & 354 \\
& 1,25 & 226 \\
$0,90(1,64)$ & 1,50 & 157 \\
& 1,75 & 115 \\
& 2,00 & 88 \\
\hline & 1,00 & 502 \\
& 1,25 & 321 \\
$0,95(1,96)$ & 1,50 & 223 \\
& 1,75 & 164 \\
& 2,00 & 126 \\
\hline
\end{tabular}

$\mathrm{Na}$ TABELA 4, observa-se, por exemplo, que para uma confiança de $95 \%$ e erro máximo de estimação do \%G de 1,25\% seria preciso uma amostra total de tamanho $=321$. Nesse caso seriam necessários $\cong 161$ indivíduos $\left(\cong \frac{321}{2}\right)$ em cada grupo (ES e NE). Esta previsão para a amostra final deste estudo $(n=408)$ foi superada tanto no número de ES ( $\mathrm{n}=181)$ como NE $(\mathrm{n}=227)$.

Os estudos relacionados à precisão dos modelos matemáticos atuais para estimativa da CC apresentam variação entre 2,8\% (WELTMAN, SEIP \& TRAN, 1987) a 4,58\% (TERAN, SPARKS, QUINN, FERNANDEZ, KREY \& STEFFEE, 1991). $\mathrm{Na}$ relação entre a margem de erro $(\varepsilon)$ e o tamanho da amostra (n) para uma 
confiança $\gamma=95 \%$, observa o decréscimo de $\mathrm{n}$ à medida que se aceita uma margem de erro maior (TABELA 4).

\section{$5.2 \quad$ Sujeitos da amostra}

Foram recrutados e medidos 430 jovens do sexo masculino em centros esportivos e escolas (pública e particular) de Presidente Prudente/SP. Os sujeitos deveriam ter idades entre oito e 18 anos de idade, ser aparentemente saudáveis, sem restrições médicas, sem partes do corpo amputadas, sem uso declarado de medicamentos ou tratamento clínico que pudessem afetar o metabolismo, o apetite ou o crescimento. Foram excluídos 22 participantes por não atenderem aos critérios estabelecidos para o estudo, resultando no $n$ final da amostra de 408 sujeitos.

\subsubsection{Classificação de esportistas e não-esportistas}

Todos os sujeitos do estudo eram do sexo masculino. As modalidades esportivas (futebol de campo, atletismo, futsal e judô) foram abrangidas em virtude da disponibilidade dos praticantes e das praças esportivas. O grupo de ES eram aqueles sujeitos engajados em programas de prática esportiva mínima de dois anos, com 3 sessões semanais de uma hora de duração, com experiência em competições no último ano na modalidade praticada. O grupo NE eram aqueles não participantes em algum programa de atividade esportiva sistemática ou com fins competitivos, considerados como escolares. Embora a seleção da amostra tenha sido intencional, realizada num mesmo município, os sujeitos eram provenientes de todo o perímetro urbano da cidade.

Do total final da amostra $(n=408)$, o grupo de ES provinha da prática de futebol de campo $(n=143)$, atletismo $(n=11)$, futsal $(n=20)$ e judô $(n=3)$; os demais (NE) vinham da escola particular $(n=90)$ e pública $(n=141)$. Todavia, foram identificados dentre os escolares, ES praticantes de modalidades já citadas $(n=34)$, como também dentre os praticantes esportivos, sujeitos que não atendiam aos critérios estabelecidos para ES $(n=30)$, classificados então como NE, resultando no total de ES $(n=181)$ e NE $(n=227)$ selecionados. 
Embora o estudo amostral inicialmente tenha indicado um $n$ mínimo necessário de 321 sujeitos, havendo possibilidade de um aumento de 87 sujeitos, obviamente incidiria proporcionalmente na robustez do modelo e na diminuição do erro pretendido entre 1,25 e 1,00 (TABELA 4).

\subsection{Coleta dos dados}

As avaliações foram realizadas no laboratório da UNESP - Campus de Presidente Prudente, onde eram realizados os exames de DXA de corpo total e medidas antropométricas numa única sessão e sempre pelos mesmos avaliadores.

Os dados foram divididos em variáveis dependentes (de resposta) e independentes (explicativas). Como variáveis de resposta aquelas representativas dos componentes corporais, a saber; MG, MO e MM. Como explicativas aquelas com caráter preditivo da $\mathrm{CC}$, as variáveis de caracterização (idade, sexo e prática esportiva), medidas de dimensões corporais (estatura, peso, ATC, comprimento de membros inferiores, dobras cutâneas, perímetros e diâmetros ósseos) e maturação pela idade do PVC.

\subsubsection{Idade milesimal}

A amostra foi classificada etariamente dos oito aos 18 anos por idade milesimal. A idade foi determinada calculando-se a fração milesimal estimada de acordo com o método desenvolvido por HEALY² (citado e adaptado por GUEDES \& GUEDES, 2006). O cálculo matemático se baseia na obtenção de frações equivalentes à data da avaliação (Fda) e à data de nascimento do avaliado (Fdn), a partir da operação $($ Fda e Fdn $)=(($ Dia -1$)+30,3($ Mês -1$)) / 365$.

O cálculo da idade milesimal é definido pelos valores iniciais dessas frações (Fda e Fdn). Quando Fda é menor que Fdn, tanto a fração quanto os anos calculados precisam ser extraídos de 1 (um). Ou seja:

Se Fda > Fdn, então:

Fração $=$ Fda - Fdn, e

\footnotetext{
${ }^{2}$ HEALY, M.J.R.; LOVAIC, J.A.; MANDEL, S.P.H. et al. The individual and the group. In.: WEINER, J.S.; LONNIE, J.A. (eds.) Practical Human Biology. New York, Academic Press, p.11-23, 1981.
} 
Ano $=$ Ano da Avaliação - Ano de Nascimento

Idade milesimal $=$ Ano + Fração

Se Fda < Fdn, então:

Fração $=F d a+(1-F d n)$, e

Ano $=($ Ano da Avaliação - Ano de Nascimento $)-1$

Idade milesimal $=$ Ano + Fração

Uma vez calculada a idade milesimal, foi definido o intervalo para cada idade, determinado para aqueles sujeitos que estivessem entre $-0,500$ a 0,499 do valor inteiro de cada idade. Por exemplo: a idade de 10 anos compreendeu por todos que tivessem idade milesimal entre 9,500 a 10,499 anos.

\subsubsection{Medidas Antropométricas}

As medidas antropométricas foram realizadas sem que fosse seguida alguma padronização específica, embora se tenham adotados os procedimentos mais utilizados atualmente da prática antropométrica. Uma vez que todo procedimento era realizado em sessão única, antes das medidas os avaliados eram convidados a esvaziar a bexiga para obtenção das medidas.

As medidas de peso corporal foram realizadas utilizando-se uma balança antropométrica eletrônica da marca Filizola $\Theta$, (modelo Personal, para até 180 kg, Campo Grande, MS). O avaliado posicionava-se sobre a plataforma da balança trajando um mínimo de vestimenta (short e camiseta), com braços estendidos ao longo do corpo em posição estática, quando era registrado o peso corporal em kg com precisão de 100 gramas.

A estatura foi medida com o auxílio de um estadiômetro de alumínio fixo de parede (Sanny ${ }^{\circledR}$ Professional - ES2020), com escala de precisão de $0,1 \mathrm{~cm}$, mediante um cursor móvel era determinada a estatura do avaliado. O sujeito colocava-se em posição estática, braços ao longo do corpo, tendo os pés descalços, procurando tocar à escala de medidas com a nuca, costas, quadril, pernas e calcanhares. A cabeça era sustentada no plano de Frankfurt por um dos avaliadores 
de forma alongada, enquanto o outro registrava $(\mathrm{em} \mathrm{cm})$ a medida ao tocar o cursor na parte superior da cabeça do avaliado.

A ATC foi definida pela distância vértico-isquiática, medida a partir da posição sentada em um banco de $50 \mathrm{~cm}$, colocado junto à escala de medidas do estadiômetro. O avaliado colocava-se sentado no banco, joelhos flexionados, pés paralelos apoiados ao solo, braços estendidos ao longo do corpo, tendo a cabeça orientada no plano de Frankfurt. Procurava manter-se uma postura ereta, tocando a escala de medidas pela nuca, costas e quadril, semelhantemente ao procedimento para estatura. A cabeça era sustentada no plano de Frankfurt por um dos avaliadores de forma alongada, enquanto o outro registrava $(\mathrm{em} \mathrm{cm})$ a medida ao tocar o cursor na parte superior da cabeça do avaliado A medida era repetida numa série de 3 vezes, sendo registrada a mediana. Quando havia variação das medidas maior que 5 $\mathrm{mm}$, nova série de 3 medidas era tomada.

A APfoi obtida pela diferença entre a estatura e a ATC.

Foram mensuradas as espessuras de dobras cutâneas com precisão em $\mathrm{mm}$ das regiões: bicipital, tricipital, subescapular, peitoral, axilar média, cristailíaca, abdominal vertical, abdominal horizontal, coxa média e panturrilha medial. Para todas as medidas foi utilizado um mesmo plicômetro do tipo Harpenden, Scientific da marca Sanny®, de pressão constante de $10 \mathrm{~g} / \mathrm{mm}^{2}$. O avaliado permanecia em pé, posição relaxada e as medidas eram efetuadas em triplicata sendo registrada a mediana. Quando havia variação maior que 5\% entre as medidas, uma nova série de medidas era tomada. As regiões destacadas para as medidas foram aquelas descritas em LOHMAN et al. (1988).

Foram mensurados os perímetros do tórax (meso-external), braçorelaxado, braço-contraído, antebraço, punho, cintura (menor diâmetro), abdome (cicatriz umbilical), quadril (maior diâmetro), coxa e perna-medial (máximo) com precisão de 0,01m. Foi utilizada uma fita metálica de $2 \mathrm{~m}$ da marca Sanny ${ }^{\circledR}$, tendo na extremidade um dispositivo de látex, que era substituído a cada 20 sujeitos avaliados, na tentativa de uniformizar a pressão das medidas em todos os perímetros. Os sujeitos permaneciam em pé, trajando apenas short e tendo os pés descalços sendo obtidas as medidas no hemicorpo dominante. Para a medida de braço contraído, os sujeitos mantinham o braço em posição horizontal em ângulo de 
90ํ na altura do cotovelo. Sustentavam esta posição pelas palmas das mãos, fazendo contração isométrica. A medida de maior perímetro do bíceps era registrada em cm. Os procedimentos descritos por Callaway et al. (1988) foram seguidos para as medidas de perímetros.

Foram mensurados os diâmetros biacromial, bicrista-ilíaco, tórax transverso, biepicondilar do úmero, bitrocantérico, biepicondilar de rádio e ulna, biepicondilar do fêmur e bimaleolar utilizado se de paquímetros de alumínio anodizado (Antrop - $720 \mathrm{~mm}$ e $300 \mathrm{~mm}$ - Sanny®), com precisão de 0,01m e tolerância de $0,1 \mathrm{~mm}$. Os sujeitos permaneciam em pé, posição estática, tendo livre de vestimentas as regiões medidas. Para as medidas biepicondilar de fêmur, úmero e bimaleolar, os avaliados ficavam em posição sentada com os pés apoiados ao chão.

\subsubsection{Maturação}

Os sujeitos foram classificados por níveis de maturação, baseado no PVC proposto por MIRWALD et al. (2002). Nesse modelo, são incluídas interações entre altura de perna e ATC, idade e altura de pernas, idade e ATC, bem como razão entre peso e estatura.

É importante ressaltar que a idade em que ocorre o pico de crescimento variou entre sujeitos, estando próximos à idade média de 14 anos para sujeitos do sexo masculino (MIRWALD et al., 2002). A determinação da idade do PVC foi possível a partir das informações antropométricas da estatura, ATC, AP, peso corporal e idade. O PVC pôde ser expresso mediante a seguinte equação para rapazes: $P V C=-9,236+0,0002708($ AP $\times$ ATC $)-0,001663(I \times A P)+0,007216(I \times$ $A T C)+0,02292(P / E)$, onde $A P=$ altura de pernas $(\mathrm{cm}), A T C=$ altura tronco-cefálica (cm), I=idade (anos), $P=$ peso corporal $(\mathrm{kg})$ e $E=$ =estatura (cm).

O modelo para estimativa do PVC retorna valores contínuos, assim esse resultado foi utilizado como variável independente na proposição dos modelos preditivos da CC. Todavia, para efeito descritivo do comportamento das variáveis de CC, foi adotado agrupamento etário do PVC, mediante agrupamento para o valor inteiro mais próximo. Uma vez que a maturação foi categorizada em valores inteiros, e sendo Yi o nível de maturação para o i-ésimo indivíduo, a classificação foi definida 
na forma expressa na TABELA 5. O agrupamento resultou em nove níveis na forma de escala: $-5,-4,-3,-2,-1,0,1,2$ e 3 anos para o PVC.

O nível de maturação de idade 0 (zero) indica que o indivíduo estava em seu pico máximo de crescimento. Esta escala é interpretada como o tempo, em anos, para atingir o pico de crescimento. Por exemplo, o nível 3 indica que o pico de crescimento foi atingido há 3 anos, e o nível -3 indica que faltam 3 anos para atingilo.

TABELA 5. Classificação do Pico de Velocidade de Crescimento

\begin{tabular}{c|c}
\hline Nível & Intervalo (anos) considerado \\
\hline-5 & $Y_{i}<-4,49$ \\
-4 & $-4,50 \leq Y_{i}<-3,50$ \\
-3 & $-2,50 \leq Y_{i}<-2,50$ \\
-2 & $\leq Y_{i}<-1,50$ \\
-1 & $-1,50 \leq Y_{i}<-0,50$ \\
0 & $0,50 \leq Y_{i}<0,50$ \\
1 & $1,50 \leq Y_{i}<1,50$ \\
2 & $Y_{i} \geq 2,50$ \\
3 &
\end{tabular}

\subsubsection{Composição corporal multicomponente}

Todas as medidas foram realizadas de outubro a dezembro de $2008 \mathrm{em}$ laboratório de avaliação física do Centro de Estudos e Laboratório de avaliação e Prescrição Motora (CELAPAM) da Faculdade de Ciência e Tecnologia (FCT) da Universidade Estadual Paulista (UNESP), com temperatura constante controlada $\left(21^{\circ} \mathrm{C}\right)$. Os voluntários eram trazidos ao laboratório em grupos de 3 a 5 sujeitos por sessão de medidas. Após preenchimento dos dados de identificação na planilha de coleta de dados (APÊNDICE C) as medidas eram iniciadas. 


\subsubsection{Medidas da DXA}

As medidas da DXA são precisas, especialmente para estimativa do tecido ósseo e apenas uma pequena participação dos sujeitos é requerida (LUKASKY, 1987). Todavia as estimativas do DXA para os valores de tecido mole dependem do software e pouco se sabe sobre os algoritmos utilizados pelos fabricantes na interpretação de cada pixel de leitura. Assim, os erros dessas estimativas são desconhecidos (ROUBENOFF et al., 1993). Entretanto, o progresso tecnológico na determinação dos tecidos moles por DXA são avanços que não devem passar despercebidos. Os softwares já são capazes de se ajustar automaticamente para a idade (pediátrica), ao tamanho (muito espessos ou delgados), largura corporal (análise hemicorporal), atenuação dos tecidos moles (magro e gorduroso) aumentando a precisão, a velocidade e a resolução das imagens obtidas na varredura de corpo total.

Entretanto, uma alternativa para minimizar estes problemas, seria a utilização da DXA conjuntamente a outras técnicas de medidas, em modelos multicomponentes. A mensuração das variáveis preditivas utilizadas em uma equação deve ser tão precisa quanto possível e uma especial atenção deve ser dada à seleção e calibração dos instrumentos, aos procedimentos de medidas e à qualidade de controle (CHUMLEA \& GUO, 2000).

O exame da CC de corpo total e regional foi realizado mediante DXA com um scanner Lunar DPX-NT (GE Medical, Software Lunar DPX enCORE 2007 version 11.40.004, Madison, WI) de varredura pencil-beam. Nesta versão de software, ao inserir os dados do avaliado, o sistema identifica suas características físicas, étnicas, sexuais e etárias, ajustando automaticamente o modo de análise. 0 sistema fornece o tecido de gordura corporal (g); percentagem de gordura (\%); massa do tecido magro (g); $\mathrm{CMO}$ (g) e massa corporal total e regional $(\mathrm{kg})$ compreendendo regiões da cabeça, membros superiores, inferiores e parte do tronco (direito e esquerdo), coluna vertebral, região pélvica e distribuição de gordura andróide e ginóide mensurados por scan.

A cada manhã antes das medidas, era realizada a calibração do equipamento por QA (Quality Assurance) descrito pelo fabricante (MANUAL, 2006) sempre pelo mesmo pesquisador, com arquivamento impresso dos registros da 
confiabilidade das medidas. Semanalmente também era realizado procedimento de calibração Phantom, em bloco padronizado com valores conhecidos de CMO (padronizados - SBMD) para coluna lombar L2-L4 e fêmur total.

As diferenças de absorção (por atenuação) determinavam em única varredura os tecidos de gordura, tecidos moles e CMO em análise. O sistema opera automaticamente na seleção da forma e tempo de varredura de corpo total, no modo fino ( $19 \mathrm{~m} 16 \mathrm{seg}$ ) para sujeitos abaixo de $15 \mathrm{~cm}$ de altura do tronco sobre a mesa de leitura, modo normal (14m21 seg.) para aqueles entre 15 e $25 \mathrm{~cm}$ e no modo espesso (28m38 seg.) para os acima de $25 \mathrm{~cm}$. A tensão média de voltagem era de $76 \mathrm{kV}$, corrente $0,100 \mathrm{~mA}$ em área de colimação de corpo total, representa uma dosagem de apenas 0,2 nGy para esta análise (MANUAL, 2006).

Para o exame, era solicitado ao avaliado a retirada de artefatos metálicos (quando não fosse possível, a ferramenta "artefato" do software era utilizada para isolar a área do dispositivo) trajando roupas leves (FIGURA 3).

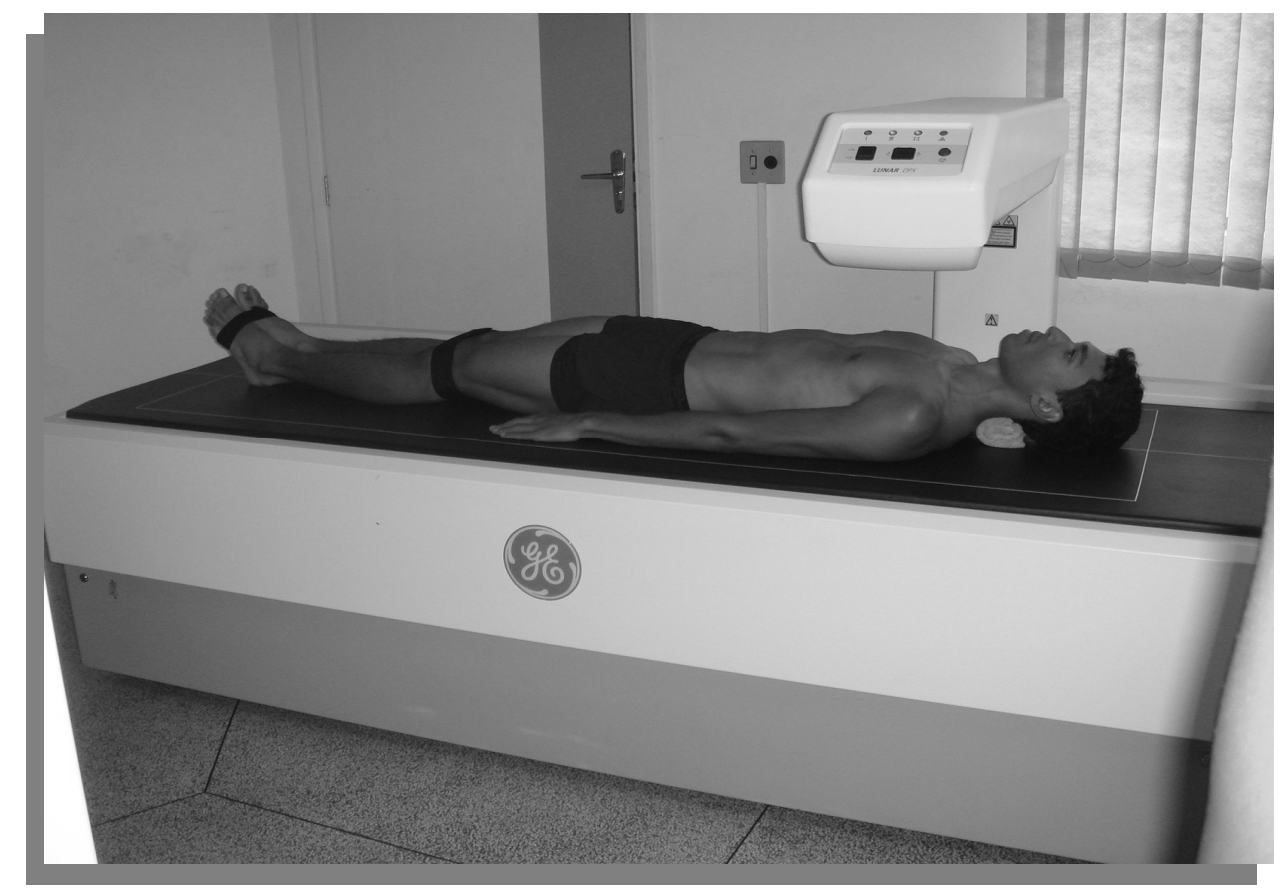

FIGURA 3. Posicionamento do avaliado no scanner.

O avaliado era posicionado pelo pesquisador em decúbito dorsal e centralizado sobre a mesa do scanner, tendo a linha central da mesa como 
referência e os membros inferiores unidos por fitas de velcro. As mãos do paciente deveriam estar abertas, com as palmas apoiadas na mesa de exame e os braços estendidos ao longo do corpo (com os braços do avaliado dentro das linhas da área de varredura na almofada da mesa).

O braço de leitura deslizava por sobre seu corpo a uma distância de 80 $\mathrm{cm}$ de maneira retilínea, realizando o rastreamento da cabeça até aos pés. $O$ detector captava as informações associadas à atenuação dos feixes de fótons, póspassagem através do corpo do avaliado, e as enviava para análise em microcomputador por meio do software específico. Todo procedimento seguiu as recomendações do fabricante para procedimento de análise de corpo total (MANUAL, 2006).

\subsubsection{Cálculo da massa de gordura}

A MG foi estimada a partir dos valores absolutos e relativos fornecidos pela DXA. Os valores absolutos foram expressos em kilogramas (MG) e utilizados para estimativa da $M G$ total, quando considerada de modo relativo $\left(M_{R}\right)$, foi estimada por:

$$
M G_{R}=(M G / P C) \times 100
$$

Onde: $M G_{R}=$ massa de gordura relativa; $M G=$ massa de gordura; $P C=$ peso corporal

\subsubsection{Cálculo da massa óssea}

Para estimar a MO, O CMO foi determinado por DXA conforme descrição anterior. Considerando que o índice mineral ósseo representa a porção óssea cinza, o produto resultante é convertido para MO total (BALLOR, 1996), multiplicando-se:

$$
\mathrm{MO}(\mathrm{kg})=\mathrm{CMO} \times 1,0436
$$

\subsubsection{Cálculo da massa muscular}

Após a transferência da imagem para a tela do computador, 0 pesquisador realizava os ajustes das linhas de definição de cabeça, membros superiores e inferiores, pélvis e coluna, uma vez que o software provê análise dos tecidos corporais de forma regionalizada. Desta forma, foi calculada a massa do 
tecido magro apendicular (TMA) pela somatória do tecido magro de membros superiores e inferiores direito e esquerdo. $O$ valor de TMA foi utilizado na equação de predição da $\mathrm{MM}$ desenvolvida e validada (método: leave-one-out) para crianças e adolescentes por Kim et al. (2006), descrita a seguir:

$$
\mathrm{MM}(\mathrm{kg})=1,003 \times \mathrm{TMA}+0,039 \times \mathrm{PC}-1,315
$$

Nota: $P C=$ peso corporal $(\mathrm{kg}) ; r^{2}=0,985 ; E P E=0,524 \mathrm{~kg}$.

\subsection{Precisão das medidas}

Para assegurar a qualidade dos dados, foi determinado o erro de medida absoluto (ETM) e relativo (ETM\%) intra-avaliador. O ETM nada mais é do que 0 desvio padrão entre medidas repetidas, que calcula a variabilidade das medidas.

Em dias subseqüentes, 13 sujeitos passaram por avaliações completas envolvendo todas as medidas utilizadas neste estudo (TABELA 6) de forma duplicada. Para estimar o ETM absoluto (Equação 14), determinou-se a diferença entre a $1^{\text {a }}$ e a $2^{\underline{a}}$ medida (que é o desvio entre elas), para cada ponto antropométrico considerado, todas as medidas foram tomadas pelo autor deste estudo. Em seguida os desvios obtidos foram elevados ao quadrado, somados $\left(\sum \mathrm{d}^{2}\right)$, divididos por $2 \mathrm{n}$ (=13) e extraída a raiz.

$$
E T M=\sqrt{\frac{\sum d_{i}^{2}}{2 n}}
$$

Onde:

$\mathrm{ETM}=$ Erro técnico de medida absoluto

$\Sigma \mathrm{d}^{2}=$ somatório dos desvios elevado ao quadrado

$\mathrm{n}=$ número de sujeitos

$i=$ quantos forem os desvios

Para obtenção do erro expresso em porcentagem (\%) bastou transformar o ETM absoluto em ETM relativo. Para isso foi necessário calcular o valor médio da variável (VMV) que é a média total dos sujeitos para cada média de 
medidas de cada sujeito. Ou seja: Obteve-se a média aritmética das duas avaliações (1 ${ }^{\text {a }}$ e $2^{\text {a }}$ medidas) de cada sujeito para uma mesma variável. Estas médias foram calculadas para os 13 sujeitos. A seguir foram somadas e divididas pelo $n$ total de sujeito (13) resultando no VMV.

Em seguida obteve-se o ETM relativo (ETM\%) conforme a Equação 15.

$$
E T M \%=\frac{E T M}{V M V} x 100
$$

Onde:

$\mathrm{ETM} \%$ = Erro técnico da medida relativo, expresso em \%.

ETM = Erro técnico de medida absoluto

$\mathrm{VMV}=$ Valor médio da variável

TABELA 6. Erro técnico de medida absoluto (ETM) e relativo (ETM\%), das medidas de dimensões corporais, DXA, dobras cutâneas, perímetros e diâmetros ósseos.

\begin{tabular}{cccc|cccccc}
\hline \multicolumn{3}{c|}{ Dimensões corporais } & \multicolumn{6}{c}{ DXA (kg) } \\
\hline \multirow{2}{*}{ ETM } & Estat. & Tr.-Cefálica & Peso & Gordo & Magro & BMC & M.Total & MaBç MaPn \\
\cline { 2 - 10 } ETM\% & 0,17 & 0,26 & 0,27 & 0,22 & 0,06 & 0,01 & 0,09 & 0,01 & 0,05 \\
& 0,11 & 0,30 & 0,29 & 1,42 & 0,15 & 0,03 & 0,16 & 0,10 & 0,18
\end{tabular}

Dobras cutâneas (mm)

\begin{tabular}{ccccccccccc}
\hline & $\mathrm{Bi}$ & Tri & $\mathrm{Se}$ & $\mathrm{Pt}$ & $\mathrm{Am}$ & $\mathrm{Si}$ & $\mathrm{AbV}$ & $\mathrm{AbH}$ & $\mathrm{Cx}$ & $\mathrm{Pm}$ \\
\cline { 2 - 10 } ETM & 0,40 & 0,12 & 0,04 & 0,54 & 0,38 & 0,35 & 1,59 & 0,82 & 0,63 & 0,23 \\
ETM\% & 6,08 & 1,09 & 0,28 & 5,10 & 4,21 & 2,27 & 7,96 & 4,20 & 3,39 & 1,88 \\
\hline \multicolumn{10}{c}{ ETM } & \multicolumn{10}{c}{ Prímetros (cm) } \\
\cline { 2 - 11 } & 0,31 & 0,08 & 0,84 & 0,06 & 0,04 & 0,37 & 0,48 & 1,33 & 0,70 & 0,11 \\
ETM\% & 1,35 & 0,30 & 1,03 & 0,25 & 0,28 & 0,56 & 0,67 & 1,50 & 1,47 & 0,33
\end{tabular}

Diâmetros ósseos (mm)

\begin{tabular}{ccccccccc}
\hline & BiAc & TxTr & BiCri & BiTr & BiEpÚm & BiEsR/U & BiEpFê & BiMa \\
\cline { 2 - 9 } ETM & 0,22 & 0,20 & 0,22 & 0,14 & 0,01 & 0,02 & 0,02 & 0,12 \\
ETM\% & 0,61 & 0,76 & 0,86 & 0,47 & 0,18 & 0,44 & 0,17 & 1,82 \\
\hline
\end{tabular}


O ETM é um índice de precisão e representa a dimensão de controle de qualidade da medida. Permite ao avaliador verificar seu grau de precisão das medidas antropométricas (intra-avaliador) e comparar suas medidas com outros avaliadores (interavaliador). Esse índice é adotado pela International Society for Advancement in Kinanthropometry (ISAK, NORTON \& OLDS, 2005) para credenciamento de antropometristas.

Este procedimento se deu para todas as medidas coletadas neste estudo. Os resultados (TABELA 6) indicaram baixos valores de ETM absoluto ( $\bar{X}=$ $0,50)$ e $\mathrm{ETM} \%(\bar{X}=2,63)$ para as variáveis, sendo considerados aceitáveis segundo os critérios estabelecidos pela ISAK, indicando boa confiabilidade das medidas.

\subsection{Procedimentos estatísticos}

Os dados são apresentados por classificação etária e nível maturacional (PVC) para as comparações descritivas da CC. Uma análise exploratória inicial foi utilizada para investigar existência de outliers e o teste de Shapiro-Wilk foi empregado para testar a normalidade dos dados. Para as comparações etárias e maturacionais, foi escolhida a análise de variância (ANOVA). O teste post hoc de Tukey foi empregado quando $p<0,05$.

A proposição de equações para estimativa da CC foi concebida, mediante um modelo de regressão multivariada. Para isso, nova submissão foi feita à assessoria estatística por meio de consultoria, para o desenvolvimento do modelo. A definição e validação do modelo serão descritas a seguir.

Finalmente, para as comparações das diferenças na CC entre ES e NE os valores foram expressos graficamente pela idade e pela maturação, sendo realizado o teste de diferenças de $U$ de Mann-Whitney para amostras independentes.

\subsection{Proposição de modelo multivariado da composição corporal}

Nesta seção, serão apresentadas as definições do modelo de regressão multivariada e as técnicas de estimação de parâmetros, para isso os seguintes passos foram seguidos: 
- Correlação entre variáveis de resposta;

- Normalidade e ajuste;

- Verificação da distribuição centralizada de resíduos;

- Redução do número de variáveis explicativas por significância (Stepwise), multicolinearidade e demais critérios;

- Ajuste por aproximação Pillai;

- Determinação dos valores de $\boldsymbol{\beta}$ no modelo multivariado; e

- Confiabilidade e validação (Correlação e PRESS).

Os componentes MG, MO e MM foram considerados como variáveis dependentes e tratadas como variáveis de resposta, enquanto caracterização, dimensões corporais, dobras cutâneas, perímetros e diâmetros (dependentes) foram considerados variáveis explicativas. Para a definição do modelo de regressão multivariada, temos três vetores de variáveis de reposta: $\mathbf{Y}_{1}, \mathbf{Y}_{2}$ e $\mathbf{Y}_{3}$ que são MG, MO e MM.

A cada um desses vetores está associado um grupo de variáveis explicativas, então para o vetor $\mathbf{Y}_{1}$, temos associado o grupo de variáveis $\mathbf{X}_{11}, \mathbf{X}_{12}, \ldots$ . , $\mathbf{X}_{1 \mathrm{k}}$ que são as variáveis explicativas (independentes). Procedendo desta forma para os demais vetores de resposta, para $\mathbf{Y}_{2}$ teríamos $\mathbf{X}_{21}, \mathbf{X}_{22}, \ldots, \mathbf{X}_{2 \mathrm{k}}$ e para $\mathbf{Y}_{3}$, teríamos $\mathbf{X}_{31}, \mathbf{X}_{32}, \ldots, \mathbf{X}_{3 k}$.

Podemos definir um modelo de regressão linear multivariada geral (JOHNSON \& WICHERN, 1992) por:

$$
{ }_{n} Y_{m}={ }_{n} X_{(r+1)(r+1)} \beta_{m}+{ }_{n} \mathcal{E}_{m}
$$

Com:

$$
\mathbf{E}\left(\varepsilon_{(\mathrm{i})}\right)=\mathbf{0} ; \operatorname{Cov}\left(\varepsilon_{(\mathrm{i})}, \boldsymbol{\varepsilon}_{(\mathbf{k})}\right)=\sigma_{\mathrm{ik}} \mathbf{I}_{\mathbf{n}} \quad \mathrm{i}, \mathrm{k}=1,2, \ldots, m
$$

As $\mathrm{m}$ observações sobre 0 i-ésimo ensaio, têm matriz de covariância $\Sigma=\left\{\sigma_{\mathbf{i k}}\right\}$, mas observações de diferentes ensaios são não-correlacionados. Aqui $\beta$ e $\sigma_{i k}$ são parâmetros desconhecidos; a matriz de incidência (delineamento) $\mathbf{X}$ tem jésima linha na forma $\left[\mathbf{X}_{\mathbf{j} 0}, \mathbf{X}_{\mathbf{j} 1}, \ldots, \mathbf{X}_{\mathrm{jr}}\right]$. 
Os elementos de $\boldsymbol{\beta}_{\mathbf{j}}$ podem ser estimados separadamente. Porém, devido à correlação entre as três variáveis de resposta, a análise conjunta se torna mais adequada. Inicia-se então a análise conjunta, definindo as matrizes que irão compor o modelo. A matriz de variável resposta pode ser descrita da seguinte forma:

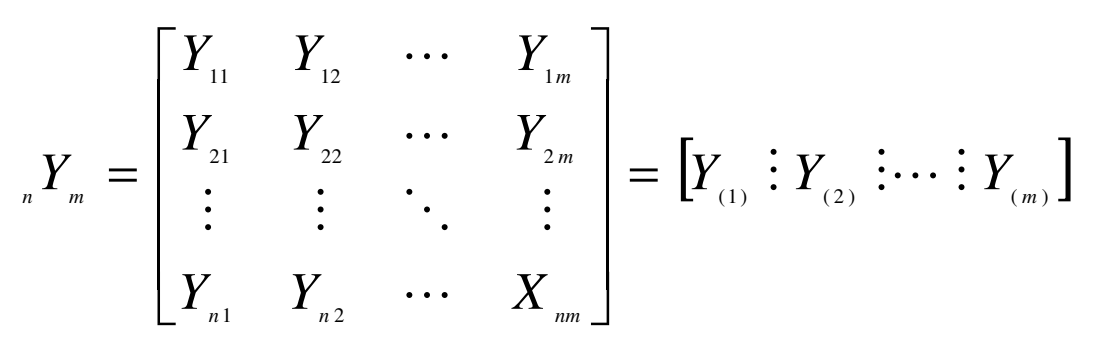

Onde $Y_{j k}$ é o k-ésimo valor da j-ésima resposta, $j=1, \ldots, m$ e $k=1 \ldots, n$.

A matriz de variáveis explicativas é dada por

$$
{ }_{n} X_{(r+1)}=\left[\begin{array}{cccc}
X_{10} & X_{11} & \cdots & X_{1 r} \\
X_{20} & X_{21} & \cdots & X_{2 r} \\
\vdots & \vdots & \ddots & \vdots \\
X_{n 0} & X_{n 1} & \cdots & X_{n r}
\end{array}\right]=\left[\begin{array}{lll}
X_{(0)} & \vdots X_{(1)} & \vdots \cdots \vdots X_{(r)}
\end{array}\right]
$$

A matriz de parâmetros pode ser escrita da seguinte forma:

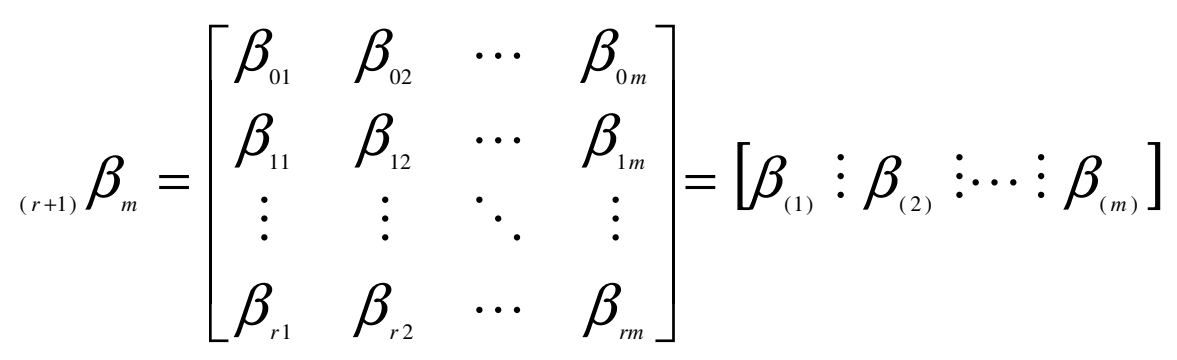

A matriz de erros:

$$
{ }_{n} \varepsilon_{m}=\left[\begin{array}{cccc}
\mathcal{E}_{11} & \mathcal{E}_{12} & \cdots & \mathcal{E}_{1 m} \\
\mathcal{E}_{21} & \mathcal{E}_{22} & \cdots & \varepsilon_{2 m} \\
\vdots & \vdots & \ddots & \vdots \\
\mathcal{E}_{n 1} & \varepsilon_{n 2} & \cdots & \varepsilon_{n m}
\end{array}\right]=\left[\varepsilon_{(1)} \vdots \varepsilon_{(2)} \vdots \cdots \vdots \varepsilon_{(m)}\right]
$$

E finalmente, a matriz de variância covariância do erro é dada por: 
$\operatorname{Var}[\varepsilon]=\left[\begin{array}{cccc}\operatorname{Var}\left[\varepsilon_{1}\right] & \operatorname{Cov}\left[\varepsilon_{1}, \varepsilon_{2}\right] & \cdots & \operatorname{Cov}\left[\varepsilon_{1}, \varepsilon_{m}\right] \\ & \operatorname{Var}\left[\varepsilon_{2}\right] & \cdots & \operatorname{Cov}\left[\varepsilon_{2}, \varepsilon_{m}\right] \\ \operatorname{Simétrica~} & \vdots & \ddots & \vdots \\ & & \cdots & \operatorname{Var}\left[\varepsilon_{m}\right]\end{array}\right]={ }_{n m} \Omega_{n m}$

\subsubsection{Estimação dos Parâmetros}

Existem algumas técnicas disponíveis para a estimação dos parâmetros. No caso deste estudo, será abordada a estimação do vetor $\beta$ pelo método de mínimos quadrados.

Um critério natural para obter estimadores de $\beta$ é minimizar $\sum_{\mathbf{i}=1}^{\mathbf{m}} \boldsymbol{\varepsilon}_{\mathbf{i}}^{\prime} \boldsymbol{\varepsilon}_{\mathbf{i}}=\sum_{\mathbf{i}=1}^{\mathbf{m}}\left(\mathbf{y}_{\mathbf{i}}-\mathbf{X} \boldsymbol{\beta}_{\mathbf{i}}\right)^{\prime}\left(\mathbf{y}_{\mathbf{i}}-\mathbf{X} \boldsymbol{\beta}_{\mathbf{i}}\right)$ em relação à matriz $\boldsymbol{\beta}=\left(\boldsymbol{\beta}_{1} \vdots \boldsymbol{\beta}_{2} \vdots \ldots \vdots \boldsymbol{\beta}_{\mathbf{m}}\right)$, resultando em um sistema de equações normais.

$$
\mathbf{X}^{\prime} \mathbf{X} \boldsymbol{\beta}=\mathbf{X}^{\prime} \mathbf{Y}
$$

Como a matriz $\mathbf{X}^{\prime} \mathbf{X}$ é positiva definida e, portanto, não singular, a estimativa de mínimos quadrados pode ser obtida como:

$$
\hat{\boldsymbol{\beta}}=\left(\mathbf{X}^{\prime} \mathbf{X}\right)^{-1} \mathbf{X}^{\prime} \mathbf{Y}
$$

É fácil observar que $\hat{\beta}$ é um estimador não viciado, ou seja, $E[\hat{\beta}]=\beta$. Além disso, $\operatorname{cov}\left[\hat{\beta}_{\mathbf{i}}, \hat{\boldsymbol{\beta}}_{\mathbf{j}}\right]=\sigma_{\mathbf{i j}}\left(\mathbf{X}^{\prime} \mathbf{X}\right)^{-1}, \forall \mathbf{i}, \mathbf{j}=\mathbf{1}, \mathbf{2}, \ldots, \mathbf{m}$. Neste caso, $\hat{\beta}$ é o melhor estimador não viciado de variância mínima (BLUE - Best Linear Unbiased Estimator). Neste caso, a matriz de valores preditos de $\mathbf{Y}$ pode ser obtida como:

$$
\hat{Y}=X \hat{\beta}
$$

\subsubsection{Teste de Hipóteses sobre os Parâmetros}

No contexto multivariado, a regra da Soma de Quadrados Total é empregada através da matriz positiva definida de Somas de Quadrados e Produtos Cruzados, definida como: 


$$
\mathbf{T}=\mathbf{Y}^{\prime} \mathbf{Y}-\frac{1}{\mathbf{n}} \mathbf{Y}^{\prime} \mathbf{1}_{\mathbf{n}} \mathbf{1}^{\prime}{ }_{\mathbf{n}} \mathbf{Y}
$$

Assumindo que posto da matriz $\mathbf{X}$ é $(r+1)$, a matriz $\mathbf{T}$ pode ser particionada como a soma de duas matrizes positiva definida, dada por:

$$
\mathbf{T}=\mathbf{R}+\mathbf{E},
$$

onde,

$$
\begin{aligned}
& R=Y^{\prime} \mathbf{X} \hat{\beta}-\frac{1}{n} Y^{\prime} \mathbf{1}_{n} \mathbf{1}_{n}^{\prime} Y \\
& E=Y^{\prime} Y-Y^{\prime} X \hat{\beta}
\end{aligned}
$$

A matriz R representa a Soma de Quadrados e Produtos Cruzados da Regressão e a matriz E corresponde à Soma de Quadrados e produtos Cruzados do Erro. Um estimador não viciado para a matriz de variância-covariância $(\Sigma)$ é obtida como:

$$
\hat{\Sigma}=\frac{\mathbf{E}}{\mathbf{n}-\mathbf{r}-1}
$$

A TABELA 7 sumariza a partição da soma de quadrados citados anteriormente.

TABELA 7. Representação para a Análise de Variância Multivariada (MANOVA) para a partição da soma de quadrados entre a regressão e o erro.

\begin{tabular}{ccccc}
\hline Fonte de Variação & G.L & Matriz de SQ e PC & E[SQ e PC] \\
\hline Regressão & $r$ & $R$ & $r \Sigma+\beta^{\prime} X^{\prime}\left(I \frac{1}{n} 11^{\prime}\right) X \beta$ \\
Erro & $n-r-1$ & E & $(n-r-1) \Sigma$ \\
\hline Total & $\mathbf{n - 1}$ & $T$ & \\
\hline
\end{tabular}

A hipótese sob $\beta$ pode ser de interesse para verificar a significância estatística do modelo de regressão multivariada. Pode ser expressa como:

$$
H_{0}: L \beta=\phi \text { vs. } L \beta \neq \phi \text {, }
$$


Sendo a matriz $\mathrm{r}_{(\mathrm{r}+1)}$ conhecida de posto completo.

Existem vários critérios estatísticos para testar a hipótese $\mathbf{H}_{\mathbf{0}}$, baseados em autovalores de certas matrizes que são funções de $\mathbf{L}$ e $\hat{\boldsymbol{\beta}}$.

Critério de Wilks $(\Lambda)$

$$
\Lambda=\left|(\mathbf{H}+\mathbf{E})^{-1} \mathbf{E}\right|=\left|\mathbf{E}^{-1} \mathbf{H}+\mathbf{I}\right|^{-1}=\Pi_{\mathbf{i}=1}^{\mathbf{m}}\left(1+\lambda_{\mathbf{i}}\right)^{-1}
$$

Critério Traço de Pillai (V)

$$
\mathbf{V}=\operatorname{tr}\left[(\mathbf{H}+\mathbf{E})^{-1} \mathbf{H}\right]=\sum_{\mathbf{i}=1}^{\mathbf{m}} \lambda_{\mathbf{i}} /\left(1+\lambda_{\mathbf{i}}\right)
$$

Critério Traço de Hotelling-Lawley (U)

$$
\mathbf{U}=\operatorname{tr}\left[\mathbf{E}^{-1} \mathbf{H}\right]=\sum_{\mathbf{i}=1}^{\mathbf{m}} \lambda_{\mathbf{i}}
$$

Critério Máxima Raiz de Roy $\left(\lambda_{\operatorname{Max}}\right)$

$$
\lambda_{\text {Max }}=\operatorname{Max}\left(\lambda_{1}, \lambda_{2}, \cdots, \lambda_{m}\right)=\lambda_{1}
$$

A TABELA 8 apresenta um resumo das aproximações para a estatística $F$, considerando os critérios acima.

TABELA 8. Critérios de aproximações de estatística F para teste de hipótese HO.

Critério Wilks $(\Lambda)$

$$
\left(\frac{g t-2 u}{\mathbf{z z}_{\mathbf{t}}}\right)\left(\frac{1-\Lambda^{1 / \mathbf{t}}}{\Lambda^{1 / \mathbf{t}}}\right)
$$

Pillai (V)

$$
\left(\frac{2 \mathbf{m}_{2}+\mathbf{s}+1}{2 \mathbf{m}_{1}+\mathbf{s}+1}\right)\left(\frac{\mathbf{V}}{\mathbf{s}-\mathbf{V}}\right)
$$

$$
\text { Hotelling - Lawley (U) } \frac{2\left(\mathbf{s m}_{2}+1\right)}{\mathbf{s}^{2}\left(2 \mathbf{m}_{1}+\mathbf{s}+1\right)} \mathbf{U}
$$

$\operatorname{Roy}\left(\lambda_{\max }\right)$

$$
\frac{\mathbf{n}-\mathbf{r}-\mathbf{h}-\mathbf{z}-1}{\mathbf{h}} \lambda_{\text {Max }} \quad \mathrm{F}\{\mathbf{h} ; \mathbf{n}-\mathrm{r}-\mathbf{h}+\mathbf{z}-\mathbf{1}\}
$$

\section{Aprox. Distrib. de F}

$$
F\left\{z z_{t} ; g t-2 u\right\}
$$

$F\left\{s\left(2 m_{1}+s+1\right) ; s\left(2 m_{2}+s+1\right)\right\}$

$$
F\left\{s\left(2 m_{1}+s+1\right) ; 2\left(s m_{1}+1\right)\right\}
$$


Várias quantidades usadas na TABELA 8 são definidas a seguir.

$\mathrm{z}_{\mathrm{t}}=$ posto $(\mathrm{H}+\mathrm{E})$

$z=$ posto $(L)$

$s=\min \left(z, z_{t}\right)$

$h=\max \left(z, z_{t}\right)$

$m_{1}=\left[\left|z-z_{t}\right|-1\right] / 2$

$m_{2}=\left(n-r-z_{t}-2\right) / 2$

$g=(n-r-1)-\left(z_{t}-z+1\right) / 2$

$u=\left(z z_{t}-2\right) / 4$

$\mathbf{t}= \begin{cases}\sqrt{\left(\mathbf{z}^{2} \mathbf{z}_{\mathbf{t}}^{2}-4\right) /\left(\mathbf{z}_{\mathbf{t}}^{2}+\mathbf{z}^{2}-5\right)} & \text { se }\left(\mathbf{z}_{\mathbf{t}}^{2}+\mathbf{z}^{2}-5\right)>0 \\ 1 & \text { c.c }\end{cases}$

\subsubsection{Critérios de seleção de variáveis}

A redução de variáveis explicativas, portanto implica num modelo mais simples, prático, porém mantendo os níveis de precisão predeterminados. Desta forma, a exclusão se deu com base nos seguintes critérios:

a. A partir dos resultados do Stepwise, quando a significância estatística foi menor que $5 \%$;

b. No que a literatura indica como variáveis explicativas mais utilizadas em modelos preditivos da CC;

c. $\mathrm{Na}$ existência de multicolinearidade entre as variáveis explicativas;

d. A cada nova exclusão de uma variável, foi considerada a manutenção do elevado coeficiente de determinação entre os valores preditos e observados da CC; e

e. No bom senso e conhecimento do assunto do pesquisador nas decisões da seleção das variáveis. 


\subsubsection{Validação do modelo}

Obviamente se seguiram os pressupostos de validação, como a análise da precisão das variáveis explicativas, relação estatística e biológica intra e intervariáveis entre as explicativas e de resposta, estruturação dos métodos estatísticos usados para formular a equação a partir do tamanho da amostra, intercolinearidade entre variáveis de resposta e homocedasticidade dos resultados.

O procedimento de validade interna PRESS (Predictive Sum of Squares ) (HOLIDAY, BALLARD \& MACKEOWN, 1995) foi adotado, a partir da exclusão de uma observação, sendo propostas equações com a amostra restante e replicados mediante validação cruzada para cada sujeito excluído. A predição da soma dos quadrados (SQ) do erro (PRESS) proposto por ALLEN $(1971,1974)$ fornece uma ferramenta útil no dimensionamento residual. Para calcular o resíduo de PRESS, seleciona-se uma observação, por exemplo, (i). Ajusta-se o modelo de regressão para as restantes observações $(n-1)$ e usa esta equação para prever a observação $\mathbf{Y}$ (i) que ficou retida.

Este procedimento é repetido para cada observação, $i=1,2, \ldots, \mathrm{n}$, produzindo um conjunto de $\mathbf{n}$ valores residuais de PRESS $e(1), e(2), \ldots, e(n)$. Assim, a estatística de PRESS é definida como a soma dos quadrados dos $\mathbf{n}$ valores residuais (PRESS):

$$
\text { PRESS }=\sum_{i=1}^{n}\left[y_{i}-\hat{y}_{(i)}\right]^{2}
$$

Desta forma, um modelo com alto grau de previsibilidade para as observações não incluídas, apresentando o valor de $\mathbf{Q}^{2}$ (Coeficiente de PRESS ) próximo de 1 (um) e S SRESs (Erro de PRESS) próximo de zero, em que:

$$
\begin{gathered}
\mathbf{Q}^{2}=1-\frac{\text { PRESS }}{\sum_{\mathbf{i}-1}^{\mathbf{n}\left(\mathbf{y}_{\mathbf{i}}-\overline{\mathbf{y}}\right)^{2}} \mathrm{e}} \\
\text { S PRESS }=\frac{\sqrt{\text { PRESS }}}{\mathbf{n}-\mathbf{k}-1}
\end{gathered}
$$


Em síntese, a estatística PRESS dá uma indicação da capacidade de previsão do modelo de regressão. A validação que usa o procedimento PRESS é similar à aplicação da equação a uma amostra independente (SUN et al., 2003).

6

\section{RESULTADOS}

A TABELA 9 expressa os valores mínimo, máximo, média e desvio padrão das principais características da amostra deste estudo. A massa residual (MR) foi calculada pela diferença do Peso pela somatória dos 3 componentes resposta, ou seja:

$$
\text { Resíduos = Peso }-(M G+M O+M M)
$$

(Equação 16)

TABELA 9. Valores mínimo, máximo, média e desvio padrão das variáveis de jovens do sexo masculino.

\begin{tabular}{lcccc}
\hline \multicolumn{1}{c}{ N=408 } & Mínimo & Máximo & Média & Desvio Padrão \\
\hline Idade & 8 & 18 & 13,17 & 3,00 \\
Estatura & 120,3 & 196,8 & 158,06 & 17,67 \\
Tronco-Cefálica & 61,5 & 99,5 & 82,29 & 8,75 \\
Peso & 20,6 & 119,4 & 50,28 & 17,41 \\
PVC & $-5,12$ & 3,42 & $-1,22$ & 2,34 \\
Class. PVC & -5 & 3 & $-1,25$ & 2,38 \\
\%G & 4,68 & 49,63 & 17,79 & 9,76 \\
MG (kg) & 1,28 & 41,79 & 9,33 & 7,48 \\
MO (kg) & 0,70 & 4,09 & 2,14 & 0,80 \\
MM (kg) & 6,29 & 37,37 & 18,65 & 7,27 \\
Resíduos & 5,38 & 35,06 & 19,39 & 5,47 \\
\hline
\end{tabular}


Nesse estudo são apresentadas três variáveis resultantes de interesse, $M G, M O$ e MM, integrantes da CC, conquanto exista um quarto componente, MR composta por órgãos viscerais e outros tecidos que não o adiposo, muscular ou ósseo (GRÁFICO 2). A partir dos dados obtidos neste estudo, temos que para meninos na faixa etária de 8 a 18 anos, os valores decrescentes médios da massa corporal estão distribuídos em MM (20,08kg), seguida dos resíduos (18,7kg), gordura $(9,34 \mathrm{~kg})$ e finalmente os ossos $(2,14 \mathrm{~kg})$.

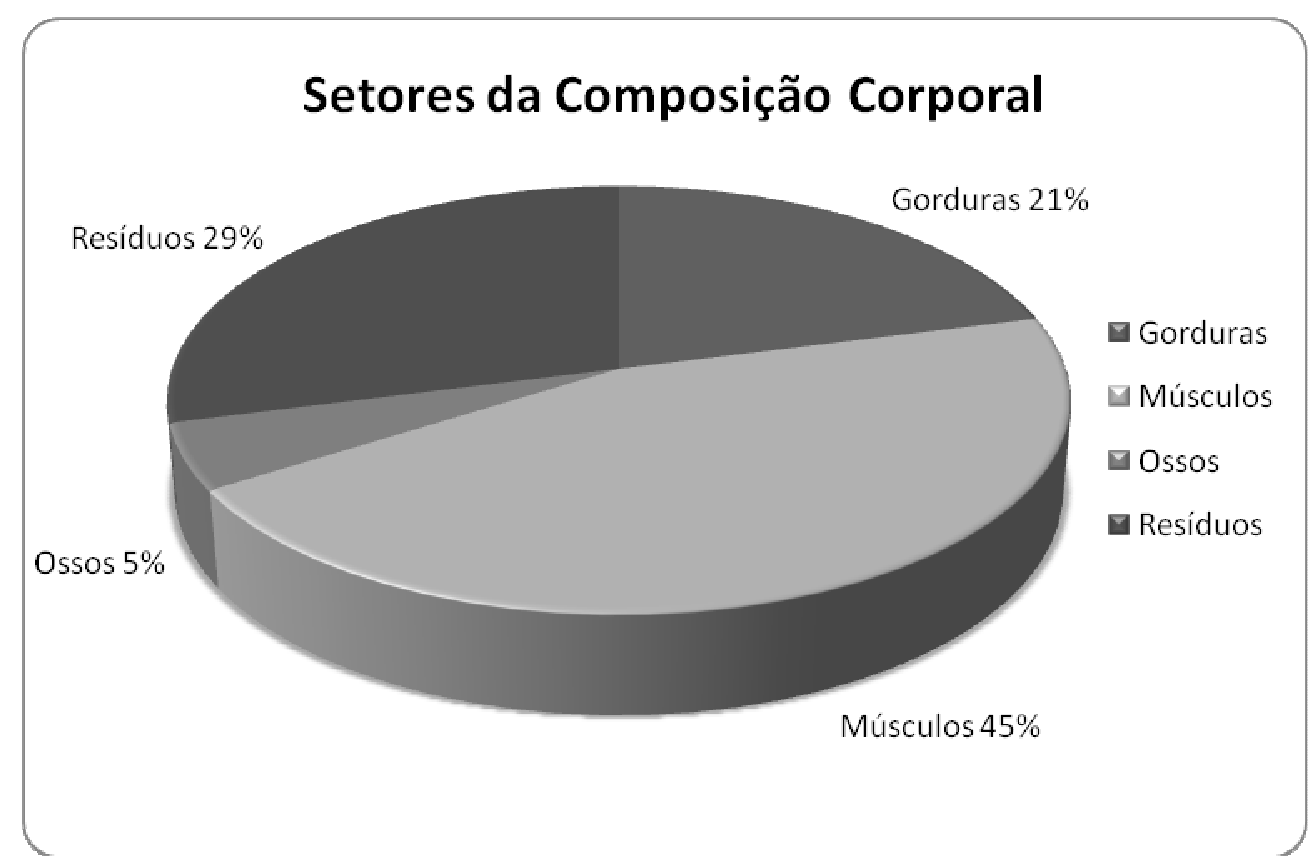

GRÁFICO 2. Setores da distribuição proporcional da composição corporal em jovens do sexo masculino.

No entanto, para identificar e quantificar os componentes corporais, os resultados serão apresentados de forma comparativa por idade cronológica (IC), idade maturacional do PVC em anos e pela prática esportiva, considerando os grupos de ES e NE.

Neste estudo as particularidades de cada modalidade esportiva ou os efeitos que pudessem trazer sobre a $\mathrm{CC}$ não foram consideradas nas análises. Uma ANOVA (one-way) prévia indicou não haver diferenças na CC dos NE da escola pública e particular, assim foram considerados como grupo único. A TABELA 10 divulga a distribuição etária total, relativa e média de PVC dos sujeitos participantes deste estudo. 
TABELA 10. Distribuição por idade cronológica, média de PVC total e relativa (\%) de jovens Esportistas (ES) e Não-esportistas (NE) de 8 a 18 anos do sexo masculino.

\begin{tabular}{ccccccc}
\hline \multirow{2}{*}{ Idade } & PVC & \multicolumn{2}{c}{ ES } & \multicolumn{2}{c}{ NE } & n total \\
\cline { 3 - 6 } & & $n$ & $(\%)$ & 22 & 78,6 & 28 \\
\hline 8 & $-4,8$ & 6 & 21,4 & 17 & 53,1 & 32 \\
9 & $-4,3$ & 15 & 46,9 & 19 & 55,9 & 34 \\
10 & $-3,8$ & 15 & 44,1 & 23 & 57,5 & 40 \\
11 & $-3,1$ & 17 & 42,5 & 19 & 51,4 & 37 \\
12 & $-2,3$ & 18 & 48,6 & 23 & 59,0 & 39 \\
13 & $-1,5$ & 16 & 41,0 & 23 & 48,9 & 47 \\
14 & $-0,6$ & 24 & 51,1 & 21 & 50,0 & 42 \\
15 & 0,3 & 21 & 50,0 & 17 & 43,6 & 39 \\
16 & 1,2 & 22 & 56,4 & 25 & 62,5 & 40 \\
17 & 1,6 & 15 & 37,5 & 18 & 60,0 & 30 \\
18 & 2,4 & 12 & 40,0 & $\mathbf{2 2 7}$ & $\bar{X}=56,4$ & $\mathbf{4 0 8}$ \\
\hline Total & $\bar{X}=-1,3$ & $\mathbf{1 8 1}$ & $\bar{X}=43,6$ & & &
\end{tabular}

6.1 Descrição da composição corporal

A análise descritiva das variáveis respostas está expressa na TABELA 11 e nos Box-plots da FIGURA 4.

TABELA 11. Análise descritiva das medidas de tendência central de massa de gordura, massa muscular e massa óssea em jovens do sexo masculino.

\begin{tabular}{c|cccccccc} 
Massa (n=408) & Média & Desv. pad. & Coef. Var. & Mínimo & 1 Quartil & Mediana & 3o Quartil & Máximo \\
\hline Gordura & 9,34 & 7,48 & 80,14 & 1,28 & 4,30 & 6,62 & 11,86 & 41,79 \\
Muscular & 20,08 & 7,43 & 36,99 & 7,56 & 13,23 & 19,92 & 26,71 & 37,83 \\
Óssea & 2,14 & 0,79 & 37,14 & 0,70 & 1,39 & 2,09 & 2,85 & 4,09 \\
\hline
\end{tabular}



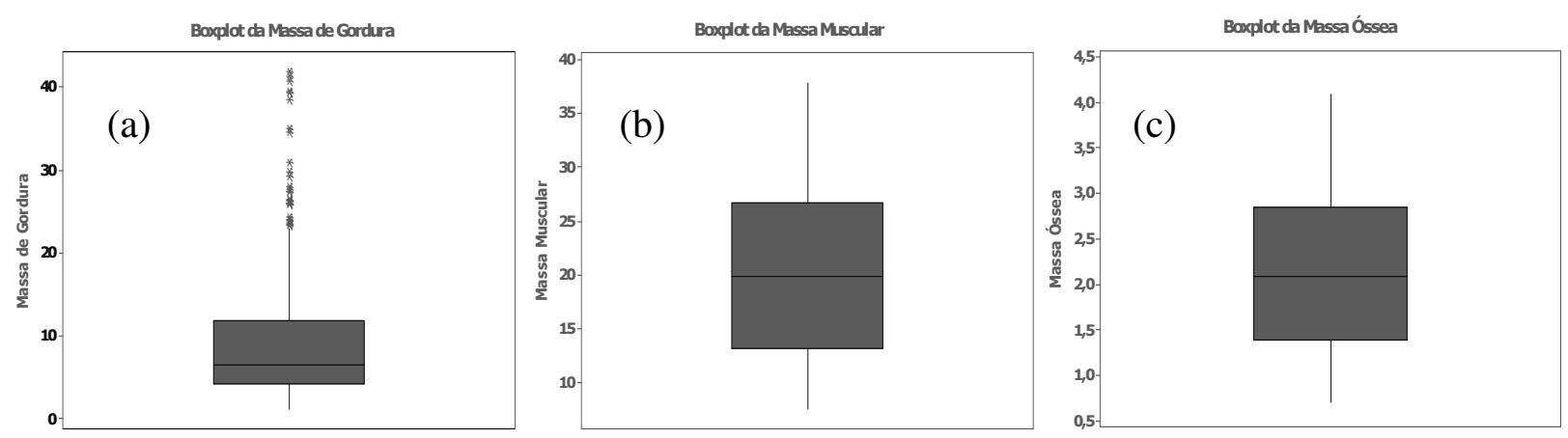

FIGURA 4. Box-plots da massa de gordura, massa muscular e massa óssea em jovens do sexo masculino.

Pode-se observar que a $M G$ é a única que apresenta distribuição (distorcida) com tendência positiva (FIGURA 4a). A existência desses sujeitos com $M G>20 \mathrm{~kg}$ indica que a representação da $M G$ pela média $(9,34 \mathrm{~kg})$ em lugar da mediana $(6,62 \mathrm{~kg})$ poderia ser enviesada (TABELA 11). Assim para essa variável a mediana oferece melhor representatividade, uma vez que a média é bastante influenciada por essa distribuição. Dessa forma, a distribuição da MG foi a que apresentou o maior coeficiente de variação $(\sigma / \bar{X})$, ou seja, foi a mais dispersa de todas. Já as outras duas massas possuem relativamente a mesma dispersão, se observados os componentes de variação que leva em conta a mediana. Observou-se ainda que o desvio padrão, a MO possui um valor relativamente menor, por sua característica de menor dimensão, situada entre 0,70 e 4,09 kg.

Para que seja possível uma comparação entre CC nas diferentes formas de classificação (idade cronológica e PVC) é necessário haver uma boa representação na distribuição da amostra nas duas formas de expressão (GRÁFICO 3). A partir desses gráficos de setores, pode ser observado que esse pressuposto foi contemplado em todas as idades e níveis de pico de crescimento de forma proporcional. Desse modo, é possível a análise dos componentes corporais em relação à idade cronológica e ao PVC. 


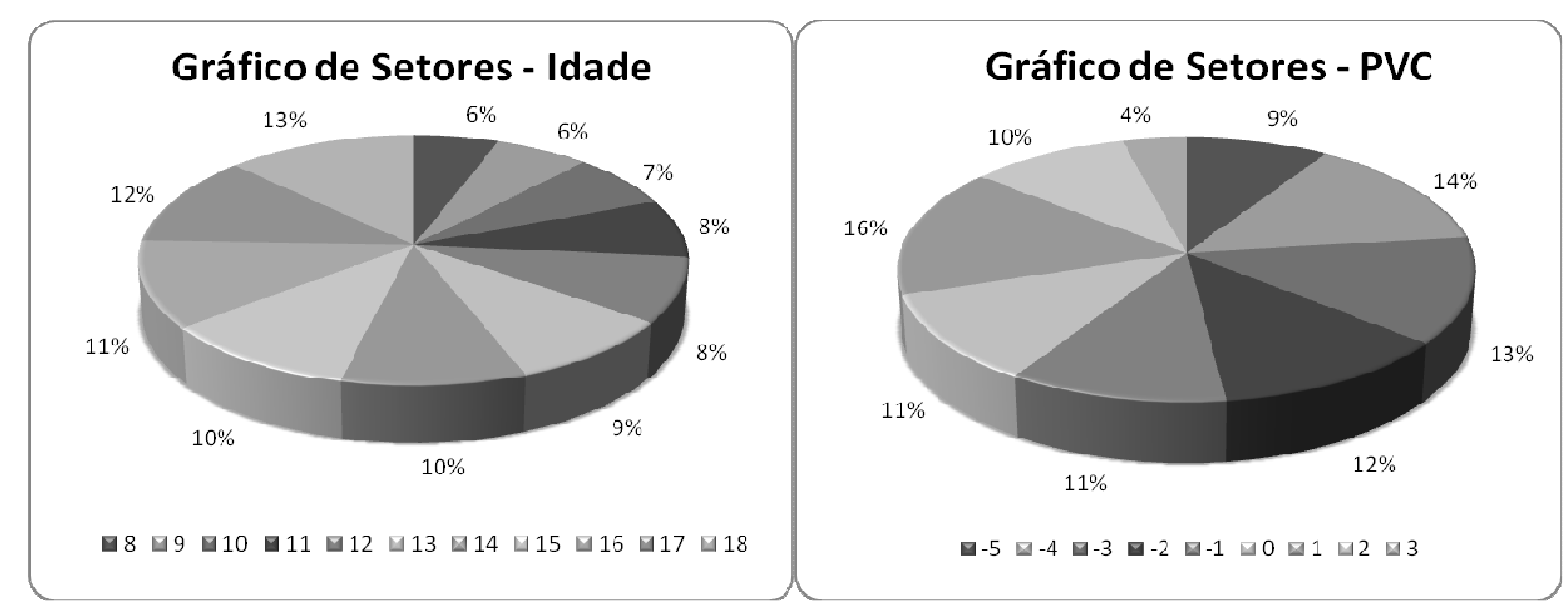

GRÁFICO 3. Distribuição amostral proporcional por idade (8 a 18 anos) e anos para o PVC (5 a 3 ) de jovens do sexo masculino.

Os componentes de MG, MM, MO foram expressos em kg (GRÁFICOS 4 a 6). Uma vez que o estudo tenha característica descritiva transversal, a representação de linha de tendência com ajuste polinomial de ordem 3 foi utilizada, para representar o aumento paralelo ao crescimento. Quando expressa pela idade cronológica a MG apresentou um comportamento de oscilação mais acentuada aos 13 e 17 anos em relação às idades próximas (GRÁFICO 4a). Entretanto quando agrupada por maturação (GRÁFICO 4c), observou-se uma tendência de comportamento mais linear, amenizando os efeitos típicos de uma representação transversal. 

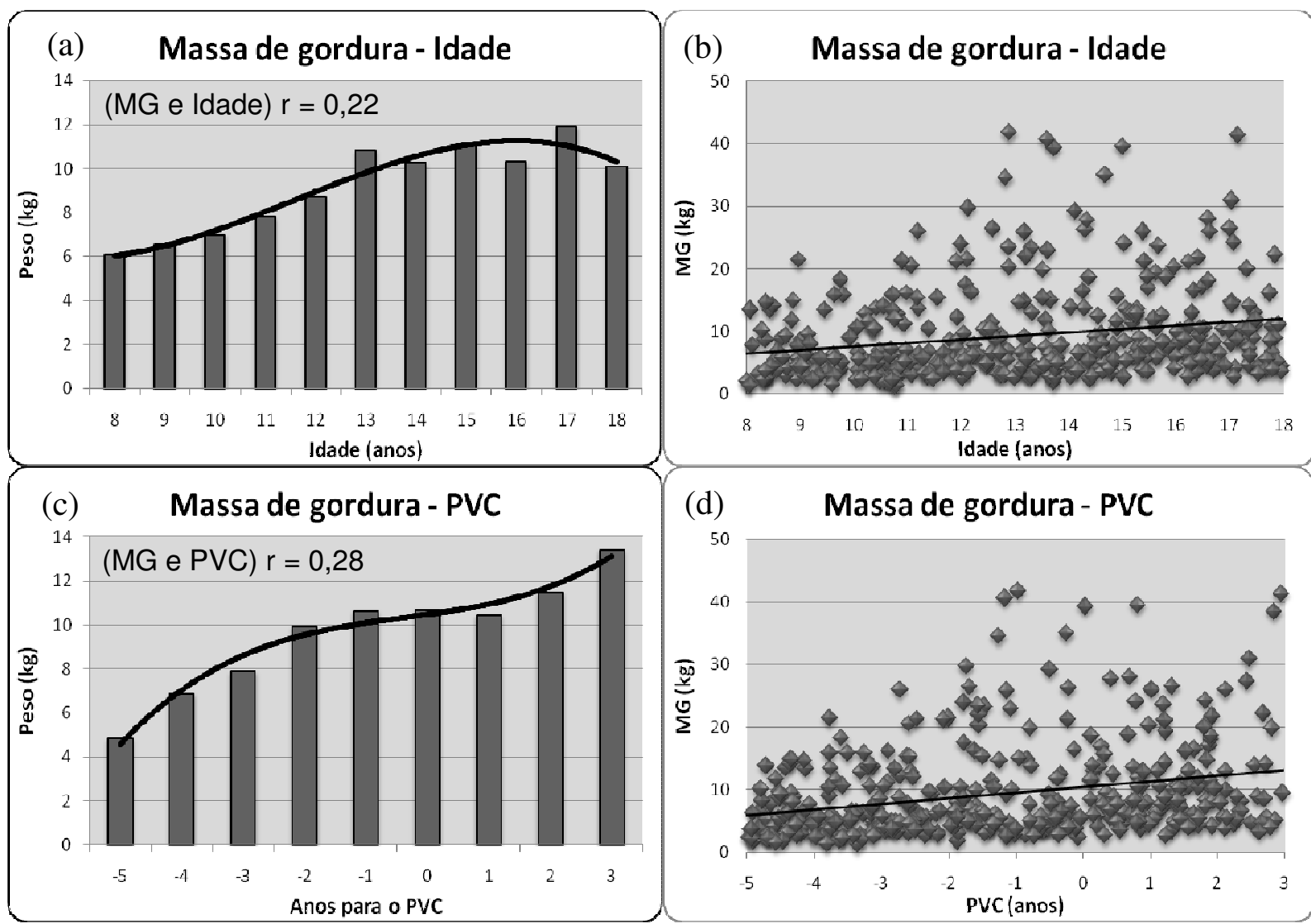

GRÁFICO 4. Representação gráfica, dispersão e tendência da gordura corporal por idade (8 a 18 anos) e anos para o PVC (-5 a 3 ) de jovens do sexo masculino.

Esses gráficos sugerem que a MG média aumenta conforme a idade e a maturação, porém, observados os gráficos de dispersão, nota-se uma grande variabilidade em cada idade (GRÁFICO 4b) e nível de maturação (GRÁFICO 4d). Os baixos coeficientes de correlação entre MG e idade $(r=0,22)$ e MG e PVC $(r=0,28)$ indicam a baixa associações entre gordura e crescimento. 

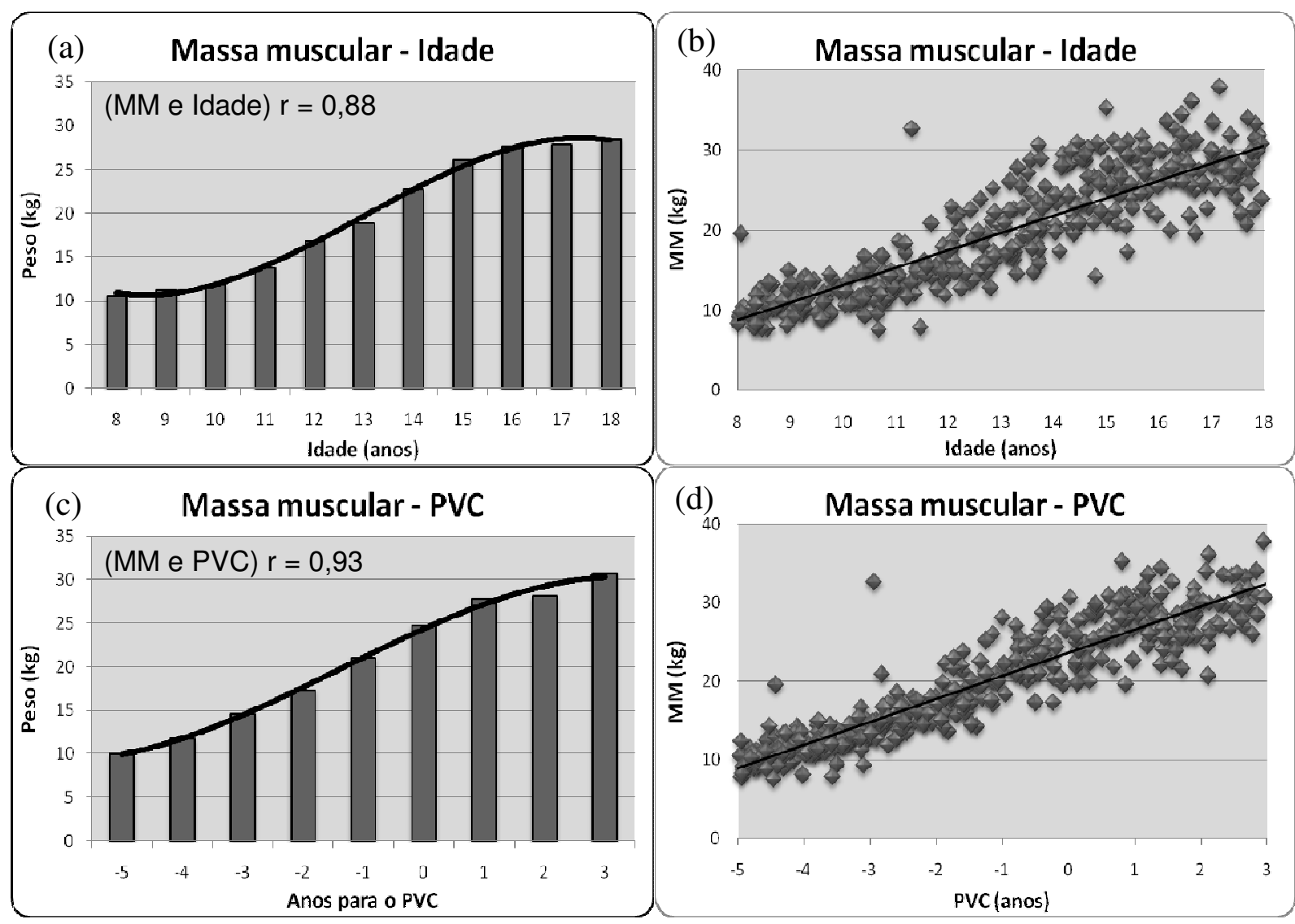

GRÁFICO 5. Representação gráfica, dispersão e tendência da massa muscular por idade (8 a 18 anos) e anos para o PVC ( -5 a 3 ) de jovens do sexo masculino.

Por outro lado, a MM comportou-se de forma inversa à MG e bastante similar, quando alinhada por idade cronológica (GRÁFICO 5a) e por anos para o PVC (GRÁFICO 5c), embora nesta última exista uma tendência linear mais suave. $O$ gráfico de dispersão sugere a existência de relação entre a MM e idade (GRÁFICO 5b) e com PVC (GRÁFICO 5d) quando são observados agrupamentos simétricos ao crescimento etário e maturacional. Analisados os coeficientes de correlação entre MM e idade $(r=0,88)$ tão altos como MM e PVC $(r=0,93)$, nota-se que a MM está mais bem correlacionada com o PVC do que com a idade. 

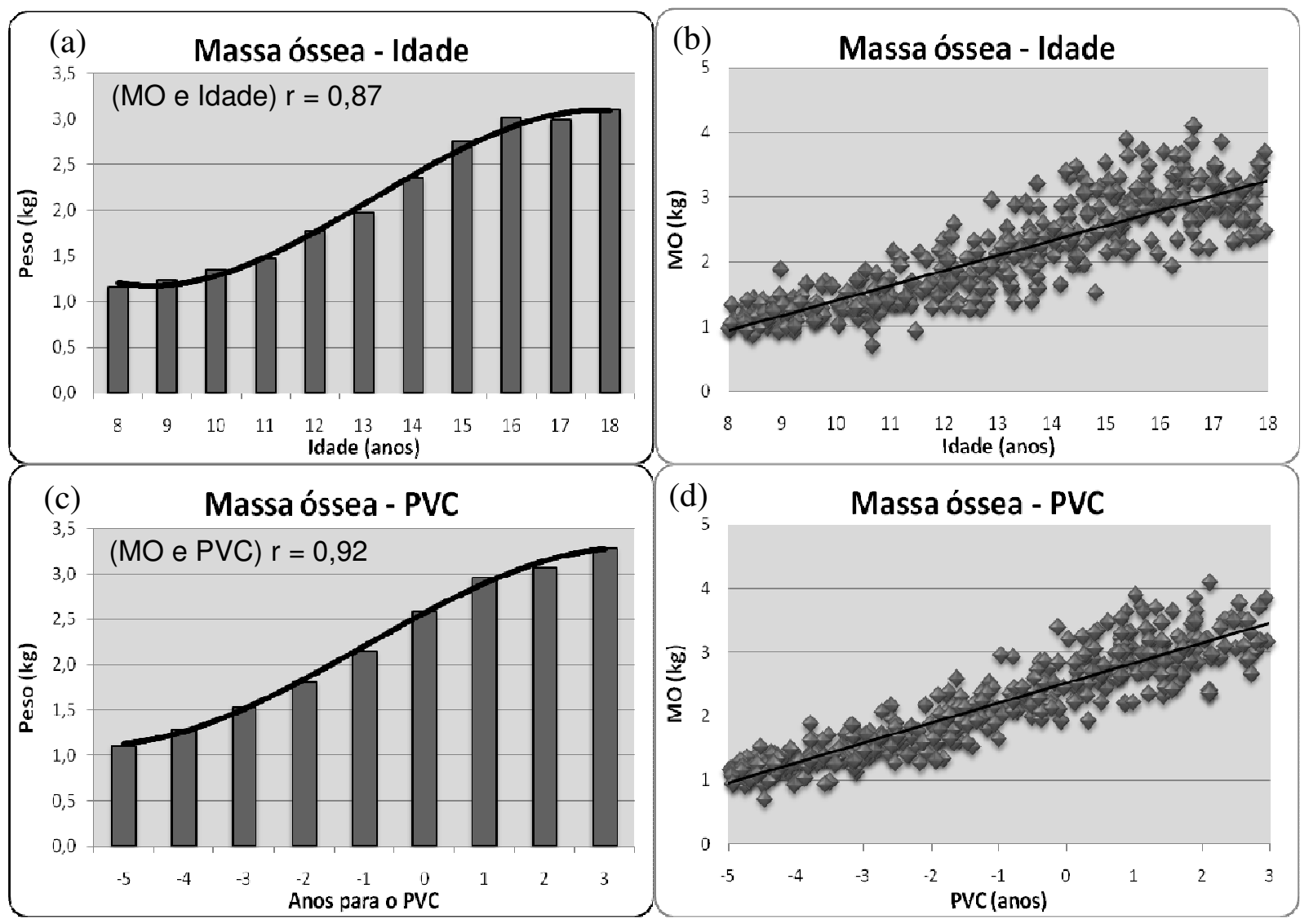

GRÁFICO 6. Representação gráfica, dispersão e tendência da massa óssea por idade (8 a 18 anos) e anos para o PVC ( -5 a 3 ) de jovens do sexo masculino.

O último componente ( $\mathrm{MO})$, também apresentou comportamento semelhante nas duas formas de expressão, por idade (Gráfico 6a) e pelo PVC (Gráfico 6b), com ligeira inversão nas idades de 16 para 17 anos, enquanto no PVC, a idéia de crescimento contínuo vai até ao final da maturação.

O gráfico de dispersão também indicou a boa associação da $\mathrm{MO}$ com a idade e com o PVC, como também pode ser observado pelos altos coeficientes de correlação tanto com idade $(r=0,87)$ como com PVC $(r=0,92)$. 


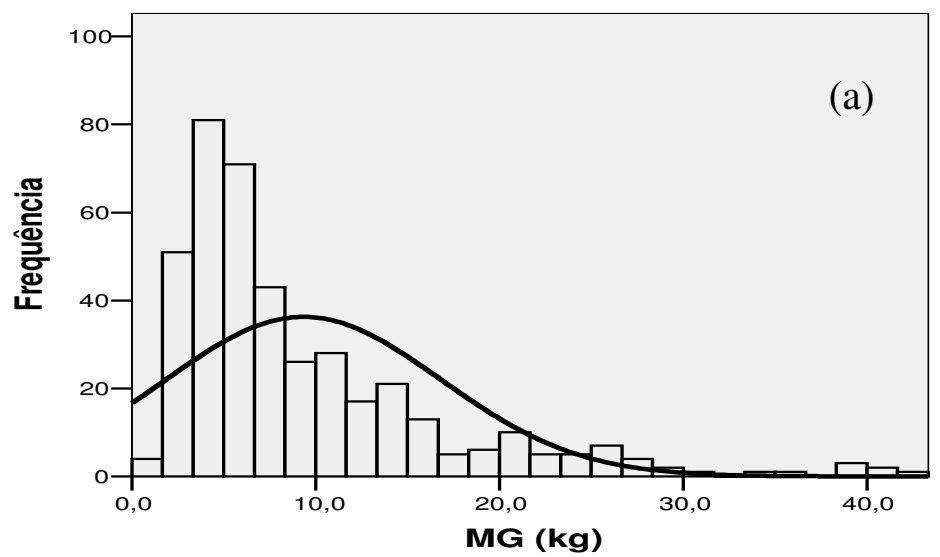

Mean $=9,3348$
Std. Dev. $=7,48053$

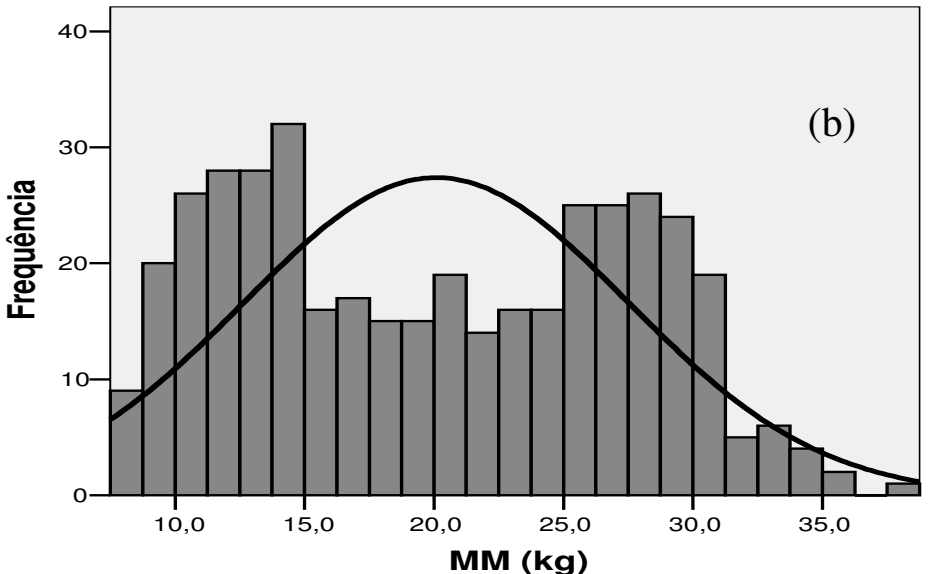

Mean $=20,082$ Std. Dev. = 7,42886 MM (kg)

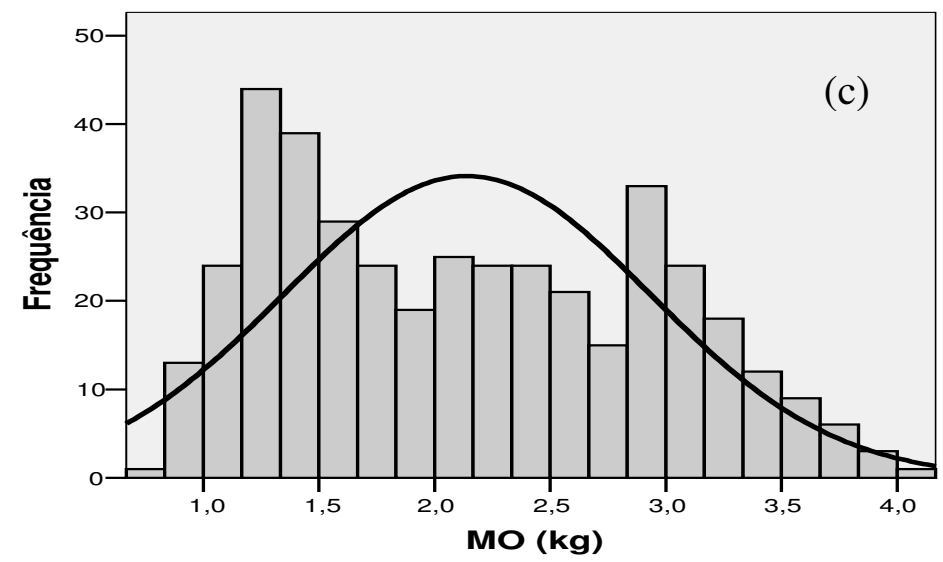

Mean $=2,14$ Std. Dev. $=0,79484$ $N=408$

FIGURA 5. Distribuição da massa de gordura (MG), massa muscular (MM) e massa óssea (MO) em jovens do sexo masculino.

Para determinar o comportamento da CC na amostra estudada, o teste de Shapiro-Wilk indicou não haver normalidade para $M G(W=0,801 ; p<0,001), M O$ $(W=0,953 ; p<0,001)$ nem $M M(W=0,949 ; p<0,001)$. A MG foi a única que apresentou comportamento de distribuição assimétrica à esquerda. Ou seja, a maioria dos sujeitos da amostra tinha menos de $10 \mathrm{~kg}$ de gordura corporal (FIGURA 5). 
Observa-se ainda tendência bimodal na MO (FIGURA 5b) e MM (FIGURA 5c), sugerindo a existência de mais de um grupo representado na distribuição. Todavia análises prévias por agrupamento etário, maturacional e categórico não confirmaram essas suspeitas, mas trata-se da distribuição típica desta amostra.

Em seguida quantificaram-se os componentes da $\mathrm{CC}$, considerando maturação, idade cronológica e prática esportiva (estatística descritiva). A TABELA 12 apresenta os valores de média e desvio padrão da CC, bem como as diferenças etárias das idades subseqüentes registradas pelo teste post-hoc (Tukey) posterior à ANOVA (one-way). Embora tenha se observado uma tendência de aumento dos tecidos corporais durante o crescimento, esse incremento não foi constante nem uniforme.

TABELA 12. Valores de média e desvio padrão (dp) dos componentes da CC e significância estatística $\left({ }^{*}\right)$ para as idades subseqüentes, em jovens de 8 a 18 anos do sexo masculino.

\begin{tabular}{|c|c|c|c|c|c|c|}
\hline \multirow{2}{*}{$\begin{array}{l}\text { Idade } \\
\text { (anos) }\end{array}$} & \multicolumn{2}{|c|}{ MG (kg) } & \multicolumn{2}{|c|}{ MO (kg) } & \multicolumn{2}{|c|}{ MM (kg) } \\
\hline & Média & (dp) & Média & (dp) & Média & (dp) \\
\hline 8 & 6,1 & 4,4 & 1,2 & 0,2 & 10,6 & 2,4 \\
\hline 9 & 6,6 & 4,2 & 1,2 & 0,2 & 11,3 & 1,8 \\
\hline 10 & 7,0 & 4,5 & 1,3 & 0,2 & 11,9 & 2,0 \\
\hline 11 & 7,8 & 6,2 & 1,5 & 0,3 & 13,8 & 3,9 \\
\hline 12 & 8,7 & 6,6 & $1,8^{*}$ & 0,3 & $16,8^{*}$ & 3,0 \\
\hline 13 & 10,8 & 9,5 & 2,0 & 0,4 & 18,9 & 3,6 \\
\hline 14 & 10,3 & 9,4 & $2,3^{*}$ & 0,5 & $22,8^{*}$ & 4,2 \\
\hline 15 & 11,1 & 8,2 & $2,7^{*}$ & 0,5 & $26,1^{*}$ & 4,0 \\
\hline 16 & 10,3 & 5,5 & $3,0^{*}$ & 0,4 & 27,6 & 3,1 \\
\hline 17 & 11,9 & 8,7 & 3,0 & 0,4 & 27,9 & 3,6 \\
\hline 18 & 10,1 & 8,7 & 3,1 & 0,4 & 28,5 & 3,7 \\
\hline$(\mathrm{Gl}=10)$ & & & $\mathrm{F}=1$ & 428 & & 621 \\
\hline
\end{tabular}

* Significância estatísticas nas idades subseqüentes $(p<0,05)$ 
Enquanto a variável MG não apresentou diferenças estatisticamente significantes em nenhuma das idades, a MM revelou um expressivo aumento aos 12 , 14 e aos 15 anos de idade em relação às idades anteriores. Do mesmo modo a MO apresenta um incremento aos 12 anos, 14, 15 e 16 anos, sugerindo aumentos evidentes num período etário até mais extenso que a MM.

TABELA 13. Valores de média e desvio padrão (dp) e significância estatística $\left({ }^{*}\right)$ para as idades subseqüentes, da CC em jovens de -5 a 3 anos do PVC.

\begin{tabular}{ccccccc}
\hline \multirow{2}{*}{ PVC } & \multicolumn{2}{c}{ MG (kg) } & \multicolumn{2}{c}{ MO (kg) } & \multicolumn{2}{c}{ MM (kg) } \\
\cline { 2 - 7 } & Média & $(\mathrm{dp})$ & Média & $(\mathrm{dp})$ & Média & $(\mathrm{dp})$ \\
\hline-5 & 4,8 & 3,1 & 8,8 & 1,4 & 1,1 & 0,1 \\
-4 & 6,9 & 4,8 & 10,5 & 2,0 & 1,3 & 0,2 \\
-3 & 7,9 & 5,1 & $13,1^{*}$ & 2,9 & $1,5^{*}$ & 0,2 \\
-2 & 9,9 & 7,4 & $16,1^{*}$ & 2,5 & $1,8^{*}$ & 0,3 \\
-1 & 10,6 & 10,4 & $19,5^{*}$ & 2,6 & $2,2^{*}$ & 0,3 \\
0 & 10,8 & 8,0 & $23,5^{*}$ & 3,5 & $2,6^{*}$ & 0,4 \\
1 & 10,4 & 7,2 & $26,2^{*}$ & 2,9 & $3,0^{*}$ & 0,4 \\
2 & 11,5 & 7,1 & 26,6 & 3,2 & 3,1 & 0,4 \\
3 & 13,4 & 11,9 & $29,3^{*}$ & 3,2 & 3,3 & 0,4 \\
\hline$G l=8$ & $F=4,618$ & $F=278,234$ & $F=306,615$ \\
\hline P<0,05 & \multicolumn{7}{c}{}
\end{tabular}

Quando expressa pela idade para o PVC (TABELA 13), a MG apresentou tendência semelhante à classificação por idade, porém com diferenças particulares nos demais componentes.

A MM apresentou um aumento com diferenças estatisticamente significantes de -3 a 2 anos para o PVC, denotando 7 anos de incremento muscular acentuado, enquanto na classificação por idade cronológica essas diferenças ocorreram em praticamente metade das idades. Novamente, as diferenças de MO foram significantes em 6 idades do PVC, contra 4 por classificação etária. $\mathrm{Na} \mathrm{MM} \mathrm{e}$ $\mathrm{MO}$, os maiores aumentos ocorreram mais definidamente nas idades anteriores ao 
pico de crescimento ( $P V C=0)$, sugerindo um tempo de estirão da $C C$ até o pico de crescimento.

\subsection{Correlações da composição corporal}

Para relacionar MM, MO, MG com idade, maturação e prática esportiva, recorreu-se às análises de correlação bivariada de Spearman para as comparações entre as variáveis qualitativas e de Pearson para as quantitativas, cujos resultados estão expressos na TABELA 14.

TABELA 14. Coeficiente de correlação entre massa de gordura (MG), massa óssea (MO), massa muscular (MM), variáveis categóricas e antropométricas, em jovens do sexo masculino.

\begin{tabular}{|c|c|c|c|c|c|c|c|c|c|}
\hline & \multicolumn{3}{|c|}{ Caracterização } & \multicolumn{3}{|c|}{ Crescimento } & \multicolumn{3}{|c|}{ CC } \\
\hline & Categ. & $\overline{P V C}$ & Idade & Estatura & $\overline{A T C}$ & Peso & $M G$ & $\mathrm{MO}$ & $\mathrm{MM}$ \\
\hline & Spear & nan & & & & son & & & \\
\hline PVC & $-0,04$ & & & & & & & & \\
\hline Idade & $-0,05$ & 0,97 & & 0,88 & 0,88 & 0,78 & 0,22 & 0,87 & 0,88 \\
\hline Estatura & $-0,04$ & 0,93 & & & 0,95 & 0,84 & 0,27 & 0,91 & 0,94 \\
\hline ATC & $-0,01$ & 0,95 & & & & 0,88 & 0,35 & 0,93 & 0,93 \\
\hline Peso & 0,03 & 0,86 & & & & & 0,69 & 0,91 & 0,89 \\
\hline MG & 0,17 & 0,32 & & & & & & 0,41 & 0,31 \\
\hline MO & $-0,07$ & 0,92 & & & & & & & 0,95 \\
\hline MM & $-0,06$ & 0,92 & & & & & & & \\
\hline
\end{tabular}

PVC=Pico de velocidade de crescimento; $A T C=a l t u r a$ tronco cefálica

A correlação de Spearman expressa associação por ranking. Nas comparações de categoria, os valores foram negativos como resultados da atribuição numérica para as categorias $(E S=1 / N E=2)$, quando $E S$ tiveram menores valores nessas variáveis. Os índices próximos de zero indicaram correlação quase nula na maioria das variáveis, em especial nas de crescimento. Em contrapartida, o PVC apresenta associação muito forte com as variáveis de crescimento, MO, MM e baixa com MG. 
No lado direito da TABELA 14, aparecem as correlações de Pearson, quando novamente, com exceção da gordura, ocorreram associações altas e muito altas $(0,78-0,95)$ entre as variáveis. Enquanto $M G$ apresentou correlação moderada com peso corporal e baixa nas demais comparações, a $\mathrm{MO}$ e a MM apresentaram altas e muito altas correlações com crescimento $(0,91$ a 0,94$)$ e com as variáveis de caracterização $(0,88$ a 0,92$)$, com exceção de categoria.

TABELA 15. Matriz de correlação entre variáveis explicativas e de respostas, em jovens do sexo masculino.

\begin{tabular}{|c|c|c|c|c|c|c|c|c|c|c|c|c|c|c|}
\hline & \multicolumn{11}{|c|}{ Explicativas } & \multicolumn{3}{|c|}{ Respostas } \\
\hline & Estat & Peso & $\begin{array}{l}\text { Dc } \\
\text { Tri }\end{array}$ & $\begin{array}{l}\text { Dc } \\
\text { Se }\end{array}$ & $\begin{array}{c}\text { Dc } \\
\text { AbV }\end{array}$ & $\begin{array}{l}\text { Dc } \\
\text { Cx }\end{array}$ & $\begin{array}{c}\mathrm{Per} \\
\mathrm{Br}\end{array}$ & $\begin{array}{l}\text { Per } \\
\text { Cin }\end{array}$ & $\begin{array}{l}\text { Per } \\
\text { Cx }\end{array}$ & $\begin{array}{l}\text { D. } \\
\text { Umer }\end{array}$ & $\begin{array}{c}\text { D. } \\
\text { Fêm }\end{array}$ & $\begin{array}{l}\text { MG } \\
\text { (kg) }\end{array}$ & $\begin{array}{l}\text { MO } \\
\text { (kg) }\end{array}$ & $\begin{array}{l}\text { MM } \\
(\mathbf{k g})\end{array}$ \\
\hline PVC & 0,94 & 0,84 & $-0,13$ & 0,18 & 0,14 & $-0,12$ & 0,71 & 0,68 & 0,76 & 0,74 & 0,65 & 0,28 & 0,92 & 0,93 \\
\hline Estat & & 0,84 & $-0,13$ & 0,14 & 0,14 & $-0,13$ & 0,67 & 0,66 & 0,74 & 0,78 & 0,70 & 0,27 & 0,91 & 0,94 \\
\hline Peso & & & 0,28 & 0,54 & 0,54 & 0,28 & 0,91 & 0,92 & 0,94 & 0,73 & 0,77 & 0,69 & 0,91 & 0,89 \\
\hline Dc Tri & & & & 0,82 & 0,86 & 0,89 & 0,44 & 0,48 & 0,36 & $-0,03$ & 0,23 & 0,81 & $-0,02$ & $-0,11$ \\
\hline $\mathrm{DcSe}$ & & & & & 0,90 & 0,78 & 0,66 & 0,72 & 0,57 & 0,21 & 0,39 & 0,89 & 0,27 & 0,18 \\
\hline Dc AbV & & & & & & 0,81 & 0,64 & 0,70 & 0,59 & 0,17 & 0,39 & 0,93 & 0,25 & 0,16 \\
\hline Dc Cx & & & & & & & 0,41 & 0,47 & 0,37 & $-0,02$ & 0,20 & 0,80 & $-0,02$ & $-0,12$ \\
\hline Per Br & & & & & & & & 0,92 & 0,91 & 0,61 & 0,67 & 0,75 & 0,77 & 0,74 \\
\hline Per Cin & & & & & & & & & 0,91 & 0,60 & 0,70 & 0,80 & 0,77 & 0,72 \\
\hline Per Cx & & & & & & & & & & 0,68 & 0,76 & 0,71 & 0,84 & 0,81 \\
\hline D. Úmer & & & & & & & & & & & 0,70 & 0,29 & 0,76 & 0,78 \\
\hline D. Fêm & & & & & & & & & & & & 0,50 & 0,73 & 0,72 \\
\hline$M G(\mathrm{~kg})$ & & & & & & & & & & & & & 0,41 & 0,31 \\
\hline MO (kg) & & & & & & & & & & & & & & 0,95 \\
\hline
\end{tabular}

Estat=estatural; Dc=dobra cutânea; Tri=tricipital; Se=subescapular; AbV=abdominal vertical;

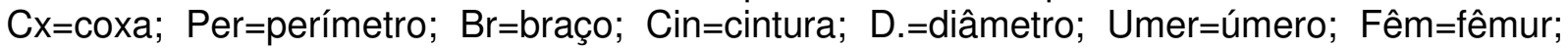
$\mathrm{MG}=$ massa de gordura; $\mathrm{MO}=$ massa óssea; $\mathrm{MM}=$ massa muscular.

A TABELA 15 apresenta a matriz de correlação de Pearson de algumas das variáveis explicativas e respostas. Lembrando que as explicativas foram escolhidas relativamente ao acaso apenas para a visualização, uma vez que temos 36 explicativas e 3 respostas. Escolheu-se o PVC, uma vez que elas possuem altos coeficientes de correlação com idade $(0,98)$, ATC $(0,96)$ e AP $(0,83)$, presentes no 
cálculo do PVC. Além do mais, as correlações da idade com as outras variáveis são muito próximas das do PVC. Utilizaram também das medidas de dimensão corporal, algumas dobras, perímetros e diâmetros ósseos.

A alta correlação entre as variáveis independentes evidencia a existência de relações lineares entre elas. Tal fato é conhecido como multicolinearidade. Multicolinearidade é a existência de relações lineares entre variáveis independentes. A multicolinearidade traz conseqüências indesejáveis para a análise inferencial, tais como: a) no caso de perfeita multicolinearidade, não é possível estimar os parâmetros do modelo pelo método de mínimos quadrados, o que traz complicações; b) na maioria das situações práticas em que há multicolinearidade, as variáveis independentes são altamente correlacionadas, mas não perfeitamente colineares.

Quando ocorre um caso extremo de multicolinearidade (variáveis perfeitamente colineares) o problema é facilmente detectado e, portanto, pode ser resolvido simplesmente eliminado uma ou mais variáveis independente do modelo. Esse procedimento foi adotado como critério de exclusão das 36 variáveis explicativas iniciais. Para verificar a existência de multicolinearidade, recorreu-se a um método, que utiliza o quociente entre o maior autovalor e o menor autovalor da matriz de correlações das variáveis independentes (HAIR, ANDERSON, TATHAM \& BLACK, 2005). Esse resultado, chamado de L, indica baixa multicolinearidade se for menor que 100, média multicolinearidade se estiver entre 100 e 1000 e alta multicolinearidade se for maior do que 1000.

O objetivo seguinte de propor equações preditivas constituiu-se no enfoque principal deste estudo. Desta forma como exposto na descrição metodológica, os resultados serão apresentados em tópicos para facilitar a compreensão.

\subsection{Análise multivariada da composição corporal}

Um pressuposto inicial que justifica a análise multivariada está na correlação entre as variáveis de resposta (FIGURA 6). A correlação moderada da $M G$ com as demais e muita alta entre $M O$ e MM sugerem interdependência. 


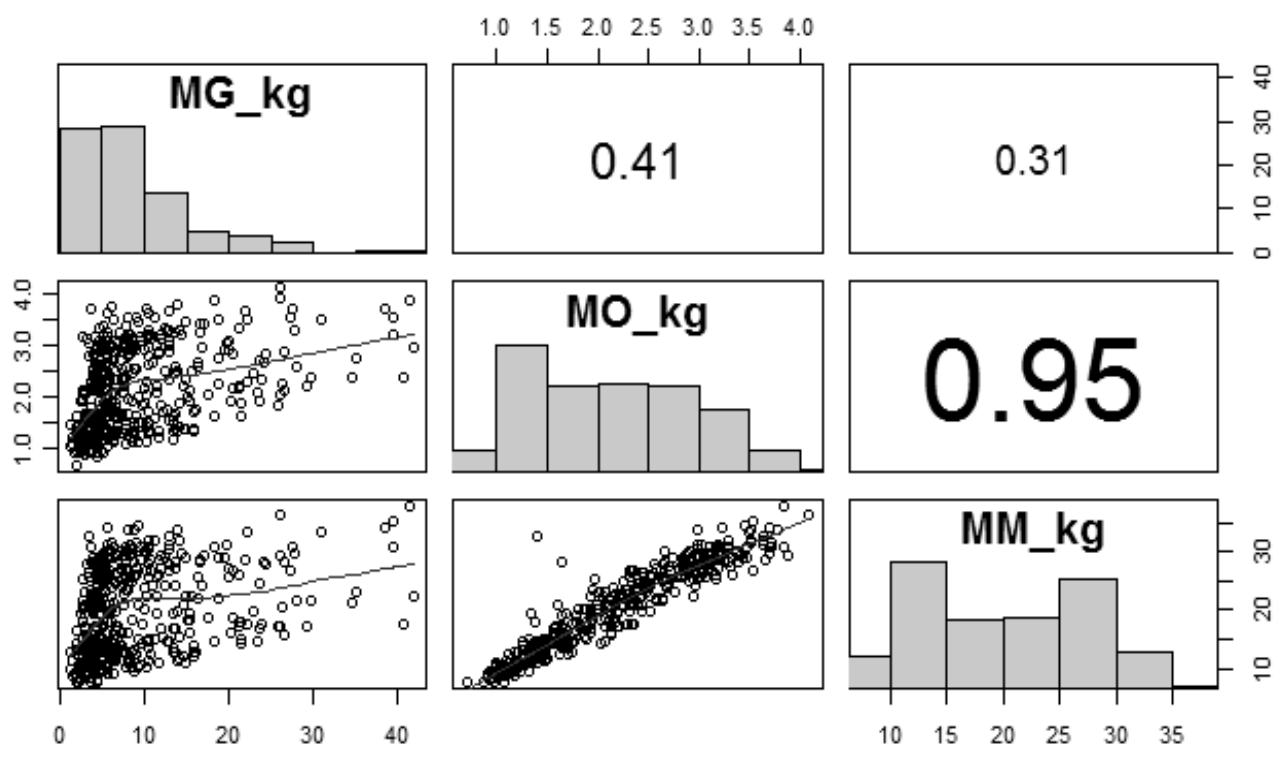

FIGURA 6. Correlação, distribuição e dispersão entre variáveis de resposta (MG, MO e MM) de jovens esportistas e não-esportistas do sexo masculino.

O teste de Shapiro-Wilk testado agora de forma multivariada também indicou não haver normalidade dos resíduos quando $W=0,9017$ e $p=1,432 e^{-15}$. Na tentativa de ajustar os dados, foi realizada regressão com transformação logarítmica dos dados (BOX \& COX, 1964), no entanto não houve melhora nos resultados; o ajuste foi positivo para $\mathrm{MO}$ e $\mathrm{MM}$, mas não para a MG. A idéia de utilizar um modelo simplificado foi mantida, dessa forma os dados foram tratados sem transformação.

Outro pressuposto para análise multivariada está na distribuição centralizada dos resíduos (erro), fato observado nos 3 componentes da CC, como pode ser vista na FIGURA 7. 


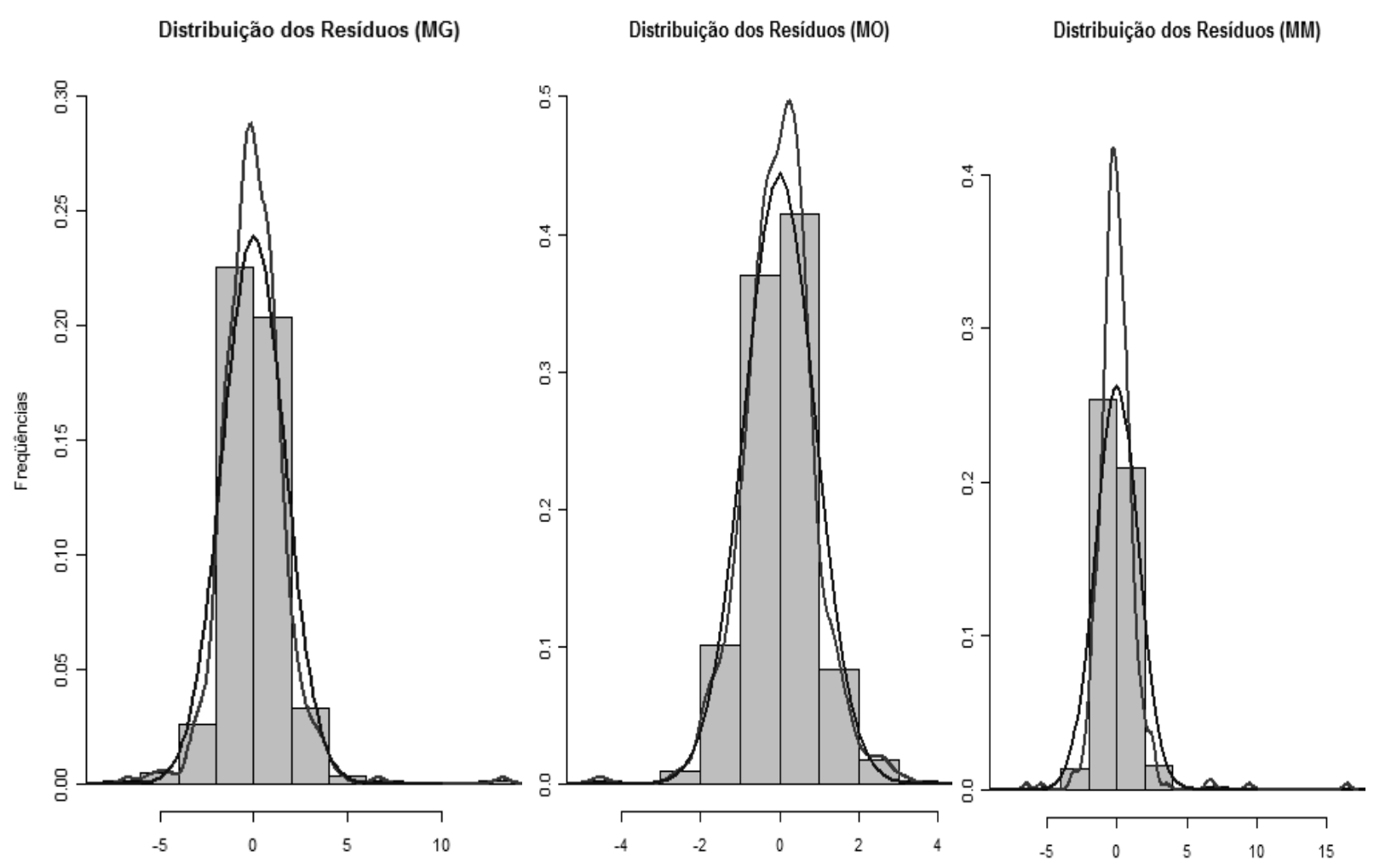

FIGURA 7. Distribuição multivariada dos resíduos para massa de gordura (MG), massa óssea (MO) e massa muscular (MM) de jovens do sexo masculino de 8 a 18 anos de idade.

Uma vez que todas as 36 variáveis explicativas poderiam entrar no modelo, foi realizado individualmente um stepwise para MG, MO e MM a fim de selecionar as variáveis comuns aos três componentes e com maiores coeficientes $\left(r^{2}\right.$ ajustado). Ao todo eram variáveis de caracterização $(n=3)$; dimensões corporais $(n=4)$; dobras cutâneas $(n=10)$; perímetros $(n=10)$ e diâmetros ósseos $(n=9)$. A redução desse número de variáveis foi necessária para se tornar em um modelo viável, de aplicação prática sem perder na precisão.

Os critérios de seleção foram seguidos em processo de repetição da modelagem, cabendo ao pesquisador a decisão pela variável a ser eliminada seguindo aos critérios metodológicos previamente descritos. Após 27 eliminações, chegou-se ao modelo final com apenas 9 variáveis explicativas (TABELA 16) e com coeficiente de determinação acima de 0,96 para explicação da variabilidade total. 
TABELA 16. Ajuste de modelo de regressão multivariada para predição da composição corporal em jovens do sexo masculino.

\begin{tabular}{lcccccc}
\hline & Gl & Aprox Pillai & F num. & Gl den. & Gl & p (>F) Sig. \\
\hline Idade & 1 & 1,00 & 4653,1 & 3 & 396 & $<2,2 \mathrm{e}-16^{* * *}$ \\
Estat & 1 & 0,90 & 835,1 & 3 & 396 & $<2,2 \mathrm{e}-16^{* * *}$ \\
Peso & 1 & 1,00 & 2876,1 & 3 & 396 & $<2,2 \mathrm{e}-16^{* * *}$ \\
Dc Tri & 1 & 0,70 & 273,8 & 3 & 396 & $<2,2 \mathrm{e}-16^{* * *}$ \\
Dc Si & 1 & 0,30 & 60,2 & 3 & 396 & $<2,2 \mathrm{e}-16^{* * *}$ \\
Dc AbV & 1 & 0,20 & 24,3 & 3 & 396 & $1,879 \mathrm{e}-14^{* * *}$ \\
Dc Cx & 1 & 0,10 & 11,8 & 3 & 396 & $2,000 \mathrm{e}-07^{* * *}$ \\
Per Br & 1 & 0,03 & 3,5 & 3 & 396 & $0,01479^{*}$ \\
Per Cx & 1 & 0,10 & 10,7 & 3 & 396 & $9,151 \mathrm{e}-07^{* * *}$ \\
\hline
\end{tabular}

Residuais 398; sig.: 0,000 (***); 0,001 (**); $0,05^{\text {(*) }}$

Estat=estatural; Dc=dobra cutânea; Tri=tricipital; Si=suprailíaca; AbV=abdominal vertical; $\mathrm{Cx}=$ coxa; Per=perímetro; $\mathrm{Br}=$ braço.

O método de Aproximação Pillai foi usado para testar os valores de F. Os elevados índices de significância $(>\mathrm{F})$ devem ser interpretados na seguinte forma de expressão: para $<2,2 \mathrm{e}-16$ implica na notação de $<2,2 \times 10^{-16}$. O vetor das estimativas dos parâmetros $(\boldsymbol{\beta})$ do modelo está descrito na TABELA 17.

A partir dos parâmetros multivariados foi possível predizer cada componente da CC (MG, MO, MM) de forma conjunta, considerando a relação intervariáveis de resposta, diferentemente de quando se propõe uma análise unidimensional tradicional. Os valores medidos e preditos estão expressos no APÊNDICE E.

Entretanto a preocupação inicial da existência de multicolinearidade entre as variáveis explicativas finais precisava ser testada, pois existem casos em que as variáveis são altamente, mas não perfeitamente colineares. 
TABELA 17. Valores de $\beta$ para cada componente da composição corporal em jovens do sexo masculino.

\begin{tabular}{lccc}
\hline & MG (kg) & MO (kg) & MM (kg) \\
\hline (Intercepto) & 7,66571177 & $-0,941635140$ & $-15,00446514$ \\
\hline Idade & $-0,14589134$ & 0,027651517 & 0,00634980 \\
\hline Estat & $-0,09523287$ & 0,005191749 & 0,10369590 \\
\hline Peso & 0,31005737 & 0,035752861 & 0,26962053 \\
\hline Dc Tri & 0,13265764 & $-0,003437299$ & $-0,07584629$ \\
\hline Dc Si & 0,12366158 & $-0,005684636$ & $-0,04932981$ \\
\hline Dc AbV & 0,17473022 & $-0,008074336$ & $-0,08341401$ \\
\hline Dc Cx & 0,11627546 & $-0,004055853$ & $-0,09684956$ \\
\hline Per Br & $-0,06843252$ & $-0,008740523$ & 0,08348542 \\
\hline Per Cx & $-0,07746492$ & 0,013819177 & 0,17455839
\end{tabular}

Estat=estatural; Dc=dobra cutânea; Tri=tricipital; Si=suprailíaca; AbV=abdominal vertical; $\mathrm{Cx}=\mathrm{coxa}$; Per=perímetro; $\mathrm{Br}=$ braço.

Neste caso, quando det $\left(\mathbf{X}^{\prime} \mathbf{X}\right) \approx 0$, MONTGOMERY, PECK e VINING (2006) sugerem um critério bastante eficiente para verificar a presença de multicolinearidade, através do cálculo das raízes características da matriz de correlação das variáveis independentes do modelo. Segundo os autores, baixos valores de uma ou mais raízes características são indícios da existência de multicolinearidade.

$\mathrm{L}=\lambda \operatorname{Max} / \lambda \operatorname{Min}$

Se $L<100$, não existe séria multicolinearidade

Se $100<L<1000$ existe multicolinearidade moderada e

Se $L$ > 1000 indica a existência séria de multicolinearidade.

Desta forma os auto-valores da raiz (eigenvalues) foram calculados para Idade (5,32754814), Estatura (2,93229043), Peso (0,17806613), Dc_Tri $(0,15681715)$, Dc_Si $(0,13199981)$, Dc_AbV $(0,10008997)$, Dc_Cx $(0,08028794)$, Per_Br $(0,06066106)$ e Per_Cx_m $(0,03223937)$ 
Nesta análise, define-se $L=\frac{\lambda_{\max }}{\lambda_{\min }}$, onde $\lambda_{\max }$ é o maior auto-valor da matriz e $\lambda_{\min }$ é o menor auto-valor da matriz.

$$
\text { Assim, } L=\frac{5,32754814}{0,03223937}=165,2498 \text { (multicolinearidade moderada) }
$$

\subsection{1}

Confiabilidade e validação do modelo

As correlações entre os valores preditos e observados na MG, MO e MM podem ser observadas no GRÁFICO 7.
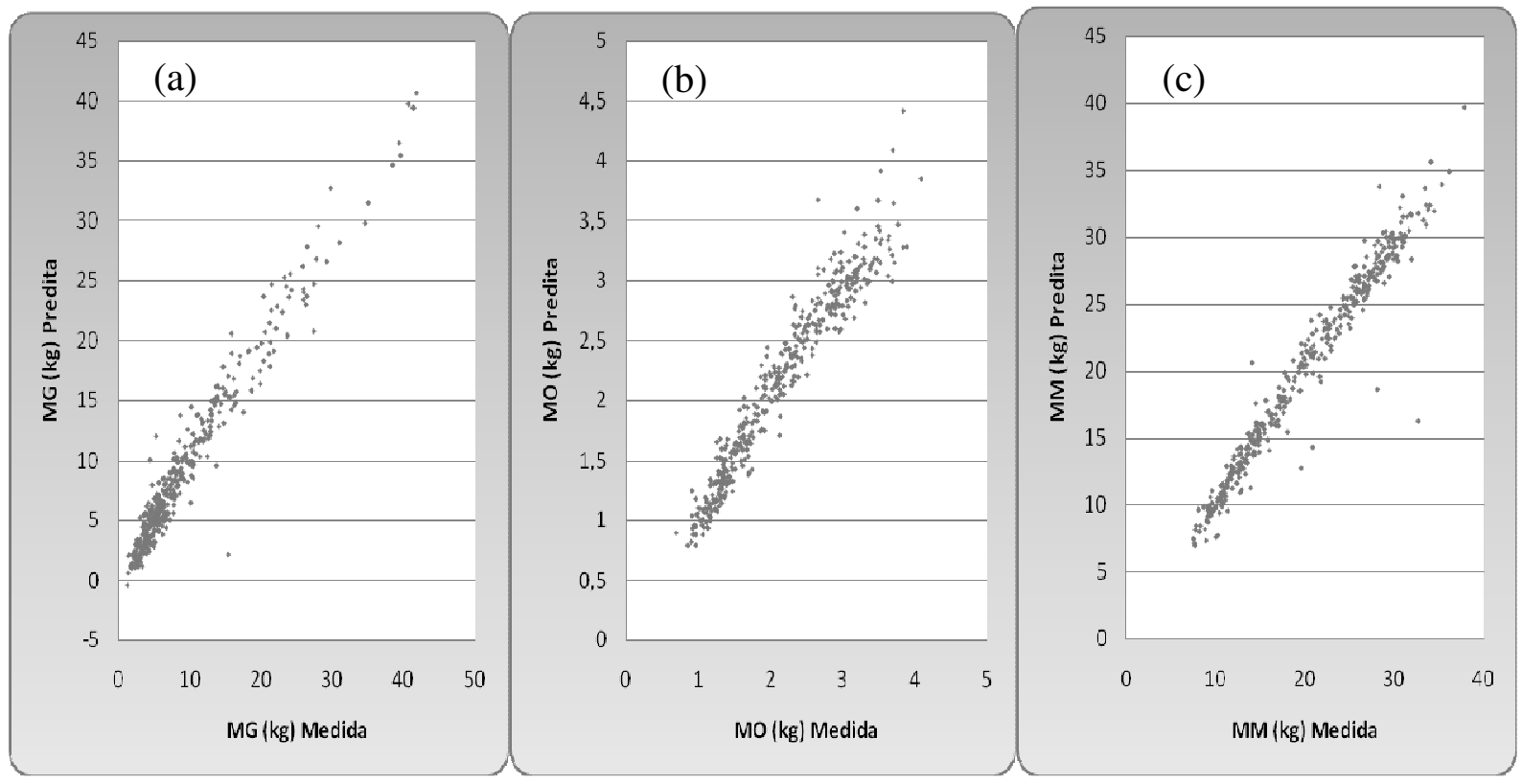

GRÁFICO 7. Dispersão entre os valores preditos e observados da composição corporal de jovens do sexo masculino.

Os valores de correlação, coeficientes de determinação $\left(r^{2}\right)$ e o erro padrão da estimativa (EPE) por análise de resíduos foram:

\begin{tabular}{lcc|c} 
& $\mathbf{R}$ & $\mathbf{R}^{2}$ & $\mathbf{E P E}$ \\
\hline Massa de Gordura & 0,9748 & 0,9502 & 1,69 \\
Massa Óssea & 0,9680 & 0,9370 & 1,82 \\
Massa Muscular & 0,9787 & 0,9579 & 1,54 \\
\hline
\end{tabular}




\section{3 .2}

\section{Validação cruzada do modelo}

A estatística PRESS é utilizada para mensurar a eficiência de uma equação preditiva, quando for aplicada à amostras independentes (MYERS, 1986), mesmo sendo estimada dentro de uma mesma amostra, conforme descrito anteriormente. $O$ processo pode ser compreendido como a eficiência do modelo estimar os parâmetros reais mediante uma simulação virtual.

No caso deste estudo, o erro foi determinado pelo resultado de $Y$ observado $-Y$ estimado. Os resultados da validade interna (PRESS), o coeficiente $\left(Q^{2}\right)$ e a confiabilidade no procedimento $\left(S_{\text {press }}\right)$ podem ser expressos por:

\begin{tabular}{rccc} 
& PRESS & $\mathbf{Q}^{2}$ & SPRESS \\
\hline Massa de Gordura & 0,9463 & 0,9748 & 0,0881 \\
Massa Óssea & 0,9324 & 0,9680 & 0,0105 \\
Massa Muscular & 0,9553 & 0,9787 & 0,0798 \\
\hline
\end{tabular}

Os resultados do modelo indicam coerência com os pressupostos definidos na metodologia, por $Q^{2}$ estar próximo de "1" e o SPRESs próximo de "0".

\subsection{Composição corporal de esportistas e não esportistas}

Como um dos objetivos foi saber como os componentes corporais se distribuem por categoria ( $E S$ e NE), também foi gerada uma tabela com as medidas descritivas e Box-plots (TABELA 18 e FIGURA 8).

TABELA 18. Medidas de tendência central comparativas entre esportistas (ES) e não esportistas (NE) de massa de gordura, massa muscular e massa óssea em jovens do sexo masculino.

\begin{tabular}{c|cccccccccc}
\hline Massa & Categ & $\mathbf{n}$ & Média & $\begin{array}{c}\text { Desvio } \\
\text { Padrão }\end{array}$ & $\begin{array}{c}\text { Coef. } \\
\text { Var. }\end{array}$ & Mínimo & 10 Quartil & Mediana & 3o Quartil & Máximo \\
\hline Gordura & ES & 181 & 7,56 & 5,69 & 75,25 & 1,52 & 4,00 & 5,98 & 8,94 & 41,79 \\
& NE & 227 & 10,75 & 8,39 & 78,1 & 1,28 & 4,48 & 7,76 & 14,67 & 40,66 \\
\multirow{4}{*}{ Muscular } & ES & 181 & 20,62 & 7,39 & 35,86 & 7,73 & 14,20 & 20,88 & 27,00 & 37,83 \\
& NE & 227 & 19,66 & 7,45 & 37,88 & 7,56 & 12,79 & 19,41 & 26,63 & 36,15 \\
& ES & 181 & 2,20 & 0,80 & 36,40 & 0,92 & 1,49 & 2,12 & 2,90 & 3,84 \\
& NE & 227 & 2,09 & 0,79 & 37,69 & 0,70 & 1,37 & 2,05 & 2,76 & 4,09 \\
\hline
\end{tabular}




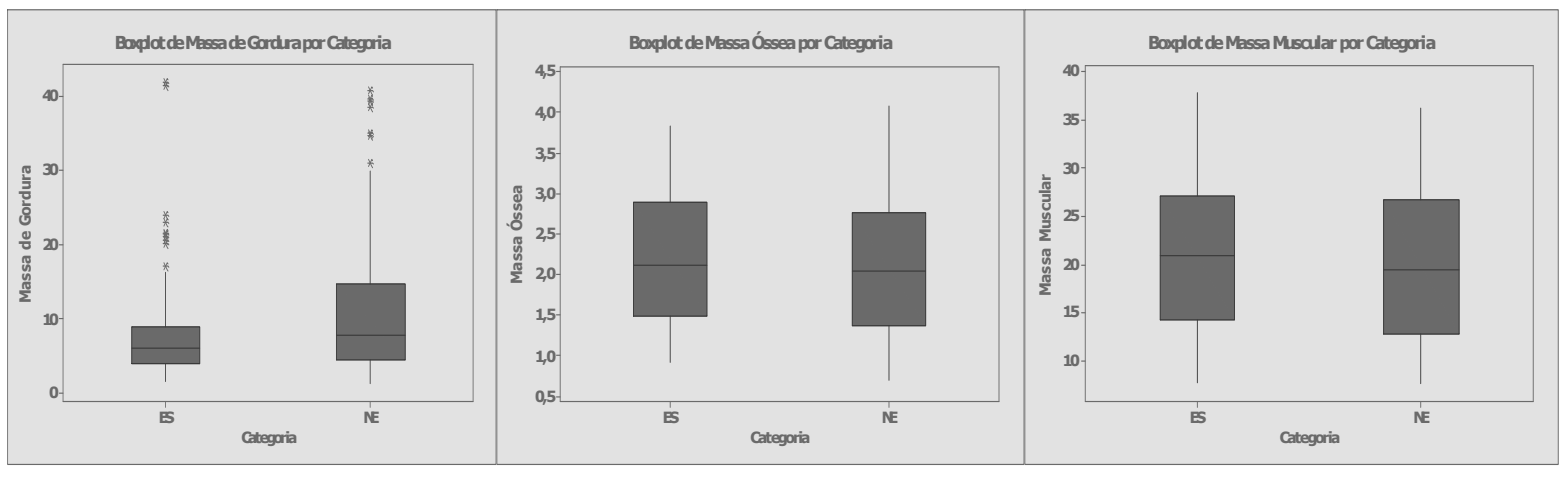

FIGURA 8. Box-plots comparativos entre esportistas (ES) e não esportistas (NE) da massa de gordura, massa muscular e massa óssea em jovens do sexo masculino.

Na FIGURA 8 observa-se que os sujeitos com menores valores de MG não são de nenhuma categoria especificamente, mas estão presentes nas duas. Todavia essa variável é sem dúvida a que mais varia dentre os grupos. O efeito da prática de exercício pode explicar parte dessa diferença, sendo a única que difere estatisticamente entre ES e NE. Isso pode ser confirmado também pelas medianas que apresentam valores menores para os ES. O coeficiente de variação por sua vez é próximo para os dois grupos, mas esse resultado pode ser tendencioso, uma vez que leva em consideração a média. Se excluíssemos os maiores valores de MG dentre os ES (um menino de 13 anos e outro de 17), o coeficiente de variação passaria a ser 61,65 e a média 7,18 , de forma mais coerente com a mediana e a visão dos box-plots da FIGURA 8.

Para as outras duas massas, não há variação visível. As caixas dos Box-plots estão praticamente na mesma linha, não há valores extremos, e as medidas descritivas são próximas: médias, desvios, coeficientes e medianas, o que indica que não há diferença entre os dois grupos nessas variáveis.

Numa visão conjunta desses componentes, considerando a não normalidade da CC, no GRÁFICO 8 estão representados os valores das medianas e desvios padrão (dp) das massas de gordura, óssea e muscular conjuntamente e de forma comparativa entre ES e NE. 


\section{Composição corporal de jovens}

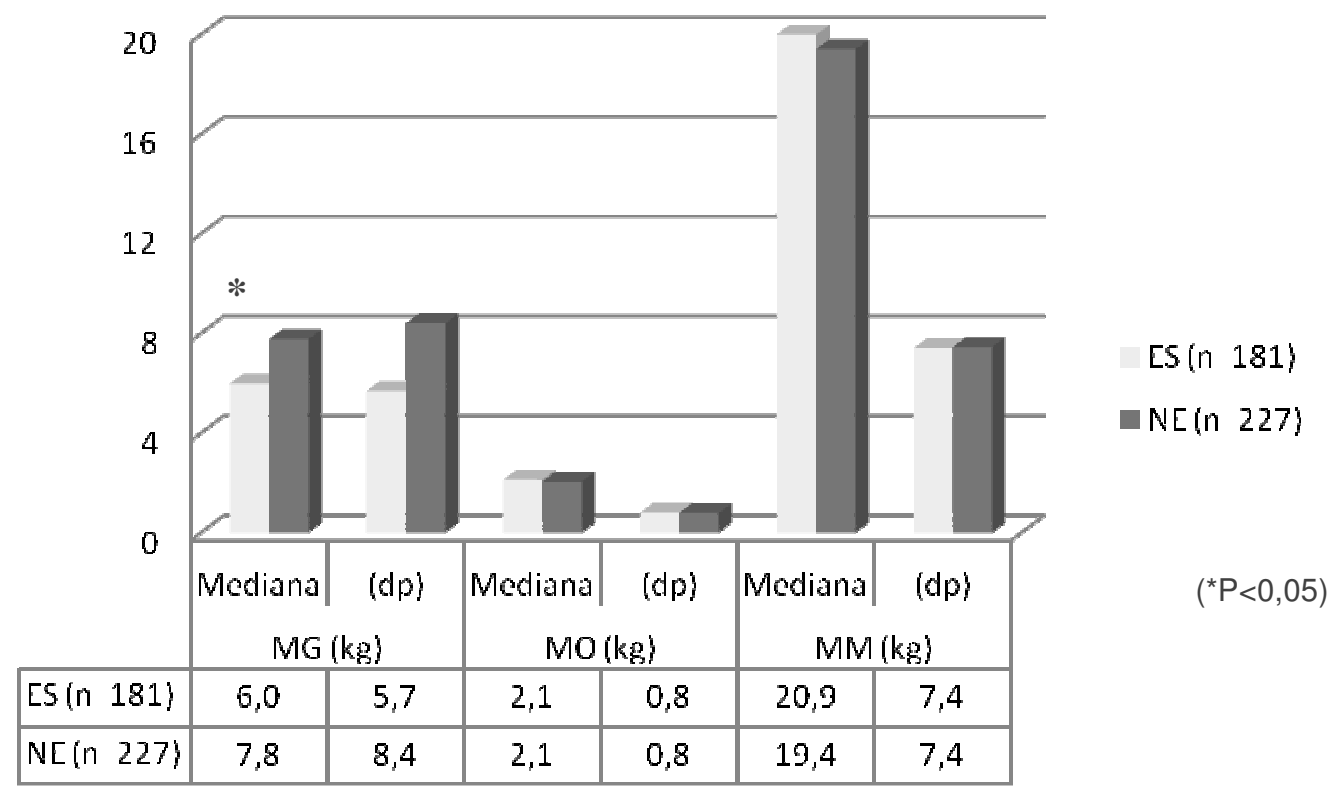

GRÁFICO 8. Proporções da composição corporal de gordura, osso e músculo de jovens esportistas e não-esportistas do sexo masculino.

Observa-se que a CC dos jovens ES apresentam maiores valores de $\mathrm{MM}$, menores quantidades de $\mathrm{MG}$ e muito similares de $\mathrm{MO}$ em relação aos $\mathrm{NE}$, entretanto, a diferença só foi estatisticamente significante na MG (U=16376,50; z=3,$521 ; p<0,000$ ). Observam-se ainda elevados desvios padrão (dp) em todos os componentes, sugerindo não haver homogeneidade nos grupos mesmo entre os ES, pois vale lembrar que não se trata de praticantes de uma única modalidade esportiva.

A comparação da CC por idade e maturação está representada nos GRÁFICOS 9 e 10. Foi realizado o teste $U$ de Mann-Whitney para amostras independentes nas duas formas de classificação. 


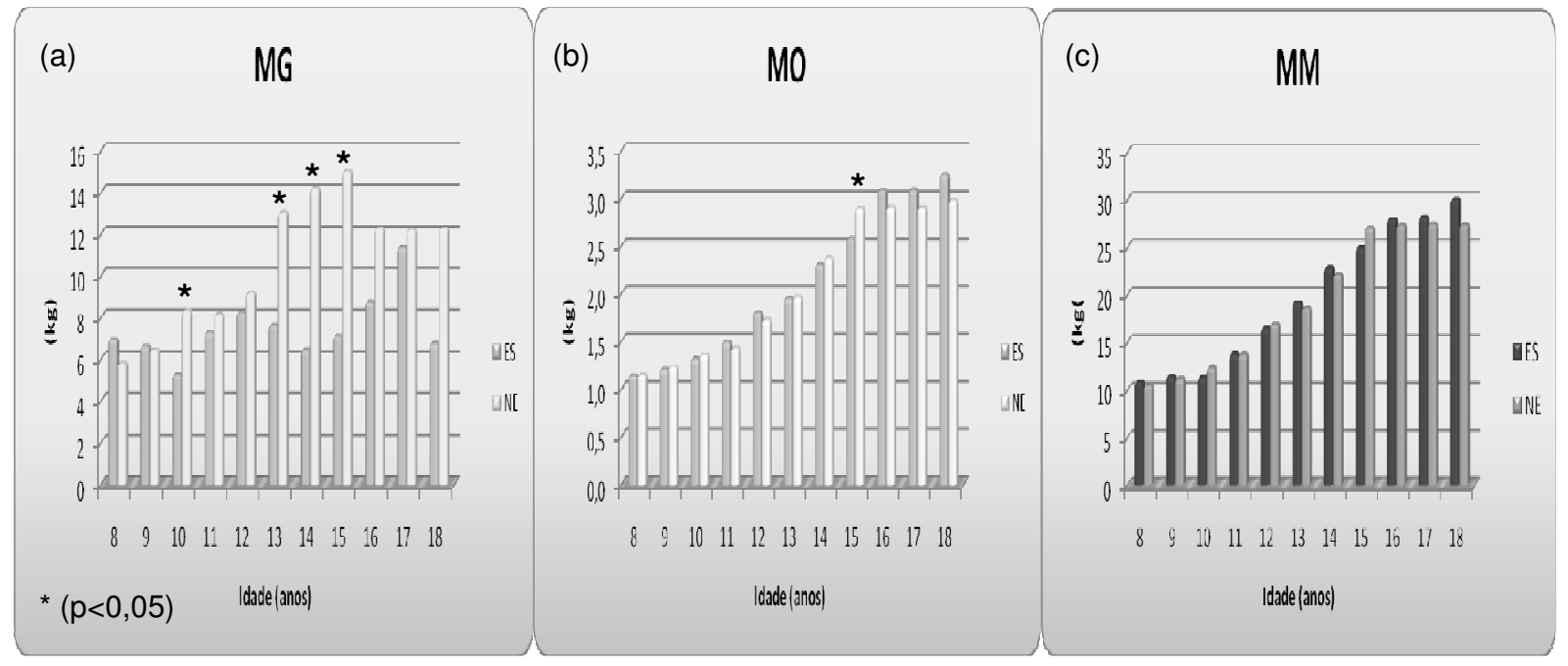

GRÁFICO 9. Valores comparativos por idade cronológica entre esportistas (ES) e não esportistas (NE) da massa de gordura (MG; a), massa óssea (MO; b) e massa muscular (MM; c) em jovens do sexo masculino de 8 a 18 anos.

Os resultados indicaram que a diferença entre ES e NE foi estatisticamente significante na MG (GRÁFICO 9a) aos 10 ( $U=83,0 ; \quad z=-0,56$; $p=0,040)$, aos $13(U=103,0 ; z=-2,31 ; p=0,020)$, aos $14(U=161,0 ; z=-2,45 ; p=0,014)$ e aos 15 anos $(U=91,0 ; z=-0,56 ; p=0,001)$, enquanto na $M O$ a diferença só foi estatisticamente significante aos 15 anos $(U=136,0 ; z=-2,13 ; p=0,034)$, sem diferenças na MM em nenhuma idade. Uma tabela descritiva dessas análises está no APÊNDICE D.

Quando expressos pelo PVC (GRÁFICO 10), a diferença entre ES e NE foi estatisticamente significante somente na MG (GRÁFICO 10a) aos -2 (U=183,0; $z=-1,98 ; p=0,048),-1 \quad(U=124,0 ; \quad z=-2,60 ; p=0,009)$ e ano $1 \quad(U=275,5 ; z=-3,16$; $\mathrm{p}=0,002)$. Embora na idade 0 do PVC, aparentemente a diferença entre ES e NE seja grande, vale lembrar que a distribuição assimétrica unicaudal (FIGURA 5) é considerada nesta análise, quando o valor de significância nessa idade $(p=0,067)$ foi maior ao limite pré estabelecido $(\mathrm{p}<0,05)$. Na $\mathrm{MO}$ não houve diferenças estatisticamente significantes e na $M M$ ela foi encontrada somente no ano 2 $(U=131,5 ; z=-1,98 ; p=0,048)$ do PVC. 


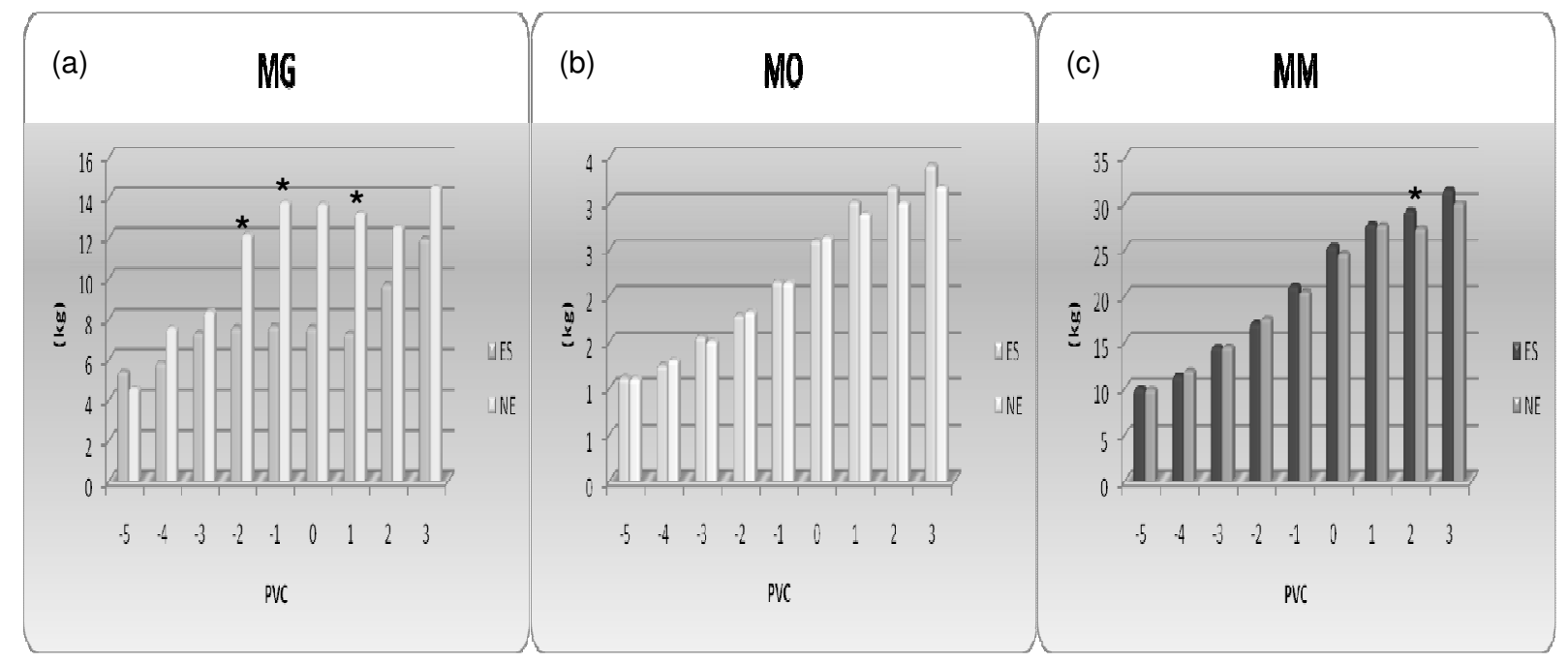

GRÁFICO 10. Valores comparativos por anos para o PVC entre esportistas (ES) e não esportistas (NE) da massa de gordura (MG; a), massa óssea (MO; b) e massa muscular (MM; c) em jovens do sexo masculino de -5 a 3 anos do PVC.

7

\section{DISCUSSÃO}

A literatura apresenta que no nível órgão tecidual (enfoque multicomponente deste estudo) os principais componentes envolvem o tecido adiposo, músculo esquelético, órgãos viscerais e ossos (SHEN et al., 2005). Alguns desses órgãos são sólidos como o cérebro, coração, fígado e pulmão, considerados geralmente como "órgãos viscerais" ou "resíduos" (ELLIS, 2001). Um ponto importante deste componente está que não se trata de uma parte insignificante como por vezes é considerado (HEYWARD \& STOLARCZYK, 2000) ou desprezível (DE ROSE, PIGATTO \& DE ROSE, 1984). O peso médio da MR obtida na amostra deste estudo (29\%) expressa uma importante participação na composição da massa corporal total, ou seja, num sujeito de $70 \mathrm{~kg}$, essa massa equivale a 20,3 kg. Embora a variação desse componente seja proporcional ao tamanho de cada pessoa, numa análise multidimensional jamais deve deixar de ser considerado.

$\mathrm{Na}$ referência humana da MR para um adulto (masc.), o peso do baço (180g), coração (330g), estômago (150g), fígado (1800g), pâncreas (100g), pulmões $(1000 \mathrm{~g})$, rins $(310 \mathrm{~g})$, peitos/mamárias $(26 \mathrm{~g})$, cérebro $(1400 \mathrm{~g})$ e cordão espinhal $(30 \mathrm{~g})$ 
(HEYMSFIELD et al., 2005) somam 5,346 Kg, sem contar os $5200 \mathrm{ml}$ de sangue circulante contido nos $42000 \mathrm{ml}$ de água corporal total ${ }^{3}$. Desta forma, os $29 \%$ de resíduos $(18,76 \mathrm{~kg})$ observados na distribuição setorial da CC deste estudo (GRÁFICO 2), são facilmente justificados.

$\mathrm{Na}$ abordagem órgão-tecidual da CC, a gordura e o tecido adiposo geralmente empregada de forma intercambiária, requerem distinção taxionômica quando são medidas as suas massas e características metabólicas. O tecido adiposo contém material que não a gordura, o que reafirma o conceito de compartimento e componente adotado neste estudo. Não se trata meramente de gordura existente no compartimento de tecido adiposo, mas além dos adipócitos, são encontrados fluídos extracelulares, nervos e vasos sanguíneos (SHEN et al., 2005).

\subsection{A composição corporal dos jovens}

A equidade da distribuição do $\mathrm{n}$ planejado no dimensionamento amostral prévio deste estudo (GRÁFICO 3), assegurou as comparações inter-classes realizadas tanto por classificação etária como por maturação (PVC). Ainda que o $n$ final (408) seja alto e contribuiu para dissolver eventuais vieses nas análises, não garantiu uniformidade na distribuição das variáveis de resposta. Este fato foi observado na assimetria da MG ao apresentar casos extremos em sua forma de distribuição (FIGURA 5) e de dispersão (GRÁFICO 4b,d).

Esse comportamento dispersivo observado na MG é típico em estudos comparativos dos componentes de MG, CMO e TM (ELLIS, 1997; RODRíGUEZ, MORENO, BLAY, BLAY, FLETA, SARRI'A \& BUENO, 2005). Em idades menores que 10 anos, a dispersão da MG tende a ser menor em relação às idades subseqüentes (ELLIS, 1997). Isso implica que no período pré puberal o crescimento e a maturação são compatíveis. Nessas idades, a variação na concentração hormonal que ocorre durante a maturação sexual ainda não iniciou. Assim, não é surpresa também encontrar altas relações entre os componentes associados à MM e $\mathrm{MO}$, como foi achado neste estudo (TABELA 15), uma vez que encontram similar

\footnotetext{
${ }^{3}$ Valor calculado a partir da estimativa de $600 \mathrm{ml} / \mathrm{Kg}$ de um adulto de $70 \mathrm{~kg}$.
} 
associação à massa total de cálcio e à MM esquelética, como acontece igualmente nos adultos (FIELDS et al., 2002).

O fato das proporções da MG apresentar tendência à diminuição com a idade em meninos também é típico dessa fase da vida (MINDERICO et al., 2006). Ainda que ocorram aumentos da MG em meninos, geralmente não apresentam significância estatística (WASHINO, TAKADA \& IWATA, 1998). Muito embora haja mudanças nos outros tecidos (MO e MM) ocorrentes durante todo o período de crescimento, essas modificações, especialmente na MG devem ser de aproximadamente $17 \%$ nas meninas e $15 \%$ nos meninos durante a puberdade (BRAILLON, 2003).

As diferenças físicas associadas ao tempo de maturação individual foram confirmadas nos níveis de gordura corporal desta amostra. A diminuição típica da gordura esperada na adolescência foi observada dos 10 aos 14 anos entre os ES (GRÁFICO 9a), mas com efeitos adversos nos NE. Este fato em vez de indicar que o exercício promove índices mais reduzidos de MG, sugere que a falta dele (exercício) pode resultar num aumento atípico da gordura corporal esperado para meninos nestas idades. Além do mais, outros fatores como hábitos alimentares e atividades do cotidiano, não investigados neste estudo, podem ter contribuído para o aumento da gordura corporal em diferentes períodos de maturação, enviesando esses resultados observados. Portanto, classificar adolescentes meramente pela idade, sem considerar seu desenvolvimento maturacional constitui-se num erro. Além do mais, a forma de classificação pelo PVC foi mais adequada que a idade cronológica, quando a intenção é reunir sujeitos com características físicas de forma mais homogênea. Deste modo, sua utilização torna-se recomendada por ser um critério mais justo na classificação de jovens ES.

De modo geral, os meninos depois dos 10 anos são magros. WASHIRO et al. (1998) acompanharam longitudinalmente mudanças no \%G de meninos japoneses dos 9 aos 10 anos, e notaram uma diminuição de 17,6\% para 15,9\% de uma ano para outro. Em meninos dos 10 para 11 anos a média de 20,4\% caiu para 19,1\%. Embora o comportamento da MG do presente estudo nessas idades (\% $\mathrm{G}=19,20)$ tenha sido semelhante aos observados por WASHIRO et al. (1998), foi notada uma minoria de casos com valores bem maiores. Essa existência de sujeitos 
acima da média $(n=40)$ poderia ser interpretada como outliers. Entretanto, trata-se apenas do tipo de distribuição desta amostra, onde a maioria dos sujeitos é magra ( $\bar{X} M G=9,34$ ) e esses casos onde a $M G$ alcançou valores aproximados de 20 a $42 \mathrm{~kg}$ fazem parte da realidade ( $\cong 10 \%)$, não significando nenhuma discrepância (ELLIS, 1997; RODRÍGUEZ et al., 2005). Por essa razão, foi mais adequada uma representação amostral neste estudo, pela mediana.

A distribuição representada da MG (GRÁFICO 4) compara as classificações por idade e PVC, mesmo se tratando de uma observação transversal. A maior correlação de MG com PVC $(r=0,28)$ do que com idade $(r=0,22)$ indica que esta pode estar mais associada à maturação do que à idade cronológica, embora ambas tenham sido baixas. Isto pode ser evidenciado no comportamento ascendente da linha de tendência de freqüência no PVC, enquanto a tendência por idade foi de diminuir nos períodos etários finais. Essa tendência de diminuição ou estabilização por idade na representação polinomial continuou na MM (GRÁFICO 5) e MO (GRÁFICO 6), enquanto as representações pelo PVC conotam tendência sempre ascendente. Além do mais, pode-se perceber maior linearidade e menor dispersão nas representações maturacionais da MM e MO (GRÁFICOS $5 d$ e $6 d$ ), sugerindo que o PVC é um recurso mais adequado para agregar semelhanças na classificação da CC durante o crescimento puberal.

Esses achados podem ter grande significado no desempenho esportivo de jovens, uma vez que diversas modalidades classificam seus atletas pelo peso corporal ou por idade. Estudos que associam o desempenho motor com PVC ainda são escassos, entretanto tem sido observado que os maiores picos de desempenho motor ocorrem de forma coincidente ao PVC (PHILIPPAERTS, VAEYENS, JANSSENS, VAN RENTERGHEM, MATTHYS, CRAEN, BOURGOIS, VRIJENS, BEUNEN \& MALINA, 2006), muito embora alguns aumentos de desempenho imediatamente após o PVC (MALINA et al., 2004), possam ser considerados como efeito do treinamento sistemático do esporte (PHILIPPAERTS et al., 2006).

De qualquer forma, a maior coesão no agrupamento por PVC do que por idade, pode ser determinante para corrigir eventuais erros de classificação entre sujeitos de mesma idade ou peso, mas em diferentes fases de desenvolvimento 
maturacional. MACHADO, BONFIM \& COSTA (2009) identificaram injustiças ao comparar o desempenho motor de 209 ES classificados por idade, maturação sexual e por PVC. Além de maior associação do desempenho motor com o PVC $(r<0,87)$ do que com a idade $(r<0,77)$, o PVC foi o principal componente de explicação presente em todos os modelos gerados da regressão linear, seguido de idade e maturação sexual. Os autores recomendaram então preferencialmente o uso dessa forma de classificação, aos critérios atualmente utilizados.

Obviamente, a justificativa dessa indicação se dá pelas diferenças observadas na $\mathrm{CC}$, mais especificamente da $\mathrm{MM}$ e $\mathrm{MO}$ entre sujeitos em diferentes estágios maturacionais. Além do mais, os maiores intervalos etários com significância estatística no PVC (TABELA 13) sugerem que as distinções etárias da CC podem ser mais evidentes do que quando classificados pela idade (TABELA 12).

Nas idades iniciais e finais do crescimento puberal, as diferenças na CC não são significativas, em contrapartida, são relevantes nas idades centrais quando observados tanto por idade cronológica como por PVC. Isto indica que o estirão de crescimento tem efeitos particulares sobre o desenvolvimento corporal dos jovens adolescentes, desta forma não deve ser considerado como um período único e homogêneo. Apresenta, portanto diferentes velocidades de desenvolvimento, de modo mais concorrente ao PVC.

Outro efeito que pode ser observado durante o crescimento, é que nem sempre a prática esportiva implica em diferenças entre os sujeitos, ou seja. Ainda que em várias tarefas motoras o desempenho continue aumentando após o PVC, o que pode ser atribuído à especificidade do treinamento (PHILIPPAERTS et al., 2006), diferenças nas velocidades do desempenho motor entre ES e NE tendem a ser menores nas idades iniciais e maiores nas idades finais de crescimento. Valores de correlação próximos de zero observado na Categoria com todos os indicadores da CC (TABELA 14) indicaram que o fato dos jovens praticarem esporte, não implica necessariamente em efeitos distintivos sobre as variáveis de crescimento, gordura corporal, MM ou estruturação óssea. Desta forma os dados não permitem afirmar que eventuais diferenças da CC entre ES e NE do presente estudo possam estar associadas ao treinamento esportivo (MALINA, 2007). Uma pesquisa específica adicional seria necessária para elucidar esta questão. 


\subsection{Composição corporal e a prática esportiva}

A análise multicomponente da CC em jovens atletas (FIGURA 1) pode ser mais adequada na estimativa do perfil da CC de interesse para direcionamento às diferentes modalidades esportivas. $O$ excesso de peso, em especial da gordura, têm efeito sobre as modalidades esportivas: a) aquelas de deslocamento ou projeção corporal como saltos, corridas, natação e pugilismo; b) aquelas de transporte corporal como ciclismo, canoagem, skate, remo; c) aquelas de lançamentos/arremessos como dardo, disco, martelo e peso; e d) as provas em que os atletas não precisam de deslocamento corporal como tiro, xadrez e halterofilismo. Com ressalvas deste último tipo, em todos os demais o excesso de gordura poderia resultar em efeitos adversos ao rendimento esportivo.

Os Box-plots da FIGURA 8 expressam uma clara distinção da MG entre ES e NE. A linha da mediana nos NE na parte inferior da caixa explica a assimetria da distribuição da MG desse grupo. Certamente, a existência de mais sujeitos com $M G$ acima da média entre os NE são a causa principal da distribuição assimétrica geral observada na FIGURA 5a. Essas evidências ficam mais fortes quando analisadas as idades etárias centrais onde esse efeito é maior (GRÁFICO 9). De forma similar, nos períodos mais próximos do PVC (GRÁFICO 10) também são encontradas as maiores diferenças da MG entre ES e NE.

Uma vez que os maiores ganhos de peso e a estatura corporal ocorrem nos períodos etários centrais (idade e PVC), este também deveria ser o momento das maiores diferenças na CC entre ES e NE, caso realmente existissem. Entretanto essa tendência de estirão da CC ocorre em todo crescimento normal, independentemente das diferenças étnicas (ELLIS 1997), sexuais (SARDINHA et al., 1999) ou de prática esportiva (PHILIPPAERTS et al., 2006).

Os maiores ganhos de força e potência muscular ocorrem após e durante o PVC (BEUNEN \& MALINA, 1988; MALINA et al., 2004) gerando uma cadeia de interdependência dos efeitos entre prática esportiva e CC. Embora as intensidades não controladas do treinamento dos ES talvez não tenham sido suficientem para promover diferenças na MO e MM em relação aos NE (GRÁFICO 
8), os efeitos sobre a MG foram mais evidentes, possivelmente em função da prática esportiva.

As diferenças morfológicas entre ES e NE geralmente observadas em atletas de alto nível não se confirmaram nas idades envolvidas neste estudo, com exceção da MG nos períodos de maior pico (estirão) do crescimento. Parece que outros fatores (não investigados aqui) associados à prática esportiva são necessários para promover diferenças na MM e MO. Embora possam existir diferenças da CC entre as diferentes idades, ela não é evidente entre ES e NE

Observou-se ainda no estudo atual diferenças entre categorias aos 15 anos na MO a favor dos NE (GRÁFICO 9) e no ano 2 (PVC), na MM a favor dos ES (GRÁFICO 10). Este fato sugere a diferença da velocidade de crescimento dos diferentes sistemas da CC. Ou seja. O crescimento ósseo tende a ser mais concordante com a idade cronológica (MACHADO, 2004) enquanto a estrutura muscular parece depender mais das alterações bioquímicas, decorrendo em variação do desempenho motor de jovens ES. A influência da maturação reflete aumento de concentração dos esteróides, sendo entendida como o principal fator do aumento muscular, enquanto as diferenças etárias aparecem como preditoras da concentração do estradiol, de forma mais significante que a CC ou à distribuição de gordura (ROEMMICH et al., 1998). Este fato sugere influência hormonal diferençada para as estruturas musculares e esqueléticas. Desta forma, uma classificação maturacional deve ser mais sensível para expressar as reais diferenças entre ES de grupos etários semelhantes.

\subsection{Proposição do modelo}

A correlação elevada na maioria das comparações entre as variáveis explicativas e de resposta evidenciou os efeitos da idade e maturação sobre a CC, com menor associação na MG. Essa alta correlação sugere a possibilidade de utilização dessas variáveis de forma substitutiva. Ou seja: medidas antropométricas são obtidas com certa facilidade e baixo custo; se mantida a precisão das medidas e os erros baixos, podem ser utilizadas de forma substitutiva aos recursos dispendiosos (como a DXA), tornando atraente a relação custo-benefício desses recursos (SARDINHA et al., 2001). Entretanto vale lembrar que são necessários 
outros pressupostos, exigindo maior elaboração metodológica para estimar a CC (SARDINHA \& TEIXEIRA, 2005) de forma precisa e confiável. Alta correlação pode implicar em alto coeficiente de determinação e este é o pressuposto básico e fundamento primário para a proposição de equações da CC.

A matriz de correlação na TABELA 15 expressa claramente esse pressuposto para a análise multivariada. É possível traçar algumas considerações a respeito dessa matriz: a primeira é a de que a $M M$ e MO são altamente correlacionadas entre si, o que é muito bom, pois se pretendia constituir um modelo de regressão multivariado, ou seja, que obtivesse as três variáveis respostas de uma vez. Embora a MG não seja altamente, mas apenas razoavelmente correlacionada, atendeu perfeitamente ao pressuposto da análise multivariada.

A segunda consideração é que as variáveis de resposta também foram altamente correlacionadas com as explicativas: a MG com as dobras cutâneas; e a $\mathrm{MM}$ e $\mathrm{MO}$ com as dimensões corporais, PVC, perímetros e diâmetros. Esse fato foi muito importante para a robustez do modelo. Porém, a última consideração é que muitas variáveis de um mesmo grupo (dobras cutâneas, perímetros e diâmetros) tinham uma alta correlação entre si, bem como as variáveis de dimensão corporal e o PVC.

A alta correlação entre as variáveis explicativas evidencia a existência de relações lineares entre elas, fato conhecido como multicolinearidade (TABELA 15). Como conseqüência, além do risco de efeitos enviesados sobre a explicação, poderia ter sérias decorrências sobre as estimativas dos coeficientes de regressão e na aplicabilidade geral do modelo (HAIR, 2005). A relação entre a variável de resposta e cada variável explicativa pode ser distorcida se ocorrer multicolinearidade entre as variáveis (HEYMSFIELD et al., 1997). Neste caso, uma regressão parcial nivelando a plotagem da variável de resposta versus a variável explicativa, após ambas terem sido ajustadas por outras variáveis explicativas na equação (MYERS ${ }^{4}$ appud SUN \& CHUMLEA, 2005), pode revelar a verdadeira relação entre variáveis explicativas e de resposta.

\footnotetext{
${ }^{4}$ MYERS, R.H. Classical \& modern regression with applications. Boston: Duxbury, 1986.
} 
A principal fonte de multicolinearidade deste estudo vem das relações naturais existentes entre as variáveis explicativas. Por exemplo, dobras cutâneas e diâmetros são todas medidas do tecido adiposo subcutâneo e muitas podem estar altamente relacionadas. Daí a necessidade de exclusão daquelas menos utilizadas na literatura ou que não se justificavam na opinião do pesquisador, em permanecer no modelo.

Neste caso as estimativas dos coeficientes de regressão tornam-se muito sensíveis a pequenas alterações na matriz de planejamento. As variâncias dos estimadores são altas, tornando os testes do tipo $\beta \mathbf{j}=0$ contra $\beta \mathbf{j} \neq 0$ (além de outros) pouco sensíveis e, assim, variáveis independentes importantes poderiam ser eliminadas. Entretanto, uma das suposições do modelo linear é que o posto da matriz $\left(X^{\prime} X\right)$ seja igual a $k+1$. Desta forma, além da multicolinearidade moderada ( $L=165,2498$ ) bem próxima do limite inferior dessa classificação (100 a 1000), e o determinante estar longe de zero, o posto da matriz $X^{\prime} X$ é completo. Então existe inversa clássica $\left(X^{\prime} X\right)-1\left[\operatorname{det}\left(X^{\prime} X\right) \neq 0\right.$ ], multiplicado pelo lado direito do sistema normal de equações, permitindo então obter o estimador de mínimos quadrados de $\beta$. O procedimento de inversa clássica de matriz calculou a raiz característica próximo da eficiência.

\section{4 $\quad 0$ modelo de análise multivariada}

Existe certa confusão quando se fala de análise de regressão. A análise de regressão univariada é o estudo de como uma variável dependente (resposta) está relacionada com duas ou mais variáveis independentes (explicativas). A regressão univariada é utilizada quando a finalidade principal é fazer previsão, por exemplo, quando se têm muitas variáveis explicativas e pretende-se encontrar uma variável de resposta (dependente). Porém quando estão envolvidas muitas variáveis explicativas e mais de uma variável de resposta, a opção é a análise multivariada, geralmente abordada somente em capítulos específicos de livros de Análise Multivariada, pois oferece aplicação prática limitada (NOGUEIRA, 2007).

A associação ou dependência entre variáveis de resposta é um dos primeiros pressupostos da análise multivariada. Essa relação de interdependência é 
observada, por exemplo, no aumento da MG, quando a MM e tecidos ósseos devem se adequar morfologicamente para dar suporte à nova estrutura. Com idosos ocorre o inverso no processo da degeneração óssea. Porém quando submetidos a exercícios musculares de pressão e impacto, desenvolvem maior proteção à decomposição óssea, de forma compensatória (SATO, DEMURA, MURASE \& KOBAYAYASHI, 2006).

Neste estudo, esta analogia foi de forte correlação (TABELA 15) entre as variáveis de resposta (MG, MO e MM), justificando a necessidade de uma análise conjunta e interdependente. Essa relação e interdependência podem ser utilizadas para tornar o modelo mais robusto. O ganho de eficiência preditiva na utilização do modelo de análise multivariada em relação aos ajustes de regressões variadas é comprovado (ZELLNER, 1962). Basicamente essa eficiência ocorre porque ao estimar conjuntamente os parâmetros, são produzidas restrições nulas nos coeficientes de outras equações (NOGUEIRA, 2007), com o mesmo erro aos betas do vetor da estimativa, potencializando assim a predição.

O segundo pressuposto prevê que o erro deve ter distribuição normal multivariada. O comportamento dos resíduos (FIGURA 7), embora apresente distribuição leptocúrtica (não-gaussiana), expressam simetria, assegurando que os erros estão com médias nulas e variância constante nos três componentes da CC. Essa centralização do resíduo permite utilização dos dados puros, sem ajustes.

A seguir, na seleção das variáveis independentes (explicativas), a decisão do pesquisador e os recursos estatísticos possíveis foram considerados no sentido de preservar a máxima precisão e erro mínimo do modelo final. Diversas variáveis explicativas são incluídas numa equação e normalmente a seleção delas se dá por regressão (MONTGOMERY, PECK, \& VINING, 2006). Como no presente estudo a pretensão principal foi a proposição de um modelo multivariado, e obviamente utilizou-se de regressão multivariada, a análise de componentes principais (ACP) foi inicialmente utilizada para identificar o agrupamento das variáveis explicativas comuns às três variáveis de resposta pretendidas.

A homogeneidade das variáveis de respostas também deve ser testada. Homogeneidade assume uma variância constante para cada variável explicativa, mas esta questão é violada se a plotagem residual demonstra um padrão 
ou uma tendência. Por exemplo, a relação entre as variáveis de resposta e explicativas deve ser não linear. Nesse caso, outras variáveis explicativas devem ser incluídas na equação. Uma tendência sobre os resíduos pode também ser causada por observações influenciadoras (outliers) dos dados. Embora a literatura expresse cuidado na estimativa da CC quando o IMC é elevando (ROUBENOFF et al., 1993; KIM et al., 2002; SARDINHA \& TEIXEIRA, 2005) o modelo multivariado proposto no presente estudo foi capaz de predizer a CC de sujeitos com IMC maiores de 35 (11 casos). Mesmo quando retirados e devolvidos à amostra, o modelo não apresentou alteração na precisão dos resultados, confirmando sua robustez preditiva.

Quando a relação entre as variáveis explicativas e de resposta não é linear ou quando a variância da variável de resposta é heterogênea, os dados devem ser transformados e diversos métodos estão disponíveis (CHATTERJEE \& PRICE, 1979; SUN \& CHUMLEA, 2005). Neste estudo o procedimento de ajuste dos dados por transformação logarítmica (Log) foi realizado, sem, contudo apresentar melhoras na normalidade $\left(\mathrm{W}=0,9249, \mathrm{p}=4,551 \mathrm{e}^{-13}\right)$ dos dados (FIGURA 9).
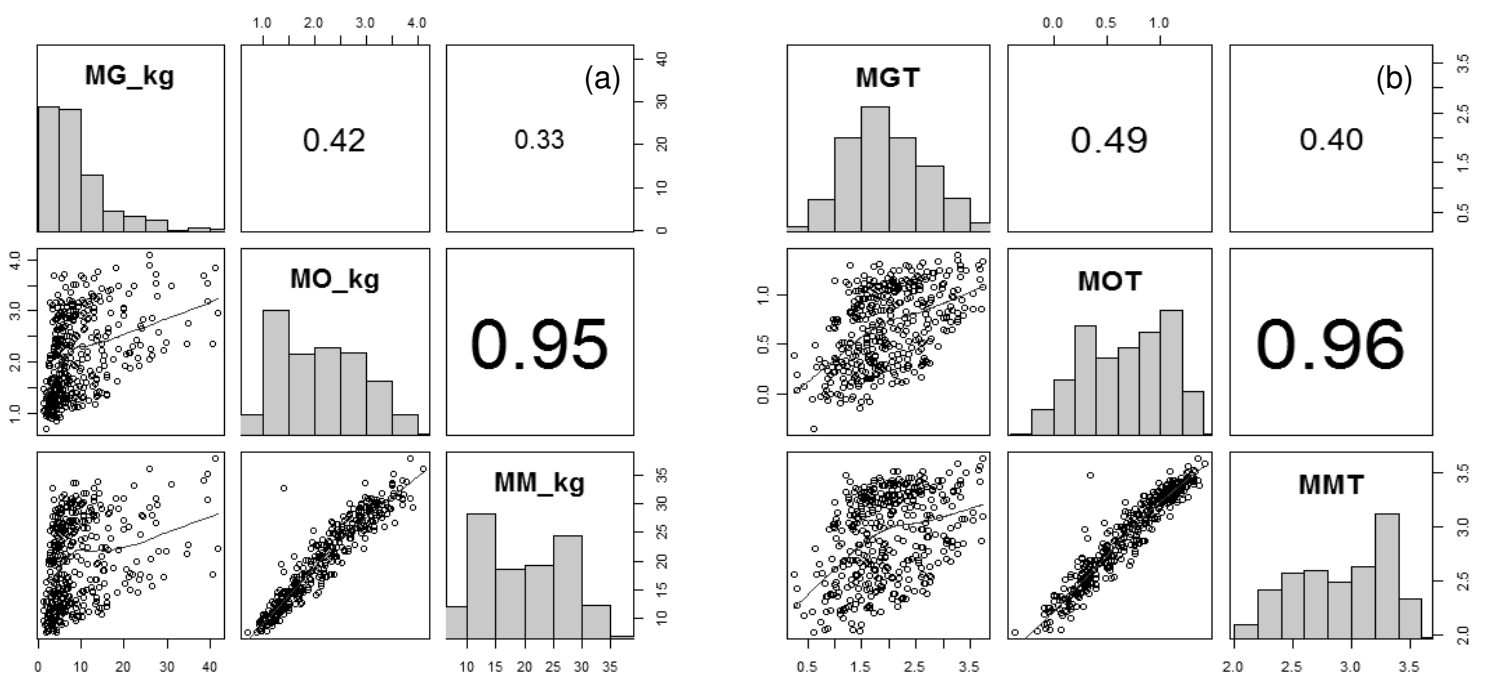

FIGURA 9. Correlação, distribuição e dispersão multivariada Sem (a) e Com (b) transformação (Log) dos dados de Massa de Gordura (MG), Massa Óssea (MO) e Massa Muscular (MM) de jovens do sexo masculino. 
A normalidade das variáveis de resposta pode ser testada, todavia não é tão importante como a ausência de multicolinearidade entre as variáveis explicativas e a homogeneidade das variáveis de resposta (SUN \& CHUMLEA, 2005), pressupostos observados e preservados no presente estudo.

Conquanto na análise multivariada o erro ainda exista principalmente no momento de estimar as variáveis dependentes, a análise preditiva de forma multivariada reduz esse erro, uma vez que é resultante do diagnóstico do conjunto, potencializando o poder preditivo das variáveis explicativas.

\subsection{Vantagens da análise multivariada}

Os modelos antropométricos ainda continuam sendo as melhores alternativas na relação custo/benefício para o estudo da CC de campo. Todavia há pelo menos duas questões problemáticas que envolvem as propostas atuais: a primeira delas está na forma de análise bicomponente da CC, quando a divide puramente em MG e massa magra. A estimativa da MG, considerando o restante da CC como massa magra (músculos, ossos, órgãos viscerais, sangue, água corporal, substratos biológicos, entre outros) pode trazer vieses na sua interpretação, mesmo quando relativa ao peso corporal. A correta quantificação de outros componentes corporais pode nortear melhor 0 trabalho de orientação de exercício físico para jovens, seja com enfoque de interesse para a saúde ou para o desempenho esportivo.

A FIGURA 10 demonstra uma comparação entre os sujeitos $A$ e B, hipoteticamente iguais na massa gorda e massa magra segundo o Modelo 1 , e diferentes segundo o Modelo 2, apenas na MM e óssea.

Observa-se que o Modelo 1 Bicomponente não é capaz de distinguir as diferenças da CC deles. Em contrapartida, o Modelo 2 Multicomponente explica melhor as eventuais variâncias individuais, mesmo com valores de MG e MR idênticos. Esta capacidade de distinção entre os modelos pode ter implicações nas interpretações da CC para a saúde e para o esporte. 


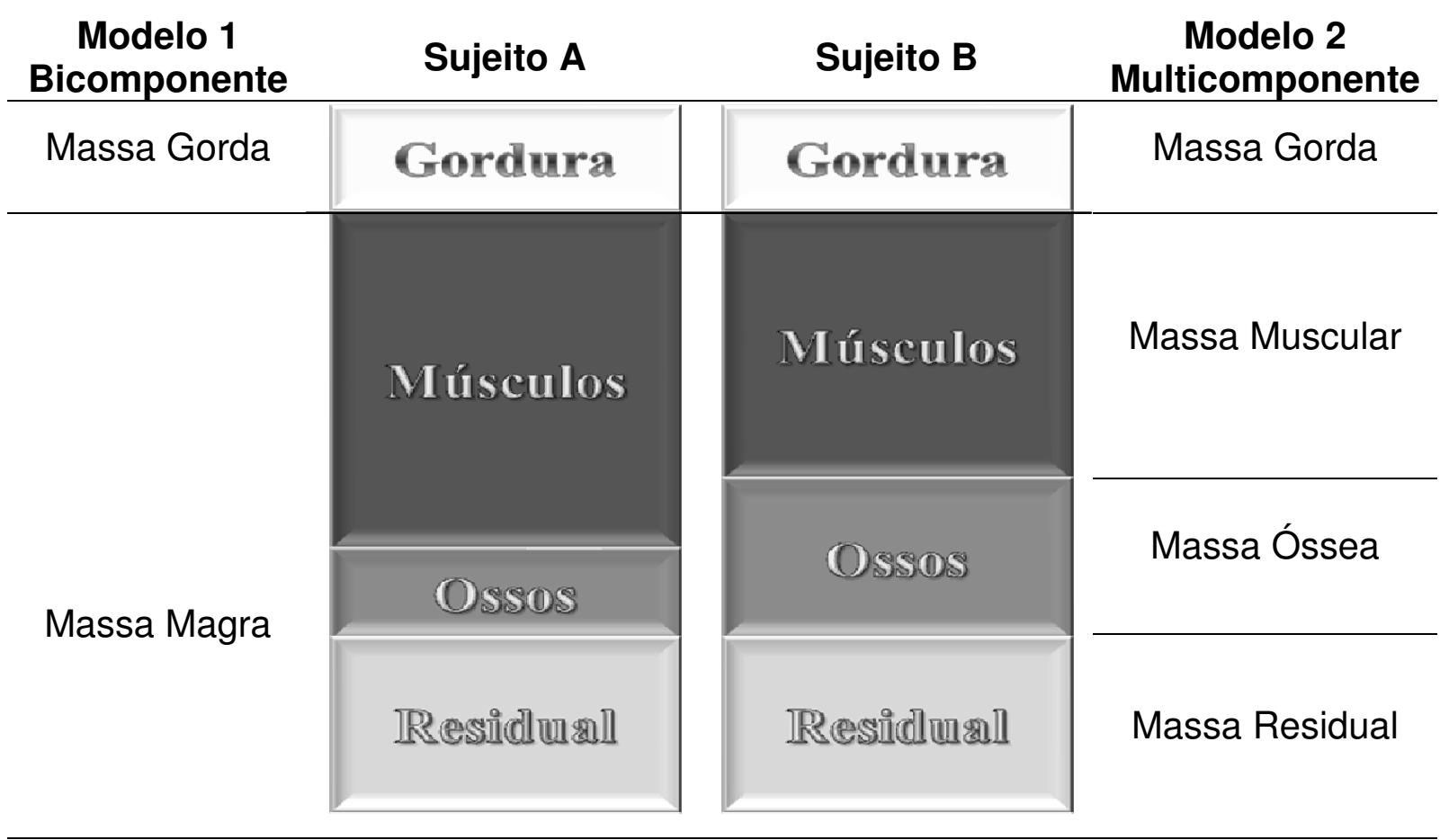

FIGURA 10. Comparação entre modelos Bicomponente e Multicomponente da Composição Corporal.

Para a saúde, a quantidade de gordura corporal (quando em valores elevados) pode implicar em maior risco ao sujeito $B$ em comparação ao $A$, considerando que possuem massas musculares diferentes. Os efeitos nocivos da distribuição relativa da gordura se dão principalmente nos tecidos moles (MM e residual). Dessa maneira, o poder de absorção (assimilação) do sujeito A é maior em função da maior MTM do que o sujeito B.

Maiores volumes musculares (sujeito A) também implicam em menor esforço e gasto energético nas atividades do cotidiano. Menores volumes de $\mathrm{MO}$ em relação à $\mathrm{MM}$ também sugerem maior solicitação da estrutura esquelética, tornando num efeito positivo sobre os osteócitos, na prevenção da degeneração óssea ao longo da vida.

Para o esporte, teoricamente espera-se que maiores volumes musculares, resultem também em maior força, resistência e conseqüentemente, sejam capazes de realizar melhor desempenho esportivo (sujeito A). Ainda em relação à estrutura esquelética, maiores volumes (sujeito $B$ ) devem representar em maior quantidade de massa inerte para o movimento. Enquanto possa ser útil em 
modalidades que exijam uma boa base estrutural esquelética, em esportes de projeção/transporte do peso corporal, o peso ósseo excedente deve ser prejudicial em algumas provas esportivas de agilidade e velocidade.

\subsection{Validade do modelo}

O método de validade interna PRESS (HOLIDAY, BALLARD \& MACKEOWN, 1995) adotado, confirmou a eficácia de o modelo predizer os componentes da CC com elevada validade interna (PRESS $=0,93$ a 0,96 ), altos coeficientes de determinação $\left(Q^{2}=0,97\right.$ a 0,98$)$ e baixos erro ( SPRESS $=0,09$ a 0,01 ). Ou seja, com um resultado PRESS $=0,9463$ para MG, pode se esperar que é capaz de explicar cerca de $94,63 \%$ da variabilidade na previsão de novas observações em amostras independentes, em comparação com os cerca de $97,48 \%$ da variabilidade dos dados originais, explicada pelo método de mínimos quadrados $\left(\mathrm{Q}^{2}\right)$. Igualmente, o elevado poder de explicação $(93,24 \%$ e $95,53 \%)$ respectivamente para $\mathrm{MO}$ e MM indicam a robustez do modelo na predição da CC de jovens ES e NE de 8 a 18 anos.

Esses escores trazem certa segurança, mesmo quando os índices da CC são elevados. A dispersão dos valores medidos e preditos (GRÁFICO 7) mesmo para altos valores de gordura, osso e músculo, não é tão esparsa, sugerindo a força do modelo em predizer também a CC de sujeitos de grande compleição física.

Um dos mais recentes estudos de referencia da CC pediátrica foi desenvolvido pelo CNRC - Children's Nutrition Research Center (ELLIS et al., 2000) que propôs ajustes aos valores preconizados por FOMON et al. (1982), e HASCHKE (1989). A partir da determinação da ACT por diluição de óxido de Deutério, $K^{40}$ por quantificação corporal total e CMO por DXA, os autores determinaram os componentes da CC mediante equações preditivas.

Uma descrição detalhada de todos os esses procedimentos pode ser obtida em HEYMSFIELD et al., (2005). Mas de forma sintética, naquele estudo foram obtidos os valores da MIG (ACT+proteína+glicogênio+CMO+minerais não-ósseos), MG (Peso corporal-MIG) e CMO (minerais ósseos) dado pela DXA.

Embora no estudo atual de Presidente Prudente (PPTE) esses valores tenham sido obtidos a partir da DXA, o GRÁFICO 11 mostra que os valores do estudo atual não são muito diferentes da referência mencionada do Children's 
Nutrition Research Center (CNRC). Os valores foram próximos com ligeiras diferenças, muito embora as diferenças etárias, de gênero e especificidade étnica devam ser observadas (ELLIS et al., 2000).

Entretanto a intenção não foi de comparar os valores, até porque os procedimentos são diferentes, mas esses resultados indicam que não houve discrepância dos valores obtidos no estudo atual (PPTE) quando comparados a referenciais internacionais. De certa forma esses resultados asseguram a utilização do modelo proposto neste estudo, uma vez que MG, MO e MM foram derivadas dessas mesmas variáveis (MIG, MG e CMO).

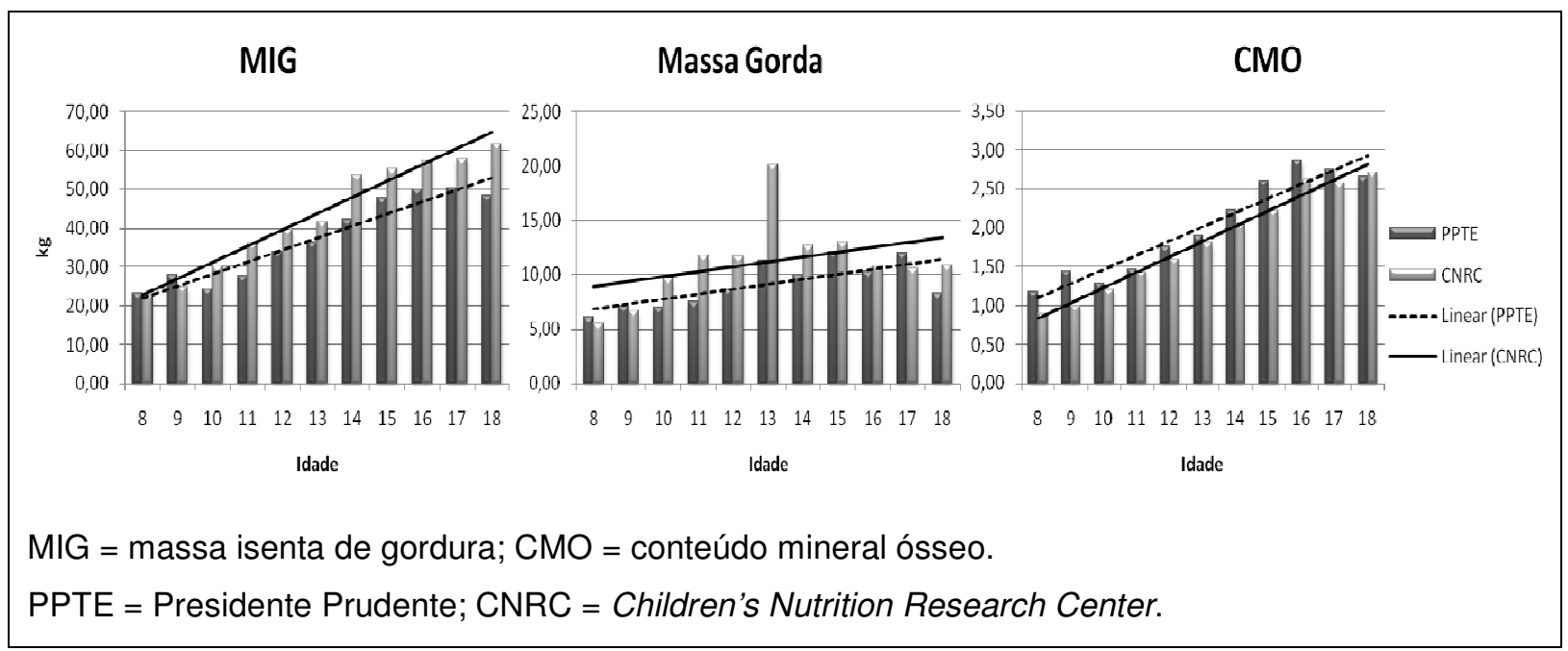

GRÁFICO 11. Comparação da Composição Corporal do estudo atual (PPTE) com modelo de referência (CNRC).

Durante o crescimento, a CC apresenta aumentos do tecido ósseo e muscular, porém diminuições relativas de gordura e água corporal. Todavia o aumento dessa água pode não ser real, uma vez que parece haver mais uma migração dos líquidos extracelulares para o interior das células do que sua diminuição relativa, o que justificaria também em parte os importantes aumentos da MM durante o estirão de crescimento (SCHOELLER, 2005). Daí a dificuldade de determinar com precisão os componentes da CC de crianças e adolescentes.

Nesse sentido, vários esforços foram feitos ao longo da história para reunir informações dos valores etários médios de diversos componentes da CC de 
crianças e adolescentes, entretanto os resultados sugerem, segundo os próprios autores, fragilidade e baixa confiabilidade dos dados (FOMON \& NELSON, 2002), além da necessidade de considerar as especificidades étnicas (ELLIS, 1997).

Ainda que apareçam propostas de modelos facilitadores de uma aplicação clínica mais ampla (KYLEA, PICCOLIB \& PICHARD, 2003), nem sempre adotam pressupostos válidos (equações do Tipo II, HEYMSFIELD et al., 1997) assumindo, por exemplo, relação constante entre MIG, gordura e ACT. Quando surgem descrições mais bem fundamentadas, são restritas aos períodos prépubertários (FOMON et al., 1982) ou quando são etariamente mais abrangentes (5 a 19 anos) sugerem o uso restrito à técnicas laboratoriais e procedimentos dispendiosos (ELLIS et al., 2000) para averiguação.

O modelo proposto aqui fornece uma possibilidade econômica e prática na estimativa da CC de campo. Basta montar uma rotina e substituir as medidas de cada avaliado. Para exemplificar, supõe-se a estimativa da CC de um sujeito de 13 anos de idade. A partir da obtenção das medidas, os cálculos são efetuados simultaneamente da forma expressa na TABELA 19.

TABELA 19. Modelo antropométrico multicomponente para cálculo simultâneo da massa de gordura (MG), massa óssea (MO) e massa muscular (MM).

\begin{tabular}{|c|c|c|c|c|c|c|c|}
\hline \multirow[b]{2}{*}{ Variáveis (V) } & \multirow[b]{2}{*}{ Medidas } & \multicolumn{6}{|c|}{ Constantes } \\
\hline & & $M G$ & $(\mathrm{MG} \times \mathrm{V})$ & $\mathrm{MO}$ & $(\mathrm{MO} \times \mathrm{V})$ & MM & $(\mathrm{MM} \times \mathrm{V})$ \\
\hline \multicolumn{2}{|l|}{ Intercepto } & & 7,6657 & & $-0,9416$ & & $-15,005$ \\
\hline Idade (anos) & 13 & $-0,1459$ & $-1,8966$ & 0,0277 & 0,3595 & 0,0063 & 0,0825 \\
\hline Estatura (cm) & 178,3 & $-0,0952$ & $-16,9800$ & 0,0052 & 0,9257 & 0,1037 & 18,4890 \\
\hline Peso (kg) & 68,8 & 0,3101 & 21,3319 & 0,0358 & 2,4598 & 0,2696 & 18,5499 \\
\hline \multicolumn{8}{|c|}{ Dobras cutâneas (mm) } \\
\hline Tricipital & 11,6 & 0,1327 & 1,5388 & $-0,0034$ & $-0,0399$ & $-0,0758$ & $-0,8798$ \\
\hline Suprailiaca & 13,4 & 0,1237 & 1,6571 & $-0,0057$ & $-0,0762$ & $-0,0493$ & $-0,6610$ \\
\hline Abdominal vertical & 21 & 0,1747 & 3,6693 & $-0,0081$ & $-0,1696$ & $-0,0834$ & $-1,7517$ \\
\hline Coxa medial & 20,5 & 0,1163 & 2,3836 & $-0,0041$ & $-0,0831$ & $-0,0968$ & $-1,9854$ \\
\hline \multicolumn{8}{|c|}{ Perímetros (cm) } \\
\hline Braço relaxado & 25 & $-0,0684$ & $-1,7108$ & $-0,0087$ & $-0,2185$ & 0,0835 & 2,0871 \\
\hline \multirow[t]{2}{*}{ Coxa medial } & 50 & $-0,0775$ & $-3,8732$ & 0,0138 & 0,6910 & 0,1746 & 8,7279 \\
\hline & Somatória & $M G=$ & 13,7859 & $\mathrm{MO}=$ & 2,9070 & $\mathrm{MM}=$ & 27,6541 \\
\hline
\end{tabular}


O valor de cada medida é multiplicado pela constante (negrito) correspondente de cada variável resposta ( $M G, M O$ e $M M$ ). Na última linha, a somatória de todos os valores obtidos, resulta no peso $(\mathrm{kg})$ dos componentes de resposta. Para calcular o resíduo, basta subtrair o peso total $(68,8 \mathrm{~kg})$ da soma dos componentes resposta $(44,347)$, o que resulta no valor residual $(24,453)$.

A análise multivariada da $\mathrm{CC}$ no nível órgão tecidual proposta neste estudo, figura numa alternativa de fácil aplicação e baixo custo de modelo antropométrico para estudos da CC de campo. A partir da obtenção de 9 medidas é possível utilizar as equações preditivas para MG, MO e MM de jovens do sexo masculino entre 8 e 18 anos de idade. Além de extensivo a sujeitos com IMC elevado, esta proposta sana as tradicionais limitações dos modelos antropométricos de análises bi componentes, por oferecer uma alternativa de análise multivariada, com aceitável fidedignidade para predizer simultaneamente MG (PRESS $=0,946$; $R^{2}=0,975 ; \quad E P E=0,088$ ), $M O \quad$ (PRESS $\left.=0,932 ; \quad R^{2}=0,968 ; \quad E P E=0,011\right)$ e $M M$ (PRESS=0,955; $\mathrm{R}^{2}=0,979 ; \mathrm{EPE}=0,080$ ).

\section{CONCLUSÕES}

A abordagem do nível órgão tecidual deste estudo, contemplou o campo etário puberal dos compartimentos da CC de jovens ES e NE, geralmente considerado como o mais crítico durante o crescimento, levando em conta ainda a variabilidade da maturação biológica. Este estudo identificou que metade do peso corporal é resultado do tecido ósseo e muscular, componentes fundamentais nos estudos da CC, além da MR (ou outros tecidos), uma vez que representou 1/5 do peso corporal total dos jovens adolescentes.

O crescimento dos constituintes corporais foi contínuo no decorrer das idades e apresentou menor variação com maior linearidade quando agrupados pela maturação biológica. Estes fatos associados à baixa dispersão da $\mathrm{MM}$ e $\mathrm{MO}$ durante 
o crescimento, indicaram que as mudanças da CC foram previsíveis. Nas idades iniciais e finais do crescimento puberal as diferenças na $\mathrm{CC}$ não foram significantes; mas foram significantes nas idades centrais uma vez que apresentaram maiores variações inter-individuais. Isto indicou que o estirão de crescimento teve efeitos particulares sobre o desenvolvimento corporal dos jovens, não se tratando de um período único e homogêneo, mas com velocidades distintas de desenvolvimento, foi mais concorrentes com a maturação.

A relação da $\mathrm{CC}$ com a prática esportiva foi quase nula, indicando que ela não teve relação com o exercício. Em compensação, apresentou alta associação com idade e maturação, concordando com a inter-dependência esperada. Com exceção da MG que apresentou correlação apenas moderada, todas as demais tiveram elevada associação com as medidas antropométricas, fato que confirmou 0 principal pressuposto para a proposição do modelo multivariado.

A análise multivariada da CC possibilitou a proposta de equações a partir de nove medidas antropométricas para predizer simultaneamente MG, MO e MM. Os critérios de confiabilidade no modelo indicaram altos coeficientes de determinação e baixa estimativa de erros. O procedimento de validação cruzada indicou alta fidedignidade preditiva do modelo, também com elevados coeficientes e confiabilidade.

Não houve diferenças significantes na MM e MO quando se comparou a CC entre jovens ES e NE. Contudo os não praticantes apresentaram valores mais elevados de MG do que os ES. 


\section{REFERÊNCIAS}

AL-SENDI, A.M.; SHETTY, P.; MUSAIGER, A.O. Anthropometric and body composition indicators of Bahraini adolescents. Annals of human biology, Basingstoke, v.30, n.4, p.367-379, 2003.

ALLEN, D.M. The Prediction Sum of Squares as a Criterion for Selecting Predictor Variables. Technical Report, University of Kentucky. n.23, 1971.

ALLEN, D.M. The relationship between variable selection and data augmentation and a method for prediction. Techno. n.16, p.125-127, 1974.

BALLOR, D.L. Exercise training and body composition changes. In: Human Body Composition, [TG Lohman, editor]. Champaign, IL: Human Kinetics Publishers, p.287-304, 1996.

BARBANTI, V.J. Formação de esportistas. Barueri: Manole, 2005.

BARBANTI, V.J. Treinamento físico - bases científicas. 3.ed. São Paulo: Balieiro, 2001.

BAUMGARTNER, R.N. In: Roche, A.F.; Heymsfield, S.B.; Lohman, T.G. (Eds). Human Body Composition. Champaign: Human Kinetics, IL, p.79, 1996.

BERGMANN, G.G.; BERGMANN, M.L.A.; LORENZI, T.C.; PINHEIRO, E.S.; GARLIPP, D.C.; MOREIRA, R.B.; MARQUES, A.C.; GAYA, A.A. Pico de velocidade em estatura, massa corporal e gordura subcutânea de meninos e meninas dos 10 aos 14 anos de idade. Revista Brasileira de Cineantropometria e Desempenho Humano, Florianópolis, v.9, n.4, p.333-338, 2007.

BOLFARINE, H.; BUSSAB, W.O. Elementos de amostragem. São Paulo: Edgard Blücher, 2005. 
BLAND, J.M.; ALTMAN, D.G. Measuring agreement in method comparison studies. Statistical Methods in Medical Research, London, v.8, n.2, p.135-160, 1999.

BOX, G.E.P.; COX, D.R. An analysis of transformation. Journal of Royal Statistical Society. London, v.26, p.211-252, 1964.

BRAILLON, P.M. Annual Changes in Bone Mineral Content and Body Composition during Growth. Hormone Research, Basel, n.60, p.284-290, 2003.

BROOK, C.G. Determination of body composition of children from skinfold measurements. Archives of Disease in Childhood. Stanford, v.46, n.246, Apr, p.182-184, 1971.

CALLAWAY, C.W.; CHUMLEA, W.C.; BOUCHARD, C.; HILMES, J.H.; LOHMAN, T.G.; MARTIN, A.D.; MITCHELL, C.D.; MUELLER, W.H.; ROCHE, A.F.; SEEFELDT, V.D. Circumferences. In: LOHMAN, T.G.; ROCHE, A.F.; MARTORELL, R. Anthropometric standardization reference manual. Champaign: Human Kinetics, cap.5, p.39-54. 1988.

CHRISTOU, M.; SMILIOS, I; SOTIROPOULOS, K; VOLAKLIS, K; PILIANIDIS, T; TOKMAKIDIS, S. Effects of resistance training on the physical capacities of adolescent soccer players. Journal of Strength \& Conditioning Research (Allen Press Publishing Services Inc.) [serial on the Internet]. (2006, Nov), [cited April 25, 2009]; v.20, n.4, p.783-791, 2006.

CHUMLEA, W.M.; GUO, S.S. Assessment and prevalence of obesity: application of new methods to a major problem. Endocrine, Springer v.13, n.2, Oct, p.135-42, 2000. 
DALEN, N.; LAFTMAN, P.; OHLSEN, H.; STROMBERG, L. The effect of athletic activity on the bone mass in human diaphyseal bone. Orthopedics, v.8, n.9, Sep, p.1139-41, 1985.

DE ROSE, E.H.; PIGATTO, E.; DE ROSE, R.C.F. Cineantropometria, Educação Física e Treinamento Desportivo. Rio de Janeiro: SEED/MEC, 1984.

DEURENBERG, P.; PIETERS, J.J.L.; HAUTVAST, J.G.A.J. The assessment of the body fat percentage by skinfold thickness measurements in childhood and young adolescence. The British Journal of Nutrition, Southampton, v.63, March, p.293303, 1990.

DRINKWATER, B.L. Physical activity, fitness and osteoporosis. In: BOUCHAR, C.; SHEPHARD, R.J.; STEPHENS (Eds.). Physical activity, fitness and health. International proceedings and consensus statement. Champaign: Human Kinetics, 1994.

DUKE, P.M.; LITT, I.F.; GROSS, R.T. Adolescent's self-assessment of sexual maturation. Pediatrics, Springfield, v.66, n.6, p. 918-920, 1980.

DURNIN, J.V.; RAHAMAN, M.M. The assessment of the amount of fat in the human body from measurements of skinfold thickness. The British Journal of Nutrition, Southampton, v.21, n.3, Aug, p.681-689, 1967.

DURNIN, J.V.; WOMERSLEY, J. Body fat assessed from total body density and its estimation from skinfold thickness: measurements on 481 men and women aged from 16 to 72 years. The British Journal of Nutrition, Southampton, v.32, n.1, Jul, p.77$97,1974$.

ELLIS, K.J. Visceral fat mass in childhood: a potential early marker for increased risk of cardiovascular disease. American Journal of Clinical Nutrition, Southampton, n.65, p.1887-1888, 1997. 
ELLIS, K.J., SHYPAILO, R.J., ABRAMS, S.A.; WONG, W.W. The reference child and adolescent models of body composition. A contemporary comparison. Annals of the New York Academy of Sciences, Houston: v.904, May, p.374-82, 2000.

ELLIS, K.J. Selected body composition methods can be used in field studies. The Journal of nutrition, Philadelphia, n.131, p.1589S-1595S, 2001. Supplement.

FIELDS, D.A., GORAN, M.I.; McCRORY, M.A. Body-composition assessment via airdisplacement plethysmography in adults and children: a review. The American Journal of Clinical Nutrition, Bethesda, v.75, n.3, Mar, p.453-67, 2002.

FLECK, S.J. Body composition of elite American athletes. American Journal of Sports Medicine, Baltimore, v.11, n.6, p.398-403, 1983.

FOMON, S.J., HASCHKE, F., ZIEGLER, E.E.; NELSON, S.E. Body composition of reference children from birth to age 10 years. The American Journal of Clinical Nutrition, Bethesda, v.35, n.5 Suppl, May, p.1169-75. 1982.

GEITHNER, C.A.; WOYNAROWSKA, B.; MALINA, R.M. The adolescent spurt and sexual maturation in girls active and not active in sport. Annals of Human Biology, Bagingstoke, v.25, n.5, Sep-Oct, p.415-23, 1998.

GENTON, L.; HANS, D.; KYLE, U.G.; PICHARD, C. Dual-energy X-ray absorptiometry and body composition: differences between devices and comparison with reference methods. Nutrition, v.18, n.1, Jan, p.66-70. 2002.

GUEDES, D.P.; GUEDES, J.E.R.P. Manual prático para avaliação em educação física. Barueri: Manole, 2006. 
GUO, S.; ROCHE, A.F.; HOUTKOOPER, L. Fat-free mass in children and young adults predicted from bioelectric impedance and anthropometric variables. American Journal of Clinical Nutrition. n.50, p.435-443, 1989.

hAAPASALO, H.; SIEVANEN, H.; KANNUS, P.; HEINONEN, A.; OJA, P.; VUORI, I. Dimensions and estimated mechanical characteristics of the humerus after long-term tennis loading. Journal of Bone and Mineral Research, v.11, n.6, Jun, p.864-72, 1996.

HAIR, J.F.; ANDERSON, R.E.; TATHAN, R.L.; BLACK, W.C. Multivariate data analysis, 5 ed., Upper Saddle, River: Prentice Hall, 1998.

HAIR, J.F.Jr.; ANDERSON, R.E.; TATHAM, R.L.; BLACK, W.C. Análise Multivariada de Dados. 5a ed. Porto Alegre: Bookman, 2005.

HARSHA, D.W.; FRERICHS, R.R.; BERENSON, G.S. Densitometry and anthropometry of black and white children. Human biology; an international record of research, Detroit, v.50, n.3, Sep, p.261-80, 1978.

HASCHKE F. Body composition during adolescence. In: Klish WJ, Kretchmer N. Body composition measurements in infants and children. Report of the 98th Ross Conference on Pediatric Research. Columbus, OH: Ross Laboratories, p.76-82, 1989.

HERGENROEDER, A.C.; KLISH, W.J. Body composition in adolescent athletes. Sports Medicine, v.37, n.5, p.1057-83, 1990.

HEYWARD, V.H.; STOLARCZYK, L.M. Avaliação da composição corporal aplicada. São Paulo: Manole, 2000. 
HEYMSFIELD, S.B., OLAFSON, R.P., KUTNER, M.H.; NIXON, D.W. A radiographic method of quantifying protein-calorie undernutrition. The American Journal of Clinical Nutrition, Bethesda, v.32, n.3, Mar, p.693-702, 1979.

HEYMSFIELD, S.B.; MCMANUS, C.; SMITH, J.; STEVENS, V.; NIXON, D.W. Anthropometric measurement of muscle mass: revised equations for calculating bone-free arm muscle area. The American Journal of Clinical Nutrition, Bethesda, v.36, n.4, Oct, p.680-90, 1982.

HEYMSFIELD, S.B., WANG, J., HESHKA, S., KEHAYIAS, J.J.; PIERSON, R.N. Dualphoton absorptiometry: comparison of bone mineral and soft tissue mass measurements in vivo with established methods. The American Journal of Clinical Nutrition, Bethesda, v.49, n.6, Jun, p.1283-1289, 1989.

HEYMSFIELD, S.B.; LICHTMAN, S.; BAUMGARTNER, R.N.; WANG, J.; KAMEN, Y.; ALIPRANTIS, A.; PIERSON, R.N., JR. Body composition of humans: comparison of two improved four-compartment models that differ in expense, technical complexity, and radiation exposure. The American Journal of Clinical Nutrition, Bethesda, v.52, n.1, Jul, p.52-8, 1990.

HEYMSFIELD, S.B., WANG, Z., BAUMGARTNER, R.N.; ROSS, R. Human body composition: advances in models and methods. Annual Review of Nutrition, v.17, p.527-58, 1997.

HEYMSFIELD, S.B.; LOHMAN, T.G.; WANG, Z.; GOING, B.F. (Editors) Human body composition. Champaign: Human Kinetics, 2005.

HEYWARD, V.H. Advanced fitness assessment and exercise prescription. Champaign: Human Kinetic, 1991. 
HOLIDAY, D.; BALLARD, J.; MCKEOWN, B. PRESS - related statistics: regression tools for cross-validation and case diagnostics. Medicine and Science of Sports Exercises, n.27, p.612-20, 1995.

IBGE. Antropometria e análise do estado nutricional de crianças e adolescentes no Brasil (Pesquisa de orçamentos familiares, 2002 e 2003). Ministério do Planejamento, Orçamento e Gestão, Instituto Brasileiro de Geografia e Estatística (IBGE), Diretoria de Pesquisas, Coordenação de Trabalho e Rendimento, Rio de Janeiro, 2006.

JAKICIC, J.M.; CLARK, K.; COLEMAN, E.; DONNELLY, J.E.; FOREYT, J.; MELANSON, E.; VOLEK, J.; VOPE, S.L. American College of Sports Medicine position stand. Appropriate intervention strategies for weight loss and prevention of weight regain for adults. Medicine and Science of Sports Exercises, n.33, v.12, p.2145-2156, 2001.

JELLIFFE, D.B. The assessment of the nutritional status of the community (WHO monograph series n.53). Geneva: World Health Organization, 1966.

JENSEN, M.D. Research techniques for body composition assessment. Journal of the American Dietetic Association, v.92, n.4, April, p. 454-456, 1992.

JOHNSON, J.; DAWSON-HUGHES, B. Precision and stability of dual-energy X-ray absorptiometry measurements. Calcified Tissue International, v.49, n.3, Sep, p.174$178,1991$.

KIM, J.; WANG, Z.; HEYMSFIELD, S.B.; BAUMGARTNER, R.N.; GALLAGHER, D. Total-body skeletal muscle mass: estimation by a new dual-energy $\mathrm{X}$-ray absorptiometry method. The American Journal of Clinical Nutrition, Bethesda, v.76, n.2, Aug, p.378-83, 2002. 
KIM, J.;.SHEN, W.; GALLAGHER, D.; JONES, A.J.; WANG, Z.; WANG, J.; HESHKA, S.; HEYMSFIELD, S.B. Total-body skeletal muscle mass: estimation by dual-energy $X$-ray absorptiometry in children and adolescents. The American Journal of Clinical Nutrition, Bethesda, v.84, n.2, Aug, p.1014-20, 2006.

KOHRT, W. M. Preliminary evidence that DXA provides an accurate assessment of body composition. Journal of Applied Physiology, Washington, v.84, n.1, Jan, p.372-7. 1998.

KOTTKE, T.E.; WU, L.A.; HOFFMAN, R.S. Economic and Psychological Implications of the Obesity Epidemic (Commentary) Mayo Clinic Proceedings, Rochester, n.78, p.92-94, 2003.

KUSHNER RF, SCHOELLER DA, FJELD CR, DANFORD L. Is the impedance index $\left(\mathrm{ht}^{2} / \mathrm{r}\right)$ significant in predicting total body water? The American Journal of Clinical Nutrition, Bethesda, n.56, p.835-839, 1992.

KYLEA, U.G; PICCOLIB, A.; PICHARD, C. Body composition measurements: interpretation finally made easy for clinical use. Current Opinion in Clinical Nutrition and Metabolic Care, London, n.6, p.387-393, 2003.

LASKEY, M.A.; LYTTLE, K.D.; FLAXMAN, M.E.; BARBER, R.W. The influence of tissue depth and composition on the performance of the Lunar dual-energy X-ray absorptiometer whole-body scanning mode. European Journal of Clinical Nutrition, London, v.46, n.1, Jan, p.39-45, 1992.

LOHMAN, T.G. Applicability of body composition techniques and constants for children and youths. Exercise and Sport Science Review, v.14, p.325-57, 1986.

LOHMAN, T.G. Advances in body composition assessment. Champaign: Human Kinetics, p.63-78, 1992. 
LOHMAN, T.G. Exercise training and bone mineral density. Quest. v.47, n.3, August, p.354-361, 1995.

LOHMAN, T.G.; HARRIS, M.; TEIXEIRA, P.J.; WEISS, L. Assessing body composition and changes in body composition. Another look at dual-energy X-ray absorptiometry. Annals of the New York Academy of Sciences, v.904, May, p.45-54, 2000.

LOHMAN, T.G.; CHEN, Z. Dual-energy X-ray absortiometry. p.63-67 In: HEYMSFIELD, S.B.; LOHMAN, T.G.; WANG, Z.; GOING, B.F. (Editors) Human Body Composition. Champaign: Human Kinetics, 2005.

LUKASKI, H. C. Methods for the assessment of human body composition: traditional and new. The American Journal of Clinical Nutrition, Bethesda, v.46, n.4, Oct, p.537-56, 1987.

LUKASKI, H.C. Soft tissue composition and bone mineral status: evaluation by dualenergy X-ray absorptiometry. The Journal of Nutrition, v.123, n.2 Suppl, Feb, p.43843. 1993.

LUKASKI, H.C. Assessing muscle mass. p.203-218 In: HEYMSFIELD, S.B.; LOHMAN, T.G.; WANG, Z.; GOING, B.F. (Editors) Human Body Composition. Champaign: Human Kinetics, 2005.

MACHADO, D.R.L. Maturação esquelética e desempenho motor em crianças e adolescentes. Dissertação (Mestrado em Educação Física). Universidade Estadual Paulista, 2004.

MACHADO, D.R.L.; BONFIM, M.R.; COSTA, L.T. Pico de velocidade de crescimento como alternativa para classificação maturacional associada ao desempenho motor. Revista Brasileira de Cineantropometria e Desempenho Humano, Florianópolis, v.11, n.1, p.14-21, 2009. 
MALINA, R.M.; BOUCHARD, C. Growth, maturation and physical activity. Champaign: Humain Kinetics, p.70-83, 1991.

MALINA, R.M.; BOUCHARD, C.; BAR-OR, O. Growth, maturation and physical activity. 2.ed. Champaign: Human Kinetics, 2004.

MALINA, R.M. Variation in body composition associated with sex and ethnic. In: HEYMSFIELD, S.B.; LOHMAN, T.G.; WANG, Z.; GOING, B.F. (Editors) Human body composition. Champaign: Human Kinetics, 2005.

MALINA, R.M. Body composition in athletes: assessment and estimated fatness. Clinics in Sports Medicine, Philadelphia, v.26, n.1, p.37-68, 2007.

MANUAL. Manual do operador enCORE. Versão 11.x Revisão E9/2006. GE Healthcare, 2006.

MATTHEWS, B.L.; BENNELL, K.L.; MCKAY, H.A.; KHAN, K.M.; BAXTER-JONES, A. D.; MIRWALD, R.L.; WARK, J.D. The influence of dance training on growth and maturation of young females: a mixed longitudinal study. Annals of Human Biology, Bagingstoke, v.33, n.3, May-Jun, p.342-56, 2006.

MAZESS, R.B.; BARDEN, H.S.; BISEK, J.P.; HANSON, J. Dual-energy x-ray absorptiometry for total-body and regional bone-mineral and soft-tissue composition. The American Journal of Clinical Nutrition, Bethesda, v.51, n.6, Jun, p.1106-12, 1990.

MINDERICO, C.S.; SILVA, A.M.; TEIXEIRA, P.J.; SARDINHA, L.B.; HULL, H.R.; FIELDS, D.A. Validity of air-displacement plethysmography in the assessment of body composition changes in a 16-month weight loss program. Nutrition \& Metabolism, London, v.3, n.32, p.1-8, 2006. 
MIRWALD, R.L.; BAXTER-JONES, A.D.G.; BAILEY, D.A.; BEUNEN, G.P. An assessment of maturity from anthropometric measurements. Medicine Science of Sports and Exercise, Madison, v.34, n. 4, p.689-694, 2002.

MODLESKY, C.M.; EVANS, E.M.; MILLARD-STAFFORD, M.L.; COLLINS, M.A.; LEWIS, R.D.; KURETON, K.J. Impact of bone mineral estimates on percent fat estimates for a four-component model. Medicine Science of Sports and Exercise, Madison, v.31, p.1861-1868, 1999.

MONTEIRO, C.A.; CONDE, W.L. A tendência secular da obesidade segundo estratos sociais: Nordeste e Sudeste do Brasil, 1975-1989-1997. Arquivos Brasileiros de Endocrinologia e Metabologia, Rio de Janeiro, v.43, p.186-94, 1999.

MONTEIRO, C.A.; SILVA, N.N.; NAZÁRIO, C.L. A pesquisa de campo de 1995/96. In: MONTEIRO, C.A. (organizador). Como e por que melhoram (ou pioram) os indicadores de saúde e nutrição na infância? O caso da cidade de São Paulo na segunda metade do século XX, São Paulo, NUPENS/USP, 1999. (Relatório Técnico FAPESP).

MONTEIRO, C.A.; BENICIO, M.H.D'A.; CONDE, W.L.; POPKIN, B.M. Shifting obesity trends in Brazil. European Journal of Clinical Nutrition, London, v.54, p.1-5, 2000.

MONTGOMERY, D.C.; PECK, E.A.; VINING, G.G. Introduction to Linear Regression Analysis. 4ed., New York: John Wiley, p.640, 2006.

MYERS, R.H. Classical and Modern Regression with Applications. Boston: Duxbury Press, 1986.

NAKAO, T.; KOMIYA, S. Reference norms for a fat-free mass index and fat mass index in the Japanese child population. Journal of Physiological Anthropology and Applied Human Science, Tokyo, v.22; p.293-298, 2003. 
NORTON K, OLDS T, (editors). Antropométrica. Porto Alegre: Artmed, 2005.

PACE, N.; RATHBUN, E.N. Studies on body composition, III: The body water and chemically combined nitrogen content in relation to fat content. Journal of Biology Chemistry, Baltimore, v.158, p.685-691, 1945.

PETROSKI, E.L.; PIRES-NETO, C.S. Validação de equações antropométricas para a estimativa da densidade corporal em homens. Revista Brasileira de Atividade Física e Saúde, Pelotas, v.1, n.3, p.5-14,1996.

PETROSKI, E.L. Equações antropométricas: subsídios para uso no estudo da composição corporal. In: Petroski EL, editor. Antropometria: técnicas e padronizações. 2.ed. Porto Alegre: Pallotti, p.107-26, 2003.

PHILIPPAERTS, R.M.; VAEYENS, R.; JANSSENS, M.; VAN RENTERGHEM, B.; MATTHYS, D.; CRAEN, R.; BOURGOIS, J.; VRIJENS, J.; BEUNEN, G.; MALINA, R.M. The relationship between peak height velocity and physical performance in youth soccer players. Journal of Sports Sciences, London, March v.24, n.3, p.221-230, 2006.

PICAUD, J.C.; RIGO, J.; NYAMUGABO, J.; MILET, J.; SENTERRE, J. Evaluation of dual-energy X-ray absorptiometry for body-composition assessment in piglets and term human neonates. The American Journal of Clinical Nutrition, Bethesda, n.63, p.157-163, 1996.

PIETROBELLI, A.; WANG, Z.; FORMICA, C.; HEYMSFIELD, S.B. Dual-energy X-ray absorptiometry: fat estimation errors due to variation in soft tissue hydration. The American Journal of Physiology, Washington, v.274, n.5 p.E808-E816, 1998.

PREECE, M.A.; BAINES, M.J. A new family of mathematical models describing the human growth curve. Annals of Human Biology, Basingstoke, v.5, n.1, p.1-24, 1978. 
PRIBERAM. Dicionário Priberam da Língua Portuguesa [on-line], 2009, http://www.priberam.pt/dlpo/dlpo.aspx?pal=componente [consultado em 2009-04-11].

RECH, C.R.; SANTOS, D.L.; SILVA, J.C.N. Desenvolvimento e validação de equações antropométricas para a predição da gordura corporal em mulheres entre 50 e 75 anos de idade. Revista Brasileira de Cineantropometria e Desempenho Humano, Florianópolis, v.8, p.5-13, 2006.

RODRÍGUEZ, G.; MORENO, L.A; BLAY, M.G; BLAY, V.A.; FLETA, J.; SARRI'A, A.; BUENO, M. Body fat measurement in adolescents: comparison of skinfold thickness equations with dual-energy X-ray Absorptiometry. European Journal of Clinical Nutrition, London, n.59, p.1158-1166, 2005.

ROTH, S.M.; IVEY, F.M.; MARTEL, G.F.; LEMMER, J.T.; HURLBUT, D.E.; SIEGEL, E.L.; METTER, E.J.; FLEG, J.L.; FOZARD, J.L.; KOSTEK, M.C.; WERNICK, D.M.; HURLEY, B.F. Muscle size responses to strength training in young and older men and women. Journal of the American Geriatrics Society, Malden, v.49, n.11, Nov, p.1428-33, 2001.

ROUBENOFF, R.; KEHAYIAS, J.J.; DAWSON-HUGHES, B.; HEYMSFIELD, S.B. Use of dual-energy $\mathrm{x}$-ray absorptiometry in body-composition studies: not yet a "gold standard". The American Journal of Clinical Nutrition, Bethesda, v.58, n.5, Nov, p.589-91, 1993.

SARDINHA, L.B.; TEIXEIRA, P.J.; GUEDES, D.P.; GOING, S.B.; LOHMAN, T.G. Subcutaneous central fat is associated with cardiovascular risk factors in men independently of total fatness and fitness. Metabolism, Clinical and Experimental, v.49, n.11, p.1379-1385, 2000. 
SARDINHA, L.B; TEIXEIRA, P.J. Measuring adiposity and fat distribution in relation to health. p. 177-201. in: HEYMSFIELD, S.B.; LOHMAN, T.G.; WANG, Z.; GOING, B.F. (Editors) Human body composition. Champaign: Human Kinetics, 2005.

SATO, T.; DEMURA, S.; MURASE, T.; KOBAYAYASHI, Y. Contribution of physical fitness component to health status in middle-aged and elderly males. Journal of physiological anthropology, Tokyo, v.25, n.5, p.311-319, 2006.

SCHOELLER, D.A.; TYLAVSKY, F.A., BAER, D.J.; CHUMLEA, W.C., EARTHMAN, C.P.; FUERST, T.; HARRIS, T.B.; HEYMSFIELD, S.B.; HORLICK, M.; LOHMAN, T.G.; LUKASKI, H.C.; SHEPHERD, J.; SIERVOGEL, R.M.; BORRUD, L.G. QDR 4500A dual-energy X-ray absorptiometer underestimates fat mass in comparison with criterion methods in adults. The American Journal of Clinical Nutrition, Bethesda, v.81, n.5, May, p.1018-1025, 2005.

SCHUTZ, Y.; KYLE, U.U.G.; PICHARD, C. Fat-free mass index and fat mass index percentiles in Caucasians aged 18-98 y. International Journal of Obesity and Related Metabolic Disorders, Hampshire, v.26, n.7, p. 953-960, 2002.

SHEN, W.; ST-ONGE, M.P.; WANG, Z.; HEYMSFIELD, S.B. Study of body composition: an overwiew. In: HEYMSFIELD, S.B.; LOHMAN, T.G.; WANG, Z.; GOING, B.F. (Editors) Human body composition. Champaign: Human Kinetics, 2005.

SHERAR, L.B.; BAXTER-JONES, A.D.; MIRWALD, R.L. Limitations to the use of secondary sex characteristics for gender comparisons. Annals of Human Biology, Bagingstoke, v.31, n.5, Sep-Oct, p.586-93. 2004.

SHERAR, L.B.; MIRWALD, R.L.; BAXTER-JONES, A.D.; THOMIS, M. Prediction of adult height using maturity-based cumulative height velocity curves. The Journal of Pediatrics, St. Louis, v.147, n.4, p.508-14, 2005. 
SHYPAILO, R.J.; BUTTE, N.F.; ELLIS, K.J. DXA: can it be used as a criterion reference for body fat measurements in children? Obesity, Silver Spring, n.16, p.457-462, 2008.

SILVA, A.M; BAPTISTA, F.; MINDERICO, C.S.; RODRIGUES, A.R.; PIETROBELLI, A.; TEIXEIRA, P.J.; SARDINHA, L.B. Calibration models to measure body composition in taller subjects using DXA. International Journal of Body Composition Research, v.2, n.4, p.165-173, 2004.

SILVA, A.M.; MINDERICO, C.S.; TEIXEIRA, P.J.; PIETROBELLI, A.; SARDINHA, L.B. Body fat measurement in adolescent athletes: multicompartment molecular model comparison. European Journal of Clinical Nutrition, London, n.60, p.955-964, 2006.

SLAUGHTER, M.H.; LOHMAN, T.G.; BOILEAU, R.A.; HORSWILL, C.A.; STILLMAN, R.J.; VAN LOAN, M.D.; BEMBEN, D.A. Skinfold equations for estimation of body fatness in children and youth. Human biology; an international record of research, Detroit, v.60, n.5, Oct, p.709-23, 1988.

SOPHER, A.; SHEN, W.; PIETROBELLI, A. Pediatric body composition methods. P.129-139. in: HEYMSFIELD, S.B.; LOHMAN, T.G.; WANG, Z.; GOING, B.F. (Editors) Human body composition. Champaign: Human Kinetics, 2005.

SUN, S.S.; CHUMLEA, W.C.; HEYMSFIELD, S.B., LUKASKI, H.C.; SCHOELLER, D.; FRIEDL, K.; KUCZMARSKI, R.J., FLEGAL, K.M.; JOHNSON, C.L.; HUBBARD, V.S. Development of bioelectrical impedance analysis prediction equations for body composition with the use of a multicomponent model for use in epidemiologic surveys The American Journal of Clinical Nutrition, Bethesda, v.77, p.331-340, 2003.

SUN, S.S.; CHUMLEA, W.C. Statistical Methods. P. 151-160. in: HEYMSFIELD, S.B.; LOHMAN, T.G.; WANG, Z.; GOING, B.F. (Editors) Human body composition. Champaign: Human Kinetics, 2005. 
SVENDSEN, O.L.; HAARBO, J.; HASSAGER, C.; CHRISTIANSEN, C. Accuracy of measurements of body composition by dual-energy $x$-ray absorptiometry in vivo. The American Journal of Clinical Nutrition, Bethesda, v.57, n.5, May, p.605-608, 1993.

TANNER, J. M. Growth at adolescence, 2nd ed. Oxford: Blackwell Scientific, 1962.

TATARANNI, P.A.; RAVUSSIN, E. Use of dual-energy X-ray absorptiometry in obese individuals. The American Journal of Clinical Nutrition, Bethesda, v.62, n.4, Oct, p.730-4. 1995.

TEIXEIRA, P.J.; SARDINHA, L.B.; GOING, S.B.; LOHMAN, T.G. Total and regional fat and serum cardiovascular disease risk factors in lean and obese children and adolescents. Obesity Research, Baton Rouge, v.9, n.8, Aug, p.432-42, 2001.

TERAN, J.C.; SPARKS, K.E.; QUINN, L.M.; FERNANDEZ, B.S.; KREY, S.H.; STEFFEE, W.P. Percent body fat in obese white females predicted by anthropometric measurements. The American Journal of Clinical Nutrition, Bethesda, v.53, n.1, Jan, p.7-13, 1991.

TROTTER, M.; HIXON, B. B. Sequential changes in weight, density, and percentage ash weight of human skeletons from an early fetal period through old age. The Anatomical Record, New York, v.179, n.1, May, p.1-18. 1974.

WANG, Z.M., PIERSON JR, R.N.; HEYMSFIELD, S.B. The five-level model: a new approach to organizing body-composition research. The American Journal of Clinical Nutrition, Bethesda, v.56, n.1, Jul, p.19-28. 1992.

WASHINO, K.; TAKADA, H.; IWATA, H. The Accelerated Increase in Lean Body Mass of Pre-pubescent Japanese Boys at 10 to 11 Years of Age. Environmental Health and Preventive Medicine, Sapporo, n.3, p.102-105, 1998. 
WELLS, J.C. A critique of the expression of paediatric body composition data. Archives of Disease in Childhood, London, v.85, n.1, Jul, p.67-72. 2001.

WELTMAN, A.; SEIP, R.L.; TRAN, Z.V. Practical assessment of body composition in obese males. Human biology; an international record of research, Detroit, v.59, p.523-535, 1987.

WESTSTRATE, J.A.; DEURENBERG, P. Body composition in children: proposal for a method for calculating body fat percentage from total body density or skinfoldthickness measurements. The American Journal of Clinical Nutrition, Bethesda, v.50, n.5, Nov, p.1104-15, 1989.

WILLIAMS, D.P; TEIXEIRA, P.J.; GOIG, S.B. Exercise. In: HEYMSFIELD, S.B.; LOHMAN, T.G.; WANG, Z.; GOING, B.F. (Editors) Human Body Composition. Champaign: Human Kinetics, 2005.

WILMORE, J.H.; BROWN, C.H.; DAVIS, J.A. Body physique and composition of the female distance runner. Annals of New York Academy Science, New York, v.301, p.764-76, 1977. 
APÊNDICES 


\title{
APÊNDICE 1 - Autorização da Instituição de Ensino
}

\author{
UNIVERSIDADE DE SÃO PAULO - ESCOLA DE EDUCAÇÃO FÍSICA E ESPORTE \\ DOUTORADO EM BIODINÂMICA DO MOVIMENTO HUMANO
}

\begin{abstract}
Autorização da Instituição de Ensino
Pesquisador: Dalmo Roberto Lopes Machado Local: Presidente Prudente

Título da Pesquisa: Modelo Multicompartimental da Composição Corporal em

Crianças e Adolescentes
\end{abstract}

Declaro que após convenientemente esclarecido pelo pesquisador e após ter compreendido a importância do projeto de pesquisa apresentado, na função de Diretor Escolar desta unidade de ensino, eu, responsável legal pela , consinto em autorizar a coleta de dados

para a pesquisa citada acima nas dependências da escola, de todos os alunos que se propuserem a participar como voluntários, mediante prévia autorização dos seus pais ou responsáveis.

Os dados coletados na escola serão:

- Antropometria: Estatura, peso corporal e medidas de dobras cutâneas;

- Maturação sexual: auto avaliação;

- Bioimpedância elétrica;

- Questionários do nível de atividade física (NAF) e estimativa do estado nutricional.

- E para a medida de Densitometria óssea (DXA), será providenciada junto aos pais/responsáveis autorização específica para deslocamento até a clínica responsável.

Presidente Prudente, de de 2007. 
APÊNDICE 2 - Termo de Consentimento Livre e Esclarecido

\section{ESCOLA DE EDUCAÇÃO FÍSICA E ESPORTE DA UNIVERSIDADE DE SÃO PAULO TERMO DE CONSENTIMENTO LIVRE E ESCLARECIDO}

(Instruções para preenchimento no verso)

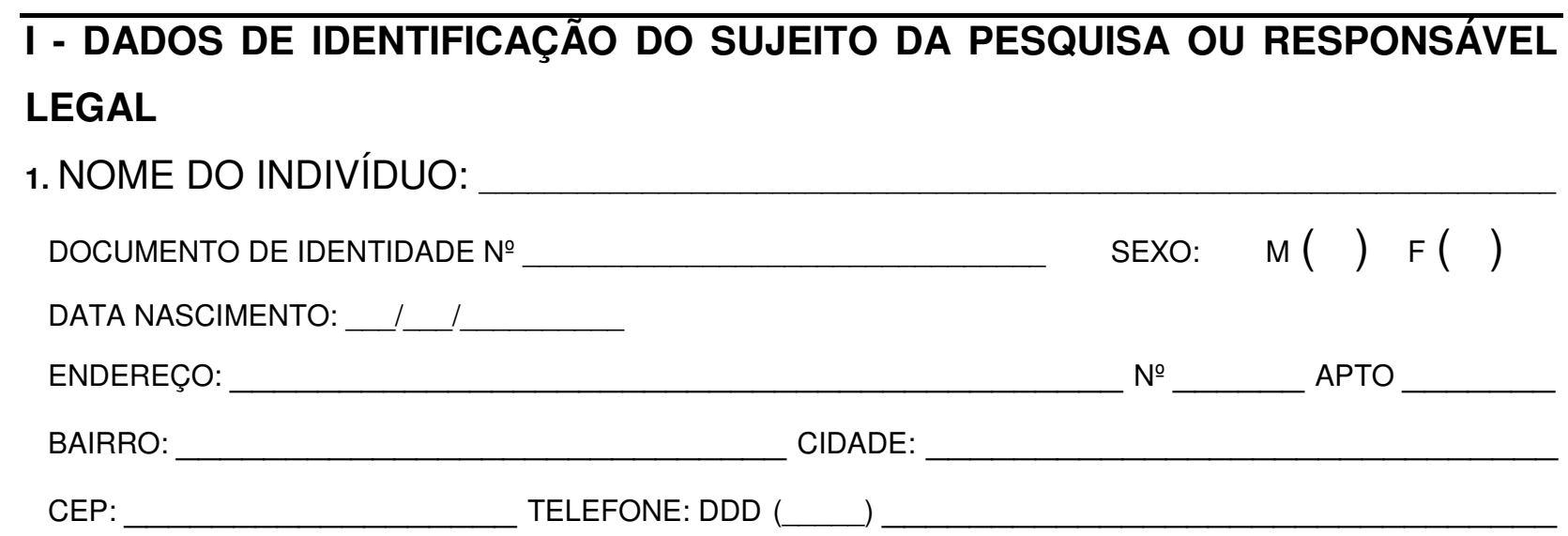

2. RESPONSÁVEL LEGAL:

NATUREZA (grau de parentesco, tutor, curador, etc.)

DOCUMENTO DE IDENTIDADE №: SEXO: $M(\quad) \quad F(\quad)$

DATA NASCIMENTO:

ENDEREÇO:

№ APTO

BAIRRO: CIDADE:

CEP: TELEFONE: DDD

\section{II - DADOS SOBRE A PESQUISA CIENTÍFICA}

1. TÍTULO DO PROJETO DE PESQUISA: MODELO MULTICOMPARTIMENTAL DA COMPOSIC̣ÃO CORPORAL EM CRIANCCAS E ADOLESCENTES

2. PESQUISADOR RESPONSÁVEL: Prof. Dr. VALDIR JOSÉ BARBANTI

3. CARGO/FUNÇÃO: Professor Titular do Depto de Esportes da EEFEUSP

4. AVALIAÇÃO DO RISCO DA PESQUISA:

$\begin{array}{lll}\text { RISCO MÍNIMO } & (\mathrm{x}) & \text { RISCO MÉDIO } \\ \text { RISCO BAIXO } & (\text { ) }\end{array}$

(probabilidade de que o indivíduo sofra algum dano como conseqüência imediata ou tardia do estudo)

5. DURAÇÃO DA PESQUISA: 3 anos 


\section{III - EXPLICAÇÕES DO PESQUISADOR AO INDIVÍDUO OU SEU REPRESENTANTE}

LEGAL SOBRE A PESQUISA, DE FORMA CLARA E SIMPLES, CONSIGNANDO:

Eu, Dalmo Roberto Lopes Machado, Doutorando em Educação Física pela Universidade de São Paulo (USP), realizo o projeto de estudo intitulado "Modelo Multicompartimental da Composição Corporal em Crianças e Adolescentes", o qual se reverterá em tese de doutorado. Este projeto foi aprovado pelo Comitê de Ética em Pesquisa da Escola de Educação Física e Esporte da USP - Protocolo 2006/32 em 29/03/2007.

A idéia deste projeto surgiu a partir das observações que no meio escolar, clínico e esportivo, a estimativa da composição corporal em crianças e adolescentes é um dos fatores preponderantes para a correta prescrição e orientação da atividade física. Os recursos atualmente disponíveis além de escassos envolvem análises limitadas e geralmente são dirigidos a populações específicas. Assim o objetivo deste estudo será investigar as mudanças corporais na infância e adolescência, sua relação com maturação biológica e crescimento físico, assim, este estudo prevê as seguintes medidas:

- Antropometria: estatura, peso corporal, medidas de dobras cutâneas, diâmetros ósseos e perímetros.

- Maturação sexual: auto-avaliação (cada criança indicará num quadro de figuras, qual delas mais se assemelha às suas características).

- Densitometria óssea (DXA): uma varredura realizada em nosso laboratório no DPX-NT da Lunar-GE por pessoal especializado.

- Bioimpedância elétrica - o avaliado permanece deitado e uma baixa corrente elétrica (a partir do aparelho) estima a quantidade de água corporal.

A partir dos dados, pretende-se chegar a um modelo estatístico (fórmula preditiva) da Composição Corporal de crianças/adolescentes, útil na prática da educação física, nutrição, clínica pediátrica, programas de intervenção em saúde e treinamento com jovens.

Serão necessários cerca de 450 escolares, entre 7 e 17 anos, portanto precisamos muito da sua colaboração, o que de antemão já agradecemos. Em contrapartida, cada participante terá cópias dos seus exames, com avaliação precisa da composição corporal, para apreciação dos pais. 
Para a realização das medidas as crianças serão levadas (em grupos de cinco) ao CELAPAM (Laboratório de Avaliação Física da Unesp) no horário de aulas de educação física (sem comprometer às demais disciplinas) e retornarão à escola sempre acompanhadas por monitores/professores do laboratório sob minha responsabilidade.

Qualquer dúvida pode ser esclarecida pelo fone 8127-9284 ou dalmomachado@yahoo.com.br .

Agradeço desde já a colaboração.

Sem mais,

IV - ESCLARECIMENTOS DADOS PELO PESQUISADOR SOBRE GARANTIAS DO SUJEITO DA PESQUISA:

Aos pais ou responsáveis será concedido a qualquer tempo, acesso às informações sobre procedimentos, riscos e benefícios relacionados à esta pesquisa, inclusive para dirimir eventuais dúvidas;

É assegurada ainda a liberdade de retirar seu consentimento a qualquer momento, deixando de participar do estudo, sem que isto traga prejuízo à continuidade da assistência; e

Esclarecemos ainda que a salvaguarda da confidencialidade, sigilo e privacidade dos seus filhos serão asseguradas.

$\mathrm{V}$ - ABAIXO SEGUEM INFORMAÇÕES DOS RESPONSÁVEIS PELO ACOMPANHAMENTO DA PESQUISA, PARA CONTATO EM CASO DE INTERCORRÊNCIAS RELACIONADAS A ESTE ESTUDO.

Dalmo Roberto Lopes Machado, telefone 8127-9284 ou e-mail: dalmomachado@yahoo.com.br. Endereço: Rua Maria Madalena Mazucheli Caravina, 100 Jd Maracanã CEP 19026-430 Pres. Prudente/SP 


\section{VII - CONSENTIMENTO PÓS-ESCLARECIDO}

Declaro que, após convenientemente esclarecido pelo pesquisador e ter entendido o que me foi explicado, consinto em autorizar o(a) menor a participar do presente Projeto de Pesquisa.

Declaro ainda que a criança/adolescente foi consultado(a) e concordou em participar voluntariamente da pesquisa.

Presidente Prudente, 20 de setembro de 2008. 


\section{APÊNDICE 3 - Planilha de coleta de dados}

\section{Planilha de Avaliação}

Data Avaliação

ANÁLISE MULTICOMPARTIMENTAL DA COMPOSIÇÃO CORPORAL EM JOVENS ESPORTISTAS E NÃO ESPORTISTAS FCT - Unesp - Presidente Prudente/SP
Identificação
Celapam - Geciaf
Dobras Cutâneas

Dobras Cutâneas

Nome Dt Nasc Sexo Categ. Modal. Comp Dc Bi Dc Tri Dc Se Dc Pt Dc Am Dc Di DcAbv

\begin{tabular}{|c|c|c|c|c|c|c|c|c|c|c|c|c|c|c|c|c|c|c|c|}
\hline \multirow{3}{*}{1} & do Avaliado & (dd/mm/aaaa) & $(\mathrm{M} / \mathrm{F})$ & $(\mathrm{Es} / \mathrm{Ne})$ & (origem) & (mod) & $(\mathrm{mm})$ & $(\mathrm{mm})$ & $(\mathrm{mm})$ & $(\mathrm{mm})$ & $(\mathrm{mm})$ & $(\mathrm{mm})$ & $(\mathrm{mm})$ & $(\mathrm{mm})$ & $(\mathrm{mm})$ & $(\mathrm{mm})$ & Braços & Pernas & (Abrev) \\
\hline & & & & & & Sanny & & & & & & & & & & & & & \\
\hline & & & & & & Lange & & & & & & & & & & & & & \\
\hline \multirow{2}{*}{2} & & & & & & Sanny & & & & & & & & & & & & & \\
\hline & & & & & & Lange & & & & & & & & & & & & & \\
\hline \multirow{2}{*}{3} & & & & & & Sanny & & & & & & & & & & & & & \\
\hline & & & & & & \begin{tabular}{|l} 
Lange \\
\end{tabular} & & & & & & & & & & & & & \\
\hline \multirow{2}{*}{4} & & & & & & Sanny & & & & & & & & & & & & & \\
\hline & & & & & & \begin{tabular}{|l|} 
Lange \\
\end{tabular} & & & & & & & & & & & & & \\
\hline \multirow{2}{*}{5} & & & & & & Sanny & & & & & & & & & & & & & \\
\hline & & & & & & Lange & & & & & & & & & & & & & \\
\hline
\end{tabular}

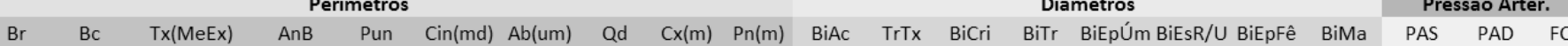

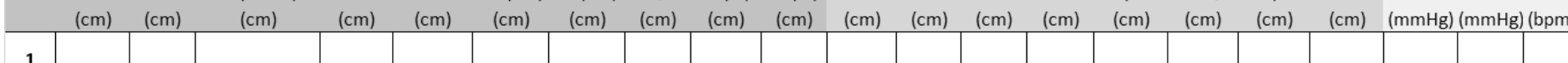

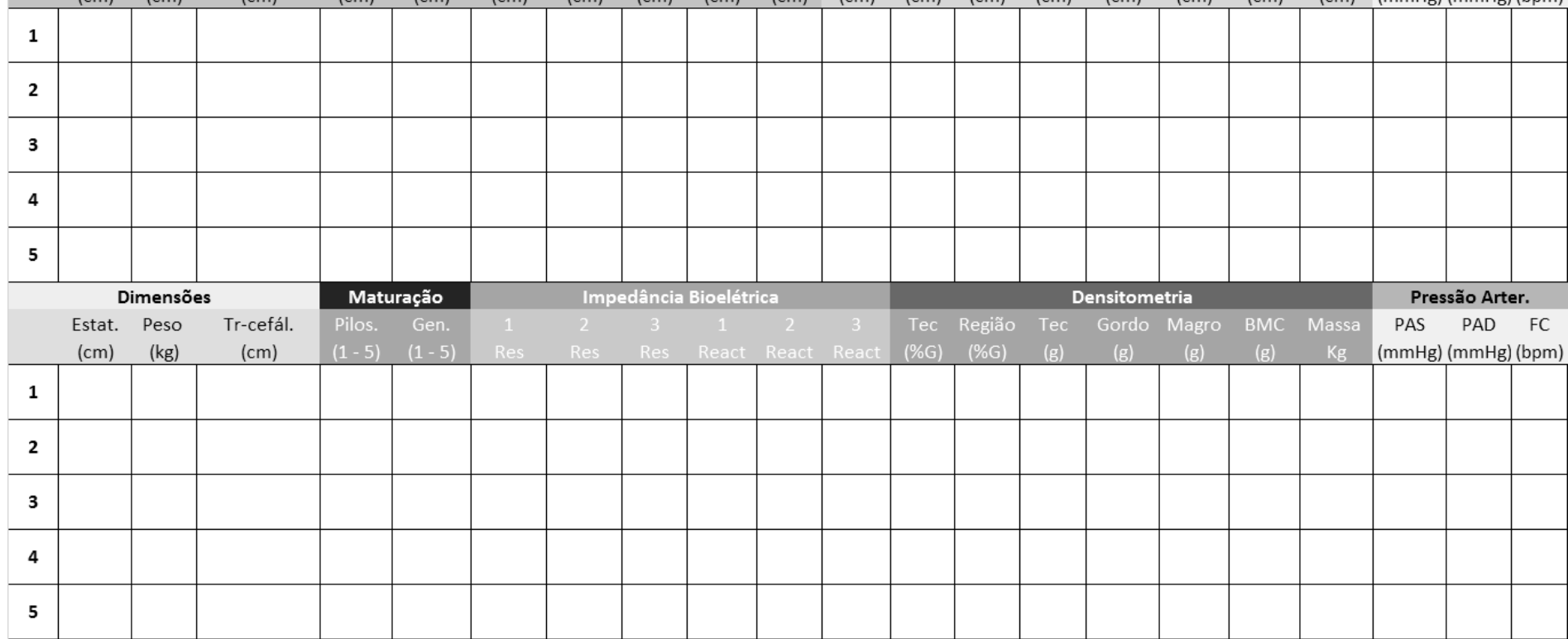


APÊNDICE 4 - Valores comparativos do teste $t$ (Student) para amostras independentes, de média e desvio padrão (dp) da CC, e significância estatística (Sig.), valores de $\mathrm{F}, \mathrm{t}$ e graus de liberdade ( $\mathrm{gl}$ ), entre jovens esportistas (ES) e não esportistas (NE) do sexo masculino de 8 a 18 anos.

\begin{tabular}{|c|c|c|c|c|c|c|c|c|}
\hline Idade & & Categ. & Média & (dp) & $\mathrm{F}$ & $t$ & Sig. & gl \\
\hline \multirow[t]{6}{*}{8} & $\mathrm{MG}(\mathrm{kg})$ & ES & 6,99 & 4,68 & \multirow{2}{*}{0,159} & \multirow{2}{*}{0,556} & \multirow{2}{*}{0,583} & \multirow{6}{*}{26} \\
\hline & & NE & 5,84 & 4,45 & & & & \\
\hline & $\mathrm{MO}(\mathrm{kg})$ & ES & 1,15 & 0,20 & \multirow{2}{*}{0,022} & \multirow{2}{*}{$-0,089$} & \multirow{2}{*}{0,929} & \\
\hline & & NE & 1,16 & 0,17 & & & & \\
\hline & $\mathrm{MM}(\mathrm{Kg})$ & ES & 10,91 & 2,20 & & & 735 & \\
\hline & & $\mathrm{NE}$ & 10,52 & 2,46 & 0,009 & 0,343 & 0,135 & \\
\hline \multirow[t]{6}{*}{9} & $M G(k g)$ & ES & 6,82 & 5,20 & \multirow{2}{*}{0,500} & \multirow{2}{*}{0,373} & 0,711 & \multirow{6}{*}{34} \\
\hline & & NE & 6,26 & 3,71 & & & & \\
\hline & $\mathrm{MO}(\mathrm{kg})$ & ES & 1,24 & 0,22 & \multirow{2}{*}{0,407} & \multirow{2}{*}{0,085} & \multirow[t]{2}{*}{0,933} & \\
\hline & & NE & 1,23 & 0,21 & & & & \\
\hline & $\mathrm{MM}(\mathrm{Kg})$ & ES & 11,46 & 2,00 & \multirow{2}{*}{0,036} & \multirow{2}{*}{0,309} & \multirow[t]{2}{*}{0,759} & \\
\hline & & NE & 11,26 & 1,77 & & & & \\
\hline \multirow[t]{6}{*}{10} & MG $(\mathrm{kg})$ & ES & 5,88 & 4,10 & \multirow{2}{*}{2,861} & \multirow{2}{*}{$-1,742$} & \multirow[t]{2}{*}{0,090} & \multirow{6}{*}{35} \\
\hline & & NE & 8,89 & 5,90 & & & & \\
\hline & $\mathrm{MO}(\mathrm{kg})$ & ES & 1,33 & 0,24 & 1091 & -1 & 0,324 & \\
\hline & & NE & 1,40 & 0,21 & וזע, & $-1,000$ & & \\
\hline & $\mathrm{MM}(\mathrm{Kg})$ & ES & 11,37 & 2,54 & & & 0,119 & \\
\hline & & NE & 12,42 & 1,43 & 6,112 & $-1,591$ & & \\
\hline 11 & $M G(k g)$ & ES & 7,32 & 5,24 & & & 0,603 & \\
\hline & & NE & 8,35 & 6,81 & 2,069 & $-0,525$ & & \\
\hline & $\mathrm{MO}(\mathrm{kg})$ & ES & 1,50 & 0,29 & 0002 & 0630 & 0,533 & 39 \\
\hline & & NE & 1,44 & 0,29 & $0,00<$ & 0,030 & & 39 \\
\hline & $\mathrm{MM}(\mathrm{Kg})$ & ES & 13,86 & 2,51 & 0298 & 0037 & 0,971 & \\
\hline & & NE & 13,82 & 4,57 & 0,298 & 0,031 & & \\
\hline 12 & $M G(k g)$ & ES & 8,10 & 6,02 & & & 0,610 & \\
\hline & & NE & 9,19 & 7,05 & 0,248 & $-0,514$ & & \\
\hline & $\mathrm{MO}(\mathrm{kg})$ & ES & 1,80 & 0,28 & 2259 & 0715 & 0,479 & 36 \\
\hline & & NE & 1,73 & 0,34 & $<,<39$ & 0,110 & & 30 \\
\hline & $\mathrm{MM}(\mathrm{Kg})$ & ES & 16,56 & 2,85 & & & 0,647 & \\
\hline & & NE & 17,01 & 3,18 & 0,321 & $-0,462$ & & \\
\hline 13 & $M G(k g)$ & ES & 7,67 & 9,41 & 1846 & -1784 & 0,083 & \\
\hline & & NE & 13,06 & 9,17 & & & & \\
\hline & $\mathrm{MO}(\mathrm{kg})$ & ES & 1,96 & 0,43 & 0177 & & 0,945 & \\
\hline & & NE & 1,97 & 0,37 & $0,1 / 7$ & $-0,0 / 0$ & & 31 \\
\hline & $\mathrm{MM}(\mathrm{Kg})$ & ES & 19,27 & 3,56 & 188 & $\cap 489$ & 0,627 & \\
\hline & & $\mathrm{NE}$ & 18,70 & 3,69 & 0,100 & 0,409 & & \\
\hline 14 & $\mathrm{MG}(\mathrm{kg})$ & ES & 6,50 & 4,56 & 17217 & 51 & 0,004 & \\
\hline & & NE & 14,23 & 11,51 & $1 \pi,<1 /$ & 8,051 & & \\
\hline
\end{tabular}




\begin{tabular}{|c|c|c|c|c|c|c|c|c|}
\hline & \multirow[t]{2}{*}{$\mathrm{MO}(\mathrm{kg})$} & ES & 2,32 & 0,48 & \multirow{2}{*}{0,120} & \multirow{2}{*}{$-0,442$} & \multirow[t]{2}{*}{0,661} & \\
\hline & & NE & 2,38 & 0,46 & & & & \\
\hline & \multirow[t]{2}{*}{$\mathrm{MM}(\mathrm{Kg})$} & ES & 22,90 & 4,40 & \multirow{2}{*}{0,122} & \multirow{2}{*}{0,568} & \multirow[t]{2}{*}{0,573} & \\
\hline & & NE & 22,20 & 3,95 & & & & \\
\hline \multirow[t]{6}{*}{15} & \multirow[t]{2}{*}{ MG (kg) } & ES & 7,14 & 3,27 & \multirow{2}{*}{11,453} & \multirow{2}{*}{$-3,553$} & \multirow[t]{2}{*}{0,001} & \multirow{6}{*}{40} \\
\hline & & NE & 15,03 & 9,63 & & & & \\
\hline & \multirow[t]{2}{*}{$\mathrm{MO}(\mathrm{kg})$} & ES & 2,59 & 0,49 & \multirow{2}{*}{0,247} & \multirow{2}{*}{$-2,193$} & 0,034 & \\
\hline & & NE & 2,90 & 0,42 & & & & \\
\hline & \multirow[t]{2}{*}{$\mathrm{MM}(\mathrm{Kg})$} & ES & 25,06 & 3,71 & \multirow{2}{*}{0,510} & \multirow{2}{*}{$-1,713$} & 0,095 & \\
\hline & & $\mathrm{NE}$ & 27,14 & 4,14 & & & & \\
\hline \multirow[t]{6}{*}{16} & \multirow[t]{2}{*}{ MG (kg) } & ES & 8,79 & 4,20 & \multirow{2}{*}{7,596} & \multirow{2}{*}{$-2,259$} & \multirow[t]{2}{*}{0,030} & \multirow{6}{*}{38} \\
\hline & & NE & 12,56 & 6,32 & & & & \\
\hline & \multirow[t]{2}{*}{$\mathrm{MO}(\mathrm{kg})$} & ES & 3,10 & 0,38 & \multirow{2}{*}{1,009} & \multirow{2}{*}{1,151} & 0,257 & \\
\hline & & NE & 2,94 & 0,48 & & & & \\
\hline & \multirow[t]{2}{*}{$\mathrm{MM}(\mathrm{Kg})$} & ES & 28,06 & 2,90 & \multirow{2}{*}{0,091} & & 0,543 & \\
\hline & & $\mathrm{NE}$ & 27,44 & 3,51 & & 0,614 & & \\
\hline 17 & MG (kg) & ES & 10,95 & 9,30 & 0163 & & 0,651 & \\
\hline & & NE & 12,23 & 8,45 & 0,103 & $-U, 450$ & & \\
\hline & $\mathrm{MO}(\mathrm{kg})$ & ES & 3,06 & 0,41 & רחم $\cap$ & 1157 & 0,254 & 39 \\
\hline & & NE & 2,90 & 0,44 & 0,001 & וכו, ו & & 35 \\
\hline & $\mathrm{MM}(\mathrm{Kg})$ & ES & 28,27 & 4,14 & 0697 & 0639 & 0,527 & \\
\hline & & NE & 27,54 & 3,17 & ונס, & 0,000 & & \\
\hline 18 & $M G(k g)$ & ES & 6,78 & 3,17 & 13438 & -1756 & 0,090 & \\
\hline & & NE & 12,30 & 10,51 & & & & \\
\hline & $\mathrm{MO}(\mathrm{kg})$ & ES & 3,26 & 0,35 & & & 0,086 & \\
\hline & & NE & 2,99 & 0,44 & $1,4 / 6$ & $1, / 82$ & & 28 \\
\hline & $\mathrm{MM}(\mathrm{Kg})$ & ES & 30,13 & 2,70 & 3487 & ? 011 & 0,054 & \\
\hline & & NE & 27,48 & 4,00 & $3,40 /$ & 2,011 & & \\
\hline
\end{tabular}


APÊNDICE 5 - Valores medidos e preditos da CC de jovens de 8 a 18 anos de idade do sexo masculino.

\begin{tabular}{|c|c|c|c|c|c|c|}
\hline & \multicolumn{2}{|c|}{ MG (kg) } & \multicolumn{2}{|c|}{ MO (kg) } & \multicolumn{2}{|c|}{ MM (kg) } \\
\hline Sujeito & Medido & Predito & Medido & Predito & Medido & Predito \\
\hline 1 & 12,78 & 12,076 & 1,75 & 1,735 & 14,72 & 16,107 \\
\hline 2 & 24,27 & 24,242 & 2,84 & 3,182 & 27,81 & 29,418 \\
\hline 3 & 28,03 & 29,613 & 2,58 & 2,383 & 21,78 & 19,241 \\
\hline 4 & 8,65 & 13,746 & 1,13 & 0,942 & 10,06 & 7,660 \\
\hline 5 & 5,63 & 8,147 & 2,90 & 2,769 & 28,49 & 27,295 \\
\hline 6 & 4,45 & 5,835 & 2,43 & 2,693 & 26,54 & 26,148 \\
\hline 7 & 6,17 & 7,555 & 3,72 & 3,151 & 31,64 & 30,510 \\
\hline 8 & 4,36 & 5,874 & 1,38 & 1,209 & 12,48 & 11,615 \\
\hline 9 & 10,49 & 12,151 & 3,16 & 3,039 & 30,29 & 28,626 \\
\hline 10 & 27,38 & 20,759 & 3,54 & 3,348 & 26,67 & 29,767 \\
\hline 11 & 3,52 & 4,744 & 3,04 & 2,678 & 26,51 & 25,877 \\
\hline 12 & 10,99 & 13,751 & 2,67 & 2,667 & 24,04 & 24,025 \\
\hline 13 & 3,51 & 2,354 & 1,52 & 1,629 & 14,24 & 14,663 \\
\hline 14 & 7,35 & 6,918 & 1,62 & 1,767 & 16,24 & 16,001 \\
\hline 15 & 3,15 & 1,851 & 1,26 & 1,651 & 14,56 & 15,918 \\
\hline 16 & 5,83 & 5,121 & 2,43 & 2,357 & 20,86 & 22,783 \\
\hline 17 & 3,13 & 2,236 & 1,17 & 0,999 & 8,68 & 9,859 \\
\hline 18 & 3,19 & 2,381 & 1,06 & 0,960 & 9,33 & 9,470 \\
\hline 19 & 3,05 & 2,660 & 1,58 & 1,781 & 17,23 & 17,249 \\
\hline 20 & 2,03 & 2,107 & 1,41 & 1,416 & 14,32 & 14,045 \\
\hline 21 & 4,02 & 3,399 & 1,28 & 1,329 & 12,02 & 12,515 \\
\hline 22 & 13,46 & 14,981 & 1,33 & 1,262 & 19,57 & 12,773 \\
\hline 23 & 8,58 & 9,032 & 1,29 & 1,265 & 12,66 & 12,071 \\
\hline 24 & 13,40 & 14,735 & 1,18 & 1,337 & 12,62 & 12,405 \\
\hline 25 & 8,16 & 8,305 & 2,90 & 2,597 & 24,88 & 24,124 \\
\hline 26 & 4,14 & 4,574 & 2,47 & 2,445 & 23,25 & 23,708 \\
\hline 27 & 12,25 & 12,187 & 1,72 & 1,703 & 15,49 & 15,348 \\
\hline 28 & 19,84 & 17,521 & 3,03 & 3,408 & 31,00 & 31,506 \\
\hline 29 & 4,48 & 4,955 & 2,90 & 2,874 & 27,51 & 27,369 \\
\hline 30 & 19,38 & 19,484 & 2,92 & 3,087 & 29,07 & 28,370 \\
\hline 31 & 3,27 & 2,894 & 1,12 & 1,064 & 9,28 & 9,904 \\
\hline
\end{tabular}




\begin{tabular}{|c|c|c|c|c|c|c|}
\hline 32 & 6,68 & 4,363 & 1,28 & 1,415 & 12,05 & 13,444 \\
\hline 33 & 18,64 & 15,890 & 2,26 & 2,427 & 21,94 & 22,399 \\
\hline 34 & 4,30 & 3,284 & 1,38 & 1,512 & 14,45 & 14,707 \\
\hline 35 & 6,91 & 7,585 & 1,73 & 1,639 & 15,24 & 15,907 \\
\hline 36 & 6,88 & 8,438 & 2,90 & 2,713 & 26,30 & 25,729 \\
\hline 37 & 4,94 & 2,766 & 1,17 & 1,345 & 11,26 & 12,930 \\
\hline 38 & 7,76 & 9,413 & 1,10 & 1,105 & 10,37 & 10,322 \\
\hline 39 & 10,12 & 11,156 & 3,69 & 2,994 & 29,87 & 28,366 \\
\hline 40 & 13,58 & 15,073 & 3,25 & 2,941 & 28,10 & 27,712 \\
\hline 41 & 9,54 & 9,933 & 3,08 & 2,934 & 28,74 & 28,094 \\
\hline 42 & 2,91 & 2,073 & 1,64 & 1,800 & 16,79 & 17,312 \\
\hline 43 & 7,41 & 8,046 & 2,34 & 2,766 & 26,72 & 26,307 \\
\hline 44 & 5,72 & 5,053 & 2,73 & 2,667 & 25,19 & 25,504 \\
\hline 45 & 6,24 & 6,313 & 1,71 & 1,400 & 12,51 & 13,125 \\
\hline 46 & 8,08 & 8,984 & 3,51 & 3,422 & 33,58 & 32,377 \\
\hline 47 & 2,36 & 2,067 & 1,16 & 1,040 & 10,53 & 10,543 \\
\hline 48 & 21,79 & 19,179 & 3,65 & 3,265 & 28,73 & 30,358 \\
\hline 49 & 3,43 & 2,332 & 1,33 & 1,276 & 11,54 & 12,341 \\
\hline 50 & 8,33 & 7,955 & 3,00 & 3,109 & 29,47 & 30,039 \\
\hline 51 & 11,18 & 11,492 & 1,60 & 1,615 & 14,94 & 15,067 \\
\hline 52 & 17,04 & 18,771 & 3,42 & 3,155 & 29,26 & 28,677 \\
\hline 53 & 9,46 & 10,558 & 3,16 & 3,202 & 30,70 & 30,323 \\
\hline 54 & 10,81 & 11,684 & 3,20 & 3,023 & 28,55 & 28,115 \\
\hline 55 & 4,11 & 2,737 & 1,35 & 1,472 & 12,86 & 13,853 \\
\hline 56 & 8,87 & 10,223 & 2,53 & 2,624 & 25,65 & 25,068 \\
\hline 57 & 5,19 & 4,788 & 2,98 & 3,079 & 29,37 & 29,690 \\
\hline 58 & 35,01 & 31,490 & 2,76 & 2,894 & 22,90 & 24,798 \\
\hline 59 & 2,75 & 2,859 & 2,14 & 2,186 & 21,55 & 20,882 \\
\hline 60 & 11,12 & 13,818 & 3,52 & 3,151 & 31,91 & 28,355 \\
\hline 61 & 5,16 & 5,353 & 0,92 & 1,039 & 9,46 & 9,210 \\
\hline 62 & 5,56 & 7,083 & 1,07 & 1,008 & 9,00 & 8,870 \\
\hline 63 & 18,16 & 19,129 & 3,84 & 3,280 & 30,89 & 29,304 \\
\hline 64 & 1,87 & 1,206 & 1,63 & 1,701 & 16,36 & 16,431 \\
\hline 65 & 10,82 & 10,584 & 3,13 & 3,017 & 26,89 & 28,531 \\
\hline 66 & 7,89 & 7,262 & 3,14 & 2,969 & 28,58 & 28,904 \\
\hline
\end{tabular}




\begin{tabular}{|c|c|c|c|c|c|c|}
\hline 67 & 8,90 & 10,012 & 3,52 & 3,313 & 31,44 & 31,514 \\
\hline 68 & 11,39 & 11,778 & 2,09 & 2,187 & 19,57 & 20,571 \\
\hline 69 & 4,43 & 5,448 & 1,14 & 1,102 & 10,21 & 10,486 \\
\hline 70 & 2,51 & 2,388 & 1,12 & 0,985 & 9,28 & 9,598 \\
\hline 71 & 8,68 & 8,740 & 1,32 & 1,208 & 9,62 & 11,072 \\
\hline 72 & 4,94 & 3,983 & 0,97 & 1,182 & 9,45 & 10,575 \\
\hline 73 & 5,61 & 7,136 & 3,63 & 3,039 & 31,07 & 29,663 \\
\hline 74 & 12,63 & 11,823 & 3,30 & 3,013 & 28,26 & 28,608 \\
\hline 75 & 4,83 & 5,238 & 2,64 & 2,587 & 24,95 & 24,465 \\
\hline 76 & 26,49 & 27,892 & 2,86 & 3,003 & 28,07 & 26,691 \\
\hline 77 & 4,22 & 4,482 & 1,10 & 1,194 & 11,34 & 11,355 \\
\hline 78 & 11,49 & 11,814 & 3,01 & 2,712 & 25,67 & 27,058 \\
\hline 79 & 10,56 & 10,696 & 1,50 & 1,584 & 14,83 & 14,939 \\
\hline 80 & 39,31 & 36,534 & 3,20 & 3,598 & 30,65 & 32,178 \\
\hline 81 & 3,95 & 2,999 & 1,48 & 1,482 & 12,93 & 14,265 \\
\hline 82 & 3,13 & 1,488 & 1,34 & 1,514 & 13,95 & 14,835 \\
\hline 83 & 16,89 & 18,112 & 2,96 & 2,572 & 24,01 & 23,379 \\
\hline 84 & 6,36 & 6,258 & 2,70 & 2,819 & 27,40 & 27,330 \\
\hline 85 & 8,06 & 7,070 & 1,67 & 1,854 & 15,97 & 17,008 \\
\hline 86 & 6,89 & 6,327 & 1,58 & 1,922 & 17,32 & 17,761 \\
\hline 87 & 7,76 & 7,298 & 3,11 & 2,857 & 27,20 & 27,327 \\
\hline 88 & 6,29 & 6,328 & 2,34 & 2,547 & 24,98 & 24,481 \\
\hline 89 & 11,42 & 10,360 & 2,21 & 2,485 & 22,45 & 23,178 \\
\hline 90 & 12,49 & 13,301 & 3,34 & 3,001 & 28,83 & 27,797 \\
\hline 91 & 6,02 & 5,818 & 1,28 & 1,385 & 12,57 & 12,450 \\
\hline 92 & 3,94 & 5,446 & 2,55 & 2,709 & 27,81 & 26,928 \\
\hline 93 & 4,19 & 6,463 & 2,84 & 2,906 & 28,41 & 28,129 \\
\hline 94 & 7,95 & 8,363 & 3,08 & 2,782 & 26,92 & 25,970 \\
\hline 95 & 1,78 & 1,177 & 0,95 & 0,959 & 9,16 & 9,189 \\
\hline 96 & 26,44 & 23,700 & 2,13 & 2,049 & 15,66 & 17,818 \\
\hline 97 & 7,16 & 9,025 & 3,22 & 3,099 & 30,17 & 29,340 \\
\hline 98 & 10,48 & 9,814 & 2,78 & 2,761 & 25,71 & 25,924 \\
\hline 99 & 16,52 & 15,731 & 3,25 & 3,126 & 28,53 & 29,455 \\
\hline 100 & 13,82 & 15,328 & 1,35 & 1,206 & 11,13 & 10,653 \\
\hline 101 & 21,49 & 24,708 & 1,88 & 2,018 & 17,95 & 17,660 \\
\hline
\end{tabular}




\begin{tabular}{|c|c|c|c|c|c|c|}
\hline 102 & 25,86 & 26,223 & 1,82 & 1,944 & 17,06 & 15,899 \\
\hline 103 & 6,47 & 7,999 & 2,86 & 2,791 & 25,95 & 25,957 \\
\hline 104 & 18,83 & 16,892 & 2,74 & 3,093 & 29,09 & 28,526 \\
\hline 105 & 4,06 & 3,971 & 1,17 & 1,296 & 12,89 & 12,709 \\
\hline 106 & 19,87 & 16,412 & 2,92 & 2,917 & 27,10 & 27,401 \\
\hline 107 & 13,03 & 14,951 & 2,98 & 3,153 & 31,17 & 30,190 \\
\hline 108 & 17,50 & 14,014 & 2,06 & 2,274 & 18,70 & 20,762 \\
\hline 109 & 2,79 & 1,540 & 1,42 & 1,312 & 12,07 & 12,778 \\
\hline 110 & 9,08 & 8,477 & 2,52 & 2,631 & 26,06 & 26,006 \\
\hline 111 & 5,53 & 4,121 & 1,39 & 1,624 & 14,74 & 15,086 \\
\hline 112 & 7,84 & 10,655 & 3,10 & 3,023 & 30,92 & 29,746 \\
\hline 113 & 5,34 & 5,702 & 1,36 & 1,445 & 14,21 & 13,844 \\
\hline 114 & 12,45 & 10,380 & 2,49 & 2,615 & 24,34 & 24,901 \\
\hline 115 & 6,80 & 5,662 & 1,63 & 1,679 & 15,20 & 16,063 \\
\hline 116 & 6,49 & 7,189 & 1,29 & 1,214 & 11,47 & 11,830 \\
\hline 117 & 5,98 & 5,992 & 2,69 & 2,570 & 23,95 & 24,619 \\
\hline 118 & 23,92 & 23,633 & 2,33 & 2,206 & 17,65 & 18,596 \\
\hline 119 & 3,05 & 3,417 & 1,69 & 1,941 & 19,47 & 18,578 \\
\hline 120 & 29,20 & 26,625 & 2,22 & 2,274 & 17,33 & 18,058 \\
\hline 121 & 5,11 & 4,184 & 1,48 & 1,246 & 11,33 & 11,843 \\
\hline 122 & 8,71 & 9,301 & 1,49 & 1,330 & 11,83 & 11,950 \\
\hline 123 & 2,67 & 3,376 & 1,24 & 1,101 & 10,67 & 9,996 \\
\hline 124 & 3,56 & 4,541 & 2,26 & 2,443 & 24,89 & 23,529 \\
\hline 125 & 13,71 & 15,133 & 1,69 & 1,817 & 16,69 & 16,175 \\
\hline 126 & 3,02 & 5,211 & 0,91 & 0,820 & 8,95 & 7,366 \\
\hline 127 & 4,22 & 3,236 & 2,64 & 2,566 & 21,64 & 24,218 \\
\hline 128 & 13,01 & 13,289 & 2,35 & 2,790 & 26,63 & 26,368 \\
\hline 129 & 12,84 & 12,796 & 1,53 & 1,647 & 14,47 & 14,597 \\
\hline 130 & 2,35 & 2,952 & 0,97 & 0,951 & 9,19 & 8,774 \\
\hline 131 & 21,25 & 17,882 & 2,17 & 2,201 & 17,96 & 19,604 \\
\hline 132 & 6,62 & 7,426 & 2,51 & 2,569 & 24,63 & 24,707 \\
\hline 133 & 3,99 & 3,799 & 1,19 & 1,077 & 9,88 & 9,746 \\
\hline 134 & 34,58 & 29,853 & 2,36 & 2,607 & 21,28 & 23,059 \\
\hline 135 & 5,67 & 4,089 & 1,70 & 1,540 & 13,48 & 14,240 \\
\hline 136 & 4,71 & 5,675 & 3,31 & 2,814 & 27,47 & 27,060 \\
\hline
\end{tabular}




\begin{tabular}{|c|c|c|c|c|c|c|}
\hline 137 & 3,85 & 3,928 & 1,18 & 1,028 & 9,44 & 9,823 \\
\hline 138 & 20,33 & 18,342 & 2,81 & 2,963 & 26,62 & 27,780 \\
\hline 139 & 3,61 & 3,951 & 2,30 & 2,281 & 22,58 & 22,741 \\
\hline 140 & 2,83 & 2,916 & 2,12 & 2,177 & 20,99 & 21,177 \\
\hline 141 & 8,18 & 7,846 & 2,83 & 2,769 & 25,80 & 26,172 \\
\hline 142 & 3,74 & 2,948 & 1,36 & 1,348 & 11,81 & 12,945 \\
\hline 143 & 6,50 & 5,392 & 1,78 & 1,829 & 16,32 & 16,781 \\
\hline 144 & 9,32 & 10,298 & 1,52 & 1,560 & 14,91 & 13,983 \\
\hline 145 & 8,86 & 9,996 & 1,41 & 1,361 & 13,20 & 12,758 \\
\hline 146 & 4,19 & 2,536 & 1,59 & 1,788 & 15,83 & 16,957 \\
\hline 147 & 13,60 & 14,914 & 2,58 & 2,831 & 27,15 & 26,901 \\
\hline 148 & 26,28 & 22,995 & 2,26 & 2,434 & 20,40 & 22,332 \\
\hline 149 & 15,63 & 15,269 & 2,51 & 2,516 & 22,37 & 23,818 \\
\hline 150 & 8,75 & 8,944 & 2,94 & 2,917 & 28,38 & 27,558 \\
\hline 151 & 14,84 & 15,525 & 2,35 & 2,380 & 22,44 & 22,504 \\
\hline 152 & 15,05 & 15,737 & 2,02 & 1,995 & 18,35 & 18,000 \\
\hline 153 & 6,14 & 8,475 & 1,92 & 2,120 & 22,24 & 20,903 \\
\hline 154 & 1,28 & $-0,377$ & 1,48 & 1,325 & 12,88 & 13,075 \\
\hline 155 & 13,66 & 16,168 & 1,39 & 1,320 & 12,95 & 11,131 \\
\hline 156 & 5,21 & 5,370 & 1,16 & 1,030 & 9,69 & 9,607 \\
\hline 157 & 4,83 & 5,040 & 2,91 & 2,805 & 26,66 & 27,075 \\
\hline 158 & 9,51 & 10,216 & 1,27 & 1,075 & 10,46 & 9,468 \\
\hline 159 & 5,69 & 6,772 & 1,22 & 1,307 & 12,82 & 12,724 \\
\hline 160 & 14,15 & 14,020 & 1,43 & 1,371 & 11,85 & 12,787 \\
\hline 161 & 4,98 & 4,676 & 1,46 & 1,571 & 14,19 & 15,218 \\
\hline 162 & 6,39 & 8,535 & 3,47 & 3,067 & 30,93 & 30,036 \\
\hline 163 & 13,45 & 14,573 & 1,65 & 1,512 & 13,68 & 13,860 \\
\hline 164 & 6,85 & 7,090 & 1,35 & 1,403 & 13,43 & 13,429 \\
\hline 165 & 7,22 & 5,031 & 1,66 & 1,641 & 13,79 & 15,340 \\
\hline 166 & 15,88 & 18,977 & 1,36 & 1,315 & 12,79 & 10,926 \\
\hline 167 & 15,85 & 20,572 & 1,70 & 1,386 & 13,94 & 11,282 \\
\hline 168 & 18,30 & 19,202 & 1,62 & 1,590 & 14,47 & 13,819 \\
\hline 169 & 21,20 & 21,459 & 2,19 & 2,122 & 17,29 & 17,778 \\
\hline 170 & 3,50 & 2,653 & 1,24 & 1,090 & 9,63 & 10,103 \\
\hline 171 & 9,14 & 8,397 & 1,99 & 2,235 & 20,94 & 20,981 \\
\hline
\end{tabular}




\begin{tabular}{|c|c|c|c|c|c|c|}
\hline 172 & 2,87 & 2,972 & 1,00 & 1,106 & 10,56 & 10,489 \\
\hline 173 & 2,31 & 2,102 & 1,03 & 1,101 & 10,62 & 10,363 \\
\hline 174 & 4,30 & 2,346 & 2,32 & 2,628 & 25,48 & 27,802 \\
\hline 175 & 3,82 & 3,044 & 2,20 & 2,247 & 19,62 & 21,308 \\
\hline 176 & 3,73 & 4,722 & 2,30 & 2,361 & 23,41 & 22,542 \\
\hline 177 & 2,74 & 1,693 & 1,44 & 1,368 & 13,54 & 13,786 \\
\hline 178 & 41,34 & 39,478 & 3,84 & 4,420 & 37,83 & 39,700 \\
\hline 179 & 5,77 & 4,951 & 1,47 & 1,450 & 13,64 & 14,462 \\
\hline 180 & 10,47 & 10,742 & 2,64 & 2,799 & 27,71 & 26,978 \\
\hline 181 & 11,81 & 13,200 & 2,85 & 2,920 & 28,71 & 27,573 \\
\hline 182 & 11,58 & 13,456 & 1,33 & 1,144 & 10,89 & 10,094 \\
\hline 183 & 3,09 & 1,828 & 1,38 & 1,426 & 12,80 & 13,224 \\
\hline 184 & 7,42 & 8,986 & 2,52 & 2,682 & 24,32 & 25,522 \\
\hline 185 & 2,16 & 1,818 & 1,31 & 1,405 & 13,08 & 13,554 \\
\hline 186 & 7,29 & 7,908 & 2,69 & 2,626 & 25,43 & 25,152 \\
\hline 187 & 4,19 & 5,139 & 1,07 & 1,091 & 10,53 & 10,404 \\
\hline 188 & 5,04 & 4,126 & 1,17 & 1,109 & 9,62 & 10,147 \\
\hline 189 & 5,28 & 11,993 & 2,66 & 3,670 & 28,34 & 33,769 \\
\hline 190 & 5,00 & 4,218 & 1,41 & 1,321 & 11,86 & 12,523 \\
\hline 191 & 8,92 & 8,584 & 2,92 & 2,833 & 27,22 & 27,092 \\
\hline 192 & 5,56 & 5,511 & 1,37 & 1,419 & 13,55 & 13,171 \\
\hline 193 & 2,58 & 1,502 & 1,31 & 1,527 & 14,89 & 14,846 \\
\hline 194 & 12,88 & 12,381 & 3,07 & 3,031 & 27,93 & 28,823 \\
\hline 195 & 23,29 & 25,281 & 2,07 & 2,031 & 14,54 & 17,605 \\
\hline 196 & 7,77 & 6,289 & 1,39 & 1,510 & 12,66 & 13,785 \\
\hline 197 & 5,77 & 4,765 & 2,31 & 2,170 & 19,95 & 20,892 \\
\hline 198 & 7,05 & 5,578 & 1,68 & 1,591 & 13,86 & 15,026 \\
\hline 199 & 2,70 & 3,239 & 3,16 & 2,687 & 25,35 & 26,230 \\
\hline 200 & 9,90 & 9,750 & 2,90 & 3,065 & 29,93 & 29,594 \\
\hline 201 & 5,48 & 5,336 & 1,58 & 1,689 & 16,12 & 16,082 \\
\hline 202 & 4,00 & 4,493 & 2,17 & 2,388 & 22,83 & 23,456 \\
\hline 203 & 3,33 & 1,171 & 1,40 & 1,624 & 32,67 & 16,256 \\
\hline 204 & 2,67 & 2,725 & 2,12 & 2,142 & 20,62 & 21,087 \\
\hline 205 & 13,03 & 13,851 & 3,64 & 3,376 & 32,67 & 31,758 \\
\hline 206 & 3,65 & 4,180 & 1,12 & 1,181 & 12,35 & 11,644 \\
\hline
\end{tabular}




\begin{tabular}{|c|c|c|c|c|c|c|}
\hline 207 & 6,35 & 6,086 & 2,07 & 2,240 & 21,19 & 21,412 \\
\hline 208 & 10,45 & 8,541 & 1,33 & 1,596 & 13,64 & 15,309 \\
\hline 209 & 10,52 & 9,730 & 2,97 & 2,943 & 27,98 & 28,374 \\
\hline 210 & 3,69 & 3,917 & 1,81 & 2,105 & 20,16 & 20,434 \\
\hline 211 & 14,74 & 13,096 & 3,44 & 3,188 & 29,08 & 30,015 \\
\hline 212 & 15,36 & 2,097 & 2,13 & 1,707 & 16,11 & 16,671 \\
\hline 213 & 8,09 & 10,059 & 1,95 & 2,374 & 23,34 & 22,412 \\
\hline 214 & 11,95 & 12,475 & 3,13 & 2,974 & 29,26 & 28,356 \\
\hline 215 & 5,56 & 6,392 & 2,66 & 3,106 & 30,11 & 29,866 \\
\hline 216 & 2,46 & 1,928 & 1,93 & 2,213 & 19,57 & 22,033 \\
\hline 217 & 4,45 & 10,090 & 0,92 & 1,251 & 8,12 & 9,683 \\
\hline 218 & 16,14 & 16,852 & 1,75 & 1,429 & 12,71 & 12,702 \\
\hline 219 & 20,55 & 20,689 & 2,16 & 2,062 & 18,63 & 18,733 \\
\hline 220 & 23,67 & 20,432 & 2,70 & 2,810 & 24,55 & 24,873 \\
\hline 221 & 6,19 & 3,822 & 2,10 & 2,009 & 17,77 & 19,921 \\
\hline 222 & 16,20 & 15,444 & 2,66 & 2,855 & 25,82 & 26,818 \\
\hline 223 & 4,25 & 3,693 & 1,64 & 1,814 & 17,13 & 17,394 \\
\hline 224 & 4,74 & 4,622 & 2,12 & 2,235 & 20,94 & 21,325 \\
\hline 225 & 2,90 & 3,325 & 1,31 & 1,181 & 10,96 & 11,142 \\
\hline 226 & 7,26 & 8,511 & 2,86 & 2,807 & 27,17 & 26,342 \\
\hline 227 & 3,58 & 3,220 & 1,08 & 1,071 & 10,24 & 10,240 \\
\hline 228 & 6,57 & 8,108 & 2,86 & 2,787 & 29,46 & 27,019 \\
\hline 229 & 6,66 & 5,319 & 1,90 & 1,910 & 17,12 & 18,087 \\
\hline 230 & 4,96 & 6,834 & 2,72 & 2,670 & 26,61 & 25,376 \\
\hline 231 & 4,50 & 3,600 & 2,21 & 2,482 & 22,68 & 23,305 \\
\hline 232 & 12,99 & 13,798 & 2,87 & 2,906 & 27,75 & 27,649 \\
\hline 233 & 5,31 & 5,733 & 2,34 & 2,298 & 21,00 & 21,899 \\
\hline 234 & 2,82 & 3,134 & 2,06 & 2,235 & 22,93 & 21,861 \\
\hline 235 & 4,95 & 4,874 & 1,75 & 1,812 & 17,61 & 16,896 \\
\hline 236 & 2,50 & 1,921 & 1,21 & 1,149 & 10,82 & 11,593 \\
\hline 237 & 3,31 & 3,810 & 0,95 & 0,955 & 9,53 & 9,287 \\
\hline 238 & 4,09 & 3,190 & 1,54 & 1,582 & 14,76 & 15,406 \\
\hline 239 & 25,97 & 23,409 & 2,06 & 2,127 & 17,13 & 18,793 \\
\hline 240 & 2,07 & 2,010 & 0,97 & 0,883 & 8,31 & 8,485 \\
\hline 241 & 2,61 & 1,564 & 1,98 & 2,021 & 20,11 & 19,816 \\
\hline
\end{tabular}




\begin{tabular}{|c|c|c|c|c|c|c|}
\hline 242 & 6,29 & 6,563 & 1,13 & 1,097 & 9,15 & 9,858 \\
\hline 243 & 10,34 & 9,557 & 2,05 & 2,290 & 22,52 & 22,101 \\
\hline 244 & 7,27 & 7,571 & 2,85 & 2,724 & 26,98 & 25,766 \\
\hline 245 & 21,44 & 22,518 & 1,88 & 1,746 & 14,94 & 15,315 \\
\hline 246 & 6,08 & 6,305 & 2,98 & 2,591 & 25,44 & 24,982 \\
\hline 247 & 5,41 & 7,197 & 1,96 & 2,448 & 25,22 & 23,991 \\
\hline 248 & 5,92 & 5,844 & 2,62 & 2,749 & 26,60 & 26,522 \\
\hline 249 & 15,38 & 15,311 & 1,94 & 1,910 & 18,33 & 17,848 \\
\hline 250 & 9,94 & 9,952 & 2,15 & 2,398 & 23,83 & 22,820 \\
\hline 251 & 4,68 & 6,226 & 3,06 & 2,976 & 29,10 & 28,403 \\
\hline 252 & 14,67 & 17,853 & 1,40 & 1,299 & 11,93 & 11,243 \\
\hline 253 & 10,34 & 9,896 & 1,41 & 1,674 & 14,79 & 15,090 \\
\hline 254 & 18,67 & 15,783 & 3,48 & 3,181 & 29,05 & 30,454 \\
\hline 255 & 14,07 & 12,818 & 1,86 & 1,744 & 15,43 & 15,992 \\
\hline 256 & 8,97 & 8,941 & 1,62 & 1,462 & 12,48 & 13,066 \\
\hline 257 & 7,58 & 6,930 & 2,32 & 2,392 & 22,55 & 22,603 \\
\hline 258 & 13,36 & 15,087 & 1,57 & 1,741 & 16,72 & 15,915 \\
\hline 259 & 20,32 & 23,683 & 1,92 & 1,747 & 16,04 & 14,108 \\
\hline 260 & 6,62 & 7,393 & 3,09 & 3,162 & 29,70 & 29,975 \\
\hline 261 & 3,83 & 3,491 & 2,11 & 2,205 & 20,44 & 21,329 \\
\hline 262 & 9,68 & 12,564 & 1,52 & 1,432 & 14,25 & 13,751 \\
\hline 263 & 6,85 & 7,647 & 3,05 & 2,958 & 29,43 & 28,652 \\
\hline 264 & 6,54 & 5,601 & 2,03 & 2,097 & 14,12 & 20,584 \\
\hline 265 & 5,56 & 7,094 & 3,15 & 3,068 & 28,88 & 29,195 \\
\hline 266 & 7,64 & 8,376 & 2,87 & 2,987 & 29,39 & 28,522 \\
\hline 267 & 16,22 & 14,591 & 2,58 & 2,438 & 22,05 & 23,723 \\
\hline 268 & 20,04 & 19,834 & 3,06 & 3,012 & 25,58 & 26,646 \\
\hline 269 & 7,68 & 7,236 & 2,21 & 2,429 & 22,75 & 23,185 \\
\hline 270 & 4,71 & 7,974 & 2,87 & 2,781 & 26,94 & 25,580 \\
\hline 271 & 15,86 & 14,237 & 1,37 & 1,499 & 12,11 & 13,687 \\
\hline 272 & 21,11 & 18,943 & 3,34 & 2,973 & 26,05 & 26,610 \\
\hline 273 & 3,27 & 2,734 & 1,68 & 1,589 & 14,85 & 15,522 \\
\hline 274 & 6,40 & 5,604 & 1,35 & 1,374 & 11,66 & 12,276 \\
\hline 275 & 2,76 & 1,963 & 1,38 & 1,597 & 18,03 & 15,423 \\
\hline 276 & 5,07 & 5,413 & 1,89 & 1,759 & 17,01 & 16,310 \\
\hline
\end{tabular}




\begin{tabular}{|c|c|c|c|c|c|c|}
\hline 277 & 30,98 & 28,215 & 3,49 & 3,665 & 33,44 & 33,665 \\
\hline 278 & 6,11 & 6,658 & 2,94 & 2,804 & 25,22 & 26,819 \\
\hline 279 & 4,83 & 5,740 & 3,00 & 2,788 & 27,83 & 26,736 \\
\hline 280 & 27,40 & 24,749 & 3,71 & 3,643 & 30,96 & 33,049 \\
\hline 281 & 7,69 & 10,156 & 3,37 & 2,995 & 30,20 & 28,431 \\
\hline 282 & 2,78 & 1,190 & 1,37 & 1,189 & 11,54 & 12,073 \\
\hline 283 & 4,89 & 3,203 & 1,56 & 1,619 & 14,42 & 15,523 \\
\hline 284 & 26,01 & 24,052 & 3,89 & 3,286 & 29,46 & 29,301 \\
\hline 285 & 1,35 & 1,988 & 1,04 & 0,998 & 9,69 & 9,548 \\
\hline 286 & 3,97 & 6,171 & 2,84 & 2,714 & 28,88 & 26,549 \\
\hline 287 & 3,64 & 4,007 & 1,66 & 1,651 & 16,12 & 16,145 \\
\hline 288 & 39,52 & 35,489 & 3,53 & 3,913 & 35,29 & 33,945 \\
\hline 289 & 6,34 & 4,920 & 1,31 & 1,677 & 15,06 & 16,002 \\
\hline 290 & 8,24 & 10,026 & 1,21 & 1,154 & 10,83 & 10,121 \\
\hline 291 & 14,92 & 15,557 & 1,39 & 1,238 & 10,82 & 10,962 \\
\hline 292 & 11,87 & 11,577 & 3,18 & 2,913 & 27,07 & 26,792 \\
\hline 293 & 5,35 & 5,827 & 1,16 & 1,141 & 10,58 & 10,852 \\
\hline 294 & 2,70 & 1,791 & 2,08 & 2,151 & 20,67 & 21,653 \\
\hline 295 & 4,06 & 3,640 & 2,39 & 2,198 & 20,89 & 21,248 \\
\hline 296 & 12,89 & 14,215 & 3,30 & 3,148 & 30,46 & 29,936 \\
\hline 297 & 9,28 & 11,103 & 3,46 & 3,350 & 34,43 & 31,916 \\
\hline 298 & 4,46 & 5,034 & 2,47 & 2,590 & 23,89 & 24,110 \\
\hline 299 & 4,92 & 5,207 & 1,78 & 1,968 & 18,85 & 19,301 \\
\hline 300 & 22,97 & 22,364 & 2,44 & 2,331 & 19,88 & 20,368 \\
\hline 301 & 3,64 & 5,515 & 3,69 & 3,215 & 30,74 & 31,087 \\
\hline 302 & 7,84 & 6,737 & 2,39 & 2,518 & 23,37 & 23,925 \\
\hline 303 & 5,23 & 7,009 & 3,38 & 3,096 & 29,88 & 29,227 \\
\hline 304 & 8,16 & 10,290 & 2,80 & 2,792 & 27,15 & 26,082 \\
\hline 305 & 3,54 & 5,359 & 2,79 & 2,594 & 25,80 & 25,221 \\
\hline 306 & 2,98 & 2,986 & 0,98 & 1,051 & 9,23 & 9,670 \\
\hline 307 & 22,08 & 20,994 & 2,30 & 2,128 & 17,74 & 17,337 \\
\hline 308 & 10,65 & 11,541 & 1,33 & 1,378 & 12,39 & 12,485 \\
\hline 309 & 2,40 & 1,483 & 1,26 & 1,164 & 10,63 & 11,456 \\
\hline 310 & 3,98 & 2,591 & 2,19 & 2,052 & 19,33 & 19,948 \\
\hline 311 & 2,29 & 2,207 & 1,00 & 1,060 & 10,08 & 9,878 \\
\hline
\end{tabular}




\begin{tabular}{|c|c|c|c|c|c|c|}
\hline 312 & 5,84 & 6,297 & 1,21 & 1,176 & 11,08 & 10,907 \\
\hline 313 & 14,39 & 14,722 & 3,19 & 3,060 & 29,79 & 28,793 \\
\hline 314 & 13,73 & 9,606 & 2,44 & 2,692 & 24,26 & 25,428 \\
\hline 315 & 4,57 & 3,681 & 1,26 & 1,526 & 13,84 & 14,253 \\
\hline 316 & 3,76 & 5,606 & 0,97 & 0,790 & 7,73 & 6,989 \\
\hline 317 & 10,56 & 9,679 & 1,71 & 1,663 & 14,80 & 15,651 \\
\hline 318 & 23,51 & 24,517 & 1,92 & 1,899 & 16,74 & 16,017 \\
\hline 319 & 5,69 & 6,111 & 1,29 & 1,234 & 10,94 & 11,333 \\
\hline 320 & 5,99 & 6,579 & 1,33 & 1,295 & 11,90 & 12,294 \\
\hline 321 & 4,77 & 3,780 & 1,25 & 1,312 & 11,73 & 12,381 \\
\hline 322 & 41,79 & 40,659 & 2,95 & 2,894 & 22,21 & 23,212 \\
\hline 323 & 5,19 & 3,140 & 1,39 & 1,431 & 12,84 & 14,390 \\
\hline 324 & 4,87 & 3,745 & 1,68 & 1,657 & 15,36 & 15,773 \\
\hline 325 & 7,73 & 5,598 & 1,48 & 1,423 & 12,47 & 14,207 \\
\hline 326 & 4,66 & 3,655 & 1,53 & 1,637 & 15,46 & 15,638 \\
\hline 327 & 8,47 & 11,592 & 2,47 & 2,502 & 25,07 & 23,221 \\
\hline 328 & 10,53 & 11,399 & 3,29 & 3,183 & 30,83 & 29,970 \\
\hline 329 & 9,68 & 8,213 & 1,83 & 1,880 & 17,61 & 17,811 \\
\hline 330 & 4,41 & 4,956 & 2,45 & 2,489 & 24,46 & 24,221 \\
\hline 331 & 6,32 & 6,396 & 1,20 & 1,215 & 11,28 & 11,592 \\
\hline 332 & 27,76 & 26,849 & 3,30 & 3,284 & 29,85 & 30,298 \\
\hline 333 & 16,44 & 14,819 & 3,39 & 3,128 & 28,15 & 29,732 \\
\hline 334 & 10,19 & 9,962 & 2,31 & 2,864 & 26,81 & 26,321 \\
\hline 335 & 7,69 & 7,580 & 2,59 & 2,641 & 25,43 & 25,399 \\
\hline 336 & 9,31 & 10,478 & 1,12 & 1,156 & 10,35 & 10,363 \\
\hline 337 & 8,29 & 9,108 & 3,18 & 3,201 & 31,21 & 30,046 \\
\hline 338 & 21,32 & 19,925 & 1,63 & 1,706 & 14,30 & 14,832 \\
\hline 339 & 5,23 & 5,283 & 2,40 & 2,625 & 24,73 & 25,426 \\
\hline 340 & 1,93 & 1,378 & 1,31 & 1,319 & 13,02 & 12,909 \\
\hline 341 & 1,36 & 0,651 & 1,21 & 1,181 & 11,30 & 11,363 \\
\hline 342 & 3,50 & 2,200 & 1,60 & 1,502 & 20,88 & 14,356 \\
\hline 343 & 4,31 & 3,144 & 2,14 & 1,866 & 17,03 & 18,093 \\
\hline 344 & 15,36 & 17,069 & 2,13 & 2,092 & 19,42 & 18,524 \\
\hline 345 & 10,19 & 8,769 & 3,21 & 3,099 & 29,93 & 29,815 \\
\hline 346 & 2,70 & 1,275 & 1,93 & 2,176 & 19,97 & 20,831 \\
\hline
\end{tabular}




\begin{tabular}{|c|c|c|c|c|c|c|}
\hline 347 & 5,11 & 6,750 & 3,18 & 2,986 & 28,42 & 28,113 \\
\hline 348 & 5,47 & 7,048 & 2,28 & 2,388 & 23,61 & 23,106 \\
\hline 349 & 8,59 & 7,272 & 1,92 & 2,043 & 18,21 & 19,358 \\
\hline 350 & 13,91 & 15,054 & 2,51 & 2,217 & 19,77 & 20,360 \\
\hline 351 & 24,11 & 25,581 & 2,66 & 3,052 & 28,09 & 27,218 \\
\hline 352 & 3,71 & 3,666 & 1,64 & 1,949 & 28,09 & 18,661 \\
\hline 353 & 22,25 & 22,850 & 3,49 & 3,459 & 33,27 & 31,234 \\
\hline 354 & 6,13 & 4,515 & 1,77 & 1,689 & 14,55 & 16,149 \\
\hline 355 & 6,17 & 5,221 & 1,87 & 2,199 & 20,17 & 21,477 \\
\hline 356 & 8,75 & 9,423 & 2,98 & 3,239 & 33,59 & 30,902 \\
\hline 357 & 4,06 & 4,175 & 2,12 & 2,275 & 21,86 & 21,216 \\
\hline 358 & 4,35 & 4,489 & 0,86 & 0,788 & 7,69 & 7,163 \\
\hline 359 & 4,51 & 4,911 & 2,64 & 2,491 & 22,11 & 23,046 \\
\hline 360 & 13,89 & 16,256 & 3,77 & 3,472 & 33,79 & 32,030 \\
\hline 361 & 4,42 & 4,387 & 1,33 & 1,338 & 13,33 & 13,278 \\
\hline 362 & 5,48 & 6,899 & 2,45 & 2,558 & 26,45 & 24,583 \\
\hline 363 & 4,55 & 2,967 & 1,93 & 2,100 & 19,41 & 20,311 \\
\hline 364 & 5,39 & 5,187 & 3,06 & 2,831 & 25,71 & 27,833 \\
\hline 365 & 40,66 & 39,747 & 2,36 & 2,414 & 17,64 & 18,009 \\
\hline 366 & 11,75 & 13,096 & 1,24 & 1,155 & 11,12 & 10,349 \\
\hline 367 & 5,53 & 7,000 & 3,22 & 3,311 & 33,97 & 32,360 \\
\hline 368 & 8,04 & 8,763 & 1,25 & 1,181 & 10,80 & 10,714 \\
\hline 369 & 11,62 & 11,693 & 2,83 & 2,733 & 25,84 & 25,783 \\
\hline 370 & 38,46 & 34,684 & 3,70 & 4,090 & 34,08 & 35,646 \\
\hline 371 & 2,39 & 1,110 & 0,93 & 0,932 & 7,84 & 8,488 \\
\hline 372 & 7,67 & 9,238 & 2,08 & 2,117 & 20,92 & 19,872 \\
\hline 373 & 29,77 & 32,728 & 2,38 & 2,364 & 21,65 & 19,636 \\
\hline 374 & 1,86 & 1,050 & 0,70 & 0,896 & 7,56 & 7,511 \\
\hline 375 & 5,42 & 6,078 & 2,01 & 2,207 & 22,95 & 21,532 \\
\hline 376 & 1,52 & 2,080 & 1,08 & 0,943 & 8,83 & 8,236 \\
\hline 377 & 4,72 & 6,007 & 2,63 & 2,625 & 25,80 & 25,222 \\
\hline 378 & 10,16 & 14,458 & 1,14 & 0,934 & 10,28 & 7,784 \\
\hline 379 & 4,94 & 5,101 & 1,64 & 2,022 & 18,89 & 19,579 \\
\hline 380 & 7,97 & 9,182 & 3,18 & 3,087 & 30,18 & 28,605 \\
\hline 381 & 5,27 & 6,524 & 2,45 & 2,743 & 25,63 & 25,930 \\
\hline
\end{tabular}




\begin{tabular}{|c|c|c|c|c|c|c|}
\hline 382 & 7,26 & 7,223 & 1,29 & 1,412 & 12,79 & 12,827 \\
\hline 383 & 12,01 & 11,778 & 1,82 & 1,826 & 16,76 & 16,770 \\
\hline 384 & 25,98 & 24,292 & 4,09 & 3,849 & 36,15 & 34,896 \\
\hline 385 & 4,99 & 5,296 & 2,23 & 2,306 & 22,76 & 22,433 \\
\hline 386 & 2,69 & 1,850 & 1,25 & 1,327 & 11,77 & 12,915 \\
\hline 387 & 14,65 & 16,051 & 2,23 & 2,292 & 20,93 & 21,267 \\
\hline 388 & 3,79 & 3,048 & 1,46 & 1,528 & 14,86 & 14,528 \\
\hline 389 & 2,48 & 2,958 & 1,00 & 1,030 & 10,76 & 9,942 \\
\hline 390 & 5,76 & 5,637 & 1,45 & 1,332 & 13,39 & 12,324 \\
\hline 391 & 2,28 & 2,258 & 1,36 & 1,334 & 11,97 & 12,545 \\
\hline 392 & 2,24 & 2,404 & 1,07 & 0,883 & 7,79 & 8,201 \\
\hline 393 & 3,89 & 2,193 & 2,36 & 2,459 & 20,73 & 23,795 \\
\hline 394 & 10,39 & 12,194 & 1,29 & 1,120 & 11,39 & 9,600 \\
\hline 395 & 10,58 & 11,241 & 3,63 & 3,342 & 31,90 & 31,604 \\
\hline 396 & 8,29 & 9,897 & 2,99 & 2,990 & 30,40 & 28,205 \\
\hline 397 & 4,05 & 5,499 & 3,16 & 2,834 & 26,01 & 26,799 \\
\hline 398 & 14,14 & 16,056 & 3,30 & 3,388 & 31,81 & 31,712 \\
\hline 399 & 3,70 & 4,587 & 0,94 & 0,884 & 8,24 & 8,057 \\
\hline 400 & 3,93 & 3,378 & 2,42 & 2,504 & 22,51 & 23,590 \\
\hline 401 & 5,44 & 4,800 & 2,96 & 2,788 & 26,03 & 27,111 \\
\hline 402 & 6,61 & 5,071 & 2,32 & 2,160 & 19,87 & 20,958 \\
\hline 403 & 5,50 & 4,534 & 1,79 & 1,888 & 17,79 & 18,043 \\
\hline 404 & 6,56 & 7,389 & 1,59 & 1,645 & 15,86 & 14,883 \\
\hline 405 & 10,09 & 6,459 & 1,88 & 2,297 & 20,05 & 21,939 \\
\hline 406 & 3,29 & 4,434 & 3,10 & 2,933 & 27,85 & 28,046 \\
\hline 407 & 8,57 & 8,467 & 2,89 & 3,229 & 29,73 & 30,332 \\
\hline 408 & 3,58 & 2,787 & 1,68 & 1,629 & 14,80 & 15,663 \\
\hline
\end{tabular}


APÊNDICE 6 - Dados da amostra de referência.

Tabela F1. Estatísticas descritivas do porcentual de gordura da amostra de referência.

\begin{tabular}{lccc}
\cline { 2 - 4 } & Esportistas (a) & Não-esportistas (b) & Geral (a+b) \\
\hline média amostral & 20,69 & 22,80 & 21,52 \\
desvio padrão & 10,17 & 13,11 & 11,43 \\
máximo & 66,59 & 66,90 & 66,90 \\
mínimo & 5,58 & 6,90 & 5,58 \\
n & 277 & 177 & 454 \\
\hline
\end{tabular}

Gráfico F1. Boxplots do porcentual de gordura.

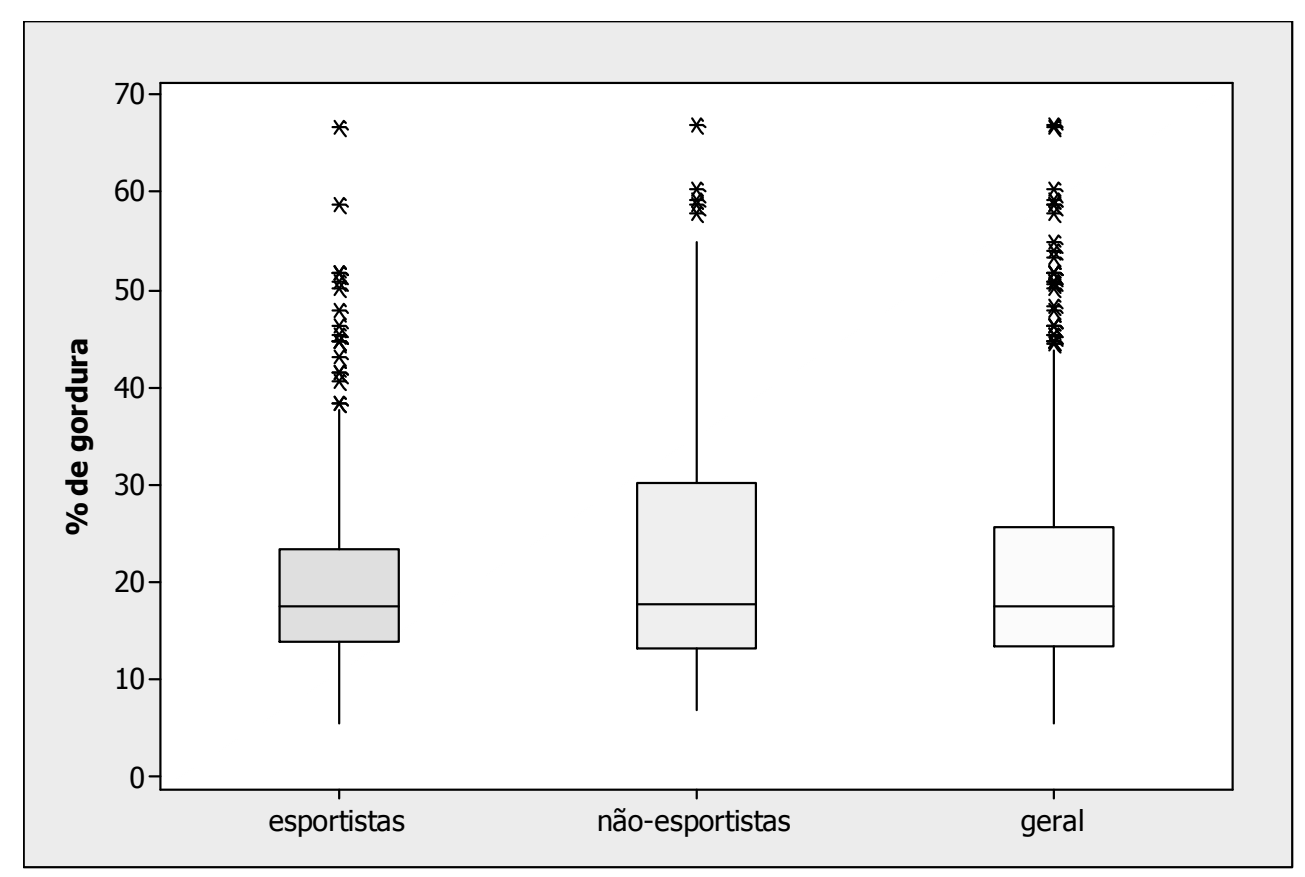


Gráfico F2. Histogramas do porcentual de gordura para esportistas (E), nãoesportistas (NE) e geral (G, esportistas e não-esportistas) .

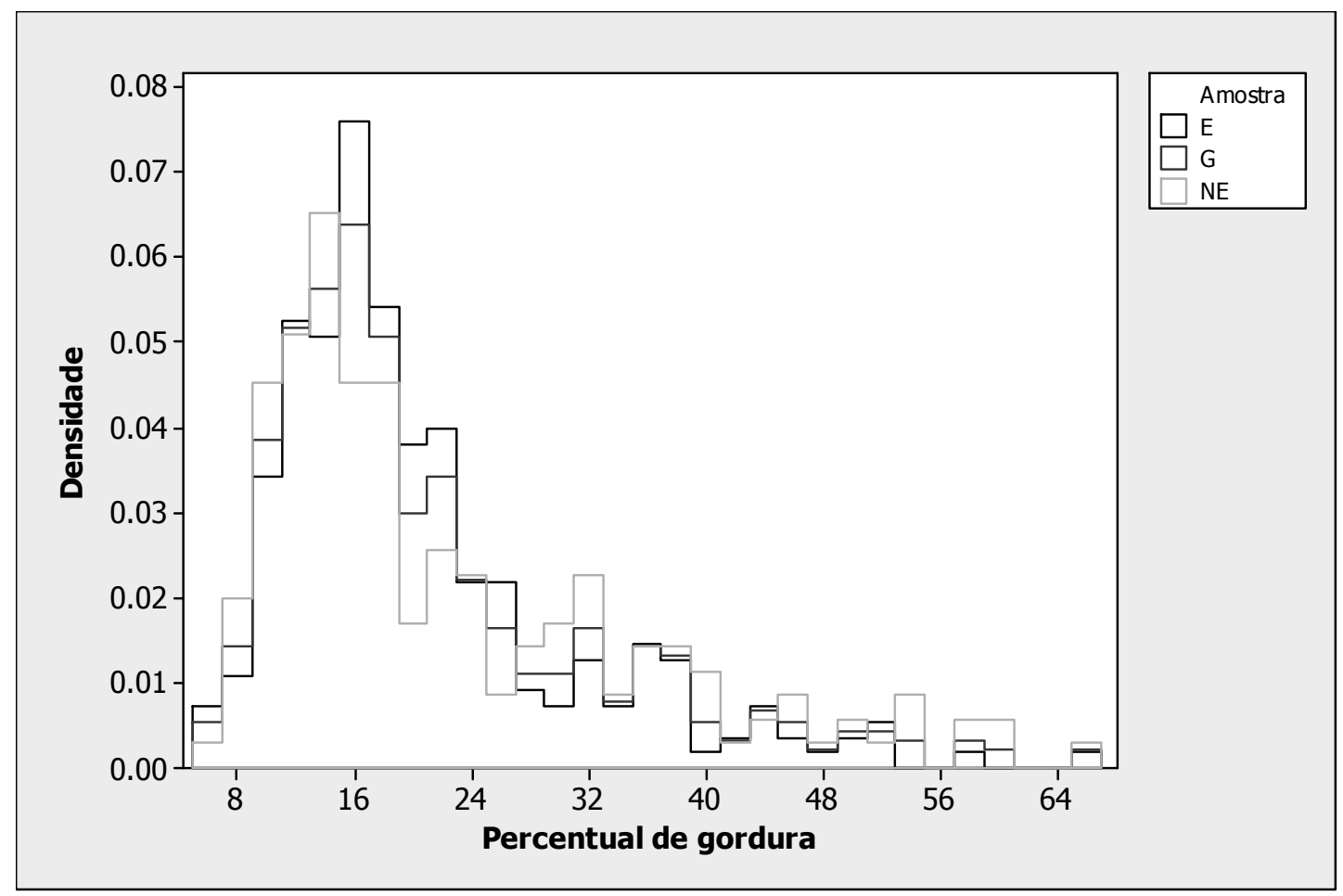

Gráfico F3. Relação entre o Tamanho da Amostra e o Porcentual do erro máximo de estimação com $95 \%$ de confiança.

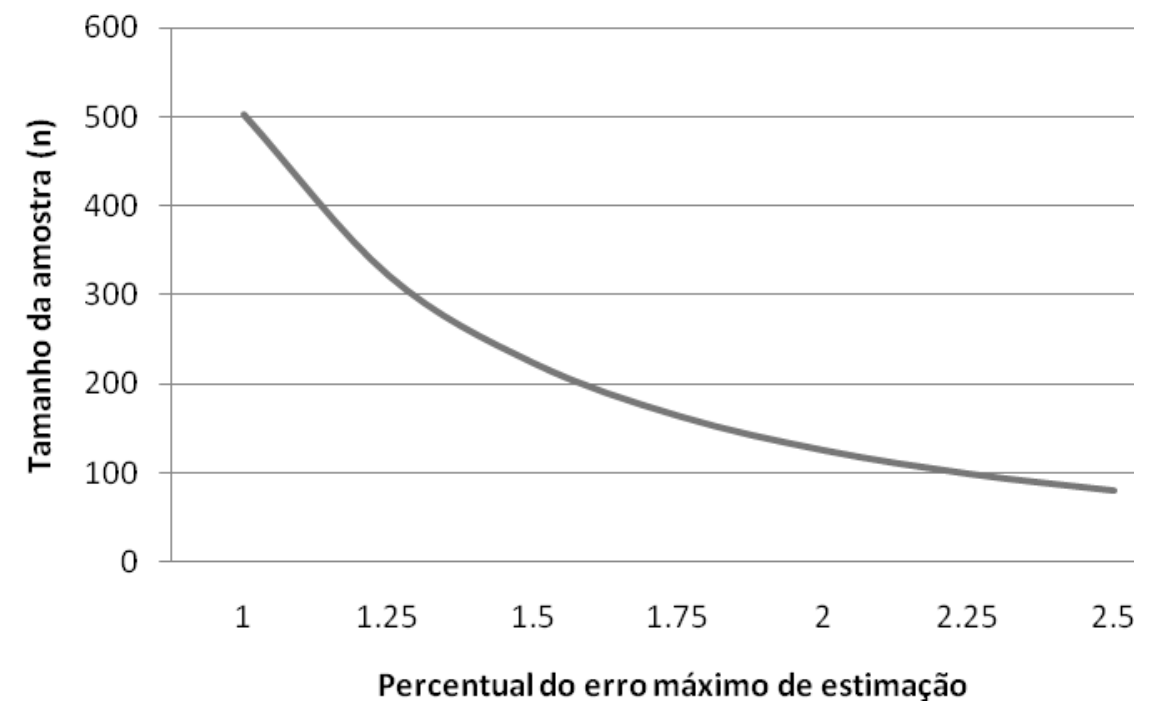

